\title{
Locoregional control of breast cancer with an emphasis on the role of young age and lobular histology
}

Citation for published version (APA):

Van der Sangen, M. J. C. (2013). Locoregional control of breast cancer with an emphasis on the role of young age and lobular histology. [Doctoral Thesis, Maastricht University]. Maastricht University. https://doi.org/10.26481/dis.20131127ms

Document status and date:

Published: 01/01/2013

DOI:

10.26481/dis.20131127ms

Document Version:

Publisher's PDF, also known as Version of record

Please check the document version of this publication:

- A submitted manuscript is the version of the article upon submission and before peer-review. There can be important differences between the submitted version and the official published version of record.

People interested in the research are advised to contact the author for the final version of the publication, or visit the DOI to the publisher's website.

- The final author version and the galley proof are versions of the publication after peer review.

- The final published version features the final layout of the paper including the volume, issue and page numbers.

Link to publication

\footnotetext{
General rights rights.

- You may freely distribute the URL identifying the publication in the public portal. please follow below link for the End User Agreement:

www.umlib.nl/taverne-license

Take down policy

If you believe that this document breaches copyright please contact us at:

repository@maastrichtuniversity.nl

providing details and we will investigate your claim.
}

Copyright and moral rights for the publications made accessible in the public portal are retained by the authors and/or other copyright owners and it is a condition of accessing publications that users recognise and abide by the legal requirements associated with these

- Users may download and print one copy of any publication from the public portal for the purpose of private study or research.

- You may not further distribute the material or use it for any profit-making activity or commercial gain

If the publication is distributed under the terms of Article $25 \mathrm{fa}$ of the Dutch Copyright Act, indicated by the "Taverne" license above, 
Locoregional control of breast cancer with an

emphasis on the role of young age and

lobular histology 
(c) Copyright Maurice van der Sangen, Maastricht 2013

Layout: Tiny Wouters

Cover: Stephan van Oppenraaij

Production: Kampert-Nauta, Oss

ISBN: 978-90-9027821-6

Printing of this thesis was financially supported by:

- Comprehensive Cancer Center South (Integraal Kankercentrum Zuid, IKZ)

- Catharina Ziekenhuis, Eindhoven 


\title{
Locoregional control of breast cancer with an emphasis on the role of young age and lobular histology
}

\author{
PROEFSCHRIFT \\ ter verkrijging van de graad van doctor \\ aan de Universiteit Maastricht, \\ op gezag van de Rector Magnificus, Prof. dr. L.L.G. Soete, \\ volgens het besluit van het College van Decanen, \\ in het openbaar te verdedigen \\ op woensdag 27 november 2013 om 14.00 uur
}

door

Maurice van der Sangen 


\section{Promotor}

Prof. dr. V.C.G. Tjan-Heijnen

Prof. dr. J.W.W. Coebergh

\section{Copromotor}

Dr. A.C. Voogd

\section{Beoordelingscommissie}

Prof. dr. P. Lambin (voorzitter), MAASTRO Clinic, Maastricht

Dr. L. Boersma, MAASTRO Clinic, Maastricht

Dr. P.S.G.J. Hupperets

Prof. dr. E.J.Th. Rutgers, Antoni van Leeuwenhoek/NKI, Universiteit van Amsterdam 


\section{Contents}

$\begin{array}{lll}\text { Chapter } 1 & \text { Introduction and Outline } & 7\end{array}$

Chapter 2 Local control in young women 17

$\begin{array}{lll}2.1 & \text { Are breast conservation and mastectomy equally effective } & 19\end{array}$ in the treatment of young women with early breast cancer? Long-term results of a population-based cohort of 1451 patients aged $\leq 40$ years.

2.2 Local recurrence following breast-conserving therapy in women aged 40 years or younger: Trends in risk and the impact on prognosis in a cohort of 1143 patients.

2.3 Detection of local recurrence following breast-conserving therapy in young women with early breast cancer: Optimization of long-term follow-up strategies.

Chapter 3 Local control in lobular breast cancer

3.1 Margin status and the risk of local recurrence after breastconserving therapy of lobular breast cancer.

3.2 The impact of postmastectomy radiotherapy on local control in patients with invasive lobular breast cancer.

Chapter 4 Prognosis following local relapse

4.1 The prognosis of patients with local recurrence more than five years after breast-conserving therapy for invasive breast carcinoma.

4.2 Prognosis following local recurrence after breast-conserving therapy in young women with early breast cancer.

Chapter 5 Regional relapse

5.1 Diagnosis, treatment and prognosis of internal mammary lymph node recurrence in breast cancer patients.

5.2 Detection, treatment, and outcome of isolated supraclavicular recurrence in 42 patients with invasive breast carcinoma.

Chapter 6 General discussion and future perspectives

Summary

Nederlandse samenvatting

Abbreviations

List of publications

Dankwoord 

Chapter 1

Introduction and outline 


\section{Introduction and outline of this thesis}

\section{Epidemiology}

Breast cancer is by far the most common female cancer, accounting for approximately $30 \%$ of all malignancies among women in Europe in $2012^{1,2}$. The incidence rates are highest in Western European countries like the Netherlands with a $13 \%$ life time risk of developing the disease ${ }^{3}$. The occurrence of breast cancer is strongly age-related and increases sharply after the fourth decade. In the Netherlands, almost 14000 women were diagnosed with breast cancer in 2011, of whom $5 \%$ were younger than 40 years at the time of diagnosis. (www.cijfersoverkanker.nl) In the last two decades there has been no remarkable increase in the incidence of breast cancer in women younger than 40 years in contrast to the older age groups ${ }^{4}$.

\section{Mastectomy versus breast-conserving therapy}

For a long time ablative surgery was the standard local treatment for woman with non-metastatic breast cancer. Several factors led to a critical reassessment of the value of this radical surgical approach. In the first place it was realized that even with Halstedian radical surgery a significant part of the breast cancer patients could not be cured and that survival did not increase with ever more radical procedures. A better understanding of breast cancer biology resulted in the rejection of the centrifugal lymphatic permeation theory that assumed that breast cancer spreads from the primary tumour through the lymphatics in a contiguous manner and from there eventually can give rise to distant metastases. Laboratory and clinical investigation by Fisher et al. made it clear that in many cases early systemic spread was a plausible cause of incurability by surgery ${ }^{5-8}$. A pioneer of the principle of breast-conserving surgery was Keynes. Already in 1927 he had abandoned the radical mastectomy in favor of breast-conserving surgery combined with radium irradiation. In 1937 after having treated 325 patients he wrote: 'This clinical investigation, which has now extended over fourteen years, seems to me to show that the treatment of carcinoma of the breast may justifiably be made much more conservative than it usually is, provided that the necessary facilities for irradiation are available ${ }^{\prime 9}$. Nevertheless, it was not until the seventies before more widespread interest in breast-conserving therapy (BCT) arose. The first randomised controlled trial of conservative surgery and radiotherapy versus radical mastectomy and radiotherapy was published in 1972 by Atkins ${ }^{10}$. The results were rather disappointing probably due to insufficient radiation doses. However in the late seventies BCT was increasingly used and reports of various groups were promising ${ }^{11-14}$. Both European and American randomised trials comparing BCT with mastectomy eventually showed good local control after BCT with no significant survival differences, even after twenty-year follow-up ${ }^{15-21}$. Nowadays BCT is an accepted treatment for women with stage I and II breast cancer. 


\section{Young age as risk factor for locoregional recurrence}

In the first decades of BCT there was still some concern about local disease control, despite the favourable results of sparing treatment. Increasing knowledge about risk factors for the development of local and regional recurrence occurred ${ }^{22,23}$. In addition to tumour-related factors such as tumour size, nodal status, grade, degree of proliferation, hormone and later human epidermal growth factor receptor 2 (HER2) status, also patient-related factors such as age and co-morbidity turned out to be of major prognostic value. Especially young age was found to be a strong risk factor for the occurrence of both locoregional recurrence, distant metastases and death from breast cancer ${ }^{24-27}$. As mentioned above only $5 \%$ of all women with breast cancer are younger than 40 years at time of diagnosis. Because of this relatively low incidence, subgroup analyses in randomised controlled trials could not answer the question whether BCT is as safe as mastectomy in the treatment of early-stage breast cancer in young women. Even by pooling data derived from all available trials, the number of young patients would be too small to draw conclusions ${ }^{28}$.

\section{Local control in lobular breast cancer}

Invasive lobular carcinoma (ILC), which accounts for up to $10 \%$ of all breast cancers, has been associated with distinct clinical-pathologic features when compared to the much more common (80\%) invasive ductal carcinoma (IDC). Characteristics are an average older age of onset, lacking of sharp circumscription, higher incidence of contralateral breast cancer, lower sensitivity of mammography and relative chemoinsensitivity. More than $90 \%$ of ILC is oestrogen receptor positive and most of the time HER2-negative ${ }^{29-31}$. ILC has its own pattern of recurrence, but the timing of recurrence seems to be correlated to hormone receptor status ${ }^{30}$. Because of the more diffuse, less solid growth pattern, the percentage of incomplete resections is significantly higher compared to IDC. This questions the safety of BCT in patients with a lobular histology.

Radiotherapy has generally proven to be effective in reducing the locoregional recurrence rate ${ }^{17}$. However, most randomised studies of radiotherapy in breast cancer did not distinguish between different histological types. The question which applies both to BCT as to mastectomy is whether these trial outcomes can be extrapolated to patients being treated for ILC. Subgroup analyses of randomised controlled trials do not show significant differences in local recurrence rates after BCT when comparing ILC and IDC. However, after mastectomy the recurrence rate after ILC appears to be higher $^{32}$.

\section{Follow-up, local and regional recurrence}

The follow-up care of patients with breast cancer has more than one purpose. In addition to psychosocial support, watching for treatment-related side effects and 
early detection of contralateral and recurrent locoregional disease are main reasons for regular control visits. There has always been much debate on the low efficiency of follow-up in early detection of recurrent disease. This should improve by adding other modalities, without losing sight of their cost-effectiveness. The unfavourable prognostic impact of locoregionally recurrent and contralateral breast cancer stresses the relevance of their early detection in a way to improve the chances of cure ${ }^{33-35}$. One of the main objectives of non-metastatic breast cancer treatment is to prevent local recurrence. If despite appropriate treatment a local recurrence appears, it has a negative impact on prognosis. Knowledge of prognostic factors accompanying a local recurrence is important because they can affect treatment decisions at initial diagnosis $^{34,35}$.

Regional recurrences of breast cancer are rare in comparison with local recurrences, but have a worse prognosis ${ }^{34,35}$. The diagnosis and treatment of patients with a regional recurrence nevertheless needs special attention as curative treatment may still be possible. Multimodality treatment is usually required to achieve this goal.

\section{The Eindhoven Cancer Registry}

In the early eighties at the time of the introduction of BCT surgeons, radiation oncologists and pathologists in the southeastern part of the Netherlands met to exchange their experiences with this new treatment and founded the regional Breast Cancer Study Group (BCSG). The development of clinical guidelines in 1981 was the first step of the BCSG towards a more uniform approach to the treatment of early breast cancer. The next step was to initiate the collection of data for monitoring clinical practice and evaluating treatment outcome; this was done in close collaboration with the Eindhoven Cancer Registry (ECR), which had already started in 1955. In 1984 this collaboration resulted in the initiation of the 'Breast Cancer Documentation Project', which offered the members of the BCSG unique facilities to study trends in the use and outcome of BCT in the eight community hospitals in the region $^{36-38}$. The studies in this thesis are based on patients selected from the population-based ECR, which is currently serving a population of almost 2.4 million inhabitants in the southeastern part of the Netherlands $(14 \%$ of the Dutch population). Since 1989 the ECR is part of the National Cancer Registry, which covers the entire Dutch population. Patient data have been collected by registry clerks of the ECR from pathology reports of 6 pathology laboratories, and medical records of currently 10 general hospitals and 2 radiotherapy institutes. For most of the studies presented here medical records were reassessed to extract additional information with respect to patient, tumour and treatment characteristics as well as to outcome.

This thesis contains a number of observational studies which had the aim to elucidate various aspects of local and regional tumour control in patients with breast cancer. The emphasis is on young age and on patients with a lobular tumour type. The studies are population-based and cover a period of more than 20 years. This also made it 
possible to look at time trends and to identify significant changes in a number of important prognostic factors.

\section{Outline of this thesis}

In Chapter 2.1 we compare the effectiveness of BCT and mastectomy of young women treated for early-stage breast cancer in the southern part of the Netherlands between 1988 and 2005. It is an evaluation of a large cohort of 1451 patients aged $\leq 40$ years with a sufficiently long follow-up to determine treatment results up to 15 years. The endpoints of this study were local relapse, distant recurrence and death.

In Chapter 2.2 we evaluate the trends in the risk of local recurrences after BCT and examines the impact of local recurrence on distant relapse-free survival of young women with early-stage breast cancer. All women $(n=1143)$ aged $\leq 40$ years with earlystage (pT1-2/cT1-2, N0-2, M0) breast cancer who underwent BCT in the south of the Netherlands between 1988 and 2010 were included. Special attention was paid to the influence of (neo)adjuvant systemic therapy.

In Chapter 2.3 we investigate the detection of a local recurrence in young women with breast cancer after BCT to compare the impact of different long-term follow-up strategies. Between 1988 and 2005, 937 women aged $\leq 40$ years were treated with BCT for early-stage breast cancer. Up to October 2009, 152 had developed an isolated local recurrence. Information on follow-up visits was available for 124 of them. It was hypothesized that a more frequent and prolonged follow-up for these patients would result in an earlier detection of local recurrence.

In Chapter 3.1 we evaluate the influence of positive surgical margins on the local recurrence rate in patients diagnosed with invasive lobular cancer and treated with BCT. 416 women diagnosed with invasive lobular breast cancer and undergoing BCT between 1995 and 2002 were selected from the population-based ECR. The medical record of each of these 416 patients was reviewed for detailed information with respect to the locoregional and systemic treatment of the primary tumour. Information was recorded on the presence and extent of tumour involvement of the margins of the specimen of the primary tumour and the specimen taken at reexcision.

In Chapter 3.2 we examine the impact of the use of postmastectomy radiotherapy on the risk of local recurrence in patients with invasive lobular breast cancer. Of the 499 patients who underwent mastectomy in five general hospitals in the southern part of the Netherlands between 1995 and 2002 a number of 383 patients fulfilled the 
eligibility criteria. Of these patients, 170 (44.4\%) had received postmastectomy radiotherapy. The median follow-up was 7.2 years.

In Chapter 4.1 we examine the characteristics and the prognosis of patients with a local recurrence in the breast occurring more than 5 years after BCT. In the period 1982-1997, 3280 patients with invasive breast cancer underwent BCT in one of the eight community hospitals in the southeastern part of the Netherlands. Of these patients, 98 developed a local recurrence in the breast more than 5 years after BCT. A comparison was made with the characteristics and the prognosis of patients with a local recurrence occurring within 5 years after breast-conserving therapy who were described in a previously published study.

In Chapter 4.2 we study the outcome and related prognostic factors in 124 patients with an isolated local recurrence in the breast following breast-conserving surgery and radiotherapy for early stage breast cancer diagnosed at the age of 40 years or younger. Data from the population-based ECR were used to select the patients who were diagnosed with breast cancer and received BCT between 1988 and 2005. In particular, the influence of tumour size and the mode of detection of the local recurrence in the breast were determined.

In Chapter $\mathbf{5 . 1}$ we assess the chance for internal mammary lymph nodes recurrence in a large patient series of nearly 6000 patients and gets insight into diagnostics, treatment and prognosis of this type of recurrence.

In Chapter $\mathbf{5 . 2}$ we study the diagnosis, treatment, outcome and prognostic factors of patients with an isolated supraclavicular recurrence. In the period 1984-1994, 4669 patients with invasive breast carcinoma underwent axillary dissection in 8 community hospitals in the southeastern part of the Netherlands. During follow-up, 42 patients with isolated supraclavicular recurrence were identified.

In Chapter 6 we provide a summary, general discussion and future perspectives, thereby focusing on less extensive locoregional treatment and personalised cancer treatment. 


\section{References}

1. Ferlay J, Shin HR, Bray F, Forman D, Mathers C, Parkin DM. Estimates of worldwide burden of cancer in 2008: GLOBOCAN 2008. Int J Cancer 2010;127:2893-917.

2. Ferlay J, Steliarova-Foucher E, Lortet-Tieulent J, Rosso S, Coebergh JW, Comber H, Forman D, Bray F. Cancer incidence and mortality patterns in Europe: estimates for 40 countries in 2012. Eur J Cancer 2013;49:1374-403.

3. Kiemeney LA, Lemmers FA, Verhoeven $\mathrm{RH}$, et al. [The risk of cancer in the Netherlands]. Ned Tijdschr Geneeskd 2008;152:2233-41.

4. van der Sangen MJ, Voogd AC, van de Poll-Franse LV, Tjan-Heijnen VC. [Breast cancer in young women: epidemiology and treatment dilemmas]. Ned Tijdschr Geneeskd 2008;152:2495-500.

5. Fisher B, Slack NH, Bross ID. Cancer of the breast: size of neoplasm and prognosis. Cancer 1969;24:1071-80.

6. Engell HC. Cancer cells in the circulating blood; a clinical study on the occurrence of cancer cells in the peripheral blood and in venous blood draining the tumour area at operation. Acta Chir Scand Suppl 1955;201:1-70.

7. Fisher B, Fisher ER. Barrier function of lymph node to tumor cells and erythrocytes. I. Normal nodes. Cancer 1967;20:1907-13.

8. Fisher ER, Turnbull RB, Jr. The cytologic demonstration and significance of tumor cells in the mesenteric venous blood in patients with colorectal carcinoma. Surg Gynecol Obstet 1955;100:102-8.

9. Keynes G. Conservative Treatment of Cancer of the Breast. BMJ 1937;2:643-66 3.

10. Atkins $\mathrm{H}$, Hayward JL, Klugman DJ, Wayte AB. Treatment of early breast cancer: a report after ten years of a clinical trial. BMJ 1972;2:423-9.

11. Kurtz JM, Amalric R, Santamaria F, et al. Radiation therapy after breast-conserving surgery for Stage I and II mammary carcinoma. Results of the Marseille experience 1961 to 1976. Strahlentherapie 1984;160:239-43.

12. Delouche G, Bachelot F, Premont M, Kurtz JM. Conservation treatment of early breast cancer: long term results and complications. Int J Radiat Oncol Biol Phys 1987;13:29-34.

13. Montague ED, Gutierrez AE, Barker JL, Tapley ND, Fletcher GH. Conservation surgery and irradiation for the treatment of favorable breast cancer. Cancer 1979;43:1058-61.

14. Durand JC, Pilleron JP. [Breast cancer: limited excision followed by irradiation. Results and therapeutic indications in 150 cases treated at the Curie Foundation in 1960-1970]. Bull Cancer 1977;64:611-8.

15. Fisher B, Anderson S, Bryant J, et al. Twenty-year follow-up of a randomized trial comparing total mastectomy, lumpectomy, and lumpectomy plus irradiation for the treatment of invasive breast cancer. N Engl J Med 2002;347:1233-41.

16. Veronesi U, Cascinelli N, Mariani L, et al. Twenty-year follow-up of a randomized study comparing breast-conserving surgery with radical mastectomy for early breast cancer. N Engl J Med 2002;347:1227-32.

17. Clarke M, Collins R, Darby S, et al. Effects of radiotherapy and of differences in the extent of surgery for early breast cancer on local recurrence and 15-year survival: an overview of the randomised trials. Lancet 2005;366:2087-106.

18. Lichter AS, Lippman ME, Danforth DN, Jr., et al. Mastectomy versus breast-conserving therapy in the treatment of stage I and II carcinoma of the breast: a randomized trial at the National Cancer Institute. J Clin Oncol 1992;10:976-83.

19. Sarrazin D, Le MG, Arriagada R, et al. Ten-year results of a randomized trial comparing a conservative treatment to mastectomy in early breast cancer. Radiother Oncol 1989;14:177-84.

20. Poggi MM, Danforth DN, Sciuto LC, et al. Eighteen-year results in the treatment of early breast carcinoma with mastectomy versus breast conservation therapy: the National Cancer Institute Randomized Trial. Cancer 2003;98:697-702.

21. Litiere S, Werutsky G, Fentiman IS, et al. Breast conserving therapy versus mastectomy for stage I-II breast cancer: 20 year follow-up of the EORTC 10801 phase 3 randomised trial. Lancet Oncol 2012;13:412-9. 
22. Kurtz JM, Jacquemier J, Amalric R, et al. Risk factors for breast recurrence in premenopausal and postmenopausal patients with ductal cancers treated by conservation therapy. Cancer 1990;65:186778.

23. Voogd AC, Nielsen M, Peterse JL, et al. Differences in risk factors for local and distant recurrence after breast-conserving therapy or mastectomy for stage I and II breast cancer: pooled results of two large European randomized trials. J Clin Oncol 2001;19:1688-97.

24. Kurtz JM, Spitalier JM, Amalric R, et al. Mammary recurrences in women younger than forty. Int J Radiat Oncol Biol Phys 1988;15:271-6.

25. Nixon AJ, Neuberg D, Hayes DF, et al. Relationship of patient age to pathologic features of the tumor and prognosis for patients with stage I or II breast cancer. J Clin Oncol 1994;12:888-94.

26. Recht A, Connolly JL, Schnitt SJ, et al. The effect of young age on tumor recurrence in the treated breast after conservative surgery and radiotherapy. Int J Radiat Oncol Biol Phys 1988;14:3-10.

27. Anders CK, Johnson R, Litton J, Phillips M, Bleyer A. Breast cancer before age 40 years. Semin Oncol 2009;36:237-49.

28. Woodward WA, Buchholz TA. Should breast conservation be offered to young women with breast cancer? Breast Cancer Res Treat 2011;127:217-9.

29. Li Cl, Uribe DJ, Daling JR. Clinical characteristics of different histologic types of breast cancer. Br J Cancer 2005;93:1046-52.

30. Kwast $A B$, Groothuis-Oudshoorn KC, Grandjean I, et al. Histological type is not an independent prognostic factor for the risk pattern of breast cancer recurrences. Breast Cancer Res Treat 2012;135:271-80.

31. Arpino G, Bardou VJ, Clark GM, Elledge RM. Infiltrating lobular carcinoma of the breast: tumor characteristics and clinical outcome. Breast cancer research : BCR 2004;6:R149-56.

32. Poortmans PM, Bollet M, Van Limbergen E. Infiltrating lobular breast cancer: truly a separate entity! Consequences for radiation therapy. Radiother Oncol 2013;106:1-4.

33. Lu W, Schaapveld M, Jansen L, et al. The value of surveillance mammography of the contralateral breast in patients with a history of breast cancer. Eur J Cancer 2009;45:3000-7.

34. Anderson SJ, Wapnir I, Dignam JJ, et al. Prognosis after ipsilateral breast tumor recurrence and locoregional recurrences in patients treated by breast-conserving therapy in five National Surgical Adjuvant Breast and Bowel Project protocols of node-negative breast cancer. J Clin Oncol 2009; 27:2466-73.

35. Wapnir IL, Anderson SJ, Mamounas EP, et al. Prognosis after ipsilateral breast tumor recurrence and locoregional recurrences in five National Surgical Adjuvant Breast and Bowel Project node-positive adjuvant breast cancer trials. J Clin Oncol 2006;24:2028-37.

36. Voogd AC, Coebergh JW, Crommelin MA, van der Heyden LH, Kluck HM. Breast-conserving treatment of early breast cancer: survival and recurrence in community hospitals in southeastern Netherlands. Neth J Surg 1991;43:105-9.

37. Voogd AC, Repelaer van Driel OJ, Roumen RM, Crommelin MA, van Beek MW, Coebergh JW. Changing attitudes towards breast-conserving treatment of early breast cancer in the south-eastern Netherlands: results of a survey among surgeons and a registry-based analysis of patterns of care. Eur J Surg Oncol 1997;23:134-8.

38. Voogd AC, van Beek MW, Crommelin MA, Kluck HM, Repelaer van Driel OJ, Coebergh JW Management of early breast cancer in southeast Netherlands since 1984. A population-based study. Regional Breast Cancer Study Group. Acta Oncol 1994;33:753-7. 


\section{Chapter 2}

Local control in young women 


\section{Chapter 2.1}

Are breast-conservation and mastectomy equally effective in the treatment of young women with early breast cancer? Long-term results of a population based cohort of 1451 patients aged $\leq 40$ years

MJC van der Sangen FMM van de Wiel PMP Poortmans VCG Tjan-Heijnen GAP Nieuwenhuijzen

RMH Roumen MF Ernst CBJE Tutein Nolthenius-Puylaert AC Voogd 


\section{Abstract}

To compare the effectiveness of breast-conserving therapy (BCT) and mastectomy, all women aged $\leq 40$ years treated for early-stage breast cancer in the southern part of the Netherlands between 1988 and 2005, were identified. A total of 562 patients underwent mastectomy and 889 patients received BCT. During follow-up, 23 patients treated with mastectomy and 135 patients treated with BCT developed a local relapse without previous or simultaneous evidence of distant disease. The local relapse risk for patients treated with mastectomy was $4.4 \%$ (95\% confidence interval $(\mathrm{Cl}), 2.4-6.4)$ at 5 years and reached a plateau after 6 years at $6.0 \%(95 \% \mathrm{Cl}$, 3.5-8.5). After $\mathrm{BCT}$, the 5-, 10- and 15-year risks were $8.3 \%(95 \% \mathrm{Cl}, 6.3-10.5), 18.3 \%(95 \% \mathrm{Cl}$, 15.0-21.8) and $27.9 \%(95 \% \mathrm{Cl}, 23.0-33.4)$, respectively $(P<.0001)$. Adjuvant systemic therapy following BCT reduced the 15-year local relapse risk from $32.9 \%(95 \% \mathrm{Cl}, 26.7-39.1)$ to $16.1 \%$ $(95 \% \mathrm{Cl}, 9.1-23.1),(P=0.0007)$. In conclusion, local tumour control in young patients with earlystage breast cancer is worse after BCT than after mastectomy. Adjuvant systemic therapy significantly improves local control following BCT and also for that reason it should be considered for most patients $\leq 40$ years. Long-term follow-up is highly recommended for young patients after $\mathrm{BCT}$, because even with systemic treatment an annual risk of local relapse of $1 \%$ remains up to 15 years after treatment. 


\section{Introduction}

Multiple randomised controlled trials have shown that survival rates for patients with early-stage breast cancer are comparable after breast-conserving therapy (BCT) and mastectomy ${ }^{1-5}$. Consequently, BCT is now widely accepted as a local treatment for early-stage breast cancer.

Some doubts still remain concerning the treatment of young women since young age has been shown to be an independent risk factor for local relapse after BCT, much more than after mastectomy ${ }^{6-10}$. The 10 -year local relapse rate for women aged $\leq 40$ years varies between $19 \%$ and $35 \%$ after BCT and between $7 \%$ and $12 \%$ after mastectomy ${ }^{6,8,9,11,12}$. In two previous reports concerning women $\leq 40$ years we found 5- and 10 -year actuarial local relapse rates of $9 \%$ and $17.9 \%$, respectively, after $\mathrm{BCT}^{13}$ and of $5.6 \%$ and $7.3 \%$ after mastectomy ${ }^{14}$.

Only $5 \%$ to $10 \%$ of all women with breast cancer are aged 40 years or younger at diagnosis. Because of this relatively low incidence, subgroup analyses of the randomised controlled trials could not confirm whether BCT is as safe as mastectomy in the treatment of early-stage breast cancer in young women. Even by pooling data derived from all available trials, the number of young patients would be too small to draw firm conclusions. Therefore, evidence for the safety of BCT was searched in a few non-randomised studies ${ }^{15-17}$. Limitations of these studies are the relatively small number of patients, ranging from 540 to 668, insufficient information on the risk factors of local relapse and a follow-up time up limited to only 10 years. Therefore, we evaluated a large cohort of 1451 patients aged $\leq 40$ years with a sufficiently long follow-up to determine treatment results up to 15 years.

\section{Patients and methods}

\section{Patients}

Patient data were obtained from the population-based Eindhoven Cancer Registry (ECR). This serves a population of approximately 2.4 million inhabitants in the south of the Netherlands and records data on all patients with newly diagnosed cancer since 1955. These data were compared to data derived from the two radiotherapy departments in this region, the Catharina Hospital in Eindhoven and the Institute Verbeeten in Tilburg. Records of patients who did not receive radiotherapy after mastectomy were provided by the surgical departments of the 10 regional hospitals. Only patients with stage I or II breast cancer (pT1-2, N0-2, M0) were considered eligible for the study. The ECR identified 846 patients aged $\leq 40$ years who underwent mastectomy between 1988 and 2005, from whom 745 medical records were available. For the other 101 patients records were either missing or incomplete after digitalising paper medical records. Over the same period, 937 patients aged $\leq 40$ years 
received $\mathrm{BCT}$, for whom all patient records were available. The medical files were reviewed to extract information with respect to patient-, tumour- and treatment characteristics as well as to outcome. After exclusion of 122 patients with stage III or IV breast cancer, 44 patients with neo-adjuvant systemic treatment, 8 patients with synchronous bilateral breast cancer, 19 patients with non-invasive breast cancer, and 8 patients without radiotherapy of the breast following breast-conserving surgery, 562 patients remained available for analysis in the mastectomy group and 889 patients in the BCT group.

\section{Treatment}

Patients underwent mastectomy or BCT. All patients received either a sentinel lymph node procedure or an axillary lymph node dissection. Indications for locoregional radiotherapy after mastectomy included an involved lymph node in the apex of the axilla, fixed axillary lymph nodes or $\geq 4$ lymph node metastases. This locoregional radiotherapy was given to a dose of 46 to $50 \mathrm{~Gy}$. In case of an incomplete tumour resection of the primary breast tumour, a boost to a dose of 13.8 to 26 Gy was given to part of the chest wall. Until 2002 the guidelines also recommended the use of postmastectomy radiotherapy for patients with extracapsular lymph node invasion. In the framework of BCT, patients received 46 to 50 Gy to the whole breast, in 796 patients $(91.8 \%)$ followed by a boost of 10 to 26 Gy to the primary tumour bed. Indications for locoregional radiotherapy after breast conserving surgery were similar to those after mastectomy.

Before 1998, adjuvant systemic treatment was based on regional guidelines and was recommended only for patients with involved axillary lymph nodes. In 1998, a new national guideline was published ${ }^{18}$, based on the St. Gallen guidelines ${ }^{19,20}$, after which lymph node-negative patients with high-risk breast cancer were advised to receive adjuvant systemic treatment, depending on size, grade, and hormone receptor status of the tumour. In 2001, the guidelines were updated, recommending adjuvant systemic treatment also for most patients aged $\leq 35$ years, irrespective of their lymph node status.

The standard chemotherapy regimen consisted of cyclophosphamide, methotrexate and 5-fluorouracil (CMF) in the early years of the study period and of anthracyclinecontaining regimens thereafter. From 1988 until 2001 there was no strict guideline for the use of hormonal therapy for pre-menopausal patients who had receptor-positive tumours. After 2001 hormonal therapy was recommended for all receptor positive high-risk patients. In the study period, trastuzumab was not yet implemented in the adjuvant setting.

\section{Follow-up}

For patients treated with mastectomy, follow-up was completed until January $1^{\text {st }}$, 2007 or death. Median duration of follow-up was 7.4 years. Patients receiving BCT 
were followed up until death or January $1^{\text {st }}, 2008$. Median duration of follow-up was 9.5 years. Seventy-three patients (5.0\%) were lost to follow-up, meaning that their last contact with the surgeon, radiation oncologist or general practitioner was before January $1^{\text {st }}, 2007$ in case of mastectomy or January $1^{\text {st }}, 2008$ in case of BCT. The median follow-up for these patients was 8.9 years and they have been included in the analysis until their last date of contact.

\section{Methods}

The endpoints of this study were local relapse, distant recurrence and death.

Local relapse was defined as reappearance of tumour growth in the treated breast or overlying skin or, in case of mastectomy, on the ipsilateral chest wall. The time to an event was estimated using the life-table method and was considered to be the interval between the date of primary treatment and occurrence of the event. Observation time was censored at January $1^{\text {st }}, 2007$ for patients undergoing mastectomy and January $1^{\text {st }}, 2008$ for those undergoing BCT, or death or the last date of contact for patients who were lost to follow-up. Local relapses that were diagnosed after distant metastases or with synchronous distant disease were not counted as events in the survival analyses, because these are considered to be of little clinical importance and because the risk of underreporting is high. These patients were censored at the date of diagnosis of distant disease.

A multivariate analysis was carried out using Cox proportional hazard model to determine the impact of the type of surgery on the risk of distant recurrence, adjusting for age at diagnosis, the period of diagnosis, tumour size, axillary nodal status and use of adjuvant systemic treatment.

\section{Results}

\section{Patient, tumour and treatment characteristics}

Table 2.1.1 lists the patient, tumour and treatment characteristics of the study population.

Median age at diagnosis was 37.2 years for patients treated with mastectomy and 37.4 years for those treated with BCT. As expected, despite the restriction to early stage breast cancer, patients treated with mastectomy generally had worse prognostic factors, when compared to those treated with BCT (Table 2.1.1). Because of worse prognostic factors, patients treated with mastectomy more often received systemic therapy $(P<0.0001)$. The proportion of young women undergoing BCT decreased from $69 \%$ in the period $1988-1993$ to $55 \%$ in the period $2000-2005$ $(P<0.0001)$. 
Table 2.1.1 General characteristics of patients aged 40 years or younger undergoing breast-conserving therapy (BCT) or mastectomy in the period 1988-2005.

\begin{tabular}{|c|c|c|c|c|c|}
\hline \multirow[t]{2}{*}{ Characteristics } & \multicolumn{2}{|c|}{$\begin{array}{c}\text { BCT } \\
(n=889)\end{array}$} & \multicolumn{2}{|c|}{$\begin{array}{c}\text { Mastectomy } \\
(n=562)\end{array}$} & \multirow[t]{2}{*}{$P$-value } \\
\hline & No. & $(\%)$ & No. & $(\%)$ & \\
\hline Age (yrs) & & & & & 0.048 \\
\hline$\leq 30$ & 69 & (8) & 65 & (12) & \\
\hline $31-35$ & 253 & (28) & 149 & (27) & \\
\hline $36-40$ & 567 & (64) & 348 & (62) & \\
\hline Period & & & & & $<0.0001$ \\
\hline 1988-1993 & 309 & (35) & 136 & (24) & \\
\hline 1994-1999 & 306 & (34) & 198 & (35) & \\
\hline $2000-2005$ & 274 & (31) & 228 & (51) & \\
\hline Tumour size (pT) & & & & & $<0.0001$ \\
\hline $\mathrm{T} 1$ & 610 & (70) & 227 & $(42)$ & \\
\hline $\mathrm{T} 2$ & 266 & (30) & 313 & (58) & \\
\hline Unknown & 13 & & 22 & & \\
\hline Nodal status (pN) & & & & & $<0.0001$ \\
\hline $\mathrm{pN}-$ & 581 & (66) & 271 & (48) & \\
\hline $\mathrm{pN}+$ & 304 & (34) & 288 & (52) & \\
\hline Unknown & 4 & & 3 & & \\
\hline Tumour type & & & & & $<0.0001$ \\
\hline Ductal & 802 & (90) & 478 & (85) & \\
\hline Lobular/mixed & 60 & (7) & 81 & (14) & \\
\hline Other & 27 & (3) & 3 & $(1)$ & \\
\hline Grade & & & & & 0.016 \\
\hline Good & 52 & (12) & 30 & (8) & \\
\hline Intermediate & 151 & (34) & 109 & (29) & \\
\hline Poor & 239 & (54) & 242 & (64) & \\
\hline Unknown & 447 & & 181 & & \\
\hline Oestrogen receptor & & & & & 0.389 \\
\hline Negative & 255 & (36) & 158 & $(32)$ & \\
\hline Positive & 455 & (64) & 314 & (68) & \\
\hline Unknown & 179 & & 90 & & \\
\hline Microscopic completeness of tumour excision & & & & & $<0.0001$ \\
\hline Complete & 836 & (94) & 477 & (85) & \\
\hline Incomplete & 39 & $(4)$ & 10 & $(2)$ & \\
\hline Doubtful or unknown & 14 & $(2)$ & 75 & $(12)$ & \\
\hline Radiotherapy & & & & & $<0.0001$ \\
\hline Yes & 889 & $(100)$ & 206 & (37) & \\
\hline No & 0 & $(0)$ & 355 & (63) & \\
\hline Unknown & & & 1 & & \\
\hline Adjuvant systemic treatment & & & & & $<0.0001$ \\
\hline Chemotherapy & 233 & (26) & 205 & (37) & \\
\hline Chemotherapy and endocrine treatment & 145 & $(16)$ & 154 & (27) & \\
\hline Endocrine treatment & 26 & (3) & 4 & $(1)$ & \\
\hline None & 483 & (54) & 198 & $(35)$ & \\
\hline Unknown & 2 & & 1 & & \\
\hline
\end{tabular}


After mastectomy, $37 \%$ of the patients received radiotherapy. The overall proportion of patients aged $\leq 40$ years receiving adjuvant systemic treatment increased from $35 \%$ in the period $1988-1993$ to $77 \%$ in the period $2000-2005$ (Figure 2.1.1).

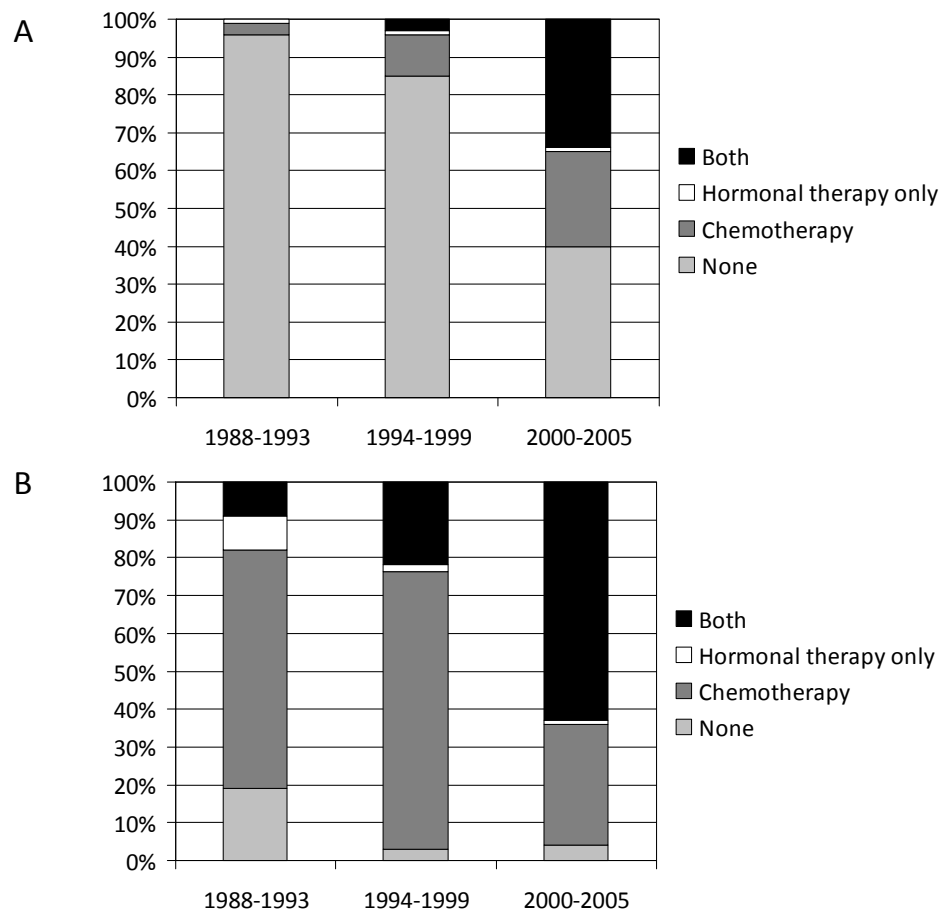

Figure 2.1.1 Proportion of patients receiving adjuvant systemic treatment, according to lymph node-status $(\mathrm{A}: \mathrm{pNO}, \mathrm{B}: \mathrm{pN}+$ ) and period of therapy.

\section{Local tumour control}

Of the 131 local relapses occurring after BCT, 61 (45\%) were diagnosed within 5 years, 44 (33\%) between 5 and 10 years, and 30 (22\%) thereafter. Twenty-three local relapses occurred after mastectomy, of which 19 (83\%) within 5 years and 4 (17\%) between 5 and 10 years after treatment. No local relapses were diagnosed more than 6 years after mastectomy.

Of the local relapses after BCT, 19 (14\%) were in situ and 111 (82\%) were invasive tumours. For five patients this information was missing. Of the 23 local relapses after mastectomy, 22 were invasive and one was an in situ lesion. Ninety (67\%) of the 135 local relapses following BCT were localized at or near the site of the primary tumour, 15 (11\%) were localized elsewhere in the breast, seven (5\%) were diffuse and one involved the skin. For 22 patients information on the location of the local relapse was missing. 
The actuarial risk of local relapse was significantly higher for patients undergoing BCT compared to patients undergoing mastectomy (Figure 2.1.2). The 5-, 10- and 15-year local relapse rates were $8.3 \%(95 \% \mathrm{Cl}, 6.3-10.5), 18.3 \%(95 \% \mathrm{Cl}, 14.9-21.7)$ and $27.9 \%$ (95\% Cl, 22.9-32.9), respectively. For the patients who underwent mastectomy, these figures were $4.4 \%(95 \% \mathrm{Cl}, 2.4-6.4)$ after 5 years and $6.0 \%(95 \% \mathrm{Cl}, 3.5-8.5)$ after 10 and after 15 years of follow-up. When also taking into account the local relapses that occurred simultaneously with distant metastases (11 after mastectomy and 19 after $\mathrm{BCT})$, the 5-, 10- and 15-year rates were $10.3 \%(95 \% \mathrm{Cl}, 8.1-12.5), 20.4 \%(95 \% \mathrm{Cl}, 17.0-$ 23.8) and $30.1 \%(95 \% \mathrm{Cl}, 25.0-35.2)$, respectively, after $\mathrm{BCT}$ and $6.4 \%(95 \% \mathrm{Cl}, 4.1-8.7)$, $8.2 \%(95 \% \mathrm{Cl}, 5.4-11.0)$ and $8.2 \%(95 \% \mathrm{Cl}, 5.4-11.0)$ after mastectomy $(P<0.0001)$.

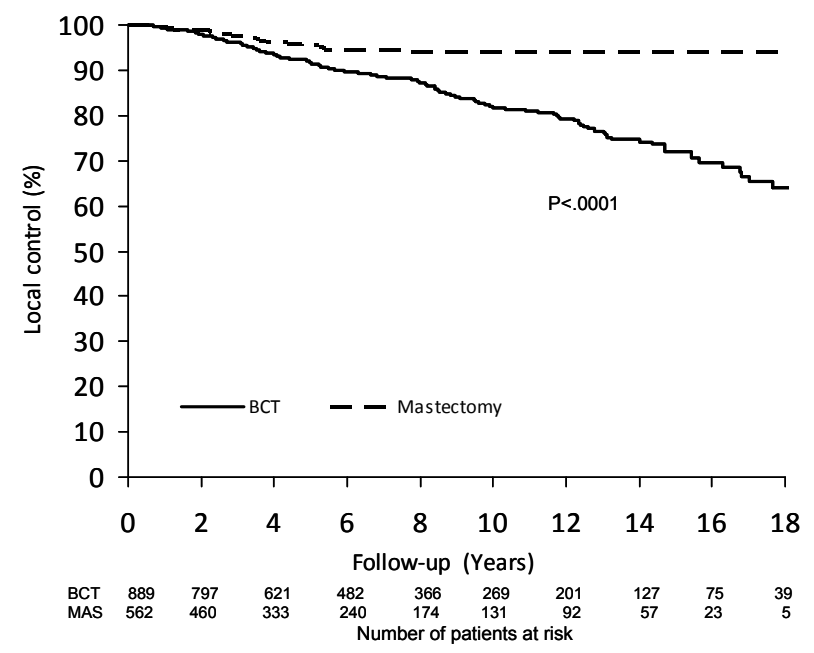

Figure 2.1.2 Actuarial local tumour control in patients aged $\leq 40$ years, according to local treatment. BCT, breast-conserving therapy.

A significant improvement was observed in the local control rate after BCT during the study period (Table 2.1.2). A stratified analysis according to axillary nodal status showed that this improvement did only occur in patients with negative lymph nodes. This appeared to be related to the increased use of systemic therapy over the years, as the risk for local relapse was significantly lower for patients who received adjuvant systemic treatment (Table 2.1.2, Figure 2.1.3). A higher local relapse risk was observed for patients whose excision of the primary tumour was incomplete or doubtful, as compared to those with a complete excision (Table 2.1.2). No significant associations were found between the risk of local relapse after BCT and tumour size and between the different age groups (<30, 30-35 and 35-40 years) (Table 2.1.2). The local relapse rate was significantly higher after BCT in the patient group without a boost dose of radiotherapy to the tumour bed (Table 2.1.2). No dose-effect relationship was observed for the patients receiving a boost dose. 
Table 2.1.2 5-, 10- and 15-year actuarial risks of local recurrence (LR) after BCT, according to patient, tumour and treatment characteristics

\begin{tabular}{|c|c|c|c|c|c|c|}
\hline Characteristics & No. & $\begin{array}{l}\text { No. } \\
\text { LRs }\end{array}$ & $\begin{array}{c}\text { 5-year rate } \\
\text { (SE) }\end{array}$ & $\begin{array}{c}\text { 10-year } \\
\text { rate } \\
\text { (SE) }\end{array}$ & $\begin{array}{l}\text { 15-year } \\
\text { rate (SE) }\end{array}$ & $P$-value \\
\hline \multicolumn{7}{|l|}{ Age (years) } \\
\hline$\leq 30$ & 69 & 9 & $2.2(2.2)$ & $16.9(6.4)$ & $28.4(9.5)$ & 0.566 \\
\hline $31-35$ & 253 & 44 & $9.3(2.0)$ & $23.6(3.6)$ & $29.9(4.5)$ & \\
\hline $36-40$ & 567 & 82 & $8.4(1.3)$ & $15.5(2.0)$ & $26.6(3.0)$ & \\
\hline \multicolumn{7}{|l|}{ Year of $\mathrm{BCT}$} \\
\hline $1988-1993$ & 309 & 74 & $11.2(2.0)$ & $20.2(2.7)$ & $30.3(3.2)$ & 0.031 \\
\hline 1994-1999 & 306 & 50 & $8.8(1.7)$ & $20.1(2.7)$ & n.a. & \\
\hline 2000-2005 & 274 & 11 & $3.8(1.3)$ & n.a. & n.a. & \\
\hline \multicolumn{7}{|l|}{ Pathological T-classification ( $\mathrm{pT}$ ) } \\
\hline $\mathrm{p} T 1$ & 610 & 99 & $8.5(1.2)$ & $18.7(2.1)$ & $27.8(2.9)$ & 0.590 \\
\hline рT2 & 266 & 32 & $6.0(1.7)$ & $16.4(3.2)$ & $27.7(5.6)$ & \\
\hline \multicolumn{7}{|l|}{ Pathological N-classification (pN) } \\
\hline $\mathrm{pNO}$ & 581 & 112 & $10.0(1.4)$ & $21.4(2.2)$ & $33.0(3.2)$ & 0.0009 \\
\hline pN1-2 & 304 & 23 & $4.5(1.4)$ & $10.6(2.5)$ & $13.9(3.4)$ & \\
\hline \multicolumn{7}{|l|}{ Radiotherapy boost } \\
\hline Yes & 815 & 113 & $8.0(1.1)$ & $17.9(1.8)$ & $26.6(2.7)$ & 0.044 \\
\hline No & 74 & 22 & $11.4(4.1)$ & $24.1(5.7)$ & $37.9(7.5)$ & \\
\hline \multicolumn{7}{|l|}{ Adjuvant systemic therapy } \\
\hline Yes & 404 & 30 & $4.2(1.1)$ & $11.3(2.4)$ & $16.1(3.5)$ & 0.0007 \\
\hline No & 483 & 105 & $11.3(1.6)$ & $22.3(2.3)$ & $32.9(3.1)$ & \\
\hline \multicolumn{7}{|c|}{ Microscopic completeness of tumour excision } \\
\hline Complete & 836 & 122 & $7.6(1.0)$ & $16.9(1.7)$ & $26.9(2.6)$ & 0.014 \\
\hline Incomplete / doubtful & 39 & 10 & $25.1(8.3)$ & $38.9(11.1)$ & n.a. & \\
\hline
\end{tabular}

n.a. not available

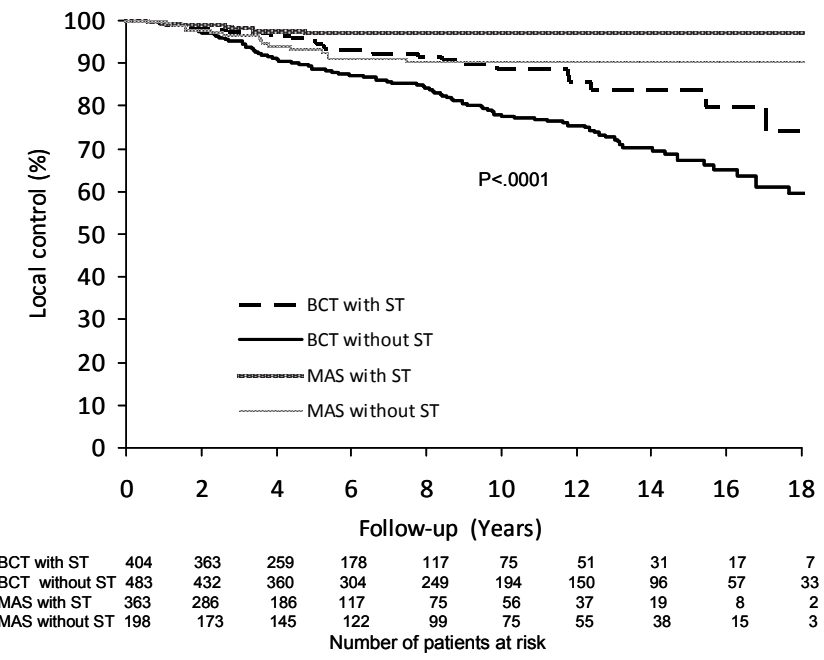

Figure 2.1.3 Actuarial local tumour control in patients aged $\leq 40$ years, according to local treatment and adjuvant systemic therapy. BCT, breast-conserving therapy; MAS, mastectomy; ST, adjuvant systemic therapy. 


\section{Distant recurrence-free and overall survival}

No statistically significant difference in distant recurrence-free survival was observed between the patients undergoing BCT or mastectomy (Figure 2.1.4). The 10-year distant recurrence-free survival rates were $71.0 \%(95 \% \mathrm{Cl}, 67.6-74.4)$ and $67.0 \%(95 \%$ $\mathrm{Cl}, 62.4-71.6)$, respectively. The 10 -year overall survival rate was $74.9 \%(95 \% \mathrm{Cl}, 71.7-$ 78.1) after $\mathrm{BCT}$ and $71.2 \%(95 \% \mathrm{Cl}, 66.4-76.0)$ after mastectomy $(P=0.215)$.

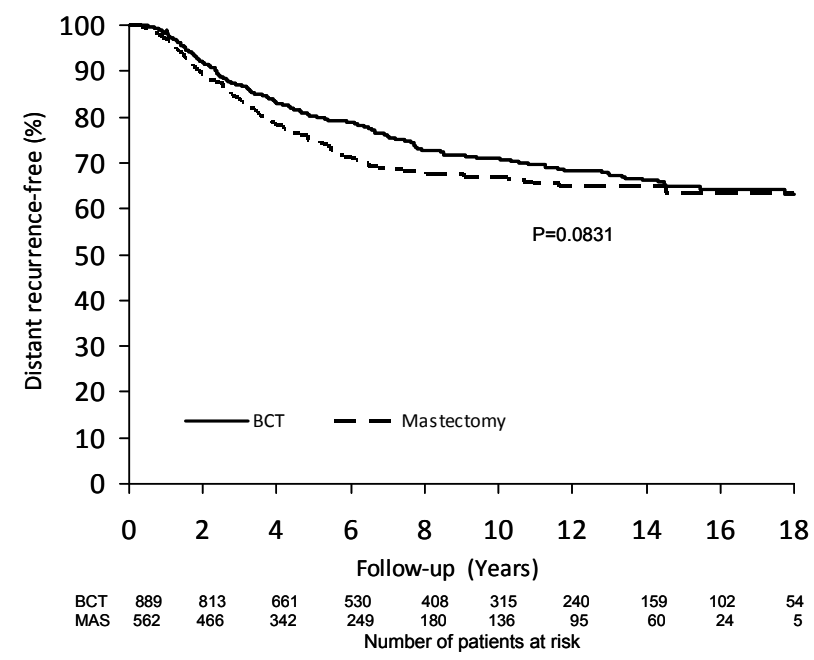

Figure 2.1.4 Actuarial distant recurrence-free survival in patients aged $\leq 40$ years, according to local treatment. BCT, breast-conserving therapy.

A stratified analysis according to tumour size (pT1 or pT2) and nodal status (pNO and pN1-2) was performed, in which four strata were created: pT1-pN0, pT2-pN0, pT1pN1-2 and pT2-pN1-2. In none of these four strata a statistically significant difference was observed in the distant recurrence-free survival between the patients undergoing BCT versus those with mastectomy, with $P$-values of $0.52,0.17,0.72$ and 0.64 , respectively.

In the first seven years after treatment, distant recurrence risk was significantly lower for the patients treated with BCT $(P=0.009)$. However, for the patients surviving without distant metastases until the seventh year of follow-up, the risk of developing distant disease is lower for the patients with mastectomy $(P=0.044)$. This reversal of the risk was also expressed by the distant disease hazard ratio (HR) for BCT compared to mastectomy, which was $0.75(95 \% \mathrm{Cl}, 0.61-0.93)$ during the first seven years of follow-up and $1.96(95 \% \mathrm{Cl}, 1.02-3.76)$ for the patients followed from seven years onward until censoring. 
A significant improvement in the distant recurrence-free survival was observed during the study period (Figure 2.1.3). The 5-year distant recurrence-free survival improved from $72.2 \%(95 \% \mathrm{Cl}, 67.9-76.5)$ in the period $1988-1993$ to $84.8 \%$ (95\% Cl, 81.0-88.6) in the period 2000-2005 (HR, 0.61; 95\% Cl, 0.45-0.82) (Table 2.1.3). Other independent favourable prognostic factors were: a negative axillary nodal status, a tumour size of $2 \mathrm{~cm}$ or less and the use of adjuvant systemic treatment.

Also the multivariate analysis showed no statistically significant difference in distant recurrence-free survival between patients treated with BCT and mastectomy (HR, $0.97 ; 95 \% \mathrm{Cl}, 0.78-1.20)$.

Table 2.1.3 Multivariable analysis for time until distant metastases for patients aged 40 years or younger $(n=1408)$.

\begin{tabular}{|c|c|c|c|}
\hline Characteristics & HR & $(95 \% \mathrm{Cl})$ & $P$-value \\
\hline \multicolumn{4}{|l|}{ Period of diagnosis } \\
\hline 1988-1993 & 1 (Ref) & & \\
\hline 1994-1999 & 0.75 & $(0.60-0.95)$ & 0.016 \\
\hline 2000-2005 & 0.61 & $(0.45-0.82)$ & 0.001 \\
\hline \multicolumn{4}{|l|}{ Age at diagnosis (years) } \\
\hline$\leq 35$ & 1 (Ref) & & \\
\hline $36-40$ & 1.12 & $(0.91-1.37)$ & 0.296 \\
\hline \multicolumn{4}{|c|}{ Pathologic tumour classification } \\
\hline pT1 & 1 (Ref) & & \\
\hline pT2 & 1.39 & $(1.13-1.70)$ & 0.002 \\
\hline \multicolumn{4}{|c|}{ Pathologic lymph node status } \\
\hline pNO & 1 (Ref) & & \\
\hline pN1-2 & 2.51 & $(1.85-3.40)$ & $<0.0001$ \\
\hline \multicolumn{4}{|l|}{ Type of surgery } \\
\hline Mastectomy & 1 (Ref) & & \\
\hline BCT & 0.97 & $(0.78-1.20)$ & 0.771 \\
\hline \multicolumn{4}{|l|}{ Adjuvant systemic therapy } \\
\hline No & 1 (Ref) & & \\
\hline Yes & 0.66 & $(0.48-0.91)$ & 0.012 \\
\hline
\end{tabular}

\section{Discussion}

The current study is one of the few studies focussing on young women with early stage breast cancer, comparing local control and survival after BCT and mastectomy. Our results indicate a worse local control after BCT with a linearly increasing cumulative risk of developing a local relapse even after more than 15 years of followup, whereas a plateau was reached after 6 years for the patients treated with mastectomy. Despite the more favourable stage distribution of the patients who underwent BCT, distant disease-free survival at 10 years was similar for both treatment groups. The local relapse rate after BCT showed a decreasing trend during the study period but still remains at $1 \%$ annually for the patients treated in the period 
2000-2005. We also noted a significant decrease of the distant recurrence risk over time, associated with increased use of systemic therapy, irrespective of the type of surgery.

Many studies on BCT have shown that young women have an increased local relapse risk compared to older women ${ }^{6-10,21}$. However, few data are available from studies in young women on treatment outcomes after BCT compared to mastectomy. Our data show that local relapses keep on occurring after BCT, even after prolonged follow-up. This continuing risk was previously reported by Kreike et al who report 10- and 15 -year local relapse-rates of $9.3 \%$ and $13.8 \%$, respectively, in a cohort of 1024 patients with a mean age of 50 years ${ }^{22}$. A possible explanation for at least part of the late local relapses is the occurrence of new primary tumours.

Minimising the risk of local relapse remains an important clinical issue. The EBCTCG meta-analysis has shown that local control has an influence on long term breast cancer related mortality: for every 4 local relapses prevented at 5 years, 1 breast cancer related death is avoided at 15 years ${ }^{23}$. Punglia et al emphasize the importance of a careful selection of patients for BCT as this strategy leads to a decrease in breast cancer-related and overall mortality ${ }^{24}$. Although the proportion of local relapses is higher after BCT, studies among young women show no difference in distant recurrence-free survival ${ }^{17,15}$. Neither did we find a significant difference, with a distant recurrence-free survival at 10 year of $67.0 \%$ after mastectomy and $71.1 \%$ after BCT. The multivariate analysis also showed no difference in distant recurrence-free survival after treatment with BCT and mastectomy. Results from retrospective studies are harder to interpret than results from randomised controlled studies, because of a possible bias due to differences in baseline characteristics and the selection of treatments. However, randomised studies were not able to give a definitive answer and new randomised controlled trials are hard to imagine. So far, our study is the largest with long-term follow-up comparing the outcome after BCT and mastectomy in young women with early-stage breast cancer. Moreover, it is population-based and follow-up was meticulously done. One could argue that the poor local control after $\mathrm{BCT}$ is dominated by a group of patients treated rather shortly after the introduction of BCT in the Netherlands, when less attention was given, for example, to preoperative imaging of the tumour and inking of surgical margins (both invasive and DCIS). Fact is however, that a poor local tumour control was also observed in the patients treated in the second period (1994-1999) (Table 2.1.2). Fortunately, in the period 2000-2005, we observed a clear trend towards improved local control. There are several factors which could have contributed to this improvement. First of all, the awareness of different risk factors for local relapse after BCT, not only may have led to a more stringent selection of patients for $\mathrm{BCT}^{25}$, but also to a certain reluctance towards treating young women with BCT. Over time, the BCT rate decreased from $69 \%$ to $55 \%$. Secondly, improvements in the locoregional treatment of breast cancer have taken place over the past decades. However, the most important reason for the better local control is the increased use of adjuvant systemic treatment. Table 2.1.2 
shows a significant increase in local tumour control over time for patients treated with BCT. This can be largely explained by the increasing proportion of node negative patients receiving adjuvant systemic therapy. In the period 1994-1999 15\% of node negative patients received adjuvant systemic therapy, which had increased to $60 \%$ in the period 2000-2005. Apart from this, we did not notice an additional influence of second or third generation regimens over first generation regimens on the local relapse rate. Our results, showing the importance of adjuvant systemic treatment and its potential to decrease the risk of local relapse, are in line with other studies ${ }^{7,13,23,26-28}$. Patient and tumour related risk factors for local relapse besides young age, are high tumour grade, positive excision margin, and lymphovascular invasion (LVI). In our series, $94 \%$ of the patients had a reported complete tumour excision and of all local relapses, 92\% occurred in patients with a microscopically complete excision. This is in line with the results of a study by Jones et al., in which only young age, grade 3 , the lack of systemic treatment and the omission of a boost dose were found to be independent prognostic factors for local relapses after $\mathrm{BCT}^{10}$. Data on LVI and tumour grade were not or only partly available in our material.

Local control is a result of the interaction between tumour remnants, treatment and tumour biology. An ipsilateral breast tumour recurrence (IBTR) can be a new primary tumour or the result of outgrowth of a tumour remnant in the treated breast, a so called true recurrence. New primary tumours often appear later in time and there is some proof that they have a more favourable prognosis than true recurrences. Molecular clonality assays can help to establish the type of IBTR ${ }^{29,30}$, but larger studies are needed to draw conclusions about their potential prognostic and therapeutic value.

Recently, studies of tumour biology by gene expression micro-array technology have demonstrated patterns correlating with breast cancer in young women ${ }^{31}$ and even local relapses in young women ${ }^{32}$. However, this new technology is not yet robust enough for clinical use with regard to local treatment decisions until results from ongoing prospective clinical trials are available. Genetic alterations in histologically normal tissue adjacent to the breast tumour, such as chromosomal instability and DNA hypermethylation, could also play a role in the development of local recurrence ${ }^{33,34}$.

For the patients in our study information about BRCA1/2 status was largely unknown. Population-based data indicate that approximately $10 \%$ of the breast cancers in women younger than 40 years are related to a BRCA1 or BRCA2 mutation ${ }^{35}$. Although women who carry BRCA mutations have a very high risk of developing breast cancer, there is no convincing evidence that their risk of developing local relapse after BCT is significantly different from the risk in non-carriers ${ }^{36-38}$. The risk of developing a contralateral breast cancer is, on the other hand, much higher than in noncarriers $^{36,38,37}$.

The categorisation into breast cancer subtypes, based on the combination of hormonal receptor status and HER-2 status, may be predictive for recurrence risks and 
survival. Kyndi et al found a significantly lower locoregional recurrence rate and a significant survival improvement in hormone receptor positive patients treated with mastectomy and radiation therapy whereas in triple negative and hormone receptor negative patients the benefit of radiotherapy was much less pronounced ${ }^{39}$. In HER-2 positive patients, trastuzumab reduced the risk of locoregional recurrence by $57 \%{ }^{40}$. In summary, local control after BCT in patients $\leq 40$ years is significantly worse than after mastectomy with local relapses continuing to occur during long-term follow-up. Local relapses might negatively influence the long term survival of patients with breast cancer, although we were unable to demonstrate this. Adjuvant systemic therapy has been the main contributor to the observed improvement of local control over the past decades. Nevertheless, the local relapse rate remains approximately $1 \%$ per year, which underlines the necessity of improvement and continuation of followup. Whether the marked reluctance against BCT in young women is less appropriate with current, more potent systemic treatment has to be confirmed. The biggest challenge still remaining is to define the most appropriate local treatment for each individual patient by establishing new predictors for local relapse after BCT. 


\section{References}

1. Veronesi U, Cascinelli N, Mariani L, Grecco M, Saccozzi R, Luini A, Aguilar M, Marubini E. Twenty-year follow-up of a randomized study comparing breast-conserving surgery with radical mastectomy for early breast cancer. N Engl J Med 2002;347:1227-32.

2. Fisher B, Anderson S, Bryant J, Margolese RG, Deutsch M, Fisher ER, Jeong J-H, Wolmark N. Twentyyear follow-up of a randomized trial comparing total mastectomy, lumpectomy, and lumpectomy plus irradiation for the treatment of invasive breast cancer. N Engl J Med 2002;347:1233-41.

3. Van Dongen JA, Voogd AC, Fentiman IS, Legrand C, Sylvester RJ, Tong D, Van der Schueren E, Helle PA, Van Zijl K, Bartelink $\mathrm{H}$. Long-term results of a randomized trial comparing breast-conserving therapy with mastectomy: European organization for research and treatment of cancer 10801 trial. J Natl Cancer Inst 2000;92:1143-50.

4. Jacobson JA, Danforh DN, Cowan KH, D'Angelo T, Steinberg SM, Pierce L, Lippman ME, Lichter AS, Glatstein $E$, Okunieff $P$. Ten-year results of a comparison of conservation with mastectomy in the treatment of stage i and ii breast cancer. N Engl J Med 1995;332:907-11.

5. Blichert-Toft M, Rose C, Andersen JA, Overgaard M, Axelsson CK, Andersen KW, Mouridsen HT. Danish randomized trial comparing breast conservation therapy with mastectomy: Six years of lifetable analysis. Danish breast cancer cooperative group. J Natl Cancer Inst Monogr 1992;(11):19-25

6. Voogd AC, Nielsen M, Peterse JL, Blichert-Toft M, Bartelink H, Overgaard M, Van Tienhoven G, West Andersen K, Sylvester RJ, Van Dongen JA. Differences in risk factors for local and distant recurrence after breast-conserving therapy or mastectomy for stage i and ii breast cancer: Pooled results for two large european randomized trials. J Clin Oncol 2001;19:1688-97.

7. De Bock GH, van der Hage JA, Putter H, Bonnema J, Bartelink H, Van de Velde CJ. Isolated locoregional recurrence of breast cancer is more common in young patients and following breast conserving therapy: Long-term results of european organisation for research and treatment of cancer studies. Eur J Cancer 2006;42:351-6.

8. Vrieling C, Fourquet A, Hoogenraad WJ, Horiot JC, Jager JJ, Bing Oei S, Peterse HL, Pierart M, Poortmans PM, Struikmans H, Van den Bogaert W, Bartelink H. Can patient-, treatment- and pathology-related characteristics explain the high local recurrence rate following breast-conserving therapy in young patients? Eur J Cancer 2003;39:932-44.

9. Elkhuizen PHM, Van de Vijver MJ, Hermans J, Zonderland HM, Van de Velde CJ, Leer J-WH. Local recurrence after breast-conserving therapy for invasive breast cancer: High incidence in young patients and association with poor survival. Int J Radiat Oncol Biol Phys 1998;40:859-67.

10. Jones HA, Antonini N, Hart AA, Peterse JL, Horiot JC, Collin F, Poortmans PM, Oei SB, Collette L, Struikmans H, Van den Bogaert WF, Fourquet A, Jager JJ, Schinagl DA, Wárlám-Rodenhuis CC, Bartelink $\mathrm{H}$. Impact of pathological characteristics on local relapse after breast-conserving therapy: A subgroup analysis of the eortc boost versus no boost trial. J Clin Oncol 2009;27:4939-47.

11. Jobsen JJ, Van der Palen J, Ong F, Meerwaldt JH. The value of a positive margin for invasive carcinoma in breast-conservative treatment in relation to local recurrence is limited to young women only. Int J Radiat Oncol Biol Phys 2003;57:724-31.

12. Arriagada R, Lê MG, Guinebretière J-M, Dunant A, Rochard F, Tursz $T$. Late local recurrences in a randomised trial comparing conservative treatment with total mastectomy in early breast cancer patients. Annals of Oncology 2003;14:1617-22.

13. Van der Leest M, Evers L, Van der Sangen MJC, Poortmans PM, Van de Poll-Franse LV, Vulto AJ, Nieuwenhuijzen GAP, Brenninkmeijer SJ, Creemers G, Voogd AC. The safety of breast-conserving therapy in patients with breast cancer aged $\leq 40$ years. Cancer 2007;109:1957-64.

14. Lammers EJR, Huibers P, Van der Sangen MJC, Van de Poll-Franse LV, Poortmans PM, Ernst MF, Lemaire BMD, Meijs CMEM, H.K.S. N, Voogd AC. Factors contributing to improved local control after mastectomy in patients with breast cancer aged 40 years or younger. Breast 2010;19:44-9.

15. Coulombe G, Tyldesley S, Speers C, Paltiel C, Aquino-Parsons C, Bernstein V, Truong P, Keyes M, Olivotto IA. Is mastectomy superior to breast-conserving treatment for young women? Int J Radiat Oncol Biol Phys 2007;67:1282-90. 
16. Beadle BM, Woodward WA, Tucker SL, Outlaw ED, Allen PK, Oh JL, Strom EA, Perkins GH, Tereffe W, $\mathrm{Yu}$ T, Meric-Bernstam F, Litton JK, Buchholz TA. Ten-year recurrence rates in young women with breast cancer by locoregional treatment approuch. Int J Radiat Oncol Biol Phys 2009;73:734-44.

17. Kroman N, Holtveg H, Wohlfart J, Jensen M-B, Mouridsen HT, Blichert-Toft M, Melbye M. Effect of breast-conserving therapy versus radical mastectomy on prognosis for young women with breast carcinoma. Cancer 2004;100:688-93.

18. Bontenbal M, Nortier JW, Beex LV, Bakker P, Hupperets PS, Nooij MA, Van Veelen H, Vreugdenhil G, Richel DJ, Bijham GH. Adjuvant systemic therapy for patients with resectable breast cancer: Guideline from the dutch national breast cancer platform and the dutch society for medical oncology. Ned Tijdschr Geneeskd 2000;144:984-9.

19. Goldhirsch A, Glick JH, Gelber RD, Senn HJ. Meeting highlights: International consensus panel on the treatment of primary breast cancer. J Natl Cancer Inst 1998;90:1601-8.

20. Goldhirsch A, Glick JH, Gelber RD, Coates AS, Senn HJ. Meeting highlights: International consensus panel on the treatment of primary breast cancer. Sevent.h international conference on adjuvant therapy of primary breast cancer. J Clin Oncol 2001;19:3817-27.

21. Zhou P, Gautam S, Recht A. Factors affecting outcome for young women with early stage invasive breast cancer treated with breast-conserving therapy. Breast cancer research and treatment 2007; 101:51-7.

22. Kreike B, Hart AMA, Van de Velde T, Borger J, Peterse H, Rutgers E, Bartelink H, Van de Vijver MJ. Continuing risk of ipsilateral breast relapse after breast-conserving therapy at long-term follow-up. Int J Radiat Oncol Biol Phys 2008;71:1014-21.

23. Clarke M, Collins R, Darby S, Davies C, Elphinstone P, Evans E, Godwin J, Gray R, Hicks C, James S, MacKinnon E, McGale P, McHugh T, Peto R, Taylor C, Wang Y. Effects of radiotherapy and differences in the extent of surgery for early breast cancer on local recurrence and 15-year survival: An overview of the randomised trials. Lancet 2005;366:2087-106.

24. Punglia RS, Morrow M, Winer EP, Harris JR. Local therapy and survival in breast cancer. N Engl J Med 2007;356:2399-405.

25. Voogd AC, Repelaer van Driel OJ, Roumen RMH, Crommelin MA, Van Beek MWPM, Coebergh JWW. Changing attitudes towards breast-conserving treatment of early breast cancer in the south-eastern netherlands: Results of a survey among surgeons and a registry-based analysis of patterns of care. Eur J Surg Oncol 1997;23:134-8.

26. Buchholz TA, Tucker SL, Erwin J, Mathur D, Strom EA, McNeese MD, Hortobagyi GN, Cristofanilli M, Esteva FJ, Newman L, Singletary ES, Buzdar AU, Hunt KK. Impact of systemic treatment on local control for patients with lymph node-negative breast cancer treated with breast-conservation therapy. J Clin Oncol 2001;19:2240-6.

27. Kroman N, Jensen M-B, Wohlfart J, Mouridsen HT, Andersen PK, Melbye M (2000) Factors influencing the effect of age on prognosis in breast cancer: Population based study. BMJ 2000;320:474-8.

28. Park CC, Mitsumori M, Nixon A, Recht A, Connoly J, Gelman R, Silver B, Hetelekidis S, Abner A, Harris $J R$, Schnitt SJ. Outcome at 8 years after breast-conserving surgery and radiation therapy for invasive breast cancer: Influence of margin status and systemic therapy on local recurrence. J Clin Oncol 2000;18:1668-75.

29. McGrath S, Antonucci J, Goldstein N, Wallace M, Mitchell C, Grills I, Jolly S, Kestin L, Vicini F. Longterm patterns of in-breast failure in patients with early stage breast cancer treated with breastconserving therapy: A molecular based clonality evaluation. Am J Clin Oncol 2010;33:17-22.

30. Schlechter BL, Yang Q, Larson PS, Golubeva A, Blanchard RA, de las Morenas A, Rosenberg CL. Quantitative DNA fingerprinting may distinguish new primary breast cancer from disease recurrence. J Clin Oncol 2004;22:1830-8.

31. Anders CK, Hsu DS, Broadwater G, Acharya CR, Foekens JA, Zhang Y, Wang Y, Marcom PK, Marks JR, Febbo PG, Nevins JR, Potti A, Blackwell KL. Young age at diagnosis correlates with worse prognosis and defines a subset of breast cancers with shares patterns of gene expression. J Clin Oncol 2008;26:3324-30.

32. Kreike B, Halfwerk $H$, Armstrong N, Bult P, Foekens JA, Veltkamp SC, Nuyten DSA, Bartelink H, Van de Vijver MJ. Local recurrence after breast-conserving therapy in relation to gene expression patterns in a large series of patients. Clin Cancer Res 2009;15:4181-90. 
33. Ellsworth DL, Ellsworth RE, Love B, Deyarmin B, Lubert SM, Mittal V, Shriver CD. Genomic patterns of allelic imbalance in disease free tissue adjacent to primary breast carcinomas. Breast Cancer Res Treat 2004;88:131-9.

34. Yan PS, Venkataramu C, Ibrahim A, Liu JC, Shen RZ, Diaz NM, Centeno B, Weber F, Leu YW, Shapiro CL, Eng C, Yeatman TJ, Huang THM. Mapping geographic zones of cancer risk with epigenetic biomarkers in normal breast tissue. Clin Cancer Res 2006;12:6626-36.

35. De Sanjosé $S$, Léoné $M$, Bérez $\mathrm{V}$, Izquierdo A, Font $\mathrm{R}$, Brunet JM, Louat $\mathrm{T}$, Vilardell L, Borras J, Viladiu P, Bosch FX, Lenoir GM, Sinilnikova OM. Prevalence of brca1 and brca2 germline mutations in young breast cancer patients: A population based study. Int J Cancer 2003;106:588-93.

36. Pierce LJ, Levin AM, Rebbeck TR, Ben-David MA, Friedman E, Solin L, Harris EE, Gaffney DK, Haffty BG, Dawson LA, Narod SA, Olivotto IA, Eisen A, Whelan TJ, Olopade OI, Isaacs C, Merajver SD, Wong JS, Garber JE, Weber BL. Ten-year multi-institutional results of breast-conserving surgery and radiotherapy in brca1/2-associated stage i/ii breast cancer. J Clin Oncol 2006;24:2437-43.

37. Haffty BG, Harrold E, Khan AJ, Pathare P, Smith TE, Turner BC, Glazer PM, Ward B, Carter D, Matloff E, Bale $A E$, Alvarez-Franco $M$. Outcome of conservatively managed early-onset breast cancer by brca1/2 status. Lancet 2002;359:1471-7.

38. Alpert TE, Haffty BG. Conservative management of breast cancer in brca1/2 mutation carriers. Clinical breast cancer 2004;5:37-42.

39. Kyndi M, Sorensen FB, Knudsen H, Overgaard M, Melgaard Nielsen H, Overgaard M. Estrogen receptor, progesterone receptor, her-2, and response to mastectomy radiotherapy in high-risk breast cancer: The danish breast cancer cooperative group. J Clin Oncol 2008;26:1419-26.

40. Romond EH, Perez EA, Bryant J, Suman VJ, Geyer CE, Davidson NE, Tan-Chiu E, Martino S, Paik S, Kaufman PA, Swain SM, Pisansky TM, Fehrenbacher L, Kutteh LA, Vogel VG, Visscher DW, Yothers G, Jenkins RB, Brown AM, Dakhil SR, Mamounas EP, Lingle WL, Klein PM, Ingle JN, Wolmark N. Trastuzumab plus adjuvant chemotherapy for operable her2-positive breast cancer. N Engl J Med 2005;353:1673-84. 


\section{Chapter}

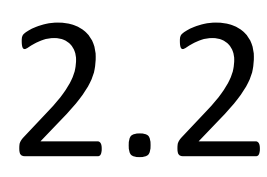

Local recurrence following breast-conserving therapy in women aged 40 years or younger: Trends in risk and the impact on prognosis in a population-based cohort of 1143 patients

C van Laar MJC van der Sangen

PMP Poortmans GAP Nieuwenhuijzen JA Roukema RMH Roumen VCG Tjan-Heijnen

AC Voogd 


\section{Abstract}

\section{Aim}

To evaluate trends in the risk of local recurrences after breast-conserving therapy (BCT) and to examine the impact of local recurrence (LR) on distant relapse-free survival in a large, population-based cohort of women aged $\leq 40$ years with early-stage breast cancer.

\section{Methods}

All women ( $n=1143$ ) aged $\leq 40$ years with early-stage (pT1-2/cT1-2, N0-2, M0) breast cancer who underwent BCT in the south of the Netherlands between 1988 and 2010 were included. BCT consisted of local excision of the tumour followed by irradiation of the breast.

\section{Results}

After a median follow-up of 8.5 (0.1-24.6) years, 176 patients had developed an isolated LR. The 5-year LR-rate for the subgroups treated in the periods 1988-1998, 1999-2005 and 2006-2010 were $9.8 \%$ (95\% confidence interval (Cl) $7.1-12.5), 5.9 \%(95 \% \mathrm{Cl} 3.2-8.6)$ and $3.3 \%(95 \% \mathrm{Cl}$ 0.6-6.0), respectively $(P=0.006)$. In a multivariate analysis, adjuvant systemic treatment was associated with a reduced risk of LR of almost $60 \%$ (HR $0.42 ; 95 \% \mathrm{Cl} 0.28-0.60 ; P<0.0001$ ). Patients who experienced an early isolated LR ( $\leq 5$ years after BCT) had a worse distant relapsefree survival compared to patients without an early LR (HR 1.83; 95\% $\mathrm{Cl} 1.27-2.64 ; P=0.001$ ). Late local recurrences did not negatively affect distant relapse-free survival (HR $1.24 ; 95 \% \mathrm{Cl}$ 0.74-2.08; $P=0.407)$.

\section{Conclusion}

Local control after BCT improved significantly over time and appeared to be closely related to the increased use and effectiveness of systemic therapy. These recent results underline the safety of BCT for young women with early- stage breast cancer. 


\section{Introduction}

Local recurrence (LR) after prior breast surgery has been linked to an increased risk of distant metastases and death ${ }^{1-5}$, where an early-LR (i.e. $\leq 5$ years) is associated with a greater risk of developing distant metastases compared to late-occurring $\mathrm{LRs}^{1-3,5}$. Young age has always been regarded as an independent prognostic factor for the risk of LR after breast-conserving therapy (BCT). The risk of developing a LR is 2-4 times higher in women younger than 40 years at the time of diagnosis of breast cancer compared to women older than 50 years ${ }^{2,3,6-11}$. Therefore, the risk of developing a LR remains a point of concern in young women treated with BCT.

Multiple studies have shown that the LR-rate after BCT is declining ${ }^{12-15}$. Explanations for this decline are suggested to be multifactorial, including a more careful evaluation of tumour margins, more extensive and accurate use of radiotherapy boost to the tumour bed and more patients receiving (neo)adjuvant systemic therapy ${ }^{8,12-14,16,17}$. The use of new combinations of (neo)adjuvant systemic therapy and the introduction of trastuzumab may have resulted in a further improvement of the local control, especially in young women. Trastuzumab is used in the adjuvant setting in the Netherlands since $2005^{18}$. Several studies that compared adjuvant chemotherapy with or without trastuzumab in women with surgically removed HER2-positive breast cancer showed that the use of trastuzumab improves LR-free survival ${ }^{19-26}$.

To evaluate the risk of LR after BCT and to determine factors that are of prognostic relevance in consecutive time era's, we studied a large cohort of 1143 patients aged $\leq 40$ years who received BCT in the period 1988-2010.

\section{Patients and methods}

\section{Study population}

Patient data were obtained from the population-based Eindhoven Cancer Registry (ECR). This serves a population of approximately 2.4 million inhabitants in the south of the Netherlands and records data on all patients with newly diagnosed cancer since 1955. These data were compared to data provided by the two radiotherapy departments in this region, the Catharina Hospital in Eindhoven and the Institute Verbeeten in Tilburg. Only patients with early-stage (pT1-2/cT1-2, N0-2, M0) breast cancer (TNM/AJCC tumour staging $7^{\text {th }}$ edition) were considered eligible for this study. The ECR identified 1200 patients aged $\leq 40$ years who were diagnosed with breast cancer and underwent BCT between 1988 and 2010. The medical files from the patients of the two radiotherapy departments were used to extract information with respect to patient, tumour and treatment characteristics as well as to outcome. When recent follow-up information was missing, we contacted the general practitioner. After exclusion of 32 patients with stage III or IV breast cancer, 9 patients with non- 
invasive breast cancer, 3 patients with synchronous bilateral breast cancer, 2 patients who underwent mastectomy instead of BCT, 10 patients who presented with a local recurrence or contralateral breast carcinoma instead of a primary breast tumour and 1 patient who had not received radiotherapy, 1143 patients remained available for the analysis.

\section{Treatment}

BCT included wide local excision of the tumour and appropriate axillary management followed by irradiation of the whole breast, mostly including a boost to the primary tumour bed. Further details about this cohort have been published before ${ }^{13,14}$.

Some major changes in the management of breast cancer in the Netherlands took place during the period covered by our study. The first major change was in 1998, with the publication of the new Dutch guideline ${ }^{27}$ according to which lymph nodenegative patients with high-risk features, depending on the size, grade and hormone receptor status of their tumour, were advised to receive adjuvant systemic therapy. The second major change was an update of the guideline in 2005, where women with HER2-positive breast cancer were recommended to receive trastuzumab in conjunction with adjuvant chemotherapy. Based on these changes in the guidelines for administering systemic therapy, we decided to divide the study population into 3 subgroups; 1988 to 1998, 1999 to 2005 and 2006 to 2010.

\section{Definition of endpoints}

The endpoints of this study were LR, distant metastasis and death. For each endpoint, the time to event was defined as the interval between the pathologic diagnosis and occurrence of the event of interest. In the absence of the event of interest, observation time was censored at the last contact date of the patient. LR was defined as any reappearance of tumour growth in the initially treated breast or overlying skin. LRs that were diagnosed after distant metastases or with synchronous distant disease were not counted as events and these patients were censored at the date of diagnosis of distant disease.

\section{Follow-up}

The median follow-up time for all 1143 patients was 6.8 (range 0.1-24.6) years, and 8.5 years for the patients still alive. The median duration of follow up was 11.5 years for the patients treated in 1988-1998 (14.4 years for those still alive), 8.1 years for the patients treated in 1999-2005 ( 8.5 years for those still alive) and 3.6 years for the patients treated in 2006-2010 (3.7 years for those still alive). On $1^{\text {st }}$ January, 2010, 78 patients $(6.8 \%)$ were lost to follow-up, which meant that their last contact date was before $1^{\text {st }}$ January, 2010. The median follow-up for these 78 patients was 9.6 years. 


\section{Statistical analysis}

The 5-,10-, and 15-year actuarial rates of LR and the curves for LR-free survival were generated using the Kaplan-Meier method, with comparisons made using the log-rank test. Multivariate analyses were carried out using Cox proportional hazards models to identify factors that were associated with an increased risk of $L R$ and factors that were associated with the occurrence of distant disease. A backward elimination model omitted covariates that had a $P$-value greater than 0.05 . The multiple imputation method was used to generate possible values for missing values of the oestrogen receptor status, tumour grade, tumour size, nodal status and the use of (neo)adjuvant systemic therapy. Multiple datasets were generated using a model that included all variables used in the Cox regression analysis. To examine the impact of LR on the subsequent occurrence of distant disease, we used the Kaplan-Meier method and the Cox proportional hazards model. All tests were two-sided, and a $P$-value $<0.05$ was considered statistically significant. All data were analysed using SPSS version 20 .

\section{Results}

\section{Patient, tumours and treatment characteristics}

The median age at diagnosis was 37 years (range, $21-40$ years). No differences were detected between the 3 subgroups (1988-1998, 1999-2005 and 2006-2010) with respect to age, nodal status, tumour type, oestrogen and HER2 status (Table 2.2.1).

All patients, except for nine, underwent axillary staging, either by axillary dissection, sentinel node biopsy or both. The proportion of patients receiving (neo)adjuvant systemic treatment increased from $32 \%$ in the period $1988-1998$ to $71 \%$ in the period $1999-2005$ and to $83 \%$ in the period $2006-2010$ (Table 2.2.1). The increase was much larger for patients with negative axillary lymph nodes (from $6 \%$ to $75 \%$ ) than for patients with positive lymph nodes (from 84\% to 98\%). Forty-nine (96\%) of the 51 patients with an HER2-positive tumour treated in the period 2006-2010, received trastuzumab in combination with chemotherapy (Table 2.2.1).

\section{Local tumour control}

During follow-up, a LR was diagnosed in 176 patients without evidence of metastatic disease at a mean of 7.9 (median 6.8) years after BCT (range 0.58-24.1). Twenty-six additional LRs diagnosed either after or at the same time as distant disease were not included in the current analyses. Characteristics of the 176 LRs are presented in Table 2.2.2. 
Table 2.2.1 Patient and treatment characteristics according to period of diagnosis ( $n=1143$ patients).

\begin{tabular}{|c|c|c|c|c|c|}
\hline Characteristics & $\begin{array}{c}\text { Period 1988- } \\
1998 \\
(n=565) \\
\text { No. }(\%)\end{array}$ & $\begin{array}{c}\text { Period 1999- } \\
2005 \\
(n=325) \\
\text { No. }(\%)\end{array}$ & $\begin{array}{c}\text { Period 2006- } \\
2010 \\
(n=253) \\
\text { No. }(\%)\end{array}$ & $\begin{array}{c}\text { Total } \\
(n=1,143) \\
\text { No. }(\%)\end{array}$ & $P$-value \\
\hline \multicolumn{6}{|l|}{ Age, yrs } \\
\hline$\leq 30$ & $48(9)$ & $22(7)$ & $15(6)$ & $85(8)$ & 0.147 \\
\hline $31-35$ & $164(29)$ & $91(28)$ & $57(23)$ & $312(27)$ & \\
\hline $36-40$ & $353(62)$ & $212(65)$ & $181(71)$ & $745(65)$ & \\
\hline \multicolumn{6}{|l|}{ Tumour size (pT) } \\
\hline pT1 & $394(71)$ & $215(67)$ & $157(62)$ & $766(67)$ & 0.037 \\
\hline рT2 & $161(29)$ & $107(33)$ & $96(38)$ & $364(32)$ & \\
\hline Unknown & 10 & 3 & 0 & $13(1)$ & \\
\hline \multicolumn{6}{|l|}{ Nodal status (pN) } \\
\hline $\mathrm{pN}-$ & $379(67)$ & $205(64)$ & $163(65)$ & $747(65)$ & 0.489 \\
\hline $\mathrm{pN}+$ & $184(33)$ & $118(36)$ & $88(35)$ & $390(34)$ & \\
\hline Unknown & 2 & 2 & 2 & 6 (1) & \\
\hline \multicolumn{6}{|l|}{ Tumour type } \\
\hline Ductal & $507(90)$ & $296(92)$ & $222(88)$ & $1025(90)$ & 0.133 \\
\hline Lobular & $26(4)$ & $15(5)$ & 11 (4) & 52 (5) & \\
\hline Mixed & $15(3)$ & $5(1)$ & $5 \quad(2)$ & $25 \quad(2)$ & \\
\hline Other & 15 (3) & $6(2)$ & $15(6)$ & 36 (3) & \\
\hline Unknown & 2 & 3 & 0 & $5(0)$ & \\
\hline \multicolumn{6}{|l|}{ Tumour grade } \\
\hline Good & $14(7)$ & $38(15)$ & $34(15)$ & $86 \quad(7)$ & 0.018 \\
\hline Intermediate & $58(31)$ & $94(37)$ & $83(36)$ & $235(21)$ & \\
\hline Poor & $117(62)$ & $122(48)$ & $113(49)$ & $352(31)$ & \\
\hline Unknown & 376 & 71 & 23 & $470(41)$ & \\
\hline \multicolumn{6}{|l|}{ Oestrogen receptor status } \\
\hline Negative & $151(38)$ & $104(33)$ & $94(37)$ & $349(31)$ & 0.414 \\
\hline Positive & $248(62)$ & $209(67)$ & $159(63)$ & $616(54)$ & \\
\hline Unknown & 166 & 12 & 0 & $178(15)$ & \\
\hline \multicolumn{6}{|l|}{ HER2 status } \\
\hline Negative & $2(40)$ & $40(77)$ & $202(80)$ & $244(21)$ & 0.092 \\
\hline Positive & $3(60)$ & $12(23)$ & $51(20)$ & $66(6)$ & \\
\hline Unknown & 560 & 273 & 0 & $833(73)$ & \\
\hline \multicolumn{6}{|l|}{ Radiotherapy boost to tumour bed } \\
\hline Yes & $493(87)$ & $323(99)$ & $253(100)$ & $1069(94)$ & $<.0001$ \\
\hline No & $72(13)$ & $2(1)$ & $0 \quad(0)$ & $74 \quad(6)$ & \\
\hline \multicolumn{6}{|l|}{ (neo)Adjuvant systemic treatment } \\
\hline Adjuvant chemotherapy & $129(23)$ & $101(31)$ & $58(23)$ & $288(25)$ & $<0.001$ \\
\hline Adjuvant endocrine treatment & $19(3)$ & $5(2)$ & $7 \quad(3)$ & $31(3)$ & \\
\hline Adjuvant chemotherapy + endocrine treatment & $31(6)$ & $111(34)$ & $78(31)$ & $220(19)$ & \\
\hline Adjuvant chemotherapy + trastuzumab & $0 \quad(0)$ & $1(0)$ & $15(6)$ & $16(2)$ & \\
\hline Adjuvant chemotherapy + trastuzumab + endocrine & & & & & \\
\hline treatment & $0 \quad(0)$ & $3(1)$ & 23 (9) & $26(2)$ & \\
\hline Neo-adjuvant chemotherapy & $0 \quad(0)$ & $2(1)$ & $8 \quad(3)$ & $10(1)$ & \\
\hline Neo-adjuvant chemotherapy + endocrine treatment & $0 \quad(0)$ & $4(1)$ & $10(4)$ & $14(1)$ & \\
\hline $\begin{array}{l}\text { Neo-adjuvant chemotherapy }+ \text { trastuzumab }+ \\
\text { endocrine treatment }\end{array}$ & $0 \quad(0)$ & $0(0)$ & 9 (3) & $9 \quad(1)$ & \\
\hline Neo-adjuvant chemotherapy + trastuzumab & $0 \quad(0)$ & $0(0)$ & $2(1)$ & $2(0)$ & \\
\hline No systemic treatment & $386(68)$ & $96(29)$ & $43(17)$ & $525(46)$ & \\
\hline Unknown & $0 \quad(0)$ & $2(1)$ & $0 \quad(0)$ & $2(0)$ & \\
\hline
\end{tabular}


Table 2.2.2 Characteristics of patients with an isolated local recurrence (LR) after BCT ( $n=176$ patients).

\begin{tabular}{|c|c|}
\hline Characteristics & $\begin{array}{c}\text { Total }(n=176) \\
\text { No. }(\%)\end{array}$ \\
\hline \multicolumn{2}{|l|}{ Age at diagnosis of LR, yrs } \\
\hline$\leq 40$ & $47(27)$ \\
\hline $41-45$ & $62(35)$ \\
\hline$\geq 46$ & $67(38)$ \\
\hline \multicolumn{2}{|l|}{ Time to LR, yrs } \\
\hline$\leq 2.5$ & $31(18)$ \\
\hline $2.6-5$ & $39(22)$ \\
\hline $5.1-10$ & $53(30)$ \\
\hline$>10$ & $53(30)$ \\
\hline \multicolumn{2}{|l|}{ Individual who detected LR } \\
\hline Patient & $74(42)$ \\
\hline Surgeon or radiation oncologist & $69(40)$ \\
\hline General practitioner & $2(1)$ \\
\hline Unknown & $30(7)$ \\
\hline \multicolumn{2}{|l|}{ Mode of detection, LR } \\
\hline Palpation & $93(53)$ \\
\hline Mammography only & $50(28)$ \\
\hline Ultrasound only & $2(1)$ \\
\hline MRI only & $2(1)$ \\
\hline Unknown & $14(8)$ \\
\hline Other & $16(9)$ \\
\hline \multicolumn{2}{|l|}{ Localization, LR } \\
\hline At site of primary tumour & $92(52)$ \\
\hline Near site of primary tumour & $24(14)$ \\
\hline Elsewhere in the breast & $24(14)$ \\
\hline Diffuse & $8(4)$ \\
\hline Unknown & $28(16)$ \\
\hline \multicolumn{2}{|l|}{ Histologic type, LR } \\
\hline Ductal & $147(84)$ \\
\hline Lobular or mixed & $20(11)$ \\
\hline Other & $6(3)$ \\
\hline Unknown & $3(2)$ \\
\hline \multicolumn{2}{|l|}{ Invasiveness, LR } \\
\hline DCIS & $24(14)$ \\
\hline Invasive & $120(68)$ \\
\hline Invasive and DCIS & $27(15)$ \\
\hline Unknown & $5(3)$ \\
\hline \multicolumn{2}{|l|}{ Oestrogen receptor status, LR } \\
\hline Negative & $39(22)$ \\
\hline Positive & $94(53)$ \\
\hline Unknown & $43(25)$ \\
\hline \multicolumn{2}{|l|}{ Tumour grade, LR } \\
\hline Good & $13(7)$ \\
\hline Intermediate & $42(24)$ \\
\hline Poor & $50(28)$ \\
\hline Unknown & $71(41)$ \\
\hline \multicolumn{2}{|l|}{ Surgical treatment, LR } \\
\hline Excision & $4(2)$ \\
\hline Mastectomy & $101(58)$ \\
\hline Wide excision with reconstruction & $69(39)$ \\
\hline No surgery & $2(1)$ \\
\hline \multicolumn{2}{|l|}{ Systemic treatment, LR } \\
\hline Yes & $69(39)$ \\
\hline No & $107(61)$ \\
\hline
\end{tabular}


The 5-, 10-, and 15-year actuarial LR-rates were 7.5\% (95\% Cl:5.7-9.3), 16.3\% (95\% Cl 13.5-19.0) and $24.6 \%$ (95\% Cl 20.6-28.5), respectively. Univariate analyses showed that a positive axillary lymph node status $(P<0.0001)$ and the use of (neo)adjuvant systemic therapy $(P<0.0001)$ were associated with a significantly lower risk of LR (Table 2.2.3 and Figure 2.2.1a). Furthermore, we observed a significant trend towards improving local control over the study period (Table 2.2.3 and Figure 2.2.1b). The 5year LR-rate decreased from $9.8 \%$ in the period $1988-1998$ to $3.3 \%$ in the period 2006 $2010(P=0.006)$. A stratified analysis according to axillary nodal status showed that this improvement only occurred in patients with negative lymph nodes (Figure 2.2.1c and Figure 2.2.1d).

Table 2.2.3 5-, 10- and 15-year actuarial risks of local recurrence after breast-conserving therapy (BCT), according to patient, tumour and treatment characteristics ( $\mathrm{n}=1143$ patients). Standard errors (SE) between parentheses.

\begin{tabular}{|c|c|c|c|c|c|c|}
\hline Characteristics & No. & No. LRs & $\begin{array}{l}\text { 5-year rate } \\
\text { (SE) }\end{array}$ & $\begin{array}{l}\text { 10-year rate } \\
\text { (SE) }\end{array}$ & 15 -year rate (SE) & $P$-value \\
\hline \multicolumn{7}{|l|}{ Age, y } \\
\hline$\leq 30$ & 85 & 11 & $5.3(3.0)$ & $15.1(5.4)$ & $23.4(7.5)$ & 0.796 \\
\hline $31-35$ & 312 & 49 & $8.0(1.7)$ & $18.3(2.8)$ & $23.5(3.5)$ & \\
\hline $36-40$ & 746 & 116 & $7.5(1.1)$ & $15.5(1.7)$ & $25.2(2.5)$ & \\
\hline \multicolumn{7}{|l|}{ Year of BCT } \\
\hline 1988-1998 & 565 & 137 & $9.8(1.4)$ & 19.7 (1.9) & $27.8(2.3)$ & 0.006 \\
\hline $1999-2005$ & 325 & 33 & $5.9(1.4)$ & 11. $9(2.1)$ & n.a. & \\
\hline 2006-2010 & 253 & 6 & $3.3(1.4)$ & n.a. & n.a. & \\
\hline \multicolumn{7}{|c|}{ Tumour size $(p T) \ddagger$} \\
\hline pT1 & 766 & 131 & 8.1 (1.1) & $17.2(1.7)$ & $(2.4)$ & 0.223 \\
\hline $\mathrm{pT} 2$ & 364 & 40 & $4.7(1.3)$ & $12.1(2.4)$ & $18.9(3.7)$ & \\
\hline \multicolumn{7}{|c|}{ Nodal status $(\mathrm{pN}) \int$} \\
\hline $\mathrm{pN}-$ & 747 & 147 & $8.8(1.2)$ & $18.8(1.8)$ & $29.2(2.5)$ & $<0.0001$ \\
\hline $\mathrm{pN}+$ & 390 & 28 & $4.8(1.3)$ & $9.8 \quad(2.1)$ & $12.0(2.5)$ & \\
\hline \multicolumn{7}{|c|}{ (neo)Adjuvant systemic therapy ${ }^{1}$} \\
\hline Yes & 616 & 42 & $4.3(1.0)$ & $9.9(1.7)$ & $13.3(2.4)$ & $<0.0001$ \\
\hline No & 525 & 134 & $10.9(1.5)$ & $21.6(2.1)$ & $31.3(2.6)$ & \\
\hline
\end{tabular}

${ }^{1}$ Number of patients treated with (neo)adjuvant systemic therapy: $n=35$ (3.1\%). Data were missing for 2 patients; ¥ Data were missing for 13 patients. cTNM is used for the patients treated with (neo)adjuvant systemic therapy; $\int$ Data were missing for 6 patients. $n$.a. not available 


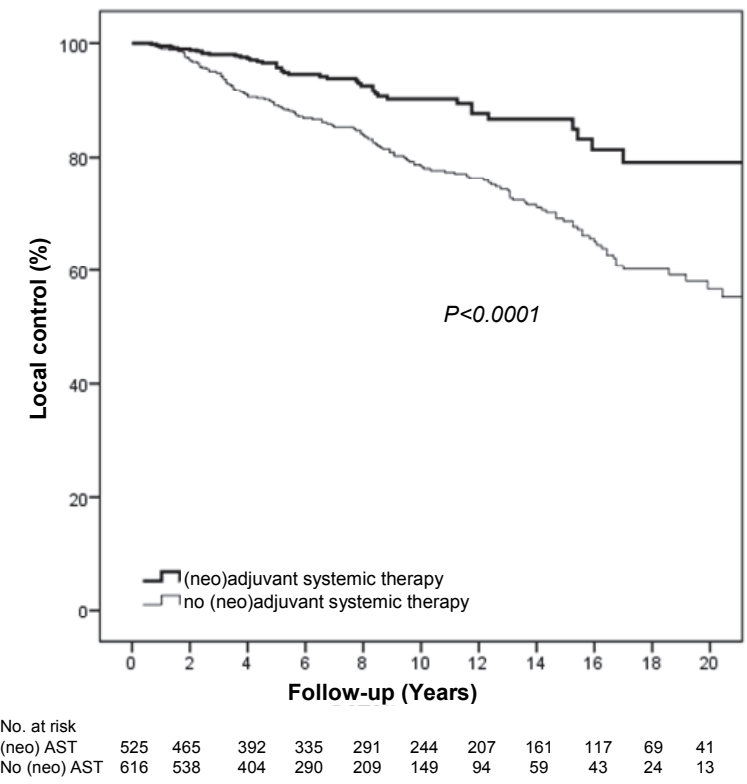

Figure 2.2.1a Actuarial local tumour control in patients $\leq 40$ years according to the use of (neo)adjuvant systemic therapy (AST).

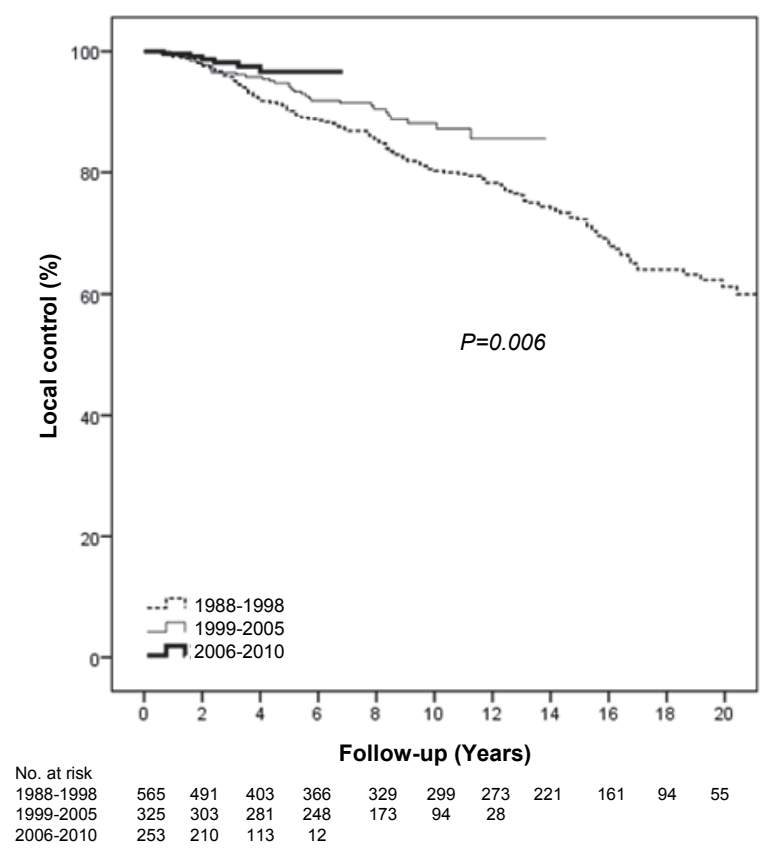

Figure 2.2.1b Actuarial local tumour control in patients $\leq 40$ years according to period of diagnosis. 


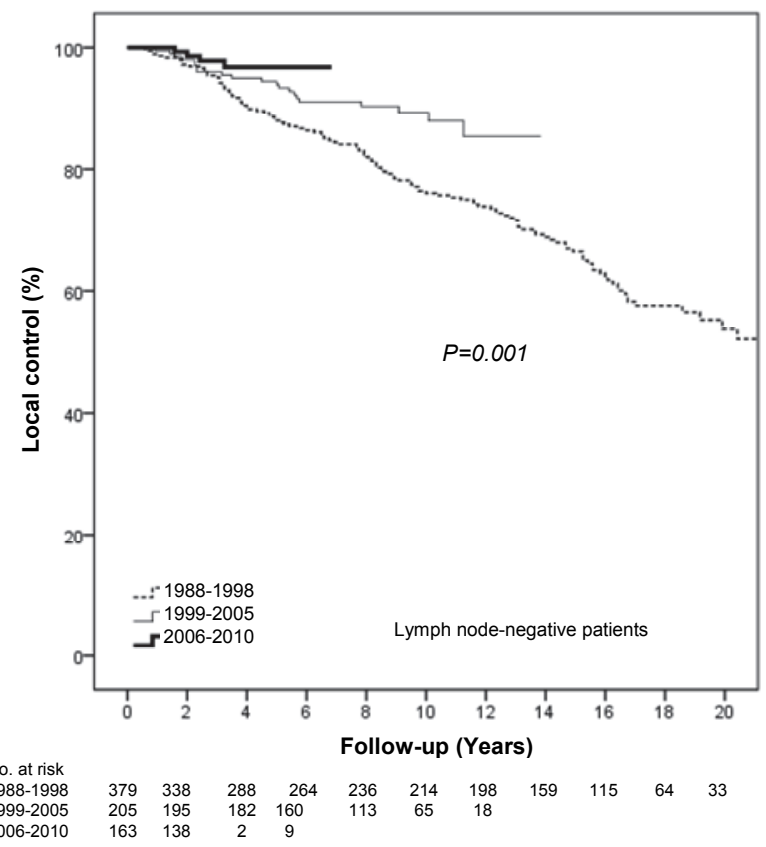

Figure 2.2.1c Actuarial local tumour control in patients $\leq 40$ years with negative axillary lymph nodes $(\mathrm{pN}-)$, according to period of diagnosis.

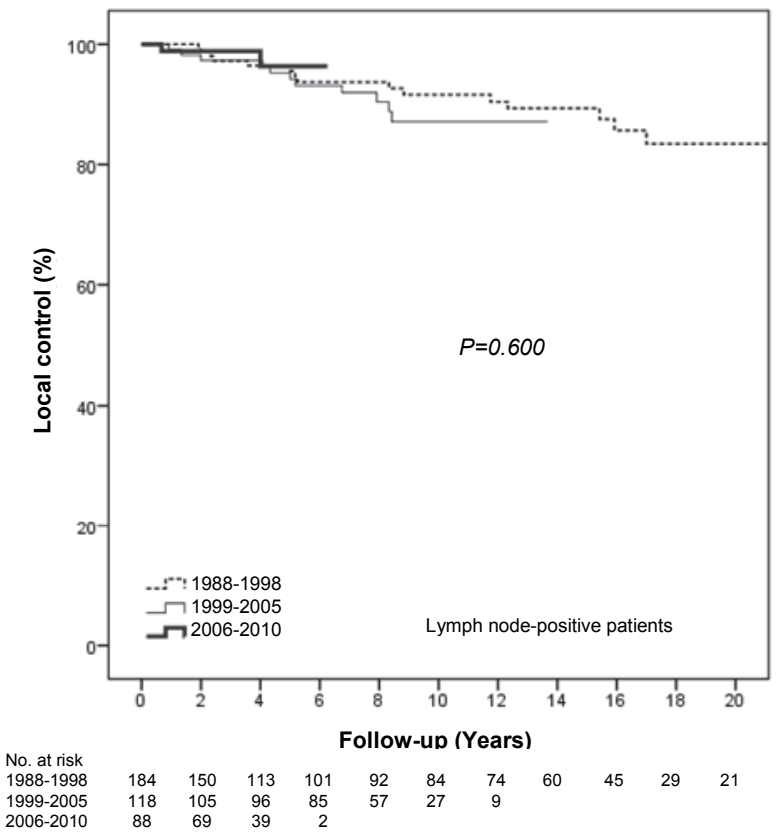

Figure 2.2.1d Actuarial local tumour control in patients $\leq 40$ years with positive axillary lymph nodes $(\mathrm{pN}+)$, according to period of diagnosis. 
The multivariate analysis was complicated by the strong concordance between axillary lymph node status and use of systemic treatment and the sharp increase in the use of systemic treatment over time. Therefore, we constructed two separate multivariate models (Table 2.2.4). The first model, in which systemic treatment was not included as a co-variate, showed that patients with a positive lymph node status had a $55 \%$ (HR $0.45 ; 95 \% \mathrm{Cl}$ 0.23-0.60) lower risk of developing a $\mathrm{LR}$, compared to those with negative lymph nodes, and that the risk was also significantly lower for patients treated more recently as compared to the patients treated in the period 1988-1998. In the second model, in which the period of diagnosis was not taken into account, the use of (neo)adjuvant systemic treatment was associated with a reduction of the LRrisk almost $60 \%$ (HR $0.42 ; 95 \% \mathrm{Cl} 0.29-0.60)$, and nodal status was no longer an independent prognostic factor for LR. Separate multivariate analyses for patient with and without (neo)adjuvant systemic treatment also demonstrated that lymph node status was not associated with the risk of LR (data not shown).

In both multivariate models the presence of a positive oestrogen receptor was the only other significant predictor of improved local control and age at diagnosis, tumour size and tumour grade were not associated with the risk of LR (Table 2.2.4).

Table 2.2.4 Results of multivariate analysis for local recurrence after breast-conserving therapy (BCT) $(n=1143) .^{*}$

\begin{tabular}{|c|c|c|c|c|c|c|}
\hline \multirow[t]{2}{*}{ Characteristics } & \multicolumn{3}{|c|}{ Multivariate model $1^{\mp}$} & \multicolumn{3}{|c|}{ Multivariate model $2^{\S}$} \\
\hline & $\mathrm{HR}$ & $95 \% \mathrm{Cl}$ & $P$-value & $\mathrm{HR}$ & $95 \% \mathrm{Cl}$ & $P$-value \\
\hline \multicolumn{7}{|c|}{ Period of diagnosis } \\
\hline 1988-1998 & 1 (Ref) & & & n.a. & & \\
\hline 1999-2005 & 0.64 & $0.43-0.96$ & 0.030 & & & \\
\hline $2006-2010$ & 0.36 & $0.16-0.84$ & 0.018 & & & \\
\hline \multicolumn{7}{|c|}{ Nodal status (pN) } \\
\hline $\mathrm{pN}-$ & 1 (Ref) & & & 1 (Ref) & & \\
\hline $\begin{array}{l}\mathrm{pN}+ \\
\text { (neo)Adjuvant s }\end{array}$ & 0.45 & $0.30-0.67$ & $<0.0001$ & 0.69 & $0.42-1.15$ & 0.155 \\
\hline No & n.a. & & & 1 (Ref) & & \\
\hline Yes & & & & 0.42 & $0.23-0.60$ & $<0.0001$ \\
\hline \multicolumn{7}{|c|}{ Oestrogen receptor status } \\
\hline Negative & 1 (Ref) & & & 1 (Ref) & & \\
\hline Positive & 0.66 & $0.48-0.92$ & 0.013 & 0.71 & $0.51-0.99$ & 0.041 \\
\hline
\end{tabular}

* Based on Cox proportional hazards analyses. Multiple imputation was used to generate possible values for patients with missing values for tumour size $(n=13)$, nodal status $(n=6)$, (neo)adjuvant systemic treatment $(n=2)$, tumour grade $(n=470)$ and oestrogen receptor status $(n=178)$; $¥$ Model 1: adjusting for period of diagnosis, nodal status $(\mathrm{pN})$, age at diagnosis, tumour size $(\mathrm{pT})$, tumour grade and oestrogen receptor status; § Model 2: adjusting for nodal status $(\mathrm{pN})$, (neo)adjuvant systemic treatment, age at diagnosis, tumour size (pT), tumour grade and oestrogen receptor status. n.a.: Not applicable (variable not included in model) 


\section{Distant relapse-free survival and other end-points}

During follow-up, 34 of the 1143 patients developed a regional (nodal) recurrence, not taking into account the regional recurrences that were diagnosed after distant metastases or with synchronous distant disease. The 5-year regional recurrence rate decreased from $3.1 \%(95 \% \mathrm{Cl} 1.5-4.7)$ in the period $1988-1998$ to $0.4 \%$ (95\% Cl 0.0 $1.2)$ in the period $2006-2010(P=0.057)$.

Ninety-nine patients developed a contralateral breast cancer, 287 patients distant metastases and 273 patients died. The 5-year distant relapse-free survival improved from $74.9 \%(95 \% \mathrm{Cl} 71.4-78.4)$ in the period $1988-1998$ to $89.4 \%$ (95\% Cl 86.1-92.7) in the period 1999-2005, and to $92.7 \%(95 \% \mathrm{Cl} 88.8-96.6)$ in the period $2006-2010$ $(P<0.0001)$.

The 10-year distant relapse-free survival rate was $78.6 \%(95 \% \mathrm{Cl} 72.3-84.9)$ for patients with and $76.3 \%(95 \% \mathrm{Cl} 73.2-79.4)$ for patients without a $\operatorname{LR}(P=0.351)$. Also the multivariate analysis showed no statistically significant difference in distant relapse-free survival between patients with and without a LR. When only the earlyLRs, occurring within 5 years after BCT, were taken into account we did find a difference in distant relapse-free survival rates. Patients with an early-LR $(n=70)$ had a worse distant relapse-free survival compared to patients without an early-LR ( $n=1073$ ) (HR 1.83; 95\% Cl 1.27-2.64; $P=0.001$ ) (Figure 2.2.2a). No independent prognostic effect of LR on distant relapse-free survival was observed in patients with a diseasefree interval of more than 5 years after BCT $(n=702)$ (HR 1.24; 95\% Cl 0.74-2.08; $P=0.407$ ) (Figure 2.2.2b).

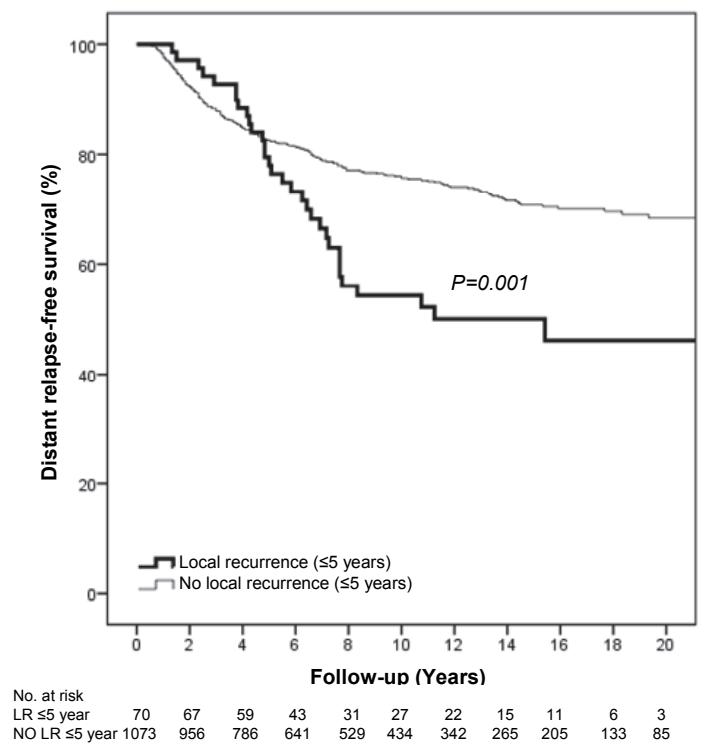

Figure 2.2.2a Actuarial distant relapse-free survival in patients with an early-local recurrence (LR) ( $\leq 5$ years) versus patients without an early-local recurrence. 


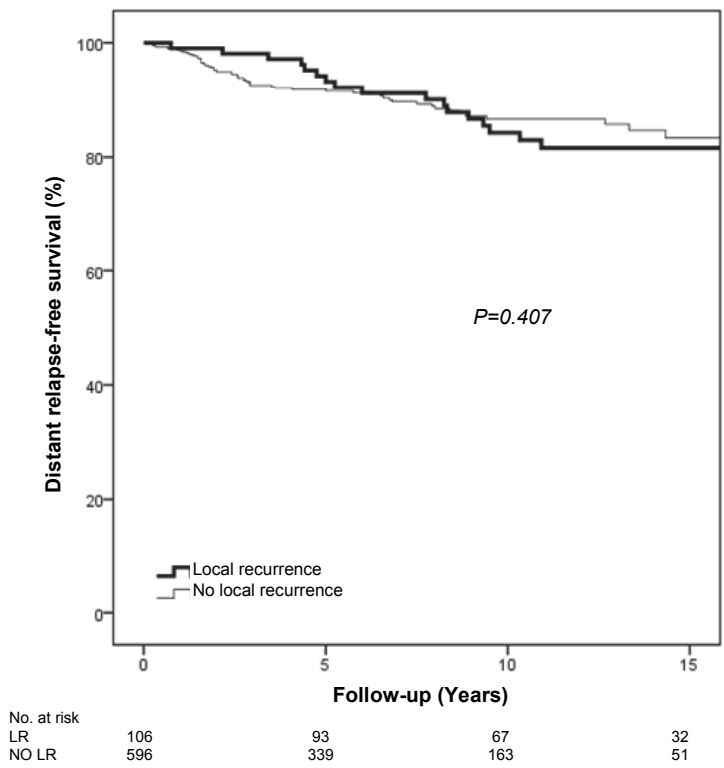

Figure 2.2.2b Actuarial distant relapse-free survival among patients with an event-free interval of $>5$ years after primary treatment who experienced a local recurrence (LR) versus patients who did not experience a local recurrence.

\section{Discussion}

The current study is the largest study so far with a long-term follow-up (up to 20 years) focusing on local control after BCT in women up to 40 years of age with early-stage breast cancer. Our results indicate a significant improvement in local control over time. A stratified analysis according to axillary nodal status showed that the improvement in local control did only occur in patients with negative lymph nodes. We also noted that early LRs had a negative impact on distant relapse-free survival.

In our series, patients who received (neo)adjuvant systemic therapy had an almost $60 \%$ lower risk of developing a LR, underlining the importance of the use of adjuvant systemic treatment in this patient group. Several studies have confirmed the possible benefit of adjuvant systemic therapy on local control after $\mathrm{BCT}^{1,7,12}$. The lower risk of LR in node-positive patients can be explained by the use of adjuvant systemic treatment, as is illustrated by our finding that lymph node status was no longer an independent prognostic factor in the subgroups of patients who did and did not receive adjuvant systemic treatment. 
Recently, studies of tumour biology by gene expression micro-array technology have demonstrated patterns correlating with breast cancer in young women ${ }^{22}$ and even LRs in young women ${ }^{28}$. Young women appear to have a higher proportion of more aggressive tumours and are, therefore, expected to benefit more from systemic therapy. Additional studies about tumour biology may be helpful to determine which patients are most likely to benefit from systemic treatment and to further optimise therapeutic options for breast cancer in young women.

Several studies, presented in 2005, showed that the use of trastuzumab in combination with chemotherapy reduced the locoregional and disease-free survival rate with approximately $50 \%{ }^{20,21}$ and the mortality rate with $33 \%^{21}$ among women with surgically removed HER2-positive breast cancer. As a result of these trials, HER2testing has become routine and trastuzumab in combination with chemotherapy is now standard treatment for most patients with HER2-positive breast cancer. After 2005 , all patients in our study were tested for HER2 status, of whom $20 \%$ presented with HER2-positive tumours (Table 2.2.1). As described previously, young women appear to have more aggressive tumours, including a higher incidence of HER2 overexpression compared to older women. ${ }^{7,18,22}$ The length of follow-up in our study is too short and the number of patients with known HER2 positivity is too small to draw definitive conclusions about the impact of trastuzumab on local control in this group of patients. However, a recent study revealed significant improved local control after $\mathrm{BCT}$ in patients with small node-negative HER2-positive breast cancer who received trastuzumab $^{23}$.

Minimising the risk of LR remains an important clinical issue since many studies on BCT have shown that a LR significantly correlates with subsequent distant metastases ${ }^{1-3,29}$. In our study women with a LR occurring within 5 years after BCT were nearly twice as likely to experience distant disease compared to women without a LR. However, no worse distant relapse-free survival was observed for women with a LR occurring more than 5 years after BCT. Late-occurring LRs are probably more often new primary tumours and are generally thought to have a more favourable prognosis than the early-occurring true recurrences. Our results seem to confirm this opinion, although we could not verify this based on histological comparison of the primary with the new/recurrent tumours. The finding that a LR is an unfavourable prognostic factor, especially the ones occurring shortly after BCT ( $\leq 2-5$ years) is in line with other studies $^{1-3,5}$.

Collecting long-term follow-up information for this group of young women was challenging. Nevertheless, we managed to limit the amount of missing disease-specific follow-up information after $1^{\text {st }}$ January, 2010 to only 78 patients (6.8\%). Most of them were treated in the group 1988-1998 and still had a median follow-up duration of 9.6 years. Another limitation of this study are the large number of missing data with respect to ER-receptor status and tumour grade for those patients treated before 1999. As these missing data were largely due to incomplete pathology reports, we 
assumed that the data were missing at random and therefore used the multiple imputation method to generate possible values.

\section{Conclusion}

Our study demonstrates that early-occurring LRs are associated with distant metastases. We found a substantial decline in the incidence of LRs after BCT in women aged $\leq 40$ years which seems to be largely attributable to the increased use and effectiveness of (neo)adjuvant systemic therapy during the study period. Therefore, we support the choice of BCT over mastectomy also for young women, especially when they will receive systemic treatment as well. 


\section{References}

1. Anderson SJ, Wapnir I, Dignam JJ, et al: Prognosis after ipsilateral breast tumor recurrence and locoregional recurrences in patients treated by breast-conserving therapy in five National Surgical Adjuvant Breast and Bowel Project protocols of node-negative breast cancer. J Clin Oncol 2009;27: 2466-73.

2. Botteri $\mathrm{E}$, Bagnardi $\mathrm{V}$, Rotmensz $\mathrm{N}$, et al: Analysis of local and regional recurrences in breast cancer after conservative surgery. Ann Oncol 2010;21:723-8.

3. Komoike $\mathrm{Y}$, Akiyama $\mathrm{F}$, lino $\mathrm{Y}$, et al: Ipsilateral breast tumor recurrence (IBTR) after breast-conserving treatment for early breast cancer: risk factors and impact on distant metastases. Cancer 2006;106: 35-41.

4. Meric F, Mirza NQ, Vlastos G, et al: Positive surgical margins and ipsilateral breast tumor recurrence predict disease-specific survival after breast-conserving therapy. Cancer 2003;97:926-33.

5. Vicini FA, Kestin L, Huang R, et al: Does local recurrence affect the rate of distant metastases and survival in patients with early-stage breast carcinoma treated with breast-conserving therapy? Cancer 2003;97:910-9.

6. Voogd, A.C., et al., Differences in risk factors for local and distant recurrence after breast-conserving therapy or mastectomy for stage I and II breast cancer: pooled results of two large european randomized trials. J Clin Oncol 2001;19:1688-97.

7. Arvold ND, Taghian AG, Niemierko A, et al: Age, breast cancer subtype approximation, and local recurrence after breast-conserving therapy. J Clin Oncol 2011;29:3885-91.

8. de Bock $\mathrm{GH}$, van der Hage JA, Putter $\mathrm{H}$, et al: Isolated loco-regional recurrence of breast cancer is more common in young patients and following breast conserving therapy: long-term results of European Organisation for Research and Treatment of Cancer studies. Eur J Cancer 2006;42:351-6.

9. Vrieling C, Collette L, Fourquet A, et al: Can patient-, treatment- and pathology-related characteristics explain the high local recurrence rate following breast-conserving therapy in young patients? Eur J Cancer 2003;39:932-44.

10. Miles RC, Gullerud RE, Lohse $\mathrm{CM}$, et al: Local recurrence after breast-conserving surgery: multivariable analysis of risk factors and the impact of young age. Ann Surg Oncol 2012;19:1153-59.

11. Anders CK, Johnson R, Litton J, et al: Breast cancer before age 40 years. Semin Oncol 2009;36:237-49.

12. Cabioglu N, Hunt KK, Buchholz TA, et al: Improving local control with breast-conserving therapy: a $27-$ year single-institution experience. Cancer 2005;104:20-9.

13. van der Leest $M$, Evers L, van der Sangen MJ, et al: The safety of breast-conserving therapy in patients with breast cancer aged $<$ or $=40$ years. Cancer 2007;109:1957-64

14. van der Sangen MJ, van de Wiel FM, Poortmans PM, et al: Are breast conservation and mastectomy equally effective in the treatment of young women with early breast cancer? Long-term results of a population-based cohort of 1,451 patients aged $</=40$ years. Breast Cancer Res Treat 2011;127: 20715.

15. Poortmans P, Aznar M, Bartelink H: Quality indicators for breast cancer: revisiting historical evidence in the context of technology changes. Semin Radiat Oncol 2012;22:29-39.

16. Beadle BM, Woodward WA, Tucker SL, et al: Ten-year recurrence rates in young women with breast cancer by locoregional treatment approach. Int J Radiat Oncol Biol Phys 2009;73:734-44.

17. Bartelink H, Horiot JC, Poortmans PM, et al. Impact of a higher radiation dose on local control and survival in breast-conserving therapy of early breast cancer: 10-year results of the randomized boost versus no boost EORTC 22881-10882 trial. J Clin Oncol 2007;25:3259-65.

18. de Munck L, Schaapveld M, Siesling S, et al: Implementation of trastuzumab in conjunction with adjuvant chemotherapy in the treatment of non-metastatic breast cancer in the Netherlands. Breast Cancer Res Treat 2011;129:229-33.

19. Marty M, Cognetti F, Maraninchi D, et al: Randomized phase II trial of the efficacy and safety of trastuzumab combined with docetaxel in patients with human epidermal growth factor receptor 2positive metastatic breast cancer administered as first-line treatment: the M77001 study group. J Clin Oncol 2005;23:4265-74.

20. Piccart-Gebhart MJ, Procter M, Leyland-Jones B, et al: Trastuzumab after Adjuvant Chemotherapy in HER2-Positive Breast Cancer. N Engl J Med 2005;353:1659-72. 
21. Romond EH, Perez EA, Bryant J, et al: Trastuzumab plus Adjuvant Chemotherapy for Operable HER2Positive Breast Cancer. N Engl J Med 2005;353:1673-84.

22. Anders CK, Hsu DS, Broadwater G, et al: Young age at diagnosis correlates with worse prognosis and defines a subset of breast cancers with shared patterns of gene expression. J Clin Oncol 2008;26: 3324-30.

23. Kiess AP, McArthur $\mathrm{HL}$, Mahoney $\mathrm{K}$, et al: Adjuvant trastuzumab reduces locoregional recurrence in women who receive breast-conservation therapy for lymph node-negative, human epidermal growth factor receptor 2-positive breast cancer. Cancer 2012;118:1982-8.

24. Kim MM, Dawood S, Allen P, et al: Hormone receptor status influences the locoregional benefit of trastuzumab in patients with nonmetastatic breast cancer. Cancer 2012;118:4936-43.

25. McArthur HL, Mahoney KM, Morris PG, et al: Adjuvant trastuzumab with chemotherapy is effective in women with small, node-negative, HER2-positive breast cancer. Cancer 2011;117:5461-8.

26. Panoff JE, Hurley J, Takita C, et al: Risk of locoregional recurrence by receptor status in breast cancer patients receiving modern systemic therapy and post-mastectomy radiation. Breast Cancer Res Treat 2011;128:899-6.

27. Bontenbal M, Nortier JW, Beex LV, et al: [Adjuvant systemic therapy for patients with resectable breast cancer: guideline from the Dutch National Breast Cancer Platform and the Dutch Society for Medical Oncology]. Ned Tijdschr Geneeskd 2000;144:984-989.

28. Kreike $\mathrm{B}$, Halfwerk $\mathrm{H}$, Armstrong $\mathrm{N}$, et al: Local recurrence after breast-conserving therapy in relation to gene expression patterns in a large series of patients. Clin Cancer Res 2009;15:4181-90.

29. Tanis $\mathrm{E}$, van de Velde $\mathrm{CJ}$, Bartelink $\mathrm{H}$, et al: Locoregional recurrence after breast-conserving therapy remains an independent prognostic factor even after an event free interval of 10 years in early stage breast cancer. Eur J Cancer 2012;48:1751-6. 


\section{Chapter}

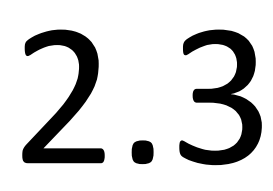

Detection of local recurrence following breastconserving therapy in young women with early breast cancer: optimization of long-term follow-up strategies

MJC van der Sangen SWM Scheepers PMP Poortmans

EJT Luiten GAP Nieuwenhuijzen AC Voogd 


\section{Abstract}

The detection of a local recurrence (LR) in young women with breast cancer after breastconserving therapy (BCT) was investigated to compare the impact of different long-term followup strategies.

Between 1988 and 2005, 937 women aged $\leq 40$ years were treated with BCT for early-stage breast cancer in the southern part of the Netherlands. Up to October 2009, 152 had developed an isolated LR. Information on follow-up visits was available for 124 of them. Fifty-four LRs (44\%) were diagnosed within 5 years and $70(56 \%)$ more than 5 years after BCT. Fifty-six LRs (45\%) were detected during routine follow-up visits and 68 (55\%) presented between two visits. Sixty-six LRs (53\%) were diagnosed in patients reporting symptoms. In 31 patients (25\%) the LR was found by mammography alone. About a quarter of the LRs was larger than $2 \mathrm{~cm}$ in diameter. These results imply that current follow-up strategies for young women with BCT do not guarantee a timely detection of LR. 


\section{Introduction}

In the United States, approximately 288130 women were diagnosed with breast cancer in 2011, of whom 13110 (4.6\%) were younger than 40 years at time of diagnosis ${ }^{1}$. In the Netherlands 13257 new patients were diagnosed in 2010, of whom 688 (5.2\%) were younger than 40 years (www.cijfersoverkanker.nl). Despite the fact that breast-conserving therapy (BCT) has proven to be equally effective in terms of survival as mastectomy, several studies show that the risk of local recurrence (LR) in young patients is higher after $\mathrm{BCT}^{2-4}$. Age $<35$ years at presentation is one of the most important risk factors for LR after BCT. The risk of developing a LR is two to four times higher in women younger than 40 at the time of diagnosis of breast cancer compared to women older than 50 years ${ }^{5-8}$. More recently however, data was published that this risk might be lower for patients treated according to more contemporary protocols ${ }^{9}$. During routine follow-up, approximately $30 \%$ of potentially treatable LRs are detected mammographically and $28 \%$ by clinical breast examination ${ }^{10}$. Despite the fact that clinical breast examination can be problematic as a consequence of surgical and radiation effects, a total of $30-40 \%$ of all LRs is detected by the patients themselves through breast self-examination ${ }^{10}$. A meta-analysis suggested a better survival for patients with an LR either detected mammographically, by clinical breast examination or without symptoms, compared to patients who presented with symptoms ${ }^{11}$.

These data argue for a policy aimed at the detection of LRs at the earliest possible stage. However, the extent to which an intensified or prolonged follow-up offers a benefit is unknown. Guidelines for the follow-up of women with a history of breast cancer are generally covering only the first three to five years after treatment. After this period the frequency of follow-up visits declines or follow-up is omitted completely. Women of 50 years or older may be referred to national breast screening programmes, as an alternative for control visits in the hospital, but younger women generally are not covered by these programmes. Previous studies have mainly focussed on the effectiveness of different follow-up strategies during the first years after treatment. Although these studies indicate that a less frequent follow-up scheme is acceptable for most patients, very little is known about its influence on the detection of LRs, especially after 5 years of follow-up. Therefore, we focussed on the long-term follow-up of a homogeneous group of young women who underwent BCT.

The aim is to evaluate the different follow-up strategies that are applied to patients treated and followed in a region with several hospitals using different follow-up strategies. It was hypothesized that a more frequent and prolonged follow-up for these patients results in an earlier detection of LR. 


\section{Patients and methods}

\section{Settings and subjects}

Data from the population based Eindhoven Cancer Registry (ECR) were used to select the patients who were diagnosed with breast cancer and received BCT between 1988 and 2005. BCT included local excision of the tumour and appropriate axillary management followed by irradiation of the whole breast, mostly including a boost to the primary tumour bed. The ECR records data on all patients newly diagnosed with cancer in the southern part of The Netherlands, an area with approximately 2.4 million inhabitants. The ECR identified 937 patients aged $\leq 40$ years who underwent BCT in the above-mentioned period. Further details about this cohort have been published previously. ${ }^{2}$ Until October 2009, after a median follow-up of 9.5 years, 187 (20\%) of the 937 patients developed an LR, defined as reappearance of tumour growth in the treated breast or overlying skin. For the purpose of this study we excluded 37 patients whose LR was diagnosed simultaneously with or after distant metastases or with a diagnosis of a second malignancy (contralateral breast cancer or non-breast cancer) before LR, and 26 patients whose medical files were lost or largely incomplete with respect to information on follow-up visits. As a result, a total of 124 patients remained available for analysis.

\section{Data extraction}

For this study data were derived from the patients files of 12 large non-university teaching hospitals and community hospitals, and from the two radiotherapy departments in this region, i.e. the Catharina Hospital in Eindhoven and the Institute Verbeeten in Tilburg. For all patients the follow-up information, including date and content of visits, self-reported symptoms, findings of clinical breast examination and diagnostic tests including mammography, ultrasound and MRI were reviewed. Furthermore we recorded information about the characteristics of the LRs, such as size, differentiation grade and localization.

We defined 'follow-up' as care after primary treatment. For each patient the number of hospital follow-up visits was assessed in the two years preceding the date of diagnosis of the LR. Routine clinical breast examination was defined as the clinical breast examination undertaken by a physician during the routine follow-up visits in the hospital. Routine mammography was defined as a mammography performed during routine follow-up visits. The method of detection of LR was classified as imaging alone (in case of a normal clinical breast examination in asymptomatic patients), clinical breast examination alone (in case of normal diagnostic tests in asymptomatic patients), both imaging and clinical breast examination and symptoms reported by the patient. When a patient presented with symptoms, the subsequent follow-up visit and/or diagnostic mammography was not considered as being part of 
routine hospital follow-up. Therefore, these visits were excluded from the analysis and we used the last regular follow-up visit as an indicator for time until LR.

\section{Statistical analysis}

All data were analyzed using SPSS version 19. Patients with LR detected within two years after BCT, between two to five years after BCT and more than five years after $B C T$ were compared with respect to follow-up history and size and histological grade of LR. Similar comparisons were made between patients with LR detected during routine follow-up visits or between two visits. Statistical significance of the comparisons was tested by the Pearson Chi-square test for class variables and the Kruskal-Wallis one-way analysis of variance for continuous variables.

\section{Results}

\section{Patients and tumour characteristics}

Patient and primary tumour characteristics of the 124 patients with an LR are presented in Table 2.3.1. Median age at the time of diagnosis of the primary tumour was 37 years (range, 24-40 years). A total number of 102 patients (82\%) had received a boost dose after whole breast irradiation. Adjuvant systemic treatment had been administered to 28 patients (23\%).

Details regarding the LRs are summarized in Table 2.3.2. Fifty-six LRs (45\%) were detected during routine follow-up visits and 68 (55\%) presented as interval cases. Time from diagnosis of the primary breast tumour until the diagnosis of LR varied from 7 to 223 months (median 65 months). Sixteen LRs (13\%) were diagnosed within 2 years, 38 (31\%) between 2 and 5 years, 44 (35\%) between 5 and 10 years, and $26(21 \%)$ more than 10 years after breast conservation. Median age at diagnosis of LR was 42 years (range, 30-56 years). The diameter of the LR was larger than $2 \mathrm{~cm}$ in 27 (27\%) of the 100 patients for whom diameter was known. Of the 106 patients for whom information on the precise location of the LR was available 91 (86\%) had a recurrence localized at or near the primary tumour bed. In 10 patients (9\%) LR occurred elsewhere in the breast and in $5(5 \%)$ it had a diffuse growth pattern. Eightteen LRs (15\%) only showed in situ cancer. Tumour grade of LR was known for 69 patients (56\%) and in 37 of them (54\%) it was poorly differentiated. 
Table 2.3.1 Characteristics at primary diagnosis of 124 patients aged $\leq 40$ years who developed a local recurrence between 1991 and 2009 after treatment for a primary breast tumour between 1988 and 2005.

\begin{tabular}{|c|c|}
\hline Characteristics & No. (\%) \\
\hline \multicolumn{2}{|l|}{ Age, in years } \\
\hline$\leq 30$ & $9(7)$ \\
\hline $31-35$ & $40(32)$ \\
\hline $36-40$ & $75(61)$ \\
\hline \multicolumn{2}{|l|}{ Year of diagnosis } \\
\hline $1988-1993$ & $60(48)$ \\
\hline 1994-1999 & $47(38)$ \\
\hline $2000-2005$ & $17(14)$ \\
\hline \multicolumn{2}{|l|}{ Tumour size in cm } \\
\hline$\leq 1$ & $26(21)$ \\
\hline $1.1-2$ & $64(52)$ \\
\hline$>2$ & $26(21)$ \\
\hline Unknown & $8(6)$ \\
\hline \multicolumn{2}{|l|}{ Histology } \\
\hline Ductal & $109(88)$ \\
\hline Lobular or mixed & $9(7)$ \\
\hline Other & $4(3)$ \\
\hline Unknown & $2(2)$ \\
\hline \multicolumn{2}{|l|}{ Tumour grade } \\
\hline Good & $5(4)$ \\
\hline Intermediate & $21(17)$ \\
\hline Poor & $26(21)$ \\
\hline Unknown & $72(58)$ \\
\hline \multicolumn{2}{|l|}{ Axillary nodal status } \\
\hline $\mathrm{pN}-$ & $106(86)$ \\
\hline $\mathrm{pN}+$ & $18(14)$ \\
\hline
\end{tabular}

Sixty-six (53\%) of the 124 patients noticed symptoms that eventually indicated recurrent disease. Fifty-nine of these patients did not wait until their scheduled visit, but arranged an earlier appointment at the hospital, whereas 7 patients reported their symptoms at the next, previously scheduled, follow-up visit. Fifty-three of the 66 patients with symptoms (80\%) reported a swelling in their breast and 6 (11\%) of these patients simultaneously experienced pain in the breast. Two patients (3\%) presented with complaints of pain only. Five patients (8\%) presented with nipple retraction, four (6\%) with nipple discharge and two (3\%) experienced other breast symptoms. In thirteen (25\%) of the 53 patients reporting a swelling no abnormalities were visible on the mammogram. Of all the LRs, $3(2 \%)$ could only be ascertained by routine clinical breast examination at a scheduled follow-up visit. Thirty-two LRs (26\%) were detected by breast imaging alone (mammography or ultrasound). In 101 of all 124 cases $(81 \%)$ radiological imaging (mammography and/or ultrasound) displayed abnormal features. 
Table 2.3.2 Characteristics at time of recurrence of 124 patients aged $\leq 40$ years who developed a local recurrence (LR) between 1991 and 2009 after treatment for a primary breast tumour between 1988 and 2005.

\begin{tabular}{|c|c|}
\hline Characteristics & No. (\%) \\
\hline \multicolumn{2}{|l|}{ Age, in years } \\
\hline$\leq 30$ & $1(1)$ \\
\hline $31-35$ & $12(10)$ \\
\hline $36-40$ & $28(22)$ \\
\hline$\geq 40$ & $83(67)$ \\
\hline \multicolumn{2}{|l|}{ Time from BCT until LR in years } \\
\hline Median (range) & $5.5(0.6-18.6)$ \\
\hline$\leq 2$ & $16(13)$ \\
\hline $2.1-5$ & $38(31)$ \\
\hline 5.1-10 & $44(36)$ \\
\hline$>10$ & $26(21)$ \\
\hline \multicolumn{2}{|l|}{ Size of $L R$, in $\mathrm{cm}$} \\
\hline$\leq 1$ & $27(22)$ \\
\hline $1.1-2$ & $46(37)$ \\
\hline$>2$ & $27(22)$ \\
\hline Unknown & $24(19)$ \\
\hline \multicolumn{2}{|l|}{ Histology of LR } \\
\hline Ductal & $100(80)$ \\
\hline Lobular or mixed & $17(14)$ \\
\hline Other & $5(4)$ \\
\hline Unknown & $2(2)$ \\
\hline \multicolumn{2}{|l|}{ Tumour grade of LR } \\
\hline Good & $9(7)$ \\
\hline Intermediate & $23(19)$ \\
\hline Poor & $37(30)$ \\
\hline Unknown & $55(44)$ \\
\hline \multicolumn{2}{|l|}{ Invasiveness of LR } \\
\hline DCIS & $18(15)$ \\
\hline Invasive & $85(68)$ \\
\hline Invasive and DCIS & $17(14)$ \\
\hline Unknown & $4(3)$ \\
\hline \multicolumn{2}{|l|}{ Method of detection of LR } \\
\hline Symptoms reported by the patient & $66(53)$ \\
\hline Both CBE and imaging & $19(16)$ \\
\hline CBE alone & $3(2)$ \\
\hline Mammography alone & $31(25)$ \\
\hline Ultrasound alone & $1(1)$ \\
\hline Other or unknown & $4(3)$ \\
\hline \multicolumn{2}{|l|}{ Site of LR } \\
\hline Primary tumour bed & $74(60)$ \\
\hline Near primary tumour bed & $17(14)$ \\
\hline Elsewhere in the breast & $10(8)$ \\
\hline Diffuse & $5(4)$ \\
\hline Unknown & $18(14)$ \\
\hline \multicolumn{2}{|l|}{ Moment of detection of LR } \\
\hline During routine follow-up & $56(45)$ \\
\hline Between two follow-up visits & $68(55)$ \\
\hline
\end{tabular}

LR, local recurrence; DCIS, ductal carcinoma in situ; CBE, clinical breast examination. 


\section{Early versus late local recurrences}

No statistically significant differences in diameter were seen between early and late recurrences $(P=0.78)$. The median diameter of the LRs diagnosed within 5 years after BCT was $15 \mathrm{~mm}$, compared to $14 \mathrm{~mm}$ for those diagnosed between 5 and 10 years or more than 10 years after BCT. Tumour grade did not differ between early and late LRs. The large majority of the patients had more than one follow-up visit per year in the two years preceding LR, irrespective of the time since BCT (Figure 2.3.1). The median number of follow-up visits in the two years preceding the diagnosis of LR decreased from 5 for the patients with an LR diagnosed within 5 years after BCT, to 3 for those with an LR diagnosed more than 10 years after BCT $(P<0.001)$.

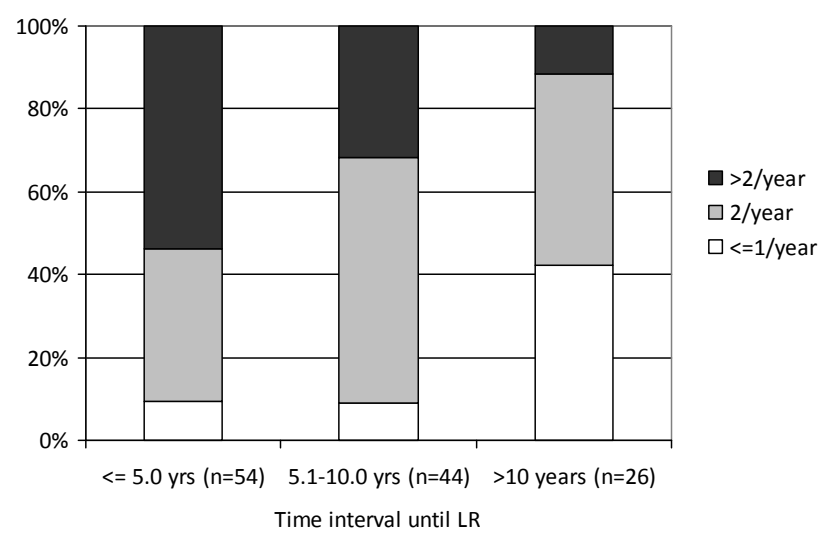

Figure 2.3.1 Number of follow-up visits per year in the 2 years preceding diagnosis of local recurrence (LR), according to time interval between diagnosis of the primary tumour and diagnosis of $L R$.

The attendance to regular mammography before the diagnosis of the LR was high (Figure 2.3.2). Of the patients with a LR diagnosed within 5 years after BCT, 72\% had at least annual mammography in the two years preceding the diagnosis of LR. compared to $98 \%$ of the patients with an LR recurrence between 5 and 10 years and $81 \%$ of those with an LR more than 10 years after BCT.

There was no statistically significant difference in the proportion of LRs detected during routine follow-up visits between patients with early or late recurrences; of the 54 LRs diagnosed within 5 years after BCT, 24 (44\%) were detected during routine follow-up visits, compared to 32 (46\%) of the 70 LRs diagnosed more than 5 years after BCT.

LRs detected during routine follow-up did not significantly differ from the recurrences detected between two routine follow-up visits with respect to tumour size, tumour grade and frequency of follow-up visits (Table 2.3.3). 


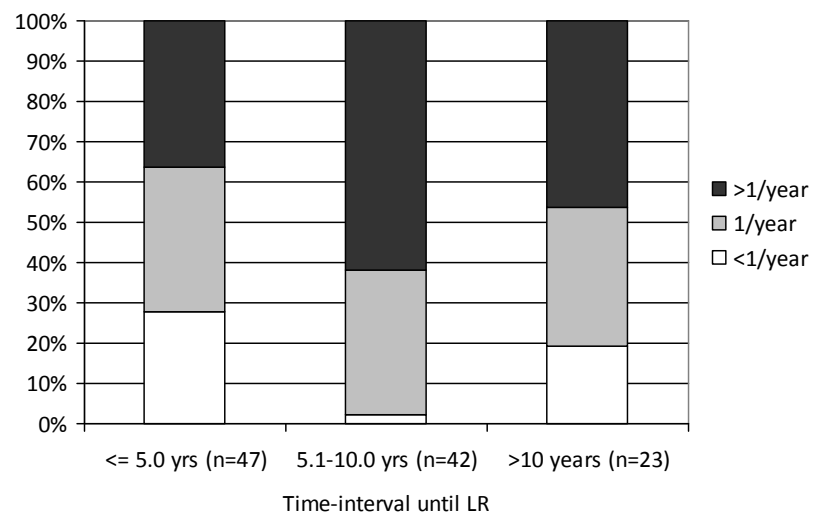

Figure 2.3.2 Number of mammograms per year in the two years preceding diagnosis of local recurrence (LR), according to time interval between diagnosis of the primary tumour and diagnosis of LR.

Table 2.3.3 Characteristics of local recurrence according to moment of detection $(n=124)$. Percentages between parentheses.

\begin{tabular}{|c|c|c|c|}
\hline \multirow[t]{2}{*}{ Characteristics } & \multicolumn{2}{|c|}{ Moment of detection of LR } & \multirow[t]{2}{*}{$P$-value } \\
\hline & $\begin{array}{l}\text { During routine FU } \\
\qquad(n=56)\end{array}$ & $\begin{array}{l}\text { Between two routine FU visits } \\
\qquad(n=68)\end{array}$ & \\
\hline \multicolumn{4}{|l|}{ Size of $L R$, in cm } \\
\hline Median (range) & $1.4(0.2-4.0)$ & $1.5(0.4-7)$ & $0.391^{b}$ \\
\hline$\leq 1$ & $11(26)$ & $16(28)$ & $0.367^{\mathrm{a}}$ \\
\hline $1.1-2$ & $23(54)$ & $23(40)$ & \\
\hline$>2$ & $9(21)$ & $18(32)$ & \\
\hline Unknown & 13 & 11 & \\
\hline Tumour grade of LR & & & $0.183^{\mathrm{a}}$ \\
\hline Good & 3 (9) & $6(17)$ & \\
\hline Intermediate & $9(27)$ & $14(40)$ & \\
\hline Poor & $22(65)$ & $15(43)$ & \\
\hline Unknown & 22 & 33 & \\
\hline \multicolumn{4}{|l|}{ Frequency of FU visits* } \\
\hline$\leq 1 /$ year & $10(18)$ & $10(15)$ & $0.635^{\mathrm{a}}$ \\
\hline$>1 /$ year & $46(82)$ & $58(85)$ & \\
\hline \multicolumn{4}{|l|}{ Frequency of $\mathrm{Mx}^{*}$} \\
\hline$<1 /$ year & 7 (14) & $12(19)$ & $0.422^{\mathrm{a}}$ \\
\hline$\geq 1 /$ year & $45(87)$ & $51(81)$ & \\
\hline Not available & 2 & 6 & \\
\hline LR only visible on $\mathrm{Mx}$ & & & $0.000^{\mathrm{a}}$ \\
\hline Yes & $31(55)$ & $3(4)$ & \\
\hline No & $25(45)$ & $65(96)$ & \\
\hline
\end{tabular}

$\mathrm{LR}$, local recurrence; FU, follow-up; Mx, mammography.

* Calculated over the 2 years preceding the diagnosis of LR; ${ }^{\text {a }}$ Pearson Chi-Square test, excluding unknown values; ${ }^{b}$ Kruskal-Wallis test. 


\section{Discussion}

The current study is one of the few studies focussing on long-term follow-up after breast cancer in women younger than 40 years treated with BCT. Approximately 22 percent of all LRs was larger than $2 \mathrm{~cm}$ at time of detection. The overall detection rate of an LR by clinical breast examination alone at a scheduled follow-up visit by the physician is only $2 \%$ in our study. Furthermore, we observed that more than half of the recurrences was noticed by the patients themselves between two control visits, regardless of the time since BCT.

For late recurrences it was hypothesized that due to the less frequent follow-up visits, an increased risk of delay in diagnosis would be observed and that this would result in larger tumours at the time of detection. However, no statistically significant difference in diameter could be demonstrated between early and late recurrences. Moreover, the recurrences detected at the regular follow-up visits were not smaller than the ones detected between two visits.

Despite a gradual, statistically significant decrease in the number of follow-up visits over time, the large majority of patients with an LR diagnosed more than 5 years after diagnosis of the primary breast tumour still had annual control visits and at least one mammogram per year. This might be explained by the young age of the patients and the tendency to continue follow-up at least to the age of 50, after which patients might be referred for national breast screening programmes.

It could be hypothesized that the early recurrences are mainly rapidly growing tumours. However, in our study this was not confirmed by a higher rate of poorly differentiated LRs among those with an early recurrence. In the first five years after BCT patients generally undergo intensive monitoring of their disease, aimed at early detection of loco-regional recurrence. For that reason we expected that the large majority of these early LRs would have been discovered during one of the routine follow-up visits. Interestingly, our results show that there is hardly any difference between patients with early and late recurrences in the proportion detected during a routine follow-up visit. Our data seem to suggest that it is not beneficial to increase the number of follow-up visits, as even among the patients with an early $L R$, who already underwent intensive routine clinical follow-up, around $50 \%$ of the recurrences was discovered between two regular control visits.

Clinical breast examination, mammography and ultrasound are the conventional diagnostic techniques for the detection and local staging of breast cancer ${ }^{12}$. While early studies reported very few LRs detected by routine mammography, the proportion detected this way has increased. In the studies published since 2000, up to $50 \%$ of all treatable breast recurrences have been diagnosed primarily by mammography ${ }^{10,13}$. In a recent Australian study, a large cohort of women across all ages with a personal history of breast cancer was matched to a similar group without such a history to study the accuracy of mammography, the interval cancer rate and stage at diagnosis for both groups ${ }^{14}$. In this study, a lower sensitivity (65\% versus $76 \%$ ) 
and a higher interval cancer rate (35\% versus $23 \%$ ) was found in the group with a personal history of breast cancer. In the younger age group ( $<50$ years) with a personal history the sensitivity of routine mammography was even lower (51\%). It is known that not only young age, but also a genetic predisposition for breast cancer, a history of previous BCT or dense breasts in general reduce the sensitivity of mammography ${ }^{15}$. These factors may explain why in our study, only 25 percent of all LRs was detected by mammography alone.

Surgery and radiation therapy induce structural changes in breast tissue and therefore negatively influence the sensitivity of clinical breast examination and mammography $^{15}$. Patients aged $\leq 40$ years benefit more from an additional boost treatment compared to older patients. In our study 82 percent received a boost dose on the tumour bed. A consequence of this strategy is development of additional fibrosis in the treated breast. Of the LRs that we identified, the majority $(74 \%)$ occurred at or near the site of the primary tumour, being the area where fibrosis is likely to be most prominent. This, together with the fact that young women in general have denser breasts, may further complicate detection. This is consistent with our finding that no mammographic abnormalities were observed in $25 \%$ of the patients reporting a swelling in their breast.

Our findings imply that the conventional diagnostic techniques, including mammography and clinical breast examination, have limited potential in young women after BCT. Ultrasound was used on regular basis in addition to mammography to explore a palpable mass or characterize opacities. However, diagnostic problems are also encountered with ultrasound because of difficult interpretation of hypoechoic areas and shadowing within scar tissue ${ }^{16}$. Perhaps that MRI may be a valuable addition to the care of these patients ${ }^{17}$. Particular diagnostic benefit has been observed with MRI-identified tumours that are mammographically, ultrasonographically, and clinically occult ${ }^{19}$. However, the relevance of these findings needs to be investigated more extensively ${ }^{12,20}$. Although the outcome of our study suggests the need the need for additional screening in these women, until now there is no evidence that MRI or other diagnostic tools will improve the prognosis ${ }^{20}$.

It may be clear that current diagnostic strategies have their shortcomings regarding the detection of LRs in women younger than 40 years treated with BCT. The developments within breast cancer research are very dynamic and the development of cost-effective follow-up strategies is nowadays a hot topic. With the recent introduction of digital mammography the sensitivity has improved ${ }^{21}$.

During the study period, MRI was mostly used for follow-up in women who are BRCA mutation carriers. It has proven its clear diagnostic benefit in this specific group of patients ${ }^{22}$. Unfortunately, for the patients in our study, information about BRCA status was largely unknown. Population-based data indicate that approximately $10 \%$ of the breast cancers in women $\leq 40$ years are related to a BRCA1 or BRCA2 mutation ${ }^{23,24}$. The gathering of long-term follow-up information was challenging for several reasons. Medical files of some patients who had died were already destroyed and a large 
number of patients $(n=26)$ could not be evaluated regarding follow-up strategy because of incomplete medical files. The latter is a consequence of the transition to electronic medical records in the Netherlands. The missing data concerning size and grade of the LR were in most cases due to omissions in the pathology reports. These points, together with the retrospective nature of this study, can be considered as limitations of our study.

Until 2002 no national or local guidelines on follow-up were available in the Netherlands. From 2002-2008 the recommended frequency of follow-up visits was every 3 months during the first year, every 6 months during the second year and once a year during the third year and beyond. In accordance with the NICE guidelines, the Dutch guidelines currently in use indicate that an individualized approach, adjusted to the medical and psychosocial needs of the patients, is justified ${ }^{25,26}$. In the absence of good quality data, these recommendations are largely based on consensus, but may be an impetus for the development and evaluation of more cost-effective follow-up strategies. Examples of such alternative strategies are follow-up by general practitioners, nurse-led follow-up or telephone follow-up ${ }^{27}$.

\section{Conclusion}

Detection of local recurrences after BCT in the earliest possible stage is a big challenge. Especially in young patients long-term follow-up remains necessary, as recurrences continue to develop, even more than 10 years after BCT. Current followup strategies, however, do not guarantee a timely detection of local recurrence. Large, prospective studies are needed to define a more cost-effective follow-up regimen, tailored to the risk of the individual patient and making use of new imaging techniques. 


\section{References}

1. DeSantis C, Siegel R, Bandi P, Jemal A. Breast cancer statistics, 2011. CA Cancer J Clin 2011;61:408-18.

2. van der Sangen $M$, van de Wiel F, Poortmans $P$, Tjan-Heijnen V, Nieuwenhuijzen G, Roumen R, et al Are breast conservation and mastectomy equally effective in the treatment of young women with early breast cancer? Long-term results of a population-based cohort of 1,451 patients aged $\leq 40$ years. Breast Cancer Res Treat 2011;127:207-15.

3. van Dongen JA, Voogd AC, Fentiman IS, Legrand C, Sylvester RJ, Tong D, et al. Long-Term Results of a Randomized Trial Comparing Breast-Conserving Therapy With Mastectomy: European Organization for Research and Treatment of Cancer 10801 Trial. J Natl Cancer Inst 2000;92:1143-50.

4. Fisher B, Anderson S, Bryant J, Margolese RG, Deutsch M, Fisher ER, et al. Twenty-Year Follow-up of a Randomized Trial Comparing Total Mastectomy, Lumpectomy, and Lumpectomy plus Irradiation for the Treatment of Invasive Breast Cancer. N Engl J Med 2002;347:1233-41.

5. van der Leest M, Evers L, van der Sangen MJC, Poortmans PM, van de Poll-Franse LV, Vulto AJ, et al. The safety of breast-conserving therapy in patients with breast cancer aged $\leq 40$ years. Cancer 2007;109:1957-64.

6. de Bock $\mathrm{GH}$, van der Hage JA, Putter H, Bonnema J, Bartelink $\mathrm{H}$, van de Velde $\mathrm{CJ}$. Isolated loco-regional recurrence of breast cancer is more common in young patients and following breast conserving therapy: Long-term results of European Organisation for Research and Treatment of Cancer studies. Eur J Cancer 2006;42:351-6.

7. Anders CK, Johnson R, Litton J, Phillips M, Bleyer A. Breast Cancer Before Age 40 Years. Semin Oncol 2009;36:237-49.

8. Voogd AC, Nielsen M, Peterse JL, Blichert-Toft M, Bartelink H, Overgaard $M$, et al. Differences in risk factors for local and distant recurrence after breast-conserving therapy or mastectomy for stage I and II breast cancer: pooled results of two large European randomized trials. J Clin Oncol 2001;19: 1688-97.

9. Poortmans P, Aznar M, Bartelink H. Quality Indicators for Breast Cancer: Revisiting Historical Evidence in the Context of Technology Changes. Semin Radiat Oncol 2012;22:29-39.

10. Montgomery DA, Krupa K, Cooke TG. Follow-up in breast cancer: does routine clinical examination improve outcome? A systematic review of the literature. Br J Cancer 2007;97:1632-41.

11. Lu W, Jansen L, Post W, Bonnema J, Van de Velde J, De Bock G. Impact on survival of early detection of isolated breast recurrences after the primary treatment for breast cancer: a meta-analysis. Breast Cancer Res Treat 2009;114:403-12.

12. Biglia N, Bounous VE, Martincich L, Panuccio E, Liberale V, Ottino L, et al. Role of MRI (magnetic resonance imaging) versus conventional imaging for breast cancer presurgical staging in young women or with dense breast. Eur J Surg Oncol 2011;37:199-204.

13. van der Sangen MJC, van de Poll-Franse LV, Roumen RMH, Rutten HJT, Coebergh JWW, Vreugdenhil $\mathrm{G}$, et al. The prognosis of patients with local recurrence more than five years after breast conservation therapy for invasive breast carcinoma. Eur J Surg Oncol 2006;32:34-8.

14. Houssami N, Abraham LA, Miglioretti DL, Sickles EA, Kerlikowske K, Buist DS, et al. Accuracy and outcomes of screening mammography in women with a personal history of early-stage breast cancer. JAMA 2011;305:790-9.

15. Schelfout K, Van Goethem M, Kersschot E, Colpaert C, Schelfhout AM, Leyman P, et al. Contrastenhanced MR imaging of breast lesions and effect on treatment. Eur J Surg Oncol 2004;30:501-7.

16. Ternier F, Houvenaeghel G, Lecrivain F, Brigand B, Margain D, Brunelle S, et al. Computed tomography in suspected local breast cancer recurrence. Breast Cancer Res Treat 2006;100:247-54.

17. Belli P, Costantini M, Romani M, Marano P, Pastore G. Magnetic Resonance Imaging in Breast Cancer Recurrence. Breast Cancer Res Treat 2002;73:223-35.

18. Li J, Dershaw DD, Lee CF, Joo S, Morris EA. Breast MRI After Conservation Therapy: Usual Findings in Routine Follow-Up Examinations. Am J Roentgenol 2010;195:799-807.

19. Hwang N, Schiller D, Crystal P, Maki E, McCready D. Magnetic Resonance Imaging in the Planning of Initial Lumpectomy for Invasive Breast Carcinoma: Its Effect on Ipsilateral Breast Tumor Recurrence After Breast-Conservation Therapy. Ann Surg Oncol 2009;16:3000-9. 
20. Punglia RS, Hassett MJ. Using lifetime risk estimates to recommend magnetic resonance imaging for breast cancer survivors. J Clin Oncol 2010;28:4108-10.

21. Timmers JM, den Heeten GJ, Adang EM, Otten JD, Verbeek AL, Broeders MJ. Dutch digital breast cancer screening: implications for breast cancer care. Eur J Public Health 2012;22:925-9.

22. Morrow M, Waters J, Morris E. MRI for breast cancer screening, diagnosis, and treatment. Lancet 2011;378:1804-11.

23. de Sanjosé $S$, Léoné $M$, Bérez $V$, Izquierdo $A$, Font $R$, Brunet JM, et al. Prevalence of BRCA1 and BRCA2 germline mutations in young breast cancer patients: A population-based study. Int J Cancer 2003;106:588-93.

24. Pierce LJ, Levin AM, Rebbeck TR, Ben-David MA, Friedman E, Solin LJ, et al. Ten-Year MultiInstitutional Results of Breast-Conserving Surgery and Radiotherapy in BRCA1/2-Associated Stage I/II Breast Cancer. J Clin Oncol 2006;24:2437-43.

25. Grogan M, Rangan A, Gebski V, Boyages J. The value of follow-up of patients with early breast cancer treated with conservative surgery and radiation therapy. Breast 2002;11:163-9.

26. Early and locally advanced breast cancer Diagnosis and treatment. NICE clinical guideline 80 Developed by the National Collaborating Centre for Cancer Issue date, February 2009. (http://www.nice.org.uk/nicemedia/pdf/CG80NICEGuideline.pdf)

27. Kimman $M L$, Voogd AC, Dirksen CD, Falger $P$, Hupperets $P$, Keymeulen $K$, et al. Follow-up after curative treatment for breast cancer: Why do we still adhere to frequent outpatient clinic visits? Eur J Cancer 2007;43:647-53. 


\section{Chapter 3}

Local control in lobular breast cancer 


\section{Chapter 3.1}

\section{Margin status and the risk of local recurrence after breast-conserving therapy of lobular breast cancer}

$\mathrm{N}$ van den Broek MJC van der Sangen

$\mathrm{LV}$ van de Poll-Franse

MWPM van Beek

GAP Nieuwenhuijzen

AC Voogd

Breast Cancer Res Treat. 2007;105:63-68 


\section{Abstract}

\section{Background}

Invasive lobular breast carcinoma is known for its multicentricity and is associated with a higher incidence of incomplete excision after breast-conserving therapy. The aim of the study was to examine the influence of positive surgical margins on the local recurrence rate in patients diagnosed with invasive lobular cancer and treated with breast-conserving therapy.

\section{Methods}

All 416 women diagnosed with invasive lobular breast cancer and undergoing breast-conserving therapy between 1995 and 2002 were selected from the population-based Eindhoven Cancer Registry. Their medical charts were reviewed and detailed information was collected.

\section{Results}

The risk of margin involvement was $29 \%$ after the first operation and $17 \%$ when taking into account the final margin status of the patients undergoing re-excision. During follow-up, 18 patients developed a local recurrence. The 5-year actuarial risk of developing a local recurrence was 3.5\% (95 per cent confidence interval 2.5 to 4.5 ) and the 8 -year risk was $6.4 \%$ $(95 \% \mathrm{Cl} 4.7$ to 8.0$)$. There was no influence of positive surgical margins on the risk of local recurrence, neither in the univariate analysis nor after adjustment for age, tumour size, nodal status and adjuvant systemic treatment.

\section{Conclusion}

Patients with invasive lobular cancer, treated with breast-conservation, have a low risk of local recurrence, despite their high risk of having a microscopically incomplete excision of the tumour. 


\section{Introduction}

The life-time risk of developing breast cancer for a woman in the Western world is $9-10 \%$, which makes it the most common type of cancer in women. Invasive lobular cancer (ILC) is accounting for $5-15 \%$ of all invasive breast cancers ${ }^{1-4}$, and the incidence seems to have been increasing disproportionately compared to the incidence of ductal cancer during the last two decades ${ }^{5}$. Data of the Surveillance, Epidemiology, and End Results (SEER) program of the National Cancer Institute demonstrated that the proportion of breast cancers with a lobular component increased from $9.5 \%$ in 1987 to $15.6 \%$ in $1999^{6}$. ILC is more difficult to diagnose clinically because it is less likely to present as a palpable lump and has a diffusely infiltrative growth which makes difficult to be visualized by mammography and to determine the extent of the lesion ${ }^{7,8}$. In addition, ILC is more likely to be multicentric, multifocal and bilateral than ductal carcinoma ${ }^{9}$. These features may explain why lobular cancers are associated with a higher risk of incomplete excisions ${ }^{9-11}$, compared to patients with invasive ductal carcinoma, and why concerns have been raised about the use of BCT for patients with ILC. However, despite their higher risk of an incomplete tumour excision patients with ILC do not seem to have a higher local recurrence risk after BCT than patients with ductal cancer ${ }^{7,9,12,13}$.

In the current study we examined the prevalence of positive surgical margins and the association with local recurrence in a series of 420 patients with ILC who underwent BCT in the period of 1995-2002 in five general hospitals in the south of the Netherlands.

\section{Patients and methods}

Patients were selected from the population-based Eindhoven Cancer Registry, which serves a population of almost two million inhabitants (which is twelve percent of the Dutch population) in the South-Eastern part of the Netherlands. Cancer registry data were retrieved from copies of the pathology reports from three different laboratories, the medical records of five hospitals and one radiotherapy institute. Between January 1995 and December 20024947 patients were diagnosed with breast cancer, of whom 969 had ILC or mixed (with a ductal component) ILC (19.6\%). Of all 4947 patients, 2653 were treated with BCT (53.6\%), compared to 416 of the 969 patients with ILC (42.9\%). These 416 patients constitute the study population. Patients who underwent lumpectomy and subsequently received a mastectomy were excluded. The medical chart of each of the 416 patients was reviewed for detailed information with respect to the locoregional and systemic treatment of the primary tumour. Information was recorded on the presence and extent of tumour involvement of the margins of the specimen of the primary tumour and the specimen taken at re-excision. 


\section{Statistics}

Follow-up was completed until the patient's death or until the date of last visit or last contact with the surgeon, radiation-oncologist or general practitioner. There were 11 patients with a last contact date before January $1^{\text {st }}, 2005(<3 \%)$. Although formally lost-to-follow up, these patients have been included in the analysis until their last contact date. The median follow-up of the patients who were still alive was 6 years (range 1.1-11.0).

The primary end-point of our study was local recurrence, which was defined as a new tumour occurring in the preserved breast or overlying skin. Survival analysis was carried out using the life-table method. For patients who did not develop a local recurrence, survival time was censored at the date of last follow-up. The logrank-test was performed to compare local recurrence rates according to excision-margin and other potential risk factors. Multivariate analysis were carried out using Cox proportional hazards models to asses the independent effect of the excision margins on the risk of local recurrence, adjusting for age at primary treatment and tumour stage. Hazard ratios with $95 \% \mathrm{Cl}$ and $P$-values were estimated with respect to the reference category for each co-variate.

\section{Results}

Characteristics of the patients, primary tumour and the treatment are presented in Table 3.1.1. The mean age at diagnosis of the primary tumour was 59.3 years (range 29.0-91.6). Of all patients, 279 patients were diagnosed with lobular carcinoma, 136 with mixed lobular carcinoma and one was diagnosed as other. Nearly all patients (99.3\%) received irradiation after the surgery. Irradiation consisted of whole breast irradiation with a total dose of 32.5-50 Gy and the large majority (95.4\%) received an additional boost to the tumour bed using either photons or electrons.

Overall, primary excisions were considered radical in 282 patients (Table 3.1.2). Reasons for a re-operation $(n=12)$ in patients with a radical primary excision were mostly due to complications of the primary treatment (infection). In 122 patients, the primary excision was irradical. Five excisions showed only focal margin involvement, 33 excisions were more than focally incomplete and in 96 cases the extent of margin involvement was not known. In this group of 122 patients, 58 re-excisions were performed, of which four were incomplete for the second time, 53 radical and one had an unknown outcome. In 12 patients completeness of the primary excision was uncertain and two re-excisions occurred in this group.

The risk of an incomplete primary excision increased from $26 \%(76 / 288)$ for patients with a tumour of $2 \mathrm{~cm}$ or less to $40 \%(40 / 100)$ for patients with a tumour of $2-5 \mathrm{~cm}$ $(P=0.01)$. No significant correlation was observed between age, nodal status and morphology (lobular versus mixed-lobular) and the risk of an incomplete primary excision. 
Table 3.1.1 Patient, disease and treatment characteristics.

\begin{tabular}{llrr}
\hline Characteristics & & No. & (\%) \\
\hline Age at diagnosis (years) & $<50$ & 95 & $(23)$ \\
& $50-69$ & 244 & $(59)$ \\
Histological type & $70+$ & 77 & $(19)$ \\
& Lobular & 279 & $(67)$ \\
Tumour size (pT) & Lobular-mixed & 136 & $(33)$ \\
& Other & 1 & $(0)$ \\
& pT1 & 296 & $(71)$ \\
Nodal status (pN) & pT2 & 102 & $(25)$ \\
& pT3 & 1 & $(0)$ \\
& pT4 & 13 & $(3)$ \\
Radiotherapy & pTX & 3 & $(1)$ \\
& pN0 & 253 & $(61)$ \\
& pN1 & 128 & $(31)$ \\
Adjuvant systemic treatment & pN2 & 3 & $(1)$ \\
& pNX & 31 & $(7)$ \\
& Whole breast and boost dose & 394 & $(95)$ \\
& Nhole breast without boost dose & 19 & $(5)$
\end{tabular}

Table 3.1.2 Margin status following primary excision and re-excision.

\begin{tabular}{|c|c|c|c|c|c|c|}
\hline & \multicolumn{6}{|c|}{ Radicality of primary excision } \\
\hline & \multicolumn{2}{|c|}{ Radical ( $n=282$ ) } & \multicolumn{2}{|c|}{ Irradical (n=122) } & \multicolumn{2}{|c|}{ Doubtful $(n=12)$} \\
\hline & No. & $(\%)$ & No. & $(\%)$ & No. & $(\%)$ \\
\hline \multicolumn{7}{|c|}{ Re-excision } \\
\hline No & 270 & (96) & 64 & $(52)$ & 10 & (83) \\
\hline Yes & 12 & (4) & 58 & (48) & 2 & (17) \\
\hline \multicolumn{7}{|c|}{ Radicality of re-excision } \\
\hline No & 1 & (8) & 4 & (9) & 0 & (0) \\
\hline Yes & 11 & (92) & 53 & (91) & 2 & $(100)$ \\
\hline
\end{tabular}

Eighteen of the 416 patients with ILC developed a local recurrence. The mean age at diagnosis of the local recurrence was 62.6 years (range 43.8-79.0). The mean time from the date of the primary tumour until date of the local recurrence was 4.1 years (range 0.8-8.7 years). The 5-year actuarial risk of developing local recurrence was 3.5\% (95\% $\mathrm{Cl} 2.5-4.5)$ and the 8-year actuarial risk was $6.4 \%(95 \% \mathrm{Cl} 4.7-8.0)$. One patient was diagnosed with a second local recurrence. Of the 18 local recurrences, 17 were isolated and one was diagnosed concurrently with distant metastases. Eight recurrences were of the lobular type, seven were ductal, two were mixed lobular and one was a Morbus Paget with invasive adenocarcinoma. One of the 18 recurrences was purely in situ, 11 were invasive and six were mixed in situ and invasive. During the same follow-up period, 15 breast tumours were diagnosed in the contralateral breast. In a univariate analysis, no significant association was found between the final margin status (including re-excision) and the risk of local recurrence ( $P=0.55$; Figure 3.1.1). 
Also, no significant difference in local control was found between patients undergoing re-excision and those who did not or the outcome of the re-excision and the risk of local recurrence $(P=0.70)$; two of the 72 patients who underwent a re-excisions developed a local recurrence, as compared to 16 of the 344 patients who did not undergo a re-excision. Neither did a re-excision following a primary incomplete tumour excision lead to a lower risk local recurrence $(P=0.63)$ (Figure 3.1.2). Also after adjusting for age, tumour size, axillary nodal status and adjuvant systemic treatment in a multivariate Cox proportional hazards model, no association was observed between margin status and the risk of local recurrence and none of the other covariates appeared to be associated with the risk of local recurrence (Table 3.1.3).

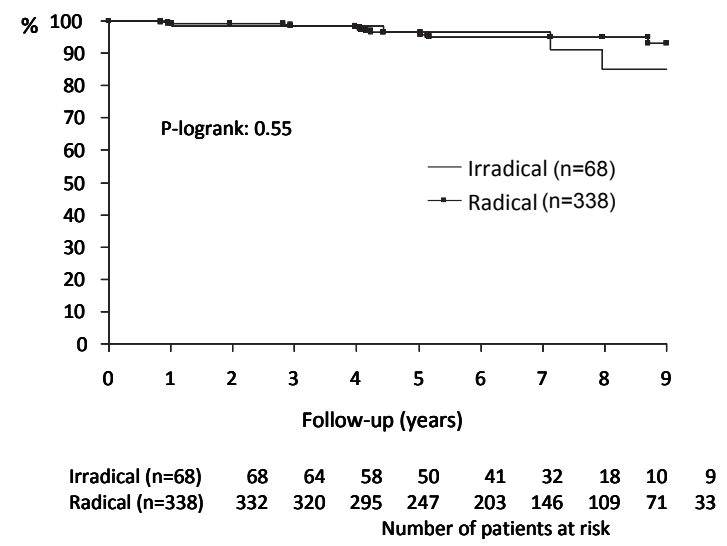

Figure 3.1.1 Local control according to definite margin status (including the results of re-excision).

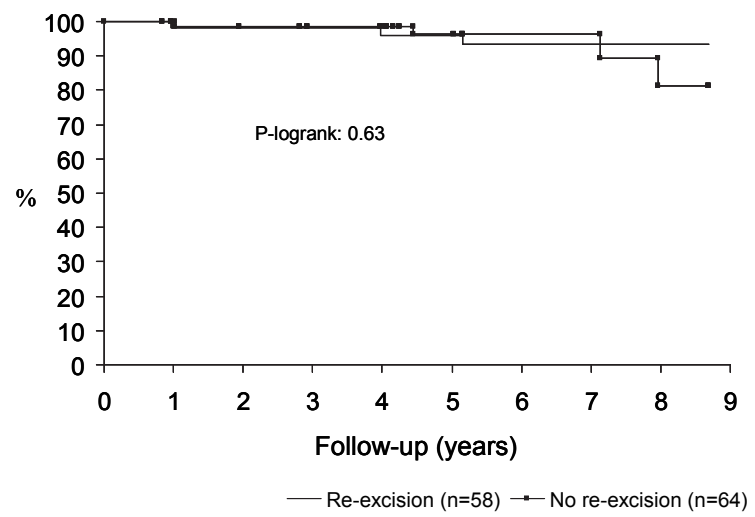

Figure 3.1.2 Local control in patients with an irradical primary excision, according whether re-excision has been performed. 
Table 3.1.3 Results of the Cox proportional hazards analysis on risk factors for local recurrence.

\begin{tabular}{llccc}
\hline \multicolumn{1}{l}{ Characteristics } & & HR & 95\% Cl & P-value \\
\hline \multicolumn{2}{l}{ Age at diagnosis (per year increase) } & 1.00 & $(0.96-1.05)$ & 0.976 \\
Tumour size & pT1 & 1 (Ref) & & \\
& pT2-4 & 1.12 & $(0.37-3.34)$ & 0.844 \\
Nodal status & pN0 & 1 (Ref) & & 0.603 \\
& pN1-2 & 0.62 & $(0.10-3.73)$ & 0.949 \\
Definite margin status* & Negative & 1 (Ref) & & \\
& Positive & 0.96 & $(0.27-3.38)$ & 0.912 \\
\hline
\end{tabular}

* including results of re-excision. HR: hazard ratio.

\section{Discussion}

The most important findings of the current study are the low risk of local recurrence in ILC after breast-conserving therapy followed by irradiation, despite frequent microscopically incomplete surgery, and the lack of a prognostic influence of positive surgical margins, which were present in $29 \%$ of all patients following their primary excision and in $17 \%$ when taking into account the final margin status of the patients undergoing re-excision.

Local recurrence rates after BCT for ILC reported by other studies vary between 5 and $13.5 \%$ after five years ${ }^{14-18}$. Chung et al. ${ }^{12}$ found a lower rate, of $2.8 \%$ at five years, which is closer to the risk of $3.5 \%$ found in our study. Some of these studies made a comparison with the risk after BCT for invasive ductal carcinoma (IDC) and only few found a higher local recurrence rate for ILC than for IDC ${ }^{16,17}$. Kurtz found a local recurrence rate of $13.5 \%$ after 5 years in 67 patients with ILC and a rate of $8.8 \%$ after five years in 709 patients with IDC $(P=0.11)^{16}$. In a study by Schnitt et al. the 5-year actuarial local recurrence risk of $12 \%$ among 49 patients with infiltrating lobular carcinoma was intermediate between that for patients with infiltrating ductal carcinomas with an extensive intraductal component (23\%) and those without an extensive intraductal component $(5 \%)^{17}$. All other studies reported equal local recurrence rates after ILC and IDC ${ }^{9,11,12,19,20}$. Of these studies, the ones of Sastre-Garau et al. and Salvadori et al. are by far the largest, including several hundreds of patients with ILC. The first reviewed 975 patients with ILC $(n=726)$ or mixed ILC and IDC $(n=249)$, and compared them to 10061 patients with non-lobular invasive carcinoma (NLIC). Four-hundred-eighty patients with ILC were treated with BCT (66\%), 154 patients with mixed ILC/IDC were treated with $\mathrm{BCT}(62 \%)$ and 6797 patients with NLIC were treated with BCT (68\%). BCT yielded similar results for local recurrence-free interval in the three groups (ILC 91\%, ILC/IDC 84\%, NLIC 86\%). Salvadori et al. found a cumulative recurrence rate of $7.0 \%$ at 10 years for 286 patients with ILC and 1903 with IDC, both treated with $\mathrm{BCT}^{19}$. A third study, by Peiro et al. reported 10 year crude 
local recurrence rates of $15 \%, 13 \%$ and $13 \%$, for patients with infiltrating lobular $(n=93)$, infiltrating ductal $(n=1089)$ and mixed histology $(n=59)$ respectively ${ }^{11}$.

Patients with ILC undergoing an attempt for breast-conservation have a high risk of tumour-positive excision margins. The reported risks of tumour-positive resection margins vary between $18 \%$ and $63 \%$ and appear to be higher than the risk for patients with ductal carcinoma ${ }^{8-10,20,21}$. However, these findings were not confirmed in a recent study by Morrow et al., who found that patients with ILC did not require more operations to obtain negative margins than those with ductal carcinoma, after controlling for age and stage ${ }^{22}$.

A positive surgical margin is an important risk factor for developing a local recurrence after $\mathrm{BCT}^{23}$, especially when an extensive intraductal component is present. Only a few studies have addressed the role of positive surgical margins in patients with ILC, of which ours is by far the largest. Bouvet et al. studied 74 patients with ILC who underwent $\mathrm{BCT}$, of whom nine developed a local recurrence ${ }^{15}$. They noted that patients with positive surgical margins or close margins $(\leq 1 \mathrm{~mm})$ were at an increased risk for developing local recurrence in a univariate analysis $(P=0.034)$, but the interpretation of their results was limited by the small number of patients which did not allow adjustment for age and tumour in a multivariate analysis. We found no influence of surgical margins on local recurrence risk, despite $29 \%$ of the primary excisions being incomplete. The low risk of local recurrence in patients with ILC and the lack of an association with margin status might be a reflection of high sensitivity of lobular carcinoma to radiation. Radiotherapy techniques may also have become more accurate and effective in eradicating microscopic disease. This hypothesis is supported by data from two randomised clinical trials in which lobular carcinoma was associated with an increased risk of local recurrence after modified radical mastectomy but not after $\mathrm{BCT}^{24}$.

The interpretation of our results concerning the impact of positive surgical margins in patients with lobular cancer is complicated by the missing data regarding the extent of the margin involvement and the low risk of local recurrence, which limits the statistical power of the study. Before the start of our study, it was our hope that margin status would have been reported more consistently, knowing that the pathologists in the three participating laboratories had started with a more systematic examination of surgical margins during the second half of the nineties. Despite this change in policy, there were still many patients for whom the tumour-free surgical margins had not been quantified microscopically and for whom no further specification of the margin width was given. According to current guidelines, the width of the tumour-free margin should be reported in millimetres. When the surgical procedure is incomplete, a distinction should be made between 'focal' and 'more than focal' involvement, depending of the extent of the margin involvement. This distinction has consequences regarding further treatment. If the procedure is focally incomplete, further treatment will consist of irradiation, but if the margin involvement is more than focal a re-excision was recommended ${ }^{25}$. However, even if the margin 
assessment had been done with greater accuracy, it seems unlikely that a microscopic incomplete excision is an important risk factor for local recurrence in patients with ILC treated with BCT and irradiation.

In conclusion, results from this study show that, despite a high incidence of incomplete tumour excisions, there is a low local recurrence risk and there is no influence of positive surgical margins in patients diagnosed with ILC and treated with BCT. 


\section{References}

1. The World Health Organization Histological Typing of Breast Tumors--Second Edition. The World Organization. Am J Clin Pathol 1982;78:806-16.

2. Wellings SR, Jensen HM, Marcum RG. An atlas of subgross pathology of the human breast with special reference to possible precancerous lesions. J Natl Cancer Inst 1975;55:231-73.

3. Fisher ER, Gregorio RM, Fisher B, Redmond C, Vellios F, Sommers SC. The pathology of invasive breast cancer. A syllabus derived from findings of the National Surgical Adjuvant Breast Project (protocol no. 4). Cancer 1975;36:1-85.

4. Martinez V, Azzopardi JG. Invasive lobular carcinoma of the breast: incidence and variants. Histopathology 1979;3:467-88.

5. Verkooijen HM, Fioretta G, Vlastos G, Morabia A, Schubert H, Sappino AP, Pelte MF, Schäfer P, Kurtz J, Bouchardy C. Important increase of invasive lobular breast cancer incidence in Geneva, Switzerland. Int J Cancer 2003;104:778-81.

6. $\mathrm{Li} \mathrm{Cl}$, Anderson BO, Daling JR, Moe RE. Trends in incidence rates of invasive lobular and ductal breast carcinoma. JAMA 2003;289:1421-4.

7. Sastre-Garau X, Jouve M, Asselain B, Vincent-Salomon A, Beuzeboc P, Dorval T, Durand JC, Fourquet A, Pouillart P. Infiltrating lobular carcinoma of the breast. Clinicopathologic analysis of 975 cases with reference to data on conservative therapy and metastatic patterns. Cancer 1996;77:113-20.

8. Yeatman TJ, Cantor AB, Smith TJ, Smith SK, Reintgen DS, Miller MS, Ku NN, Baekey PA, Cox CE. Tumor biology of infiltrating lobular carcinoma. Implications for management. Ann Surg 1995;222:549-59.

9. Silverstein MJ, Lewinsky BS, Waisman JR, Gierson ED, Colburn WJ, Senofsky GM, Gamagami P. Infiltrating lobular carcinoma. Is it different from infiltrating duct carcinoma? Cancer 1994;73:1673-7.

10. Moore MM, Borossa G, Imbrie JZ, Fechner RE, Harvey JA, Slingluff CL Jr, Adams RB, Hanks JB. Association of infiltrating lobular carcinoma with positive surgical margins after breast-conservation therapy. Ann Surg 2000;231:877-82.

11. Peiro G, Bornstein BA, Connolly JL. The influence of infiltrating lobular carcinoma on the outcome of patients treated with breast-conserving surgery and radiation therapy. Breast Cancer Res Treat 2000;59:49-54.

12. Chung MA, Cole B, Wanebo HJ, Bland KI, Chang HR. Optimal surgical treatment of invasive lobular carcinoma of the breast. Ann Surg Oncol 1997;4:545-50.

13. Singletary SE, Patel-Parekh L, Bland KI. Treatment trends in early-stage invasive lobular carcinoma: a report from the National Cancer Data Base. Ann Surg 2005;242:281-9.

14. Holland PA, Shah A, Howell A, Baildam AD, Bundred NJ. Lobular carcinoma of the breast can be managed by breast-conserving therapy. Br J Surg 1995;82:1364-6.

15. Bouvet M, Ollila DW, Hunt KK, Babiera GV, Babiera GV, Spitz FR, Giuliano AE, Strom EA, Ames FC, Ross MI, Singletary SE. Role of conservation therapy for invasive lobular carcinoma of the breast. Ann Surg Oncol 1997;4:650-4.

16. Kurtz JM, Jacquemier J, Torhorst J, Spitalier JM, Amalric R, Hünig R, Walther E, Harder F, Almendral A, Brandone $\mathrm{H}$, et al. Conservation therapy for breast cancers other than infiltrating ductal carcinoma. Cancer 1989;63:1630-5.

17. Schnitt SJ, Connolly JL, Recht A, Silver B, Harris JR. Influence of infiltrating lobular histology on local tumor control in breast cancer patients treated with conservative surgery and radiotherapy. Cancer 1989;64:448-54.

18. Poen JC, Tran L, Juillard G, Selch MT, Giuliano A, Silverstein M, Fingerhut A, Lewinsky B, Parker RG. Conservation therapy for invasive lobular carcinoma of the breast. Cancer 1992;69:2789-95.

19. Salvadori B, Biganzoli E, Veronesi P, Saccozzi R, Rilke F. Conservative surgery for infiltrating lobular breast carcinoma. Br J Surg 1997;84:106-9.

20. White JR, Gustafson GS, Wimbish K, Ingold JA, Lucas RJ, Levine AJ, Matter RA, Martinez A, Vicini FA. Conservative surgery and radiation therapy for infiltrating lobular carcinoma of the breast. The role of preoperative mammograms in guiding treatment. Cancer 1994;74:640-7.

21. Mai KT, Yazdi HM, Isotalo PA. Resection margin status in lumpectomy specimens of infiltrating lobular carcinoma. Breast Cancer Res Treat 2000;60:29-33. 
22. Morrow M, Keeney K, Scholtens D, Wei J, Steel J, Khan SA. Selecting patients for breast-conserving therapy: the importance of lobular histology. Cancer 2006;106:2563-8.

23. Newman LA, Kuerer HM. Advances in breast conservation therapy. J Clin Oncol 2005;23:1685-97.

24. Voogd AC, Nielsen M, Peterse JL, Blichert-Toft $M$, Bartelink $H$, Overgaard $M$, van Tienhoven $G$, Andersen KW, Sylvester RJ, van Dongen JA; Danish Breast Cancer Cooperative Group. Breast Cancer Cooperative Group of the European Organization for Research and Treatment of Cancer. Differences in risk factors for local and distant recurrence after breast-conserving therapy or mastectomy for stage I and II breast cancer: pooled results of two large European randomized trials. J Clin Oncol 2001;19:1688-97.

25. Rutgers EJ, Nortier JW, Tuut MK, van Tienhoven G, Struikmans H, Bontenbal M, von Meyenfeldt MF, Vreugdenhil G, Benraadt T, Garssen B, Peterse JL; Nationaal Borstkanker Overleg Nederland; Kwaliteitsinstituut voor de Gezondheidszorg. Dutch Institute for Healthcare Improvement guideline, "Treatment of breast cancer". Ned Tijdschr Geneeskd 2002;146:2144-51. 


\title{
Chapter \\ 3.2
}

\section{The impact of postmastectomy radiotherapy on local control in patients with invasive lobular breast cancer}

\author{
LA Diepenmaat \\ MJC van der Sangen \\ $L V$ van de Poll-Franse \\ MWPM van Beek \\ CLH van Berlo \\ EJT Luiten \\ GAP Nieuwenhuijzen \\ AC Voogd
}




\section{Abstract}

\section{Purpose}

The aim of this population-based study was to examine the impact of postmastectomy radiotherapy on the risk of local recurrence in patients with invasive lobular breast cancer (ILC).

\section{Methods}

The population-based Eindhoven Cancer Registry was used to select all patients with ILC who underwent mastectomy in five general hospitals in the southern part of the Netherlands between 1995 and 2002. Of the 499 patients 383 patients fulfilled the eligibility criteria. Of these patients $170(44.4 \%)$ had received postmastectomy radiotherapy. The median follow-up was 7.2 years. Fourteen patients (3.7\%) were lost to follow-up.

\section{Results}

During follow-up 22 patients developed a local recurrence, of whom four had received postmastectomy radiotherapy. The 5-year actuarial risk of local recurrence was $2.1 \%$ for the patients with and $8.7 \%$ for the patients without postmastectomy radiotherapy. After adjustment for age at diagnosis, tumour stage and adjuvant systemic treatment, the patients who underwent postmastectomy radiotherapy were found to have a more than three times lower risk of local recurrence compared to the patients without (Hazard Ratio 0.30; 95\% Confidence Interval: 0.10-0.89).

\section{Conclusion}

Local control is excellent for patients with ILC who undergo postmastectomy radiotherapy and significantly better than for patients not receiving radiotherapy. 


\section{Introduction}

Invasive lobular breast cancer (ILC) is accounting for 5-15\% of all invasive breast cancers $^{1-4}$. ILC is difficult to diagnose clinically because it often has a diffuse infiltrative growth and is less likely to present as a palpable lump. The diffuse growth pattern as well as the relatively high stromal component make ILC difficult to visualize by mammography and to determine the extent of the lesion ${ }^{5,6}$. Moreover, ILC more often presents as multicentric, multifocal or bilateral disease, as compared to invasive ductal carcinoma ${ }^{7}$. These diagnostic and histopathologic features may explain why ILC is associated with an increased risk of incomplete excision after breast conserving therapy $(B C T)^{7-9}$ and why concerns have been raised about the safe use of BCT for patients with ILC. However, these concerns seem to be unfounded based on several studies comparing the local control rates for these tumours after BCT and mastectomy $^{10-13}$. For example, a previous study from our group showed the 5-year local recurrence risk to be only $3.5 \%$ after $\mathrm{BCT}$, despite the high risk (17\%) of an incomplete excision of the tumour ${ }^{14}$.

The relatively low risk of local recurrence in patients with ILC following BCT and the absence of a clear association with margin status may be due to the high sensitivity of ILC to radiation. This hypothesis is supported by data from two randomised clinical trials in which ILC, when compared to invasive ductal carcinoma, was associated with an increased risk of local recurrence after mastectomy (18\% versus $10 \%$ after ten years), but not after $\mathrm{BCT}^{15}$. An explanation for the high risk of local recurrence after mastectomy in patients with ILC might be that only high-risk patients did receive adjuvant radiotherapy.

To support our hypothesis that ILC has a high sensitivity to radiotherapy and would therefore be associated with a high risk of local recurrence when not treated with adjuvant radiotherapy, we compared the risk of local recurrence in patients with ILC with or without postmastectomy radiotherapy.

\section{Patients and methods}

\section{Patients}

Patients were selected from the population-based Eindhoven Cancer Registry, which serves a population of almost two million inhabitants (representing twelve percent of the total Dutch population) in the South-Eastern part of the Netherlands. Cancer registry data were retrieved from copies of the pathology reports from three different laboratories, the medical records of five hospitals and one radiotherapy institute. According to data from the Cancer Registry, 4947 patients were diagnosed with invasive breast cancer in the period 1995 to 2002, of whom 969 were found to have ILC or mixed invasive ductal and lobular carcinoma (19.6\%). Of these 969 patients, 499 
underwent mastectomy. The medical records of these 499 patients were reviewed to collect detailed information with respect to the characteristics of the primary tumour, treatment and outcome.

Based on this review, 116 patients were excluded. The main reasons for exclusion were: previous invasive (breast) cancer $(n=27)$, histopathological characteristics $(n=38)$, including no ILC or an invasive ductal lesion larger than the lobular component, metastatic breast cancer at diagnosis $(n=22)$, bilateral breast cancer at diagnosis $(n=9)$ and locally advanced breast cancer treated with neo-adjuvant therapy $(n=14)$. Finally, 383 patients fulfilled the criteria for the current study, of whom 170 (44.4\%) had received postmastectomy radiotherapy.

\section{Treatment}

Until 2002 patients were treated according to regional treatment guidelines and since 2002 according to the first national multidisciplinary guideline for the treatment of breast cancer. However, there were no essential differences between the regional and national guidelines in the indications for postmastectomy radiotherapy. These indications were: an incomplete tumour resection, a tumour of more than $5 \mathrm{~cm}$ across (pT3), a tumour growing into the chest wall or skin or inflammatory breast cancer (T4), four or more positive axillary lymph nodes $(\geq \mathrm{pN} 2)$ or a positive lymph node in the apex of the axilla.

Before 1998 adjuvant systemic treatment was based on regional guidelines and was only recommended for patients with positive axillary lymph nodes. In 1998, the Dutch National Breast Cancer Platform and the Dutch Society for Medical Oncology published a new guideline ${ }^{16}$ based on the St. Gallen guidelines ${ }^{17,18}$ in which also nodenegative patients with high-risk breast cancer were advised to receive adjuvant systemic treatment, depending on the size, grade and hormone receptor status of their tumour.

\section{Statistics}

Follow-up was completed until the patient's death or last contact with the surgeon, radiation-oncologist or general practitioner. Fourteen patients $(3.7 \%)$ had a last contact date before July $1^{\text {st }}, 2006$. The median follow-up of the patients who were still alive was 7.17 years (range $0.18-11.5$, mean 7.12 ).

Local recurrence, the primary end-point of our study, was defined as the occurrence of a new tumour in or around the mastectomy scar or elsewhere in the ipsilateral chest wall. For several reasons local recurrences diagnosed more than three months after distant metastases were not included; they are considered to be clinically less important than the ones developing earlier or at the same time as distant metastasis, and the risk of underreporting and absence of confirmation by histological examination is higher. Survival analysis was carried out using the life-table method. For patients without local recurrence, survival time was censored at the date of death, 
July $1^{\text {st }}, 2006$ or the last contact date. The logrank-test was performed to compare local recurrence rates according to radiotherapy and other potential risk factors.

Multivariable analyses were carried out using Cox proportional hazards models to asses the independent effect of radiotherapy on the risk of local recurrence, adjusting for age at diagnosis, tumour stage and systemic treatment. Hazard ratios with $95 \%$ confidence intervals $(95 \% \mathrm{Cl})$ and $P$-values were estimated with respect to the reference category for each co-variate.

\section{Results}

\section{Patient, tumour and treatment characteristics}

Table 3.2.1 presents the characteristics of the patients, the primary tumour and the treatment.

The mean age at diagnosis of the primary tumour of the patients who received postmastectomy radiotherapy was 60.8 years (range 26.8-89.2, median 60.3), as compared to 62.6 years (range 30.8-94.3, median 62.5) for patients who did not receive radiotherapy. Patients who received postmastectomy radiotherapy were found to have larger tumours, were more likely to have positive lymph nodes, to have received adjuvant systemic treatment and to have tumour invasion of the margins $(P<0.001)$ (Table 3.2.1).

Fifty-six (33\%) of the 170 patients receiving postmastectomy radiotherapy were irradiated to the chest wall only, $112(66 \%)$ to the chest wall as well as the regional nodal areas and $2(1 \%)$ to the regional nodal areas only. A mean total dose of $46 \mathrm{~Gy}$ (range 11.5-59.8 Gy, fraction dose of $2.3 \mathrm{~Gy}$ ) was given to 162 patients (95.3\%). Ten patients received an additional boost to the chest wall and 1 patient to the regional nodal areas, with a total boost dose of 11.5-18.4 Gy (63.6\% $13.8 \mathrm{~Gy}$, mean $14.0 \mathrm{~Gy})$. All 24 patients with an incomplete tumour excision after mastectomy received radiotherapy and seven of them received an additional boost to the chest wall. 
Table 3.2.1 Patient, disease and treatment characteristics of 383 patients with invasive lobular breast cancer

\begin{tabular}{|c|c|c|c|c|c|}
\hline \multirow[t]{2}{*}{ Characteristics } & \multicolumn{2}{|c|}{$\begin{array}{c}\text { M with RT } \\
(n=170)\end{array}$} & \multicolumn{2}{|c|}{$\begin{array}{c}\text { M without RT } \\
(n=213)\end{array}$} & \multirow[t]{2}{*}{$P$-value } \\
\hline & No. & $(\%)$ & No. & $(\%)$ & \\
\hline \multicolumn{6}{|l|}{ Age at diagnosis (years) } \\
\hline$<50$ & 45 & (26) & 44 & $(21)$ & 0.36 \\
\hline $50-69$ & 76 & $(45)$ & 98 & $(46)$ & \\
\hline $70+$ & 49 & (29) & 71 & (33) & \\
\hline \multicolumn{6}{|l|}{ Histological type } \\
\hline Lobular & 128 & $(75)$ & 168 & (79) & 0.41 \\
\hline Lobular-ductal mixed & 42 & $(25)$ & 45 & $(21)$ & \\
\hline \multicolumn{6}{|l|}{ Tumour size $(\mathrm{pT})$} \\
\hline pT1 & 20 & $(12)$ & 86 & $(40)$ & $<0.0001$ \\
\hline pT2 & 94 & $(55)$ & 110 & $(52)$ & \\
\hline pT3 & 41 & $(24)$ & 7 & (3) & \\
\hline pT4 & 13 & (8) & 2 & (1) & \\
\hline $\mathrm{pTx}$ & 2 & $(1)$ & 8 & (4) & \\
\hline \multicolumn{6}{|l|}{ Nodal status (pN) } \\
\hline $\mathrm{pNO}$ & 31 & (18) & 131 & $(62)$ & $<0.0001$ \\
\hline $\mathrm{pN} 1$ & 56 & (33) & 69 & $(32)$ & \\
\hline $\mathrm{pN} 2$ & 48 & $(28)$ & 5 & $(2)$ & \\
\hline $\mathrm{pN} 3$ & 34 & $(20)$ & 4 & $(2)$ & \\
\hline $\mathrm{pNx}$ & 1 & (1) & 4 & $(2)$ & \\
\hline \multicolumn{6}{|l|}{ Adjuvant systemic treatment } \\
\hline Chemotherapy & 20 & $(12)$ & 16 & (8) & $<0.0001$ \\
\hline Hormonal therapy & 92 & (54) & 69 & $(32)$ & \\
\hline Chemotherapy and hormonal therapy & 31 & (18) & 11 & (5) & \\
\hline None & 27 & (16) & 117 & $(55)$ & \\
\hline \multicolumn{6}{|l|}{ Completeness of mastectomy } \\
\hline Radical & 123 & $(72)$ & 187 & $(88)$ & $<0.0001$ \\
\hline Irradical & 24 & $(14)$ & 0 & $(0)$ & \\
\hline Doubtful & 6 & (4) & 2 & $(1)$ & \\
\hline Unknown & 17 & $(10)$ & 24 & $(11)$ & \\
\hline
\end{tabular}

\section{Treatment outcome}

Twenty-two patients developed a local recurrence during the follow-up period, of which four occurred simultaneously with metastatic disease. Four local recurrences were diagnosed in the group with and 18 in the group without postmastectomy radiotherapy. The mean age at diagnosis of the local recurrence was 68.7 years (range 43.9-84.8, median 73.3). The mean interval between the diagnosis of the primary tumour and local recurrence was 2.7 years (range $0.1-8.7$, median 2.5). Characteristics of the local recurrences are presented in Table 3.2.2. The large majority of the recurrences again were ILC and were located in or nearby the mastectomy scar. 
Table 3.2.2 Characteristics of patients with local recurrence after mastectomy $(n=22)$

\begin{tabular}{|c|c|c|}
\hline Characteristics & No. & $(\%)$ \\
\hline \multicolumn{3}{|l|}{ LR in relation to presence of distant disease } \\
\hline Isolated & 18 & $(82)$ \\
\hline Concurrently with distant metastases & 4 & (18) \\
\hline \multicolumn{3}{|l|}{ Histological type of LR } \\
\hline ILC & 17 & (77) \\
\hline IDC & 2 & (9) \\
\hline Invasive carcinoma, not otherwise specified & 1 & (5) \\
\hline Unknown & 2 & (9) \\
\hline \multicolumn{3}{|l|}{ Localisation of LR } \\
\hline In or nearby mastectomy scar & 18 & $(82)$ \\
\hline Elsewhere on chest wall & 2 & (9) \\
\hline Diffuse & 2 & (9) \\
\hline \multicolumn{3}{|l|}{ Extension/distribution of LR } \\
\hline One focus & 8 & (36) \\
\hline Multiple foci & 10 & (45) \\
\hline Diffuse & 4 & (18) \\
\hline \multicolumn{3}{|l|}{ Surgical excision of LR } \\
\hline Yes & 17 & (77) \\
\hline No & 5 & (23) \\
\hline \multicolumn{3}{|l|}{ Microscopic completeness of excision } \\
\hline Complete & 7 & (41) \\
\hline Incomplete & 8 & (47) \\
\hline Unknown & 2 & $(12)$ \\
\hline \multicolumn{3}{|l|}{ Radiotherapy } \\
\hline Yes & 13 & (59) \\
\hline No & 9 & (41) \\
\hline \multicolumn{3}{|l|}{ Adjuvant systemic therapy } \\
\hline Hormonal therapy & 20 & $(90)$ \\
\hline Chemotherapy and hormonal therapy & 1 & (5) \\
\hline None & 1 & (5) \\
\hline
\end{tabular}

The 5- and 8-year actuarial local recurrence rates for patients who received postmastectomy radiotherapy were both $2.1 \%$ (95\% Cl 0.0-4.5) (Figure 3.2.1). For patients without radiotherapy the 5 - and 8 -year rates were $8.7 \%(95 \% \mathrm{Cl} 4.7-12.7)$ and 9.5\% (95\% Cl 5.3-13.7), respectively (Figure 3.2.1), which was significantly higher $(P=0.018)$. The results of the univariate analysis showed that the risk of local recurrence was not significantly associated with age at diagnosis, nodal status, tumour size and the use of adjuvant systemic therapy. In the group without adjuvant radiotherapy, a tendency was observed towards a higher risk of local recurrence for the patients with a positive nodal status compared to those with a negative nodal status $(P=0.07)$. 


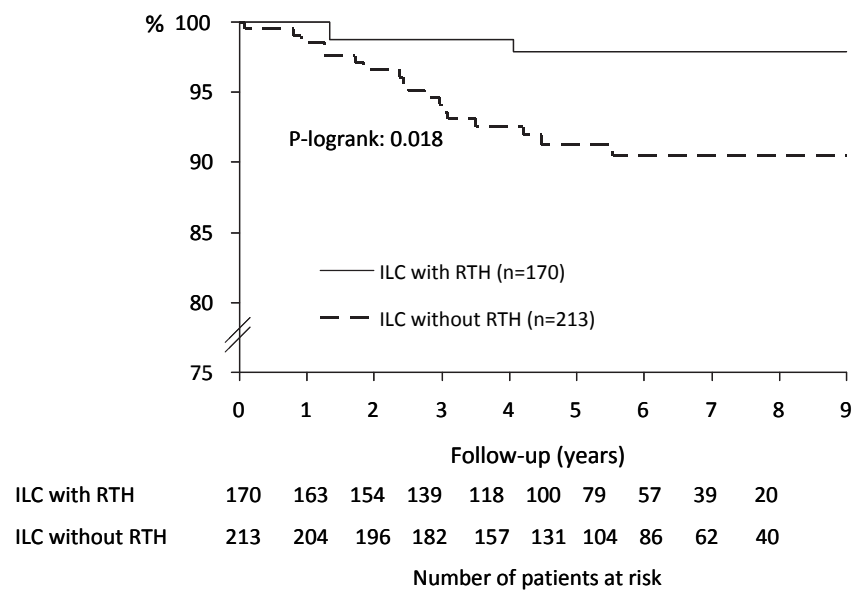

Figure 3.2.1 Local recurrence-free survival in patients with invasive lobular breast cancer (ILC), with or without postmastectomy radiotherapy $(\mathrm{RTH})$

A multivariable analysis, including age, histology, tumour size, nodal status and adjuvant systemic treatment between the patient groups, demonstrated that only radiotherapy was an independent predictor of the risk of local recurrence (Table 3.2.3). Local recurrence risk was significantly lower for patients receiving postmastectomy radiotherapy than for the patients without radiotherapy (HR 0.30; $95 \% \mathrm{Cl} 0.10-0.89)$.

Table 3.2.3 Results of the Cox proportional hazards analysis on risk factors for local recurrence following mastectomy for invasive lobular breast cancer $(n=369) *$

\begin{tabular}{|c|c|c|c|c|}
\hline Characteristics & & HR & $95 \% \mathrm{Cl}$ & P-value \\
\hline \multirow[t]{3}{*}{ Age at diagnosis (years) } & $<50$ & 1 (Ref) & & \\
\hline & $50-69$ & 1.18 & $(0.32-4.39)$ & 0.81 \\
\hline & $70+$ & 2.27 & $(0.61-8.43)$ & 0.22 \\
\hline \multirow[t]{2}{*}{ Tumour size (pT) } & pT1 & 1 (Ref) & & \\
\hline & pT2-4 & 1.02 & $(0.21-4.91)$ & 0.98 \\
\hline \multirow[t]{2}{*}{ Nodal status (pN) } & pNO & 1 (Ref) & & \\
\hline & pN1-3 & 2.42 & $(0.61-9.63)$ & 0.21 \\
\hline \multirow[t]{2}{*}{ Histological type } & Lobular & 1 (Ref) & & \\
\hline & Lobular-mixed & 0.44 & $(0.10-1.92)$ & 0.28 \\
\hline \multirow[t]{2}{*}{ Radiotherapy } & No & 1 (Ref) & & \\
\hline & Yes & 0.30 & $(0.10-0.89)$ & 0.03 \\
\hline \multirow[t]{2}{*}{ Adjuvante systemic treatment } & No & 1 (Ref) & & \\
\hline & Yes & 0.72 & $(0.18-2.83)$ & 0.64 \\
\hline
\end{tabular}

* 14 patients with missing values were excluded from the multivariate analysis; $\mathrm{HR}$ : hazard ratio. $95 \% \mathrm{Cl}$ : $95 \%$ confidence intervals 
Of the 18 patients diagnosed with an isolated local recurrence, seven patients developed distant metastases during the follow-up period. Three patients were diagnosed with a second local recurrence (after cure of the first local recurrence).

Of all 383 patients 13 developed a regional recurrence (3.4\%), of which eight were isolated and five were diagnosed concurrently with distant metastases. Of these 13 patients five had received postmastectomy radiotherapy. Eleven patients developed breast cancer in the contralateral breast, of which four were ILC, five invasive ductal cancer and two of a mixed type. The five year disease-free survival rate was $64 \%$ (95\% $\mathrm{Cl} 56-71$ ) for the patients with postmastectomy radiotherapy, compared to $78 \%$ (95\% $\mathrm{Cl} 72-84)$ for the patients not receiving radiotherapy $(P=0.0001)$.

\section{Discussion}

The results of our population-based study indicates that radiotherapy contributes significantly to the prevention of local recurrence in patients with ILC undergoing mastectomy. The 5-year local recurrence risk was only $2.1 \%$ for the patients who received postmastectomy radiotherapy despite their much less favourable tumour stage compared to the patients to whom postmastectomy radiotherapy was not offered. After adjustment for stage and other potential confounders, a threefold lower risk of local recurrence was observed. These figures illustrate that treatment with mastectomy and radiotherapy is a very effective combination to achieve local control of ILC.

Postmastectomy radiotherapy has been subject of study in several randomised trials and was shown to result in a substantial reduction of the risk of locoregional recurrence in patients with invasive breast cancer. However, only a few studies have evaluated local control after mastectomy in patients with ILC separately ${ }^{10-13,15,19,20}$. The local recurrence rates reported by others differ greatly, with a range from 1.3 to $28 \%$. Chung and colleagues, reporting data of 212 patients with ILC, found a 5-year local recurrence rate of $4.3 \%{ }^{12}$ and in a study by Holland and colleagues, including 174 patients with ILC less than $4 \mathrm{~cm}$ and a median follow-up of 55 months, local relapse occurred in 21 patients $(12 \%)^{10}$. In a large, population-based study performed by Singletary and colleagues among 13488 patients with T1 and T2 ILC local recurrence rates varied from 1.3 to $7.1 \%$, depending on tumour size and nodal status ${ }^{13}$. However, it is not exactly clear whether these estimates were based on complete follow-up data and if they were calculated by using survival time analysis. Du Toit and colleagues reported a high local recurrence risk of $28 \%$ in a series of 128 patients with ILC less than $5 \mathrm{~cm}$ and a median follow-up of 64 months $^{19}$. Warneke and colleagues found that two of the 59 patients (3\%) with ILC had a local recurrence after a median follow-up of 71 months $^{11}$. In the study of Hussien and colleagues 5 of the 101 patients with ILC developed a local recurrence after a median follow-up of 90 months ${ }^{20}$. Finally, Voogd and colleagues, in a pooled analysis of two randomised clinical trials with early-stage 
breast cancer, found a 10-year local recurrence rate of $18 \%$ among 76 patients with ILC treated with mastectomy ${ }^{15}$. None of the before mentioned studies, except the one by Hussien and colleagues reported local control rates for patients with and without postoperative radiotherapy separately. In the study by Hussien et al., which was much smaller than ours, none of the 42 patients with radiotherapy and $5.4 \%$ of the 59 patients without radiotherapy developed a local recurrence. Although in line with our results, the difference was not statistically significant, which could be explained by the small size of this study.

We previously examined the local recurrence rate in 416 patients with ILC undergoing BCT in the same population and study period as the current study and found a 5-year local recurrence rate of only $3.5 \%{ }^{14}$. This rate is even lower than the 5 -year local recurrence rate of $8.7 \%$ in our current study for patients undergoing mastectomy without radiotherapy. It appears that patients with ILC whose primary surgical treatment is followed by radiotherapy have a very low risk of local recurrence, and that this is equally true for patients undergoing breast-conserving surgery or mastectomy. The low risk could be a reflection of a high radiosensitivity of ILC, and might lead to the conclusion that all patients with ILC should receive postmastectomy radiotherapy, irrespective of their tumour stage.

Currently, according to the Dutch treatment guidelines, the indications for postmastectomy radiotherapy are an incomplete tumour resection, a tumour of more than $5 \mathrm{~cm}$ across (pT3), a tumour growing into the chest wall or skin or inflammatory breast cancer (T4), four or more positive axillary lymph nodes ( $\geq \mathrm{pN} 2$ ) or a positive lymph node in the apex of the axilla. Recently, Overgaard and colleagues concluded from their studies that postmastectomy radiotherapy should also be advised to patients with 1 to 3 positive lymph nodes, based on their observation in the DBCG 82 b \& $c$ trials that the survival benefit in this group was similar to the benefit observed in patients with more than three positive nodes ${ }^{21}$. Possibly due to the small number of patients who developed a local recurrence, we could not identify additional subgroups among the patients with ILC that might benefit from postmastectomy radiotherapy. Further research in larger populations is needed to identify these subgroups. Currently, the role of chest wall irradiation after mastectomy in intermediate risk patients is under investigation in the MRC/EORTC SUPREMO-trial. It is evident that any extension of the current indications for postmastectomy radiotherapy should be carefully weight against the risks of treatment-related morbidity, such as cardiovascular disease and second primary cancers ${ }^{22}$. However, with the implementation of modern radiation techniques, like intensity-modulated radiation therapy, the risks of early and late-onset morbidity will hopefully be lower than in the past.

Since this was a retrospective study, we were dependent on the quality and completeness of the data recorded in the medical records and the pathology reports. We did not study other potential risk factors for local recurrence, such as lymphangioinvasion and histological grade, which have been shown to have an unfavourable 
effect on the risk of local recurrence, since they were not consistently reported or investigated during the study period. However, we found a lower local recurrence rate in mastectomy patients who received adjuvant radiotherapy. Because these were the patients with larger tumours and more extensive regional disease it is very likely that other unfavourable risk factors for local recurrence are also overrepresented in this group.

\section{Conclusions}

The results from this population-based study show that patients with ILC who received postmastectomy radiotherapy have a significantly lower risk of local recurrence compared to patients who did not receive radiotherapy, despite their significantly less favourable tumour characteristics. 


\section{References}

1. The world Health Organization Histological Typing of Breast Tumors--Second Edition. The World Organization. Am J Clin Pathol 1982;78:806-16.

2. Fisher ER, Gregorio RM, Fisher B, Redmond C, Vellios F, Sommers SC. The pathology of invasive breast cancer. A syllabus derived from findings of the National Surgical Adjuvant Breast Project (protocol no. 4). Cancer 1975;36:1-85.

3. Wellings SR, Jensen HM, Marcum RG. An atlas of subgross pathology of the human breast with special reference to possible precancerous lesions. J Natl Cancer Inst 1975;55:231-73.

4. Martinez V, Azzopardi JG. Invasive lobular carcinoma of the breast: incidence and variants. Histopathology 1979;3:467-88.

5. Sastre-Garau X, Jouve M, Asselain B, Vincent-Salomon A, Beuzeboc P, Dorval T, Durand JC, Fourquet A, Pouillart P. Infiltrating lobular carcinoma of the breast. Clinicopathologic analysis of 975 cases with reference to data on conservative therapy and metastatic patterns. Cancer 1996;77:113-20.

6. Yeatman TJ, Cantor AB, Smith TJ, Smith SK, Reintgen DS, Miller MS, Ku NN, Baekey PA, Cox CE. Tumor biology of infiltrating lobular carcinoma. Implications for management. Ann Surg 1995;222:549-59.

7. Silverstein MJ, Lewinsky BS, Waisman JR, Gierson ED, Colburn WJ, Senofsky GM, Gamagami P. Infiltrating lobular carcinoma. Is it different from infiltrating duct carcinoma? Cancer 1994;73:1673-7.

8. Moore MM, Borossa G, Imbrie JZ, Fechner RE, Harvey JA, Slingluff CL, Jr., Adams RB, Hanks JB: Association of infiltrating lobular carcinoma with positive surgical margins after breast-conservation therapy. Ann Surg 2000;231:877-82.

9. Peiro G, Bornstein BA, Connolly JL, Gelman R, Hetelekidis S, Nixon AJ, Recht A, Silver B, Harris JR, Schnitt SJ. The influence of infiltrating lobular carcinoma on the outcome of patients treated with breast-conserving surgery and radiation therapy. Breast Cancer Res Treat 2000;59:49-54.

10. Holland PA, Shah A, Howell A, Baildam AD, Bundred NJ. Lobular carcinoma of the breast can be managed by breast-conserving therapy. Br J Surg 1995;82:1364-6.

11. Warneke J, Berger R, Johnson C, Stea D, Villar H. Lumpectomy and radiation treatment for invasive lobular carcinoma of the breast. Am J Surg 1996;172:496-500.

12. Chung MA, Cole B, Wanebo HJ, Bland KI, Chang HR. Optimal surgical treatment of invasive lobular carcinoma of the breast. Ann Surg Oncol 1997;4:545-50.

13. Singletary SE, Patel-Parekh L, Bland KI. Treatment trends in early-stage invasive lobular carcinoma: a report from the National Cancer Data Base. Ann Surg 2005;242:281-9.

14. van den Broek N, van der Sangen MJ, van de Poll-Franse LV, van Beek MW, Nieuwenhuijzen GA, Voogd AC. Margin status and the risk of local recurrence after breast-conserving treatment of lobular breast cancer. Breast Cancer Res Treat 2007;105:63-8.

15. Voogd AC, Nielsen M, Peterse JL, Blichert-Toft M, Bartelink H, Overgaard M, van Tienhoven G, Andersen KW, Sylvester RJ, van Dongen JA; Danish Breast Cancer Cooperative Group. Breast Cancer Cooperative Group of the European Organization for Research and Treatment of Cancer. Differences in risk factors for local and distant recurrence after breast-conserving therapy or mastectomy for stage I and II breast cancer: pooled results of two large European randomized trials. J Clin Oncol 2001;19:1688-97.

16. Bontenbal M, Nortier JW, Beex LV, Bakker P, Hupperets PS, Nooij MA, van Veelen H, Vreugdenhil G, Richel DJ, Blijham GH. [Adjuvant systemic therapy for patients with resectable breast cancer: guideline from the Dutch National Breast Cancer Platform and the Dutch Society for Medical Oncology]. Ned Tijdschr Geneeskd 2000;144:984-9.

17. Goldhirsch A, Glick JH, Gelber RD, Senn HJ. Meeting highlights: International Consensus Panel on the Treatment of Primary Breast Cancer. J Natl Cancer Inst 1998;90:1601-8.

18. Goldhirsch A, Glick JH, Gelber RD, Coates AS, Senn HJ. Meeting highlights: International Consensus Panel on the Treatment of Primary Breast Cancer. Seventh International Conference on Adjuvant Therapy of Primary Breast Cancer. J Clin Oncol 2001;19:3817-27.

19. du Toit RS, Locker AP, Ellis IO, Elston CW, Nicholson RI, Robertson JF, Blamey RW. An evaluation of differences in prognosis, recurrence patterns and receptor status between invasive lobular and other invasive carcinomas of the breast. Eur J Surg Oncol 1991;17:251-7. 
20. Hussien M, Lioe TF, Finnegan J, Spence RA. Surgical treatment for invasive lobular carcinoma of the breast. Breast 2003;12:23-35.

21. Overgaard $M$, Nielsen HM, Overgaard J. Is the benefit of postmastectomy irradiation limited to patients with four or more positive nodes, as recommended in international consensus reports? A subgroup analysis of the DBCG 82 b\&c randomized trials. Radiother Oncol 2007;82:247-53.

22. Hooning MJ, Aleman BM, van Rosmalen AJ, Kuenen MA, Klijn JG, van Leeuwen FE. Cause-specific mortality in long-term survivors of breast cancer: A 25-year follow-up study. Int J Radiat Oncol Biol Phys 2006;64:1081-91. 


\section{Chapter 4}

\section{Prognosis following local relapse}




\section{Chapter 4.1}

The prognosis of patients with local recurrence more than five years after breast-conserving therapy for invasive breast carcinoma

MJC van der Sangen

$\mathrm{LV}$ van de Poll-Franse

RMH Roumen HJT Rutten

JWW Coebergh

G Vreugdenhil

AC Voogd

Eur J Surg Oncol. 2006;32:34-38 


\section{Abstract}

\section{Aims}

The increasing use of breast-conserving therapy (BCT) and the rising incidence and improved prognosis of early breast are causing a substantial increase in the absolute number of patients with a late local recurrence following BCT. This study examined the characteristics and the prognosis of patients with a local recurrence occurring more than five years after BCT.

\section{Methods}

In the period 1982-1997, 3280 patients with invasive breast cancer underwent breastconserving therapy in one of the eight community hospitals in the southeastern part of the Netherlands. Of these patients, 98 developed a local recurrence in the breast more than 5 years after BCT.

\section{Results}

Eighty-five of the 98 recurrences were invasive, 12 were purely in situ and for one patient this information was not available. The 5 years distant recurrence-free survival rate of 85 patients with a late invasive local recurrence was $68 \%$ (95\% confidence interval [CI], 56-80) and significantly better than the rate of $41 \%(95 \% \mathrm{Cl}, 33-48)$ in an existing cohort of 173 patients with invasive recurrence within five years after BCT $(P=0.007)$. Local excision of the recurrence was followed by a significantly lower local control rate than salvage mastectomy ( $50 \%$ versus 89\%; $P=0.004)$.

\section{Conclusion}

The prognosis of patients with a local recurrence more than five years after BCT is significantly better than of patients with local recurrence within 5 years after BCT. 


\section{Introduction}

Breast-conserving therapy (BCT) is a generally accepted way of treating localized early breast cancer. In most studies evaluating the results of BCT, the actuarial freedom from mammary recurrence varies between $90 \%$ and $97 \%$ at five years and between $85 \%$ and $95 \%$ at ten years. In the second decade following BCT such local recurrences continue to occur at about $1 \%$ per year ${ }^{1}$. Because of the increasing incidence of early breast cancer and the increased use of BCT a substantial increase in the absolute number of patients with local recurrence can be expected in the coming years.

At first, the large majority of the recurrences are in the vicinity of the tumour bed, but with increasing time interval, an increasing percentage is located elsewhere in the breast $^{2-4}$. It is suggested that the majority of recurrences after ten years could be considered new primary tumours and such patients have also been reported to have a more favourable prognosis than those with an early local recurrence ${ }^{5-10}$. However, most of these studies contained only few patients with local recurrence more than five years after BCT. The largest study, consisting of 178 local recurrences occurring in 1593 patients with clinical stages I-II breast cancer treated by conservative surgery and megavoltage radiotherapy, showed 71 to be diagnosed after the 5 th year. Compared with recurrences occurring prior to 60 months, late recurrences were less frequently inoperable $(1 / 71,1.4 \%$, versus $18 / 107,17 \%, P<0.001)$, were more often located at a distance from the initial primary tumour $(23 / 71,32 \%$, versus $15 / 106$, $14 \%, P<0.005)$, and tended to have a more favourable prognosis ( 5 -year survival $84 \%$ versus $61 \%$ for late and early operable recurrences, respectively, $P=0.05){ }^{6}$

We evaluated the prognosis of 98 patients with a local recurrence, occurring more than five years after BCT for invasive breast cancer and tried to identify prognostic factors. In addition, a comparison was made with the characteristics and the prognosis of patients with a local recurrence occurring within five years after BCT who were described in a previously published study. ${ }^{11}$

\section{Patients and methods}

Patients were selected from the population-based Eindhoven Cancer Registry, which serves a population of almost two million inhabitants in the south-eastern part of the Netherlands ( $12 \%$ of the Dutch population). Cancer registry data were retrieved from copies of the pathology reports of ten pathologists from three different laboratories and the medical records of eight community hospitals and one radiotherapy institute. During the period 1982-1997 3280 patients underwent BCT, generally consisting of wide local excision of the tumour with an attempted margin of at least $1 \mathrm{~cm}$ of healthy tissue and axillary dissection. In all patients, surgery was followed by whole breast irradiation, with a total dose of 45-50 Gy, given in fractions of 1.8 or $2.3 \mathrm{~Gy}$, five times a week. The large majority of the patients received an additional boost to the tumour 
bed by an external beam technique, using either photons or electrons, or by the use of iridium 192 interstitial implants. Total boost doses varied between 13.8 and 25 Gy but were sometimes higher for iridium 192 implants. Adjuvant systemic treatment was given only to axillary node-positive patients. Chemotherapy was indicated for premenopausal node-positive patients and endocrine therapy (tamoxifen) for postmenopausal node-positive patients with an oestrogen receptor-positive tumour. The usual chemotherapy consisted of six courses cyclophosphamide, methotrexate, 5-fluorouracil (CMF).

Following treatment, patients were seen alternately by the radiation oncologist and the referring surgeon, usually every three months during the first two years, every six months during the following three years and yearly thereafter. Bone scans, chest $X$ ray, complete blood count and liver function tests were only used in case of signs and symptoms suggestive of distant disease or after the diagnosis of local or regional recurrence.

Since 1989, the Eindhoven Cancer Registry has recorded follow-up information on all patients with breast cancer, including the date and site of local, regional and distant recurrence and the date of death. This information is provided through the pathologists, the radiotherapists, and the majority of the surgeons. Between 31 October 1988 and 15 March 2003, 98 patients were reported to have local recurrence occurring more than 5 years after BCT. The patients showed no signs of distant metastases. Local recurrence was defined as a new tumour occurring in the preserved breast or overlying skin. The medical record of each patient was used to collect detailed information on the diagnosis and treatment of the local recurrence. The primary treatment of the 98 patients took place between 1 January 1982 and 1 January 1997. The mean age of the patients at the time of diagnosis of breast cancer was 51 years (range: 32-85 years). Seventy-six of the 98 patients had a primary tumour of $2 \mathrm{~cm}$ or less and 73 had tumour-negative axillary lymph nodes. Ninety-five of the 98 patients had received a radiotherapy boost to the tumour bed and 16 patients had received adjuvant systemic treatment as part of the treatment of their primary tumour.

Clinical and pathological data were used to classify each local recurrence as either a 'new primary tumour' or a 'true LR' based on changes in histology and location. Cases where both the primary and the relapse had similar histologic types and were situated within or near the quadrant of the primary tumour were classified as a 'true LR'. Relapses satisfied the criteria for designation as a 'new primary tumour' if they had a distinct change in histologic type or if they occurred in a clearly distinct location.

\section{Statistical analyses}

Follow-up was completed until the first of July 2003. Survival analysis was carried out using the life-table method to evaluate the prognosis after local recurrence. The endpoints were overall survival, distant disease-free survival and survival without 
subsequent local recurrence. Survival curves were calculated from the date of the diagnosis of local recurrence. Patient characteristics and characteristics of the primary tumour and local recurrence were analysed to assess their ability to predict distant recurrence-free survival. Actuarial curves were compared by means of the two-tailed log-rank test. Because of the small number of patients, multivariate analyses were not performed.

Data of a previously published study were used to compare the prognosis of the 98 patients in the current study with the prognosis of patients with 'early' local recurrence, occurring within five years after $\mathrm{BCT}^{11}$. This study contained 266 patients with local recurrence without clinical signs of distant metastases of which 205 (77\%) had a local recurrence within five years after BCT. Follow-up of these patients had been updated until January 2003.

\section{Results}

\section{Diagnosis and treatment}

The mean age at diagnosis of local recurrence was 60 years (range: 38-90). The mean time from the date of BCT until the diagnosis of local recurrence was 9.3 years (range 5.0-18.9). Sixty-seven of the 98 local recurrences were diagnosed between five and ten years and 31 (32\%) more than ten years after BCT. Fifty recurrences were detected by physical examination with or without mammography and 37 were detected by mammography alone. The mode of detection was unknown for 11 patients. Eighty-five recurrences were invasive, 12 were purely in situ and for one patient this information was not available. Of the non-invasive recurrences $75 \%(9 / 12)$ was detected by mammography alone, compared to $32 \%(25 / 78)$ of the invasive recurrences $(P=0.004)$. Forty-one of the 85 patients for whom this information was available had a local recurrence within the excision area or within the quadrant of the primary tumour, 20 near the quadrant of the primary tumour, 23 elsewhere in the breast and one had a diffuse recurrence. According to the definition given in the methods section, 41 recurrences were classified as 'true recurrences' and 46 as 'new primary tumours'. Eleven recurrences could not be classified because of missing data. The diameter at pathologic examination was known for 85 patients (87\%) and was $\leq 15 \mathrm{~mm}$ for 49 patients. The recurrences detected by mammography alone were $\leq 15$ $\mathrm{mm}$ in $75 \%$ of the cases (24/8) compared with $50 \%(24 / 48)$ of the recurrences detected by physical examination alone or physical examination in combination with mammography $(P=0.03)$.

Eighty-nine patients underwent salvage mastectomy. Of the eight patients who underwent local excision, four had a non-invasive recurrence. Twelve patients received radiotherapy, of whom three following local excision. Chemotherapy and/or hormonal treatment were given to 25 of the 98 patients with local recurrence. 


\section{Prognosis and prognostic factors}

Of the 98 patients with local recurrence 21 had died. Distant metastases were observed in 28 patients and subsequent local recurrence or local progression occurred in 14 patients. At five years after local recurrence, the actuarial overall survival rate was $74 \%$ (95\% confidence interval $[\mathrm{Cl}], 62-86)$, the distant recurrence-free survival rate was $69 \%(95 \% \mathrm{Cl}, 57-80)$ and the local control rate was $81 \%(95 \% \mathrm{Cl}, 70-91)$. Of the eight patients who underwent local excision, 50\% developed a second local recurrence compared with $11 \%$ of the 89 patients who underwent salvage mastectomy $(P=0.004)$. Of the 12 patients with non-invasive local recurrence two developed distant metastases compared to 26 of the 85 patients with invasive LR $(P=0.05)$. Among the 85 patients with invasive local recurrence, the risk of developing distant metastases was not significantly different between patients with a 'true local recurrence' and those with a 'new primary tumour' $(P=0.73)$. Other clinical and pathological factors in our analysis, such as age at diagnosis of the first tumour, time interval to local recurrence (i.e., more than ten versus five to ten years after $B C T$ ), size of local recurrence, histology of the primary tumour, mode of detection of local recurrence, or lymph node status of the primary tumour also did not reveal to be significant prognostic factors.

\section{Comparing early and late local recurrences}

When comparing the 98 patients with a local recurrence more than five years after BCT with the 205 patients with a local recurrence within five years after BCT, it appeared that patients with an 'early' local recurrence were significantly younger (median age: 48 years versus 59 years, $P<0.0001$ ), were more likely to have diffuse recurrences ( $12 \%$ versus $1 \%, P=0.003$ ) and less likely to have recurrences elsewhere in the breast ( $13 \%$ versus $27 \%, P=0.003$ ). There was no significant difference between 'late' and 'early' recurrences with respect to the proportion of non-invasive recurrences ( $9 \%$ versus $12 \%$ ) and the size of the recurrence at pathologic examination (median: $15 \mathrm{~mm}$ versus $15 \mathrm{~mm}$ ). However the 173 patients with an early invasive local recurrence had a significantly higher risk of developing distant metastases than the 85 patients with a late invasive local recurrence; the 5-year distant recurrence-free survival rates were $41 \%(95 \% \mathrm{Cl}, 33-48)$ and $68 \%(95 \% \mathrm{Cl}, 56-80)$ respectively $(P=0.007$; Figure 4.1.1). 


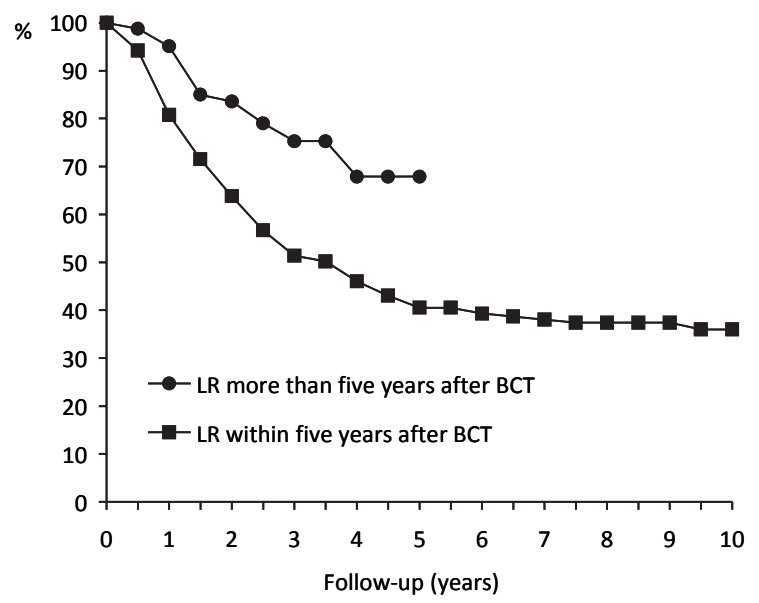

Figure 4.1.1 Distant-disease-free survival for 85 patients with invasive local recurrence (LR) more than five years after BCT compared to 173 patients with invasive local recurrence within five years after BCT (BORST-study)

\section{Discussion}

In this study, patients with a local recurrence more than five years after BCT had a significant better survival than patients with an earlier recurrence. What is special about our study is the large number of patients with a late local recurrence, with a mean interval to local recurrence of 9.3 years. In most other studies the number of patients with local recurrences more than five years after BCT was much smaller. The cut-off point of five years was based on a former study, in which no differences in the distant disease-free survival were found between patients with early and late recurrences at a cut-off point of two or three years ${ }^{11}$. In this study, there were only 53 patients with local recurrences more than five years after BCT and follow-up was still short. Our finding that patients with a local recurrence more than five years after BCT have a better prognosis than patients with an earlier local recurrence is in agreement with several other studies ${ }^{5-7}$. On the other hand, there are studies in which a poorer survival is reported for patients with a local recurrence occurring in the first two or three years after $\mathrm{BCT}^{8-10}$.

Some studies suggest that a second attempt at breast conservation for patients with local recurrence after BCT is feasible $\mathrm{B}^{12-14}$. In our study, local excision of the recurrence was followed by a significantly lower local control rate than salvage mastectomy $150 \%$ versus $89 \%$ ). Therefore, we are no advocates of local excision. The fact that patients with local recurrence run a high risk of developing distant metastases has urged many to advocate secondary systemic adjuvant treatment after local treatment. In our study, the proportion of patients receiving systemic treatment was $26 \%$. Their local 
recurrences were diagnosed in the period 1988-2003. In a previous study of patients with early local recurrence, the proportion receiving systemic treatment was only $4 \%$, but their recurrences were diagnosed in the period $1982-1993^{11}$. The figures from these two periods indicate that, at least in the Netherlands, there is a growing tendency towards the use of systemic treatment in patients with local recurrence. Still, there is currently no good evidence that adjuvant systemic treatment is effective in patients with local recurrence. A recent Cochrane systematic review of three randomised controlled trials comparing systemic therapy versus observation for women with locoregional recurrence following mastectomy or BCT without previous or synchronous distant metastases, provided insufficient evidence for an improvement in the overall survival ${ }^{15}$. No attempt was made to pool the results of the studies because of the clinical heterogeneity and the small number of randomised patients. One possible explanation for the lack of effect of systemic treatment in patients with local recurrence might be the large proportion that already received adjuvant chemotherapy or hormonal treatment on the occasion of their primary tumour.

In literature on local recurrence the distinction between 'new primary tumours' and 'true recurrences' is an important issue. A new primary tumour is defined as a de novo tumour descending from a different cell line than the original breast cancer and a true recurrence is considered to have arisen from the same clonogenic tumour cell population as the first tumour. However the distinction between a true recurrence and a new primary is not always a clear-cut case. In most studies the diagnosis 'new primary' was applied when the recurrence was located elsewhere in the breast, had a different histology, or DNA flow cytometry converted from an aneuploid primary to a diploid recurrence ${ }^{16-18}$.

The general observation in the literature is that true recurrences have a more aggressive behaviour and incorporate a greater chance of developing distant metastases with poorer prognosis than new primaries ${ }^{5-10}$. True recurrences tend to occur in the first years after first BCT and are located at or near the original tumour in most cases. New primaries, on the contrary, can occur everywhere in the breast and can have a different histology than the first tumour. In our series of late local recurrences, the majority still appeared within or near the quadrant of the original tumour, indicating that information on location alone may be insufficient to make a reliable distinction between true recurrences and new primaries. When integrating the information on the location and the histology, $42 \%$ was classified as a true recurrence and $47 \%$ as a new primary tumour. However, our results indicate that this classification is not a useful prognostic indicator for patients with a late local recurrence. In search for reliable distinction between new primary tumours and true recurrences genetic techniques have been developed ${ }^{19}{ }^{20}$. Schlechter et al. ${ }^{20}$ recently described a quantitative scoring system based on so called allele imbalance (Al) or loss of heterozygosity ( $\mathrm{LOH})$, which are traceable in archival specimens for nearly all breast cancers patients. They first validated the system on related tumour and later 
compared the unique $\mathrm{Al} / \mathrm{LOH}$ fingerprints of original breast cancers with the fingerprints of contralateral cancers, ipsilateral cancer and cancer plus contralateral positive axillary lymph nodes. After a clinical follow-up of more than four years they concluded that their approach is a potentially valuable tool in distinguishing new primary cancer from true recurrent disease. Further testing with a bigger sample size is necessary to draw conclusions about the potential prognostic and therapeutic value of this technique.

In conclusion, patients with a local recurrence diagnosed more than five years after BCT appear to have a better prognosis than patients with a local recurrence diagnosed within five years after BCT. We did not succeed in providing reliable clinical and pathological criteria to predict individual prognosis of patients with a late local recurrence. It is expected that earlier detection and individualized treatment, based on gene expression profiling, will contribute to better treatment results in this growing patient group. 


\section{References}

1. Arriagada R, Le MG, Guinebretiere JM, Dunant A, Rochard F, Tursz T. Late local recurrences in a randomised trial comparing conservative treatment with total mastectomy in early breast cancer patients. Ann Oncol 2003; 14: 1617-22.

2. Kurtz JM, Amalric R, Brandone H, Ayme Y, Jacquemier J, Pietra JC, Hans D, Pollet JF, Bressac C, Spitalier JM. Local recurrence after breast-conserving surgery and radiotherapy. Frequency, time course, and prognosis. Cancer 1989;63:1912-7.

3. Kurtz JM, Amalric R, Delouche G, Pierquin B, Roth J, Spitalier JM. The second ten years: long-term risks of breast conservation in early breast cancer. Int J Radiat Oncol Biol Phys 1987;13:1327-32.

4. Fisher B, Jeong JH, Anderson S, Bryant J, Fisher ER, Wolmark N. Twenty-five-year follow-up of a randomized trial comparing radical mastectomy, total mastectomy, and total mastectomy followed by irradiation. N Engl J Med 2002;347:567-75.

5. Haffty BG, Reiss M, Beinfield M, Fischer D, Ward B, McKhann C. Ipsilateral breast tumor recurrence as a predictor of distant disease: implications for systemic therapy at the time of local relapse. J Clin Oncol 1996;14:52-7.

6. Kurtz JM, Spitalier JM, Amalric R, Brandone H, Ayme Y, Jacquemier J, Hans D, Bressac C. The prognostic significance of late local recurrence after breast-conserving therapy. Int J Radiat Oncol Biol Phys 1990;18:87-93.

7. Le MG, Arriagada R, Spielmann M, Guinebretiere JM, Rochard F. Prognostic factors for death after an isolated local recurrence in patients with early-stage breast carcinoma. Cancer 2002;94:2813-20.

8. Fredriksson I, Liljegren G, Arnesson L, Emdin SO, Palm-Sjövall M, Fornander T, Holmqvist M, Holmberg $\mathrm{L}$, Frisell J. Local recurrence in the breast after conservative surgery-a study of prognosis and prognostic factors in 391 women. Eur J Cancer 2002;38:1860-70.

9. Fourquet A, Campana F, Zafrani B, Mosseri V, Vielh P, Durand JC, Vilcoq JR. Prognostic factors of breast recurrence in the conservative management of early breast cancer: a 25-year follow-up. Int J Radiat Oncol Biol Phys 1989;17: 719-25.

10. Elkhuizen PH, Hermans J, Leer JW, van dE Vijver MJ. Isolated late local recurrences with high mitotic count and early local recurrences following breast-conserving therapy are associated with increased risk on distant metastasis. Int J Radiat Oncol Biol Phys 2001;50:387-96.

11. Voogd AC, van Tienhoven G, Peterse HL, Crommelin MA, Rutgers EJ, van de Velde CJ, van Geel BN Slot A, Rodrigus PT, Jobsen JJ, von Meyenfeldt MF, Coebergh JW. Local recurrence after breast conservation therapy for early stage breast carcinoma: detection, treatment, and outcome in 266 patients. Dutch Study Group on Local Recurrence after Breast Conservation (BORST). Cancer 1999;85:437-46.

12. Mullen EE, Deutsch M, Bloomer WD. Salvage radiotherapy for local failures of lumpectomy and breast irradiation. Radiother Oncol 1997;42:25-9.

13. Kurtz JM, Jacquemier J, Amalric R, et al. Is breast conservation after local recurrence feasible? Eur J Cancer 1991; 7:240-4

14. Salvadori B, Marubini E, Miceli R, Conti AR, Cusumano F, Andreola S, Zucali R, Veronesi U. Reoperation for locally recurrent breast cancer in patients previously treated with conservative surgery. Br J Surg 1999;86:84-7.

15. Rauschecker H, Clarke M, Gatzemeier W, Recht A. Systemic therapy for treating locoregional recurrence in women with breast cancer. Cochrane Database Syst Rev 2001(4):CD002195.

16. Smith TE, Lee D, Turner BC, Carter D, Haffty BG. True recurrence vs. new primary ipsilateral breast tumor relapse: an analysis of clinical and pathologic differences and their implications in natural history, prognoses, and therapeutic management. Int J Radiat Oncol Biol Phys 2000;48:1281-9.

17. Haffty BG, Carter D, Flynn SD, Fischer DB, Brash DE, Simons J, Ziegler AM, Fischer JJ. Local recurrence versus new primary: clinical analysis of 82 breast relapses and potential applications for genetic fingerprinting. Int J Radiat Oncol Biol Phys 1993;27:575-83.

18. Huang E, Buchholz TA, Meric F, Krishnamurthy S, Mirza NQ, Ames FC, Feig BW, Kuerer HM, Ross MI, Singletary SE, McNeese MD, Strom EA, Hunt KK. Classifying local disease recurrences after breast conservation therapy based on location and histology: new primary tumors have more favorable outcomes than true local disease recurrences. Cancer 2002;95:2059-67. 
19. Regitnig P, Moser R, Thalhammer M, Luschin-Ebengreuth G, Ploner F, Papadi H, Tsybrovskyy O, Lax SF. Microsatellite analysis of breast carcinoma and corresponding local recurrences. J Pathol 2002;198:190-7.

20. Schlechter BL, Yang Q, Larson PS, Golubeva A, Blanchard RA, de las Morenas A, Rosenberg CL. Quantitative DNA fingerprinting may distinguish new primary breast cancer from disease recurrence. J Clin Oncol 2004;22:1830-8. 


\section{Chapter 4.2}

\section{Prognosis following local recurrence after breast- conserving therapy in young women with early breast cancer}

MJC van der Sangen

PMP Poortmans

SWM Scheepers

BMD lemaire

$\mathrm{CLH}$ van Berlo

VCG Tjan-Heijnen

AC Voogd

Eur J Surg Oncol. 2013;39:892-8 


\section{Abstract}

\section{Background}

Few studies have focussed on the prognosis of young women with local recurrence (LR) after breast-conserving therapy (BCT) and the factors that can be used to predict their prognosis.

\section{Methods}

We studied the outcome and related prognostic factors in 124 patients with an isolated local recurrence in the breast following breast-conserving surgery and radiotherapy for early stage breast cancer diagnosed at the age of 40 years or younger.

\section{Results}

The median follow-up of the patients after diagnosis of LR was 7.0 years. At 10 years from the date of salvage treatment, the overall survival rate was $73 \%(95 \% \mathrm{Cl}, 63-83)$, the distant recurrence-free survival rate was $61 \%(95 \% \mathrm{Cl}, 53-73)$, and the local control rate (i.e. survival without subsequent $\mathrm{LR}$ or local progression) was $95 \%$ (95\% Cl, 91-99). In the multivariate analysis, the risk of distant metastases also tended to be higher for patients with LR occurring within 5 years after BCT, as compared to patients with LR more than 5 years after BCT (HR 1.89; $P=0.09$ ). A worse distant recurrence-free survival was also observed for patients with a $L R$ measuring more than $2 \mathrm{~cm}$ in diameter, compared to those with a LR of $2 \mathrm{~cm}$ or smaller (HR 2.88; $P=0.007$ ), and for patients with a LR causing symptoms or suspicious findings at clinical breast examination, compared to those with a LR detected by breast imaging only (HR 3.70; $P=0.03)$.

\section{Conclusions}

These results suggest that early detection of LR after BCT in young women can improve treatment outcome. 


\section{Introduction}

Despite the fact that breast-conserving therapy $(\mathrm{BCT})$ in terms of survival has proven to be equally effective as mastectomy, several studies show that the risk of local recurrence (LR) in young patients is higher after BCT compared to mastectomy. ${ }^{1-3}$ The risk of developing a LR is 2 - 4 times higher in women younger than 40 at the time of diagnosis of breast cancer compared to women older than 50 years. ${ }^{4-6}$ More recently however, data were published that this risk might be lower for patients treated according to more contemporary protocols. ${ }^{78}$ For patients below 50 years of age, the $\mathrm{LR}$ rate more than halved per decade in 3 consecutive trials on $\mathrm{BCT} .^{8}$ But even despite this apparent progress, the LR rate for women aged 40 years or younger undergoing $\mathrm{BCT}$ remains $0.5-1 \%$ per year.

The unfavourable prognostic effect of developing a LR has been confirmed by other studies that included LR in a multivariate analysis as a time-dependent variable and showed it to be a strong independent predictor of the risk of developing distant metastatic disease and worse overall survival ${ }^{9-12}$ Whilst the poor prognosis of patients with a LR after mastectomy is well established, there has been considerable debate about the prognosis and salvage possibilities for patients with LR after BCT. Early studies reported 5-year survival rates ranging from $70 \%$ to $84 \%$ after salvage treatment for patients with LR after BCT, which is equal or only slightly worse compared with those without LR. ${ }^{13-15}$ Subsequent series from the nineties, however, reported poorer 5 -year survival rates, ranging from $55 \%$ to $68 \%$ after 5 years ${ }^{16} 17$ and one study even reached the conclusion that the survival after treatment for an early locoregional recurrence after modified radical mastectomy or BCT was similar. ${ }^{18}$

Recent series have shown that younger patients with a LR after BCT have a better prognosis than their older counterparts. ${ }^{12,19,20}$ Few studies have focussed on the prognosis of young women with LR after BCT and the factors that can be used to predict their prognosis. In this report we examined the prognosis and prognostic factors in a cohort of 124 patients with an isolated LR following BCT for early breast cancer at the age of 40 years or younger.

\section{Patients and methods}

\section{Settings and subjects}

Data from the population based Eindhoven Cancer Registry (ECR) were used to select the patients who were diagnosed with breast cancer and received BCT between 1988 and 2005. BCT included local excision of the tumour and appropriate axillary management followed by irradiation of the whole breast, mostly including a boost to the primary tumour bed. The ECR records data on all patients newly diagnosed with cancer in the southern part of the Netherlands, an area with approximately 2.4 million 
inhabitants. The ECR identified 937 patients aged $\leq 40$ years who underwent BCT in the aforementioned period. Until October 2009, after a median follow-up of 9.5 years, $187(20 \%)$ of them had developed a LR, defined as reappearance of tumour growth in the treated breast or overlying skin. For these 187 patients, follow-up information was collected. For the purpose of this study we excluded 37 patients of which the LR was diagnosed simultaneous with or after the appearance of distant metastases or diagnosis of a second malignancy elsewhere, and 26 patients of which the medical files were lost or largely incomplete with respect to information on LR. A total of 124 patients remained available for analysis.

\section{Data extraction}

For this study data were derived from the patients files of 10 large non-university teaching hospitals and community hospitals, and from the two radiation oncology departments in this region, i.e. the Catharina Hospital in Eindhoven and the Institute Verbeeten in Tilburg. For all patients the follow-up information was collected including the presence of self-reported symptoms and findings at clinical breast examination. Reports of diagnostic tests such as mammography, ultrasound and MRI were reviewed and method of detection of LR was classified as imaging alone (in case of a normal clinical breast examination in asymptomatic patients) or as clinical breast examination or symptoms (with or without suspicious findings on breast imaging). We recorded information about the characteristics of the LR from the surgical notes and pathology reports, such as the location in the breast, size, histological grade, expression of the oestrogen receptor (ER), progesterone receptor (PR) and human epidermal growth factor receptor 2 (HER2).

\section{Statistical analyses}

Survival analysis, using the life-table method, was performed to calculate the prognosis after LR. End-points were overall survival, distant recurrence-free survival (DRFS) and survival without subsequent LR, including local progression of disease. Survival curves were calculated from the date of salvage treatment of LR or the date of the diagnosis of LR when salvage treatment was not given. The following variables were analysed to assess their ability to predict DRFS: age at diagnosis of LR; time interval from initial surgery to recurrence; mode of detection, location within the breast, size and histologic type of LR; size and nodal status of the original tumour. Actuarial survival curves were compared by means of the two-tailed log-rank test. A multivariate analysis using the Cox proportional hazards model was performed to evaluate the independent predictive effect of the covariates. Hazard ratios (with 95\% confidence intervals $(95 \% \mathrm{Cl})$ and $P$-values) were estimated for each covariate in relation to their reference categories. 


\section{Results}

\section{General characteristics}

The median age at diagnosis of LR was 43 years (range: $30-61$ ). The median time from the date of BCT until the diagnosis of LR was 5.7 years (range: 0.7-21.2). Fifty-three of the 124 LRs were diagnosed within 5 years after BCT, 41 between 5 and 10 years and 30 more than 10 years after BCT. Thirty-four recurrences were detected by breast imaging only, of which 32 by mammography, one by MRI and one by ultrasound alone. The mode of detection was unknown for 13 patients (Table 4.2.1). Of the LRs $>20 \mathrm{~mm} \mathrm{73 \%}$ were symptomatic versus $57 \%$ of the LRs $\leq 20 \mathrm{~mm}(P=0.14)$, and $22 \%$ were detectable by imaging only versus $29 \%$ of the LRs $\leq 20 \mathrm{~mm}(P=0.50)$.

One-hundred-and-five recurrences were invasive, of which 18 showed an associated in situ component. Sixteen were purely in situ. Of the recurrences that were purely in situ or contained an in situ component $55 \%$ were detected by mammography alone, compared to $22 \%$ of the invasive recurrences without an in situ component ( $P=0.0009)$.

One-hundred-nine of the 124 patients for whom this information was available had a LR at or near the site of the primary tumour, 13 elsewhere in the breast and 4 had a diffuse recurrence. The diameter at pathologic examination was known for 102 patients and was $>20 \mathrm{~mm}$ in 26 of them. Initially, at time of primary BCT a pathological negative nodal status was found in $86 \%$ of the patients. Information on tumour characteristics such as hormone receptor status, HER2 status, grade and proliferation markers were only partially available; $31 \%$ of the patients with an available HER2 status were HER2-positive and $53 \%$ of the patients with an available grading status had high grade tumours. Baseline characteristics of the whole cohort of women younger than 40 at the time of diagnosis of breast cancer between 1988 and 2005 showed $21 \%$ HER2-positive tumours and $53 \%$ high grade tumours.

One-hundred-twenty-one patients underwent salvage mastectomy, with or without reconstructive surgery, two underwent local excision and one did not undergo surgery. Thirteen patients received radiotherapy. Systemic treatment, consisting of chemotherapy and/or hormonal treatment, was given to 59 patients with LR. The proportion of patients receiving systemic treatment increased from $5 \%$ in patients with LR diagnosed in the period 1988-1996 to 56\% in patients with LR diagnosed in the period 2005-2011 ( $P=0.0001)$. 
Table 4.2.1 Baseline characteristics of patients with LR following breast-conserving therapy $(n=124)$.

\begin{tabular}{|c|c|c|}
\hline Characteristics & $\begin{array}{c}\text { No. of } \\
\text { Patients }\end{array}$ & (\%) \\
\hline \multicolumn{3}{|l|}{ Age at diagnosis of primary tumour } \\
\hline$\leq 30$ & 11 & (9) \\
\hline $31-35$ & 37 & (30) \\
\hline $36-40$ & 76 & (61) \\
\hline \multicolumn{3}{|l|}{ Size primary tumour (pT) } \\
\hline pT1 & 90 & (73) \\
\hline рт2 & 29 & (23) \\
\hline рT3 & 3 & $(2)$ \\
\hline Unknown & 2 & (2) \\
\hline \multicolumn{3}{|l|}{ Nodal status of primary tumour (pN) } \\
\hline pNO & 106 & (86) \\
\hline $\mathrm{pN}+$ & 17 & (13) \\
\hline Unknown & 1 & (1) \\
\hline \multicolumn{3}{|l|}{ Adjuvant systemic treatment primary tumour } \\
\hline Chemotherapy & 20 & (16) \\
\hline Endocrine treatment & 1 & (1) \\
\hline Chemotherapy+endocrine treatment & 5 & (4) \\
\hline No & 97 & (78) \\
\hline Unknown & 1 & (1) \\
\hline \multicolumn{3}{|l|}{ Interval between diagnosis primary tumour and LR } \\
\hline$\leq 2$ years & 13 & (11) \\
\hline $2-5$ years & 40 & (32) \\
\hline $5-10$ years & 41 & (33) \\
\hline$>10$ years & 30 & (24) \\
\hline \multicolumn{3}{|l|}{ Size of LR } \\
\hline$\leq 20 \mathrm{~mm}$ & 76 & (61) \\
\hline$>20 \mathrm{~mm}$ & 26 & (21) \\
\hline Unknown & 22 & (18) \\
\hline \multicolumn{3}{|l|}{ Location of LR } \\
\hline At or near site of primary tumour & 89 & $(72)$ \\
\hline Elsewhere in the breast & 13 & (10) \\
\hline Diffuse & 4 & (6) \\
\hline Unknown & 15 & (12) \\
\hline \multicolumn{3}{|l|}{ Type of LR } \\
\hline Invasive & 87 & (70) \\
\hline In situ & 16 & (13) \\
\hline Invasive with in situ component & 18 & (15) \\
\hline Unknown & 3 & $(2)$ \\
\hline \multicolumn{3}{|l|}{ Histological grade of LR } \\
\hline Good & 9 & (7) \\
\hline Moderate & 24 & (19) \\
\hline Poor & 37 & (30) \\
\hline Unknown & 54 & (44) \\
\hline \multicolumn{3}{|l|}{ Oestrogen receptor status of LR } \\
\hline Positive & 64 & (52) \\
\hline Negative & 29 & (23) \\
\hline Unknown & 31 & (25) \\
\hline \multicolumn{3}{|l|}{ HER2 status of LR } \\
\hline Positive & 11 & (9) \\
\hline Negative & 25 & (20) \\
\hline Unknown & 88 & (71) \\
\hline
\end{tabular}


Table 4.2.1 (continued)

\begin{tabular}{|c|c|c|}
\hline Characteristics & $\begin{array}{c}\text { No. of } \\
\text { Patients }\end{array}$ & (\%) \\
\hline \multicolumn{3}{|l|}{ Mode of detection of LR } \\
\hline Imaging only & 34 & (27) \\
\hline Clinical breast examination or symptoms & 77 & (63) \\
\hline Unknown & 13 & (10) \\
\hline \multicolumn{3}{|l|}{ Symptoms at time of diagnosis of LR } \\
\hline Yes & 65 & (52) \\
\hline No & 47 & (38) \\
\hline Unknown & 12 & (10) \\
\hline \multicolumn{3}{|l|}{ Surgery for LR } \\
\hline Local excision & 2 & $(2)$ \\
\hline Ablation with or without reconstructive surgery & 121 & (97) \\
\hline No surgery & 1 & (1) \\
\hline \multicolumn{3}{|l|}{ Completeness of surgery for LR } \\
\hline Yes & 85 & (69) \\
\hline No & 9 & (7) \\
\hline Doubtful & 9 & (7) \\
\hline Unknown/not applicable & 21 & (17) \\
\hline \multicolumn{3}{|l|}{ Radiotherapy for LR } \\
\hline Yes & 13 & (11) \\
\hline No & 103 & (83) \\
\hline Unknown & 8 & (6) \\
\hline \multicolumn{3}{|l|}{ Systemic treatment of LR } \\
\hline Chemotherapy & 15 & (12) \\
\hline Endocrine treatment & 21 & (17) \\
\hline Chemotherapy+endocrine treatment & 13 & (10) \\
\hline No & 66 & (53) \\
\hline Unknown & 9 & (7) \\
\hline
\end{tabular}

\section{Prognosis and prognostic factors}

Of the 124 patients with LR 28 had died. Distant metastases were observed in 41 patients, subsequent LR or local progression occurred in 5 patients, and 14 patients developed a new primary tumour in the contralateral breast.

The actuarial five and ten year distant-recurrence free survival rates were $73 \%$ (95\% $\mathrm{Cl}, 65-81)$ and $61 \%(95 \% \mathrm{Cl}, 51-71)$ (Figure 4.2.1). The 5 and 10 -year overall survival rates were $90 \%(95 \% \mathrm{Cl}, 84-96)$ and $73 \%(95 \% \mathrm{Cl}, 63-83)$ (Figure 4.2.1). Both the 5 and 10 -year local control rate were $95 \%$ (95\% Cl, 91-99) (Figure 4.2.1). 


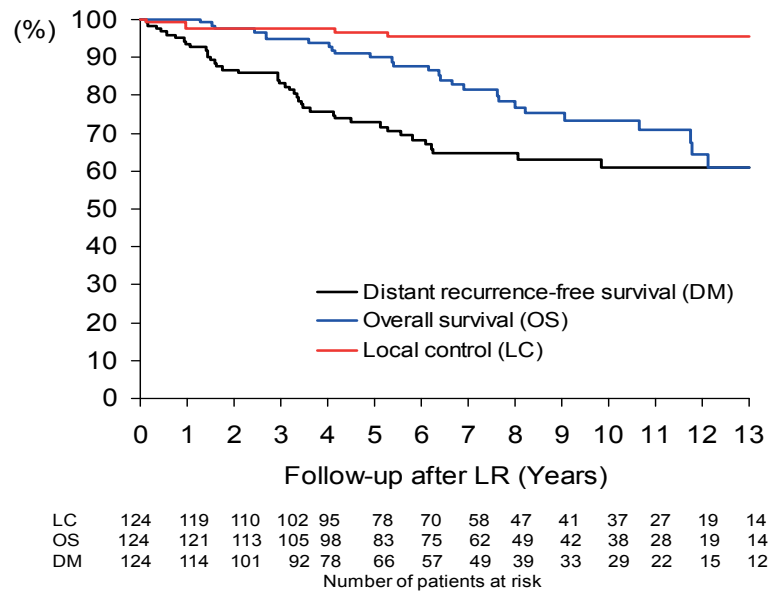

Figure 4.2.1 Overall survival, distant recurrence-free survival and local control following diagnosis of local recurrence after breast-conserving treatment $(n=124)$.

As is demonstrated in Table 4.2.2, the following factors appeared to be statistically significant prognostic factors for the development of distant disease: size of $L R$, mode of detection of LR and presence of symptoms at the time of diagnosis of LR (Figure 4.2.2). Other factors, such as age at diagnosis of $L R$, time interval to $L R$ (i.e. more than 5 versus less than 5 years after BCT), histology and axillary lymph node status of the primary tumour were not significantly associated with the risk of distant relapse after LR (Table 4.2.2).

The following variables were included in the multivariate Cox regression model: time interval from BCT until LR, size of $L R$ and method of detection. Due to missing information on one or more of these variables, 32 patients had to be excluded from the multivariate analyses. The prognosis of these patients with respect to the three end-points appeared to be similar to the prognosis for the 92 left for the multivariate model $(P=0.81)$, indicating that there was no selective drop-out of patients from the multivariate analysis. Patients with a LR measuring more than $2 \mathrm{~cm}$ in diameter had an almost three times higher risk of developing distant metastases compared to patients with a LR of $2 \mathrm{~cm}$ or smaller (HR 2.88; $95 \% \mathrm{Cl}, 1.34-6.19$ ). Though not statistically significant, the risk of distant metastases also tended to be higher for patients with LR occurring within 5 years after BCT, as compared to patients with LR more than 5 years after BCT (HR 1.89; 95\% Cl, 0.90-3.98). Patients with a LR causing symptoms or with suspicious findings at clinical breast examination had an almost four times higher risk of distant relapse compared to those with a LR detected by breast imaging only (HR 3.70; 95\% Cl, 1.14-12.50) (Figure 4.2.2). 
Table 4.2.2 Univariate analysis of distant recurrence-free survival of patients with LR, according to patients and disease characteristics.

\begin{tabular}{|c|c|c|c|c|c|}
\hline Characteristics & $\begin{array}{c}\text { No. of } \\
\text { patients }\end{array}$ & $\begin{array}{c}\text { No. with } \\
\text { DM }\end{array}$ & $\begin{array}{c}\text { 5-year DM- } \\
\text { free rate } \\
(\%)\end{array}$ & $95 \% \mathrm{Cl}$ & $P$-value \\
\hline Age at diagnosis of LR & & & & & 0.44 \\
\hline$\leq 40$ years & 40 & 13 & 74 & $(60-88)$ & \\
\hline$>40$ years & 84 & 28 & 72 & $(62-82)$ & \\
\hline Interval between primary tumour and LR & & & & & 0.17 \\
\hline$\leq 5$ years & 53 & 23 & 63 & $(50-76)$ & \\
\hline$>5$ years & 71 & 18 & 81 & $(71-91)$ & \\
\hline Period of diagnosis of LR & & & & & 0.35 \\
\hline 1988-1996 & 22 & 11 & 63 & $(53-73)$ & \\
\hline 1997-2004 & 64 & 25 & 70 & $(59-81)$ & \\
\hline $2005-2011$ & 38 & 5 & 88 & $(77-99)$ & \\
\hline Size of LR & & & & & 0.03 \\
\hline$\leq 20 \mathrm{~mm}$ & 76 & 18 & 82 & $(72-92)$ & \\
\hline$>20 \mathrm{~mm}$ & 26 & 12 & 64 & $(44-84)$ & \\
\hline Location of LR & & & & & 0.16 \\
\hline At or near site of primary tumour & 89 & 21 & 71 & $(61-81)$ & \\
\hline Elsewhere in the breast & 13 & 3 & 83 & $(61-100)$ & \\
\hline Diffuse & 7 & 3 & 34 & $(0-86)$ & \\
\hline Type of LR & & & & & 0.54 \\
\hline Invasive with or without in situ component & 105 & 36 & 73 & $(63-83)$ & \\
\hline In situ & 16 & 5 & 68 & $(47-89)$ & \\
\hline Histological grade of LR & & & & & 0.21 \\
\hline Good or moderate & 33 & 7 & 85 & $(71-99)$ & \\
\hline Poor & 37 & 14 & 69 & $(53-85)$ & \\
\hline Oestrogen receptor status of LR & & & & & 0.43 \\
\hline Positive & 64 & 23 & 71 & $(59-83)$ & \\
\hline Negative & 29 & 8 & 77 & $(61-93)$ & \\
\hline Mode of detection of LR & & & & & 0.004 \\
\hline Clinical breast examination or symptoms & 77 & 35 & 64 & $(53-75)$ & \\
\hline Imaging only & 34 & 6 & 83 & $(69-97)$ & \\
\hline Symptoms at time of diagnosis of LR & & & & & 0.001 \\
\hline Yes & 65 & 32 & 62 & $(50-74)$ & \\
\hline No & 47 & 9 & 81 & $(69-93)$ & \\
\hline Systemic treatment of primary tumour & & & & & 0.23 \\
\hline No & 96 & 35 & 69 & $(59-79)$ & \\
\hline Yes & 26 & 6 & 88 & $(75-100)$ & \\
\hline Systemic treatment of LR & & & & & 0.41 \\
\hline No & 66 & 26 & 70 & $(58-82)$ & \\
\hline Yes & 49 & 13 & 77 & $(65-89)$ & \\
\hline
\end{tabular}




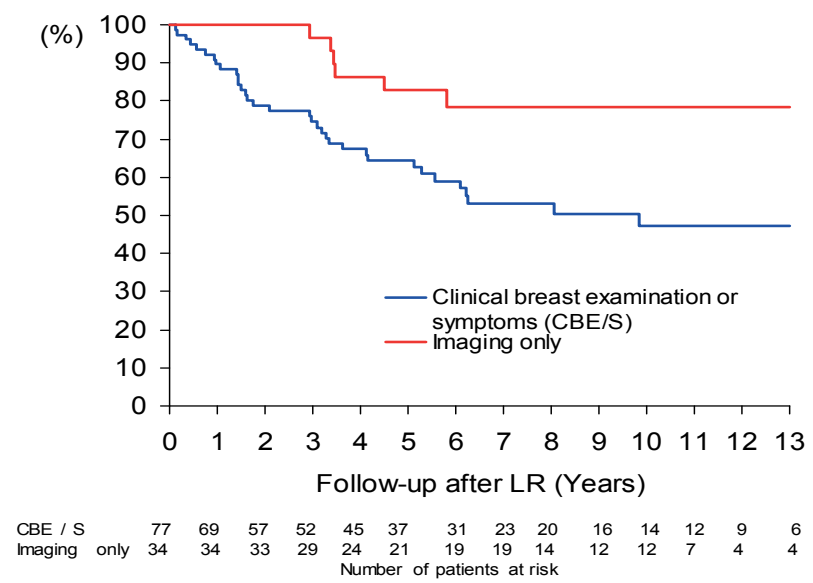

Figure 4.2.2 Distant recurrence-free survival according to mode of detection of local recurrence.

\section{Discussion}

The present study investigated the prognosis and prognostic factors in a group of patients with an isolated LR following BCT for early breast cancer at the age of 40 years or younger. Most of the recurrences (57\%) were diagnosed five or more years after BCT. A larger size of the LR (more versus less than $2 \mathrm{~cm}$ diameter) and the detection of the LR by symptoms or clinical breast examination (versus breast imaging only) were associated with a poorer distant recurrence-free survival.

Symptomatic LRs or LRs detected by clinical breast examination were not significantly larger than those detected by breast imaging only, which makes it difficult to understand the negative impact of symptoms on the prognosis. One could imagine that the proliferation rate of the tumour plays a role and that a rapidly growing tumour results in breast changes or complaints appearing in a relative short time period. These rapid changes may be easier to perceive than changes that occur very gradually. In general highly proliferative tumours have a poorer prognosis which may also be true for $\mathrm{LRs}^{21-23}$. Unfortunately, information on proliferation rate was missing for too many patients to verify this hypothesis in our study.

In many studies young age at primary diagnosis is one of the most important independent risk factors for $\mathrm{LR}$ after $\mathrm{BCT}^{4,24,25}$. At the same time it is associated with a poorer breast cancer related and overall survival ${ }^{26,27}$. However, when looking at the outcome following LR, young patients with a LR seem to have a better prognosis compared to older patients ${ }^{12,19,20}$. There may be several possible explanations for this 
observation. The most obvious one is that young women are more likely to receive and tolerate more aggressive treatment.

\section{Systemic treatment following LR}

Until recently the only evidence supporting the use of systemic therapy following LR was a relative small Swiss randomised study investigating women with a locoregional relapse after mastectomy. Twelve-year disease-free survival was better for women receiving tamoxifen, without an influence on overall survival ${ }^{28}$. Very recently, results of the CALOR randomised clinical trial were reported, which addressed the issue of adjuvant chemotherapy for radically resected local and regional relapses of breast cancer after BCT or mastectomy ${ }^{29}$. This trial was prematurely closed in 2010 because of low accrual, but analysis of the data of the only 162 included patients showed a clear benefit for adjuvant chemotherapy with an absolute difference of $12 \%$ in the 5year disease-free and overall survival rate between the chemotherapy group and the no-chemotherapy group. In spite of the fact that the evidence supporting the use of systemic therapy in patients with a LR only recently emerged, we saw an increase in the use from less than $10 \%$ in the period $1988-1996$ to $56 \%$ among the patients diagnosed in the period 2005-2011. With these new compelling data from the CALOR trial, we expect that the use of systemic treatment will even further increase.

$\mathrm{LR}$ is often a precursor or epiphenomenon of distant metastases. It is not yet clear to which extent metastases emerge as a consequence of the LR or rather from the original tumour. In our study the 10 years distant recurrence-free survival rate was $63 \%$. This contrasts sharply with the excellent 10 -year local control rate of $95 \%$ after salvage treatment for LR. The finding that a substantial proportion of patients with a LR develops distant metastases, requires the use of reliable additional tools to predict outcome and adapt treatment. Anderson et al. studied 3799 women with nodenegative breast cancer from five NSABP protocols who underwent BCT with 342 of them developing a subsequent $L R^{12}$. Older age, black race and higher body mass index were clinical factors related with decreased overall survival after LR. In addition to these clinical factors a negative ER status and, in agreement with our findings, LR size $>2 \mathrm{~cm}$ were tumour-related factors with a negative impact. Wapnir et al. did the same study on patients with initial node positive breast cancer and confirmed the prognostic value of age, tumour size and ER status ${ }^{30}$.

\section{Cancer genomics research}

The last decade there is a lot of attention for molecular and genomic profiling in relation to prognosis. Breast cancer is a heterogeneous disease and genetic profiling offers the possibility to divide patients into different prognostic subtypes. An interesting finding is the genomic analysis of Anders et al. which suggests that the aggressive biologic behaviour of breast cancer at young age is mainly determined by the predominance of genes associated with basal-like and HER2-enriched breast 
cancer subtypes and high histological grade, concluding that age as such may not have additional prognostic value above subtype and grade ${ }^{31}$. The current tumour subtypes and gene signatures are mainly used for risk assessment of distant disease on the basis of tissue of the primary tumour. It is not known to what extent we can extrapolate this prognostic information to the situation after a LR, although most of the LRs have been shown to have the same gene signature as the primary tumour ${ }^{32}$. Even though these studies are very promising, results of prospective validation studies are needed before we can use LR gene signatures to select the most appropriate treatment in daily practice.

\section{Strengths and limitations}

An important strength of our study, as compared to many other studies in this field, is that we studied prognosis and prognostic factors in a well-defined, homogenous population. All patients were 40 years or younger at the time of BCT and had an isolated LR without previous or concurrent regional or distant disease or contralateral breast cancer.

A limitation of our study is the retrospective design, implying that information on tumour characteristics such as hormone receptor status, HER2 status, grade and proliferation markers was difficult to retrieve for many patients. As a result, we are not able to reliably correlate these pathologic factors to prognosis. Another limitation is that we could not perform pathology review of both the primary and the recurrent tumour, making it difficult to discriminate a true LR from a second primary tumour in the same breast. Finally, even though it is one of the largest studies in young women, the total number of patients is still relatively small. This may be the reason why for instance the prognostic impact of time to recurrence could not be demonstrated.

\section{Conclusions}

The main current challenge for treatment of LR is preventing occurrence of distant disease. At this moment there are several clinicopathological factors which predict prognosis after LR. In a group of women with primary breast cancer at young age we found that larger size of the LR and the detection of the LR by symptoms or clinical breast examination were highly prognostic for a poorer distant recurrence-free survival. This suggests that early detection of LR can improve treatment outcome. 


\section{References}

1. Veronesi U, Cascinelli N, Mariani L, et al. Twenty-year follow-up of a randomized study comparing breast-conserving surgery with radical mastectomy for early breast cancer. N Engl J Med 2002;347:1227-32.

2. Fisher B, Anderson S, Bryant J, et al. Twenty-year follow-up of a randomized trial comparing total mastectomy, lumpectomy, and lumpectomy plus irradiation for the treatment of invasive breast cancer. N Engl J Med 2002;347:1233-41.

3. van Dongen JA, Voogd AC, Fentiman IS, et al. Long-term results of a randomized trial comparing breast-conserving therapy with mastectomy: European Organization for Research and Treatment of Cancer 10801 trial. J Natl Cancer Inst 2000;92:1143-50.

4. Voogd AC, Nielsen M, Peterse JL, et al. Differences in risk factors for local and distant recurrence after breast-conserving therapy or mastectomy for stage I and II breast cancer: pooled results of two large European randomized trials. J Clin Oncol 2001;19:1688-97.

5. de Bock GH, van der Hage JA, Putter H, Bonnema J, Bartelink $\mathrm{H}$, van de Velde $\mathrm{CJ}$. Isolated loco-regional recurrence of breast cancer is more common in young patients and following breast conserving therapy: long-term results of European Organisation for Research and Treatment of Cancer studies. Eur J Cancer 2006;42:351-6.

6. Elkhuizen PH, van de Vijver MJ, Hermans J, Zonderland HM, van de Velde CJ, Leer JW. Local recurrence after breast-conserving therapy for invasive breast cancer: high incidence in young patients and association with poor survival. Int J Radiat Oncol Biol Phys 1998;40:859-67.

7. van der Sangen MJ, van de Wiel FM, Poortmans PM, et al. Are breast conservation and mastectomy equally effective in the treatment of young women with early breast cancer? Long-term results of a population-based cohort of 1,451 patients aged $\leq 40$ years. Breast Cancer Res Treat 2011;127;207-15.

8. Poortmans $\mathrm{P}$, Aznar M, Bartelink H. Quality indicators for breast cancer: revisiting historical evidence in the context of technology changes. Semin Radiat Oncol 2012;22:29-39.

9. Fisher B, Anderson S, Fisher ER, et al. Significance of ipsilateral breast tumour recurrence after lumpectomy. Lancet 1991;338:327-31.

10. Kemperman $H$, Borger J, Hart A, Peterse $H$, Bartelink $H$, van Dongen J. Prognostic factors for survival after breast conserving therapy for stage I and II breast cancer. The role of local recurrence. Eur J Cancer 1995;31A:690-8.

11. Haffty BG, Reiss M, Beinfield M, Fischer D, Ward B, McKhann C. Ipsilateral breast tumor recurrence as a predictor of distant disease: implications for systemic therapy at the time of local relapse. J Clin Oncol 1996;14:52-7.

12. Anderson SJ, Wapnir I, Dignam JJ, et al. Prognosis after ipsilateral breast tumor recurrence and locoregional recurrences in patients treated by breast-conserving therapy in five National Surgical Adjuvant Breast and Bowel Project protocols of node-negative breast cancer. J Clin Oncol 2009;27:2466-73.

13. Kurtz JM, Amalric $\mathrm{R}$, Brandone $\mathrm{H}$, et al. Local recurrence after breast-conserving surgery and radiotherapy. Frequency, time course, and prognosis. Cancer 1989;63:1912-7.

14. Clarke DH, Le MG, Sarrazin D, et al. Analysis of local-regional relapses in patients with early breast cancers treated by excision and radiotherapy: experience of the Institut Gustave-Roussy. Int J Radiat Oncol Biol Phys 1985;11:137-45.

15. Calle R, Vilcoq JR, Zafrani B, Vielh P, Fourquet A. Local control and survival of breast cancer treated by limited surgery followed by irradiation. Int J Radiat Oncol Biol Phys 1986;12:873-8.

16. Haffty BG, Carter D, Flynn SD, et al. Local recurrence versus new primary: clinical analysis of 82 breast relapses and potential applications for genetic fingerprinting. Int J Radiat Oncol Biol Phys 1993;27:575-83.

17. Fredriksson I, Liljegren G, Arnesson L, et al. Local recurrence in the breast after conservative surgery-a study of prognosis and prognostic factors in 391 women. Eur J Cancer 2002;38:1860.

18. van Tienhoven G, Voogd AC, Peterse JL, et al. Prognosis after treatment for loco-regional recurrence after mastectomy or breast conserving therapy in two randomised trials (EORTC 10801 and DBCG82TM). EORTC Breast Cancer Cooperative Group and the Danish Breast Cancer Cooperative Group. Eur J Cancer 1999;35:32-8. 
19. Tanis E, van de Velde CJ, Bartelink H, van de Vijver MJ, Putter H, van der Hage JA. Locoregional recurrence after breast-conserving therapy remains an independent prognostic factor even after an event free interval of 10 years in early stage breast cancer. Eur J Cancer 2012;48:1751-6.

20. Courdi A, Doyen J, Gal J, Chamorey E. Local recurrence after breast cancer affects specific survival differently according to patient age. Oncology 2010;79:349-54.

21. van Diest PJ, van der Wall E, Baak JP. Prognostic value of proliferation in invasive breast cancer: a review. J Clin Pathol 2004;57:675-81.

22. Voduc KD, Cheang MC, Tyldesley S, Gelmon K, Nielsen TO, Kennecke H. Breast cancer subtypes and the risk of local and regional relapse. J Clin Oncol 2010;28:1684-91.

23. de Azambuja E, Cardoso F, de Castro G, Jr., et al. Ki-67 as prognostic marker in early breast cancer: a meta-analysis of published studies involving 12,155 patients. Br J Cancer 2007;96:1504-13.

24. Bartelink H, Horiot JC, Poortmans PM, et al. Impact of a higher radiation dose on local control and survival in breast-conserving therapy of early breast cancer: 10-year results of the randomized boost versus no boost EORTC 22881-10882 trial. J Clin Oncol 2007;25:3259-65.

25. Arvold ND, Taghian AG, Niemierko A, et al. Age, breast cancer subtype approximation, and local recurrence after breast-conserving therapy. J Clin Oncol 2011;29:3885-91.

26. Kroman N, Jensen MB, Wohlfahrt J, Mouridsen HT, Andersen PK, Melbye M. Factors influencing the effect of age on prognosis in breast cancer: population based study. BMJ 2000;320:474-8.

27. Louwman WJ, Voogd AC, van Dijck JA, et al. On the rising trends of incidence and prognosis for breast cancer patients diagnosed 1975-2004: a long-term population-based study in southeastern Netherlands. Cancer Causes Control 2008;19:97-106.

28. Waeber $M$, Castiglione-Gertsch $M$, Dietrich $D$, et al. Adjuvant therapy after excision and radiation of isolated postmastectomy locoregional breast cancer recurrence: definitive results of a phase III randomized trial (SAKK 23/82) comparing tamoxifen with observation. Ann Oncol 2003;14:1215-21.

29. Aebi S, Gelber S, Lang I, et al. Chemothrapy prolongs survival for isolated local or regional recurrence of breast cancer: The CALOR trial (Chemotherapy as Adjuvant for Locally Recurrent breast cancer; IBCSG 27-02, NSABP B-37, BIG 1-02). Cancer Res 72(24 Suppl.), 96s.

30. Wapnir IL, Anderson SJ, Mamounas EP, et al. Prognosis after ipsilateral breast tumor recurrence and locoregional recurrences in five National Surgical Adjuvant Breast and Bowel Project node-positive adjuvant breast cancer trials. J Clin Oncol 2006;24:2028-37.

31. Anders CK, Fan C, Parker JS, et al. Breast carcinomas arising at a young age: unique biology or a surrogate for aggressive intrinsic subtypes? J Clin Oncol 2011;29:e18-20.

32. Kreike B, Halfwerk $H$, Kristel $P$, et al. Gene expression profiles of primary breast carcinomas from patients at high risk for local recurrence after breast-conserving therapy. Clin Cancer Res 2006;12:5705-12. 


\section{Chapter 5}

Regional relapse 


\section{Chapter 5.1}

Diagnosis, treatment and prognosis of internal mammary lymph node recurrence in breast cancer patients

S Cranenbroek MJC van der Sangen GP Kuijt AC Voogd 


\section{Summary}

Recurrences in the internal mammary lymph nodes (IMLN) are very rare, despite the fact that these nodes remain untreated in most patients. The aim of this study was to assess the chance for IMLN recurrence in a large patient series and to get insight into diagnostics, treatment and prognosis of this type of recurrence. Follow-up of nearly 6000 breast cancer patients resulted in the tracing of only six patients with internal mammary lymph node recurrence. IMLN recurrence was defined as breast cancer recurrence in an internal mammary lymph node without a distant metastasis before the recurrence and confirmed by cytology and/or CT-scan. The time interval between diagnosis of the primary tumour and the recurrence varied between five months and eight years and six months. One patient showed no symptoms, the other five all had a swelling and one of them also had pain. The size of the parasternal swelling varied from $30 \mathrm{~mm}$ to $90 \mathrm{~mm}$; in one patient the size was unknown. Treatment resulted in a complete remission in four patients. In five of the six patients distant metastases occurred. The time interval between IMLN recurrence and the diagnosis of distant metastasis varied between 0 and 37 months. One patient was still free of distant metastasis at time of this study. This large population-based study confirms the almost negligible risk of clinically apparent IMLN recurrence. Considering the high percentage of positive lymph nodes in studies evaluating sentinel node biopsy of the internal mammary chain, it becomes clear that just a fraction of these becomes clinically apparent as a recurrence. In almost all patients with IMLN it is a forerunner of metastatic disease. 


\section{Introduction}

Axillary lymph node status is one of the most important prognostic factors in patients with breast cancer. Dissemination of tumour cells through the lymph system is not only taking place to the axillary lymph nodes but also to the internal mammary and supraclavicular lymph nodes. Studies investigating the lymphatic drainage of the breast report drainage of $64 \%$ to $95 \%$ of tumours to the axillary lymph nodes of which $9 \%$ to $45 \%$ also drains to the internal mammary lymph nodes ${ }^{1-4}$. One to five percent of the tumours exclusively drain to the internal mammary lymph nodes ${ }^{2,3}$. Drainage from the lower inner quadrant is more pronounced to the internal mammary lymph nodes (IMLN) than to the axillary nodes, as compared to the other quadrants ${ }^{5}$. Also nonpalpable tumours more often drain to the IMLN than palpable tumours, regardless of the quadrant in which the tumour is located. A possible explanation for this finding could be that non-palpable tumours are generally situated deeper in the breast ${ }^{5}$.

Studies show that recurrences in the different regional nodal areas are rare following a complete axillary dissection, and that the risk varies from $1 \%$ to $5 \%$ among breast cancer patients treated with curative intent ${ }^{6,7}$. The risk of developing an axillary recurrence is between $0.5 \%$ and $3 \%$, whereas the risk of an isolated supraclavicular recurrence is $2 \%$ at most ${ }^{8,9}$. Recurrences in the IMLN are even more rare, despite the fact that these nodes remain untreated in most patients. The slight chance of an IMLN recurrence explains why research on this phenomenon is scarce. The aim of this study was to assess the chance for IMLN recurrence in a large patient series and to get insight into diagnostics, treatment and prognosis of this type of recurrence. Follow-up of nearly 6000 breast cancer patients resulted in the tracing of only six patients with internal mammary lymph node recurrence. In our opinion the relative unfamiliarity with this phenomenon justifies a detailed description of these six patients.

\section{Patients and methods}

Patient data were retrieved from the population-based Eindhoven Cancer Registry, which serves a population of almost two million inhabitants in the southeastern part of the Netherlands (twelve percent of the Dutch population). Data have been collected by the registry clerks of the cancer registry, from copies of the pathology reports of three pathology laboratories, eight hospitals and one radiotherapy institute. During the period of 1984-1996, 6890 patients with an invasive breast carcinoma were registered, of whom 5912 had undergone an axillary lymph node dissection. In 1989 the Eindhoven Cancer Registry also started collecting follow-up information on all patients with breast cancer, including the data and site of local, regional and distant recurrence. The information is provided by the pathologists, radiotherapists and the majority of the surgeons. Until January 199953 patients with an IMLN recurrence had been recorded by the cancer registry among the 5912 
patients who had undergone an axillary lymph node dissection. In our study IMLN recurrence was defined as breast cancer recurrence in an internal mammary lymph node without a distant metastasis before the recurrence and confirmed by cytology and/or CT-scan. Studying the clinical records of these 53 patients at the Department of Radiotherapy of the Catharina Hospital in Eindhoven and the surgical records at the referring hospitals, it appeared that 44 of the recurrences did not match our definition of IMLN recurrence. These 44 patients had a local recurrence, supraclavicular or axillary recurrence instead of an IMLN recurrence, or distant metastasis before the diagnosis of IMLN recurrence. Patient records of three patients could not be retrieved. Also, five patients who had a solitary sternal metastasis were excluded, because no further diagnostics had been done to confirm a diagnosis of IMLN recurrence. Eventually, only six patients remained to be included for this study. Our study contains a detailed description of the diagnosis, treatment and prognosis of these six patients.

\section{Results}

For each of the six patients with an IMLN recurrence the most important characteristics with regard to the primary tumour and the recurrence are listed in Table 5.1.1. The age at time of diagnosis of the primary tumour was between 33 and 81 years. The diagnosis of the primary tumour took place between 1986 and 1996. In two patients the tumour was located in the lower outer quadrant, in two in the lower inner quadrant, one in the upper inner quadrant and one centrally. The size of the primary tumour varied from $18 \mathrm{~mm}$ to $50 \mathrm{~mm}$ and in all cases the tumour was of the ductal type. The surgical treatment of the primary tumour was a mastectomy in five patients and breast-conserving surgery in one. Three patients received adjuvant systemic therapy and/or radiotherapy. Two patients had positive axillary lymph nodes.

The IMLN recurrences occurred from 1991 until 1998. The time interval between diagnosis of the primary tumour and the recurrence varied between five months and eight years and six months. One patient showed no symptoms, the other five all had a swelling and one of them also had pain. The size of the parasternal swelling varied from $30 \mathrm{~mm}$ to $90 \mathrm{~mm}$; in one patient the size was unknown. In four patients the diagnosis was confirmed by CT-scan, in the other two patients the diagnosis was confirmed unambiguously by clinical examination and cytology. In one case the diagnosis was not confirmed by cytology, but was an accidental finding on a CT-scan that was made as part of the diagnostic work-up in a patient with palpable supraclavicular lymph nodes. Three of the six patients also had a hotspot on the sternum at time of diagnosis of the IMLN recurrence. 


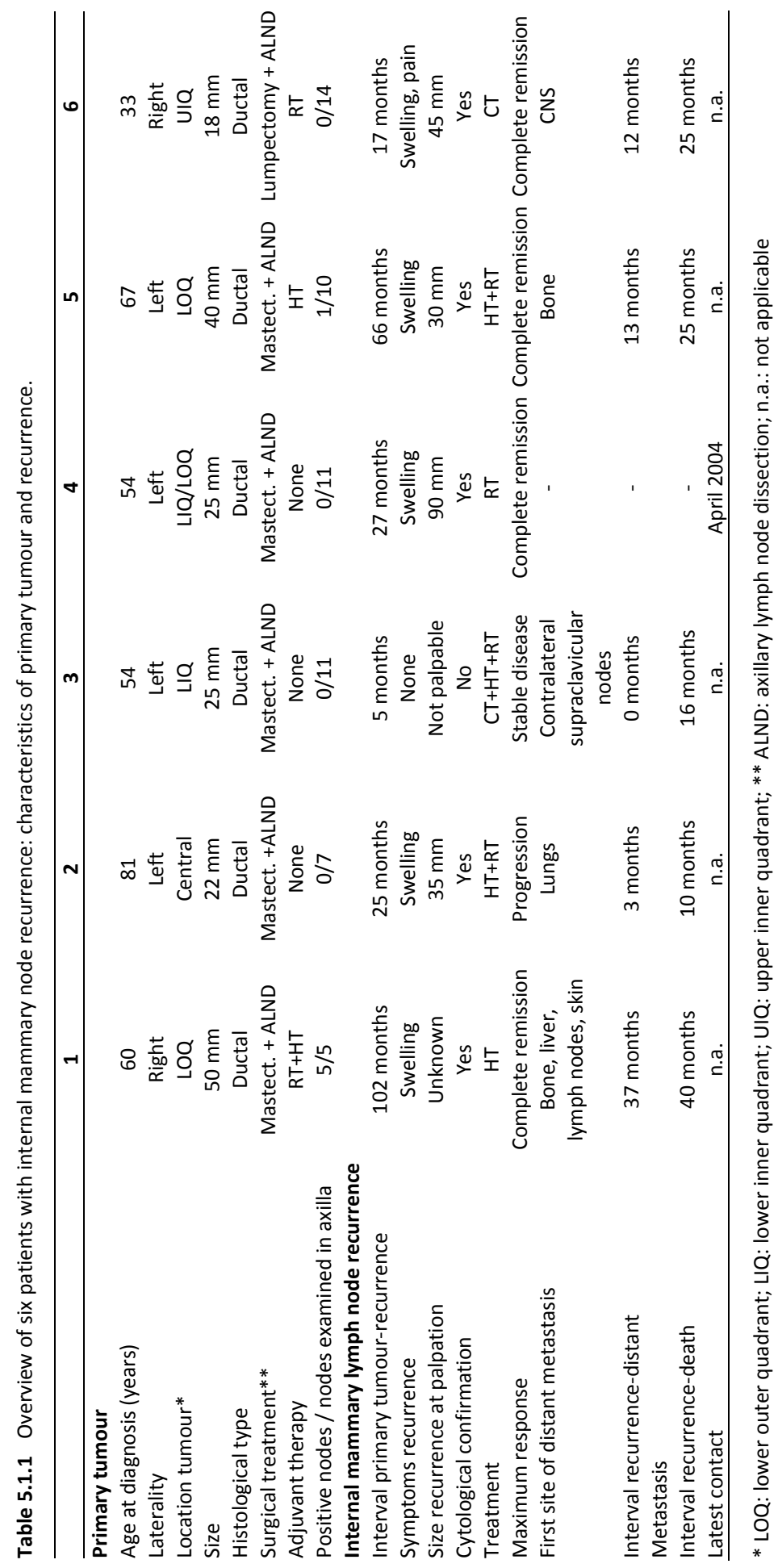


In all patients treatment was initiated following the diagnosis of the IMLN recurrence, consisting of systemic therapy, radiotherapy or a combination of both. This resulted in a complete remission in four patients. Because in most patients the effect of the treatment had not been evaluated by CT-scan, a complete remission meant that the swelling was no longer palpable.

In five of the six patients distant metastases occurred. At the same time, in one of these five patients (patient no.1) the IMLN recurrence showed progression and became palpable again. The time interval between IMLN recurrence and the diagnosis of distant metastasis varied between 0 and 37 months. One patient was still free of distant metastases at time of this study. Meanwhile five of six patients have died. The time interval between recurrence and death varied between 10 and 40 months.

\section{Discussion}

This study again shows the almost negligible risk of clinically apparent IMLN recurrence in breast cancer patients that initially have been treated with curative intent. Studies of Fowble et al. ${ }^{7}$ and Recht et al. ${ }^{10}$ showed a percentage of IMLN recurrence of $0,1 \%^{7,10}$. This corresponds to the percentage of our study, in which six recurrences occurred in a cohort of almost 6000 patients treated with curative intent, including axillary lymph node dissection.

The studies of Byrd et al. ${ }^{2}$ and Estourgie et al. ${ }^{5}$ specifically focused on the drainage of the different quadrants to the IMLN. These studies showed that the upper outer quadrant had the least drainage to the IMLN with $10 \%$ to $10.4 \%$ and that the lower inner quadrant had the most drainage to the IMLN with $25 \%$ to $52.0 \%$ of the tumours located in this quadrant. Estourgie et al. also looked at the solitary drainage of tumours to the $\mathrm{IMLN}^{5}$. This showed no solitary drainage from centrally located tumours, and again the lower inner quadrant showed the highest drainage of $5.8 \%$.

In a study by van der Ent et al., which focused on metastases in sentinel nodes located in the IMLN, IMLN metastases were found in $26.8 \%$ of the patients $(11 / 41)^{4}$. In $7.3 \%$ of the patients $(3 / 41)$ internal mammary nodes showed metastatic involvement without accompanying axillary metastases. The study of Estourgie et al. showed about similar percentages $^{11}$. They found metastasis in 22 of 130 patients (17\%) with a harvested sentinel node in the internal mammary chain (IMC). In nine patients (7\%) the IMC sentinel node was tumour positive, whereas the axilla was tumour-free. If the small risk for an IMLN recurrence is set against the high percentage of positive internal mammary sentinel nodes found in the studies of van der Ent et al. ${ }^{4}$ and Estourgie et al. ${ }^{11}$ it becomes clear that just a fraction of these becomes clinically apparent as a recurrence.

In our study there might be some underreporting. The registration of the IMLN recurrence by the cancer registry was not optimal, considering the large proportion of patients that did not meet the definition used in our study. The definition of the IMLN 
recurrence might also be of influence of the amount of IMLN recurrences found in other studies. The definition in our study corresponds to the definitions used in the studies of Fowble et al. ${ }^{7}$ and Recht et al. ${ }^{10}$. It is known that an IMLN recurrence can also present as a sternal erosion ${ }^{12}$. Among the 53 patients that were registered by the cancer registry there were five patients with a solitary bone metastasis of the sternum. These had had no further diagnostics of the IMLN and therefore have been classified as bone metastasis. Another possibility is that the IMLN recurrence gets mixed up with local recurrence, thus increasing the estimated risk ${ }^{13}$.

In the Netherlands it is recommended not to use CT-scan or other imaging or laboratory techniques at periodical check-ups if there are no symptoms. In case of active screening for metastases, the number of IMLN recurrences would probably increase. An IMLN recurrence can also be discovered by coincidence on a CT-scan made for another reason. In case of our study it concerned only one patient whose recurrence was diagnosed by coincidence on a CT-scan. The other five patients all had an obvious swelling, which probably means that the recurrences were already there for a longer time.

In this series of patients it is remarkable that none of the primary tumours was located at the upper outer quadrant, the most common site of breast cancer in the breast. This fits the findings about the drainage patterns of the breast, in which medially and centrally located breast tumours and tumours in the lower part of the breast more often drain to the IMLN. A significant relation between drainage to the IMLN and characteristics of the tumour has not be found ${ }^{13}$.

It is also noteworthy that only two of the six patients initially had positive axillary lymph nodes. The study of Harris et al. showed that $64 \%$ of the regional recurrences initially had negative axillary lymph nodes ${ }^{2}$. In this study $8 \%$ (3 of 39 ) of the regional recurrences were IMLN recurrences.

A recurrence in the IMLN is rare, but if it occurs it often goes along with distant metastasis, in which case the treatment and prognosis of the patients will not be affected by the IMLN recurrence. Four of the six patients with IMLN recurrences in our study had a complete remission following treatment. The prognosis however remained poor; only one patient was free of disease at time of the closing of this study. Thus, it can be concluded that the IMLN recurrence is, in a similar way as supraclavicular recurrence, a forerunner of distant metastases ${ }^{5}$.

With the sentinel node procedure sentinel nodes are found regularly in the IMLN. At this moment there is no standard on how to deal with these sentinel nodes. Therefore, further exploration is often abandoned. In the group of patients with negative axillary lymph nodes, biopting the internal mammary lymph nodes could change the staging, therapy and prognosis. Pathologically confirmed metastases in only the IMLN is after all classified as pN1b or pN2b in the latest $\left(6^{\text {th }}\right)$ edition of the TNM classification ${ }^{14}$. A lymph node with metastasis remains a potential source of dissemination of tumour cells and also therefore worsens the prognosis. 
Recently, the European Organization for Research and Treatment of Cancer (EORTC) has completed the patient accrual for a trial in which the effect of irradiation of the internal mammary and medial supraclavicular lymph nodes, regardless of the location of the sentinel nodes, will be studied ${ }^{15}$. This study will test the hypothesis that treatment of the IMLN reduces the chance for distant metastasis and improves (disease free) survival. Earlier studies of Overgaard et al. ${ }^{16,17}$ and Ragaz et al. ${ }^{18}$ have already shown a decrease in the number of locoregional recurrences and improvement of survival in breast cancer patients treated with a combination of locoregional irradiation and systemic therapy ${ }^{15-18}$. However it is not likely that parasternal irradiation will cause a noticeable reduction of the risk of clinically manifest IMLN recurrence, which already is negligibly small without adjuvant radiotherapy. 


\section{References}

1. Uren RF, Howman-Giles R, Renwick SB, Gillet D. Lymfatic mapping of the breast: Locating the sentinel lymph nodes. World J Surg 2001;25:789-93.

2. Byrd DR, Dunnwald LK, Mankoff DA, Anderson BO, Moe RE, Yeung RS, Schubert EK, Eary JF. Internal mammary lymph node drainage patterns in patients with breast cancer documented by breast lymphoscintigraphy. Ann Surg Oncol 2000;8:234-40.

3. Lamonica D, Edge SB, Hurd T, Proulx G, Stomper PC. Mammographic and clinical predictors of drainage patterns in breast lymphoscintigrams obtained during sentinel node procedures. Clin Nucl Med 2003;7:558-64.

4. Van der Ent FW, Kengen RA, van der Pol HA, Povel JA, Stroeken HJ, Hoofwijk AG. Halsted revisited: internal mammary sentinel lymph node biopsy in breast cancer. Ann Surg 2001;234: 79-84.

5. Estourgie SH, Nieweg OE, Olmos RA, Rutgers EJ, Kroon BB. Lymphatic drainage patterns from the breast. Ann Surg 2004;239:232-7.

6. Harris EE, Hwang W, Seyednejad F, Solin L. Prognosis after regional lymph node recurrence in patients with stage I-II breast carcinoma treated with breast conservation therapy. Cancer 2003;98: 2144-51.

7. Fowble B, Solin LJ, Schultz DJ, Goodman RL. Frequency, sites of relapse, and outcome of regional node failures following conservative surgery and radiation for early breast cancer. Int J Radiat Oncol Biol Phys 1989;17:703-10.

8. De Boer R, Hillen HF, Roumen RM, Rutten HJ, van der Sangen MJ, Voogd AC. Detection treatment and outcome of axillary recurrence after axillary clearance for invasive breast cancer. Br J Surg 2001;88: 118-22

9. van der Sangen MJ, Coebergh JW, Roumen RM, Rutten HJ, Vreugdenhil G, Voogd AC. Detection, treatment and outcome of isolated supraclavicular recurrence in 42 patients with invasive breast carcinoma. Cancer 2003;98:11-7.

10. Recht A, Pierce SM, Abner A, Vicini F, Osteen RT, Love SM, Silver B, Harris JR. Regional nodal failure after conservative surgery and radiotherapy for early-stage breast cancer. J Clin Oncol 1991;9:988-96.

11. Estourgie SH, Tanis PJ, Nieweg OE, Valdes Olmos RA, Rutgers EJ, Kroon BB. Should the hunt for internal mammary chain sentinel nodes begin? An evaluation of 150 breast cancer patients. Ann Surg Oncol 2003;10:935-41.

12. Feigen $\mathrm{M}$, Kitchen $\mathrm{P}$. Internal mammary node relapse following breast conservation therapy: a case for irradiation. Breast 1999;8:291-4.

13. Benda RK, Cendan JC, Copeland EM, Feezor RJ, Lind DS, Morris CG, Mendenhall NP. Should decisions on internal mammary lymph node irradiation be base don current lymphoscintigraphy techiniques for sentinel lymph node identification? Cancer 2004;100:518-23.

14. Sobin LH, Wittekind C (eds.). TNM classification of maligant tumours. 6th edition. New-York: Wiley, 2002:131-41.

15. Poortmans PM, Venselaar JL, Struikmans H, Hurkmans CW, Davis JB, Huyskens D, van Tienhoven G, Vlaun V, Lagendijk JJ, Mijnheer BJ, De Winter KA, Van der Hulst MH, Van den Bogaert WF. The potential impact of treatment variations on the results of radiotherapy of the internal mammary lymph node chain: a quality-assurance report on the dummy run of EORTC phase III randomized trial 22922/10925 in stage II-III breast cancer. Int J Radiat Oncol Biol Phys 2001;49:1399-408.

16. Overgaard M, Jensen MB, Overgaard J, Hansen PS, Rose C, Andersson M, Kamby C, Kjaer M, Gadeberg CC, Rasmussen BB, Blichert-Toft M, Mouridsen HT. Postoperative radiotherapy in high-risk postmenopauzal breast cancer patients given adjuvant tamoxifen: Danish Breast Cancer Cooperative Group DBCG 82c randomised trial. Lancet 1999;353:1641-8.

17. Overgaard M, Hansen PS, Overgaard J, Rose C, Andersson M, Bach F, Kjaer M, Gadeberg CC, Mouridsen $\mathrm{HT}$, Jensen $\mathrm{MB}$, Zedeler K. Postoperative radiotherapy in high-risk premenopauzal women with breast cancer who receive adjuvant chemotherapy. Danish Breast Cancer Cooperative Group 82b Trial. N Engl J Med 1997;337:949-55.

18. Ragaz J, Jackson SM, Le N, Plenderleith IH, Spinelli JJ, Basco VE, Wilson KS, Knowling MA, Coppin CM, Paradis M, Coldman AJ, Olivotto IA. Adjuvant radiotherapy and chemotherapy in node-positive premenopausal women with breast cancer. N Engl J Med 1997;337:956-62. 


\section{Chapter 5

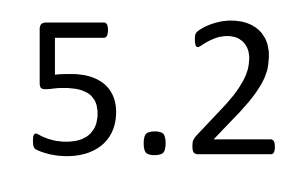

Detection, treatment and outcome of isolated supraclavicular recurrence in $\mathbf{4 2}$ patients with invasive breast cancer

MJC van der Sangen JWW Coebergh

RMH Roumen

HJT Rutten

$G$ Vreugdenhil

AC Voogd 


\section{Abstract}

\section{Background}

It is still a matter of debate if breast cancer patients with isolated supraclavicular recurrence should be considered as patients with disseminated disease or as patients for whom aggressive treatment with curative intent is justified.

\section{Methods}

In the period 1984-1994, 4669 patients with invasive breast cancer underwent axillary dissection in eight community hospitals in the southeastern part of the Netherlands. During follow-up, 42 patients with isolated supraclavicular recurrence were identified.

\section{Results}

The median interval between the treatment of the primary tumour and the diagnosis of the supraclavicular recurrence was 2.5 years (range: 0.2-11.5 years). Radiotherapy was given to 25 patients $(60 \%)$, of whom five also underwent surgery and 16 also received chemotherapy or hormonal therapy. Eleven patients received hormonal therapy only and four chemotherapy only. One patient received surgical treatment only and one patient remained untreated. Complete remission was obtained in 35 patients $(83 \%)$, but a second relapse occurred in the supraclavicular area in 12 (34\%). Of all 42 patients six (14\%) remained alive without evidence of disease after a follow-up of 4.4 to 8.3 years. The five-year actuarial overall survival and distant disease-free survival rates from the date of diagnosis of supraclavicular recurrence were $38 \%$ (95\% confidence interval ( $\mathrm{Cl}$ ): $23-53$ ) and $22 \%$ (95\% Cl: $8-35$ ) respectively. The distant diseasefree survival rate was somewhat better for the 25 patients who underwent radiotherapy as part of the treatment of supraclavicular recurrence compared to the 17 patients not receiving radiotherapy $(P=0.06)$; the difference became more pronounced after excluding eight patients who had already received axillary and supraclavicular irradiation as part of the treatment of the primary tumour $(P=0.002)$.

\section{Conclusion}

Although a complete remission of disease can be obtained in most patients with isolated supraclavicular recurrence, their prognosis is poor. Involved field radiotherapy appears to play an important role in the treatment of supraclavicular recurrence and may also improve the distant recurrence-free survival rate. 


\section{Introduction}

Together with the axillary, infraclavicular and internal mammary nodes, the supraclavicular nodes are part of a continuum of the regional lymph node drainage of the breast in which they are fed from the axillary and internal mammary region. This division in nodal regions is based on anatomical landmarks but also has prognostic significance. Tumour involvement of the supraclavicular lymph nodes is a very unfavorable prognostic indicator ${ }^{1}$. In several studies, patients with ipsilateral supraclavicular lymph node metastases at primary diagnosis or with an isolated supraclavicular recurrence (SR) during the course of their disease appeared to have the same poor outcome as patients with distant metastases elsewhere in the body ${ }^{2-5}$. However, it is still a matter of debate if they should be treated as patients with disseminated disease and receive palliative treatment or as patients for whom treatment with curative intent remains an option. Randomised trials to address this issue are difficult to conduct in view of the low risk of SR. Optimal treatment should therefore also be deduced from observation of retrospective data.

By using data of a population-based cancer registry, we were able to identify 42 patients with an isolated SR after breast cancer treatment including axillary dissection. Diagnosis, treatment and treatment outcome were studied, and prognostic factors were determined.

\section{Patients and methods}

\section{Patients}

Patients were retrieved from the population-based Eindhoven Cancer Registry, which serves a population of almost two million inhabitants in the south-eastern part of the Netherlands (twelve percent of the Dutch population). Data had been collected by the cancer registry from copies of the pathology reports of ten pathologists from three different laboratories and the medical records of eight community hospitals and one department of radiotherapy. During the period 1984-1994 4669 (86\%) of the 5408 patients with invasive breast cancer underwent axillary dissection. Two-hundred-andeight patients $(5 \%)$ had either concurrent or sequential bilateral carcinomas, resulting in a total of 4877 axillary dissections. In the treatment guidelines of the regional Breast Cancer Study Group, the borders of axillary dissection are the latissimus dorsi muscle (dorsal), the thoracic wall below the major and minor pectoral muscles (ventral) and the lower border of the axillary vein (cranial). Axillary dissection was not always considered necessary for patients with a tumour measuring $0.5 \mathrm{~cm}$ or less and was usually omitted in the case of inoperable cancer and for the very elderly. The mean number of lymph nodes examined by the pathologist was 10 . Fewer than six nodes were reported in $14 \%$ and more than 15 in $12 \%$ of the cases. Irradiation of the 
axilla and the supraclavicular field was recommended for patients with more than three positive lymph nodes, extracapsular extension of tumour growth in one or more lymph nodes or nodal involvement in the apex of the axilla. The axillary field was usually exposed to 52.5 Gy (25 fractions) and the supraclavicular field to 46 Gy (20 fractions). The prescribed doses were specified at $30 \mathrm{~mm}$ below the skin surface.

Adjuvant systemic treatment was given only to axillary node-positive patients. Chemotherapy was indicated for premenopausal node-positive patients and endocrine therapy (tamoxifen) for postmenopausal node-positive patients with an oestrogen receptor-positive tumour. The usual chemotherapy consisted of six courses cyclophosphamide, methotrexate, 5-fluorouracil (CMF). Postmenopuasal nodepositive patients with an oestrogen receptor-negative tumour were supposed not to receive any form of adjuvant systemic treatment. However, in a previous study we observed that tamoxifen was given to postmenopausal node-positive patients irrespective of the oestrogen receptor status since the early nineties ${ }^{6}$.

Following treatment, patients were seen alternately by the radiation oncologist and the referring surgeon. They were usually seen every three months during the first two years, every six month during the following three years and yearly thereafter. Bone scans, chest x-ray, complete blood count and liver function tests were only used in case of signs and symptoms suggestive of distant disease or after the diagnosis of local, regional or supraclavicular recurrence.

Since 1989, the Eindhoven Cancer Registry has recorded follow-up information on all patients with breast cancer, including the date and site of local, regional and distant recurrence and the date of death. The information is provided by the pathologists, the radiotherapists and the majority of surgeons. As of January 1998, 42 patients were reported to have isolated supraclavicular recurrence (SR) without other sites of distant disease. The medical record of each patient was used to collect detailed information on the diagnosis and treatment of the SR. The primary treatment of the 42 patients took place between 1984 and 1995 and the SRs were diagnosed between 1986 and 1998. The mean age of the patients at the time of diagnosis of breast cancer was 50 years (range: 30-76 years). Characteristics of the patients, the primary tumour and the treatment are presented in Table 5.2.1.

\section{Statistical analysis}

Follow-up was completed until the first of January 2002. Survival analysis was carried out using the life-table method to evaluate the prognosis after axillary recurrence. End-points were overall survival, distant disease-free survival and survival without subsequent recurrence in the supraclavicular area. Survival curves were calculated from the date of the treatment of diagnosis of SR. The following variables were analyzed to assess their ability to predict distant recurrence-free: age at diagnosis of SR, time interval from initial surgery to SR, detection of SR (physician vs. patient), 
radiotherapy as part of treatment of SR (yes vs. no), size of SR at palpation, size of the primary tumour, lymph node status of the primary tumour (positive vs. negative). Actuarial curves were compared by means of the two-tailed log-rank test. Because of the small number of patients, multivariate analyses were not performed.

Table 5.2.1 Characteristics related to the primary breast tumour of 42 patients with subsequent isolated supraclavicular recurrence

\begin{tabular}{|c|c|c|}
\hline Characteristics & No. & $(\%)$ \\
\hline \multicolumn{3}{|l|}{ Age at diagnosis of primary tumour (years) } \\
\hline$<50$ & 18 & (43) \\
\hline $50-69$ & 21 & $(50)$ \\
\hline $70+$ & 3 & (7) \\
\hline Mean (range) & 50 & $(30-76)$ \\
\hline \multicolumn{3}{|l|}{ Histological type of primary tumour } \\
\hline Ductal & 35 & $(83)$ \\
\hline Lobular/Mixed & 4 & $(10)$ \\
\hline Other & 3 & $(7)$ \\
\hline \multicolumn{3}{|l|}{ Surgery for primary tumour } \\
\hline Mastectomy & 29 & (69) \\
\hline Breast-conserving therapy & 13 & $(31)$ \\
\hline \multicolumn{3}{|l|}{ Size of primary tumour $(\mathrm{cm})$} \\
\hline$\leq 2.0$ & 18 & $(43)$ \\
\hline$>2.0$ & 23 & $(55)$ \\
\hline Unknown & 1 & $(2)$ \\
\hline \multicolumn{3}{|l|}{ Number of lymph nodes found in axillary specimen } \\
\hline$\leq 5$ & 6 & $(16)$ \\
\hline $6-15$ & 28 & $(67)$ \\
\hline$>15$ & 3 & (7) \\
\hline Unknown & 5 & $(12)$ \\
\hline \multicolumn{3}{|l|}{ Number of positive lymph nodes found in axillary specimen } \\
\hline 0 & 13 & (31) \\
\hline $1-3$ & 21 & $(50)$ \\
\hline$>3$ & 4 & $(10)$ \\
\hline Unknown & 4 & $(10)$ \\
\hline \multicolumn{3}{|l|}{ Extracapsular tumour growth in one or more axillary lymph nodes* } \\
\hline Yes & 10 & (34) \\
\hline No & 19 & (66) \\
\hline \multicolumn{3}{|l|}{ Positive lymph nodes in the apex of the axillary specimen* } \\
\hline Yes & 7 & (24) \\
\hline No & 22 & (76) \\
\hline \multicolumn{3}{|l|}{ Radiotherapy for primary tumour } \\
\hline Breast or chest wall only & 18 & $(43)$ \\
\hline Breast or chest wall, axillary and supraclavicular field & 7 & (19) \\
\hline No & 16 & $(38)$ \\
\hline \multicolumn{3}{|l|}{ Adjuvant systemic treatment for primary tumour } \\
\hline Chemotherapy & 12 & (29) \\
\hline Hormonal therapy & 9 & $(21)$ \\
\hline Chemotherapy and hormonal therapy & 2 & $(5)$ \\
\hline None & 19 & $(45)$ \\
\hline
\end{tabular}

* Only for patients with positive axillary lymph nodes 


\section{Results}

\section{Diagnosis}

The median interval between treatment of the primary tumour and diagnosis of SR was 2.5 years (range: 0.2-11.5 years) (Table 5.2.2). All SR's were palpable; 13 (31\%) had been detected by the surgeon or radiation oncologist during control visits and 25 $(60 \%)$ by the patients themselves (Table 5.2.2). Four patients reported pain at the time of diagnosis of SR and one patient had a restricted shoulder function. Of the 42 recurrences 23 had been confirmed by cytological and 17 by histological examination, whereas two had only been confirmed clinically (Table 5.2.2).

Table 5.2.2 Characteristics of 42 patients with isolated supraclavicular recurrence (SR)

\begin{tabular}{|c|c|c|}
\hline Characteristics & No. & $(\%)$ \\
\hline \multicolumn{3}{|l|}{ Time interval to SR (years) } \\
\hline$\leq 2.0$ & 18 & (43) \\
\hline $2.1-5.0$ & 14 & (33) \\
\hline$>5.0$ & 10 & (24) \\
\hline \multicolumn{3}{|l|}{ Detection of SR by: } \\
\hline Patient & 25 & $(60)$ \\
\hline Surgeon or radiation oncologist & 13 & (31) \\
\hline GP & 1 & (2) \\
\hline Unknown & 3 & (7) \\
\hline \multicolumn{3}{|l|}{ Pathological confirmation of SR } \\
\hline Yes, histology & 23 & $(55)$ \\
\hline Yes, cytology & 17 & $(40)$ \\
\hline No & 2 & $(2)$ \\
\hline \multicolumn{3}{|l|}{ Size of SR at palpation $(\mathrm{cm})$} \\
\hline$\leq 2.0$ & 22 & $(52)$ \\
\hline$>2.0$ or multiple nodules & 14 & (33) \\
\hline Unknown & 6 & (14) \\
\hline
\end{tabular}

\section{Treatment}

Radiotherapy was part of the treatment of recurrence for 25 patients (60\%), of whom 5 also underwent surgery and 16 also received chemotherapy or hormonal therapy (Table 5.2.3). Total doses were between $46 \mathrm{~Gy}$ and $61 \mathrm{~Gy}$ for 23 of the 25 patients receiving radiotherapy, usually with fractions of $2.3 \mathrm{~Gy}$ ( 4 or 5 times a week), specified at $30 \mathrm{~mm}$ below the skin surface. Eleven patients received hormonal therapy only and 4 chemotherapy only (Table 5.2.3). One patient received surgical treatment only and one patient remained untreated (Table 5.2.3). Nine patients suffered one or more complaints, persisting more than two months after the treatment of SR. These were: oedema $(n=9)$, pain $(n=1)$, sensory deficit $(n=1)$ and loss of strength $(n=1)$. 
Table 5.2.3 Disease outcome in 42 patients with isolated supraclavicular recurrence (SR), according to type of treatment.

\begin{tabular}{|c|c|c|c|c|c|c|c|c|c|}
\hline \multirow[t]{3}{*}{ Treatment } & \multirow[b]{3}{*}{ No. } & \multirow[b]{3}{*}{ (\%) } & \multicolumn{7}{|c|}{ Disease outcome } \\
\hline & & & \multicolumn{4}{|c|}{ Response to treatment } & \multirow{2}{*}{$\begin{array}{c}\text { Second } \\
\text { relapse in SA* }\end{array}$} & \multirow{2}{*}{$\begin{array}{l}\text { Metastases } \\
\text { at more } \\
\text { distant sites* }\end{array}$} & \multirow{2}{*}{$\begin{array}{l}\text { Still alive } \\
\text { without } \\
\text { evidence of } \\
\text { disease* }\end{array}$} \\
\hline & & & CR & PR & NC & Progression & & & \\
\hline$S$ & 1 & $(2)$ & 1 & 0 & 0 & 0 & 0 & 1 & 0 \\
\hline $\mathrm{S}+\mathrm{RT}$ & 4 & (10) & 4 & 0 & 0 & 0 & 1 & 4 & 0 \\
\hline $\mathrm{S}+\mathrm{RT}+\mathrm{HT}$ & 1 & $(2)$ & 1 & 0 & 0 & 0 & 0 & 0 & 1 \\
\hline $\mathrm{RT}$ & 5 & (12) & 5 & 0 & 0 & 0 & 0 & 4 & 1 \\
\hline $\mathrm{RT}+\mathrm{CT}$ & 2 & $(2)$ & 1 & 1 & 0 & 0 & 0 & 2 & 0 \\
\hline $\mathrm{RT}+\mathrm{HT}$ & 13 & (13) & 13 & 0 & 0 & 0 & 5 & 9 & 2 \\
\hline $\mathrm{CT}$ & 4 & (10) & 4 & 0 & 0 & 0 & 2 & 3 & 1 \\
\hline $\mathrm{HT}$ & 11 & (26) & 6 & 2 & 1 & 2 & 4 & 10 & 1 \\
\hline None & 1 & (2) & $\#$ & $\#$ & $\#$ & $\#$ & $\#$ & 0 & 0 \\
\hline Total & 42 & & 35 & 3 & 1 & 2 & 12 & 33 & 6 \\
\hline
\end{tabular}

$\mathrm{S}=$ surgery; $\mathrm{RT}=$ radiotherapy; $\mathrm{CT}=$ chemotherapy; $\mathrm{HT}=$ hormonal therapy; $\mathrm{CR}=$ complete response; $\mathrm{PR}=$ partial response; $\mathrm{NC}=$ no change; $\mathrm{SA}=$ supraclavicular area

* Follow-up until January 1, 2002; " Not applicable

\section{Remission, Relapse and Survival}

Disease outcome of all 42 patients with SR is presented in Table 5.2.3, according to treatment. Treatment led to complete remission in 35 patients (83\%) and to a partial remission in three patients. No change or progressive disease was observed in three patients. Complete remission was followed by a second relapse in the supraclavicular area in 12 of the 35 patients (34\%). Fourteen of the 42 patients with SR (33\%) developed local recurrence in the breast or chest wall and 33 patients (79\%) developed metastases at a more distant site. Sites of distant disease were: bone $(n=22)$, lung or pleura $(n=11)$, liver $(n=8)$, central nervous system $(n=5)$, contralateral axilla $(n=6)$, contralateral supraclavicular region $(n=5)$, skin $(n=4)$ or other $(n=8)$. Of all 42 patients 30 have died and six (14\%) remained alive without evidence of disease after a follow-up of 4.4, 4.7, 6.3, 6.9, 8.2 and 8.3 years respectively. The five-year actuarial overall survival and distant disease-free survival rate from the date of diagnosis of SR were $38 \%$ (95\% confidence interval (Cl): 23-53) and 22\% (95\% Cl: $8-35$ ) respectively (Figure 5.2.1). The median overall survival time (i.e. the estimated time during which $50 \%$ of the patients had died) was 41 months. 


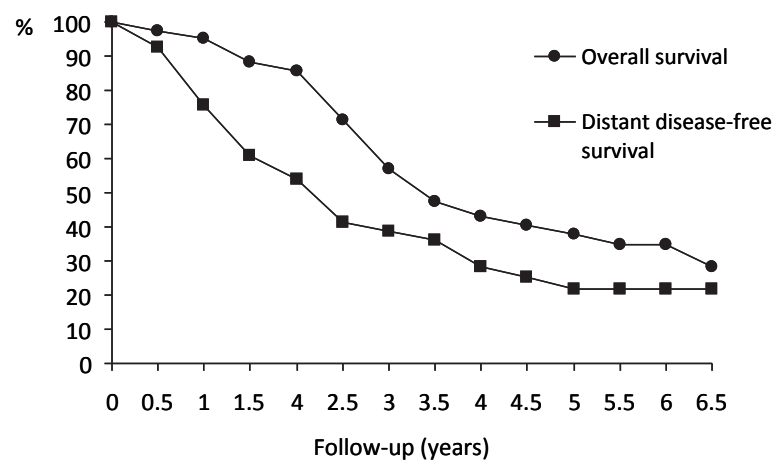

Figure 5.2.1 Overall survival and distant-disease-free survival for 42 patients with isolated supraclavicular recurrence $(S R)$.

The results of univariate analysis of prognostic variables for distant disease-free survival are shown in Table 5.2.4. Distant disease-free survival showed no significant differences when analyzed according to age at diagnosis of SR, time interval from initial surgery to SR, detection of SR (physician vs. patient), size of SR at palpation, size of the primary tumour or lymph node status of the primary tumour (positive vs. negative). Patients with a SR detected by the physician had a somewhat better distant-disease free survival than the patients who detected SR themselves $(P=0.06)$. Distant disease-free survival rate also tended to be better for the 25 patients who underwent radiotherapy as part of the treatment of SR compared to the 17 patients not receiving radiotherapy $(P=0.06)$. The difference became significant after exclusion of the eight patients who had received radiotherapy on the axillary and supraclavicular field before $(P=0.002)$. Of these eight patients only two received radiotherapy for their SR. When looking at other possible prognostic factors, as presented in Table 5.2.1 and Table 5.2.2, no significant differences were observed between the remaining 23 patients who underwent radiotherapy as part of the treatment of SR and the 11 patients not receiving radiotherapy. 
Table 5.2.4 Univariate analysis of factors related to the development of metastases at more distant sites in 42 patients with isolated supraclavicular recurrence (SR)

\begin{tabular}{|c|c|c|c|c|c|}
\hline \multirow[t]{2}{*}{ Variable } & \multirow{2}{*}{$\begin{array}{c}\text { No. of } \\
\text { patients }\end{array}$} & \multicolumn{2}{|c|}{ DM } & \multirow{2}{*}{$\begin{array}{l}\text { Median } \\
\text { survival } \\
\text { (years) }\end{array}$} & \multirow[t]{2}{*}{$P$-value* } \\
\hline & & No. & (\%) & & \\
\hline \multicolumn{6}{|l|}{ Age at diagnosis of SR } \\
\hline$<50$ & 15 & 14 & (93) & 2.3 & 0.80 \\
\hline$\geq 50$ & 27 & 19 & $(70)$ & 1.3 & \\
\hline \multicolumn{6}{|l|}{ Time interval to SR (years) } \\
\hline$\leq 2.0$ & 18 & 13 & $(72)$ & 2.0 & 0.99 \\
\hline$>2.0$ & 24 & 20 & $(83)$ & 2.1 & \\
\hline \multicolumn{6}{|l|}{ Radiotherapy as part of the treatment of SR } \\
\hline Yes & 25 & 19 & (76) & 2.6 & 0.06 \\
\hline No & 17 & 14 & $(82)$ & 1.2 & \\
\hline \multicolumn{6}{|l|}{ Detection of $S R^{a}$} \\
\hline By the patient & 25 & 22 & $(88)$ & 1.6 & 0.06 \\
\hline By the surgeon, radiation oncologist or GP & 14 & 8 & $(57)$ & 4.2 & \\
\hline \multicolumn{6}{|l|}{ Size of SR at palpation $(\mathrm{cm})^{\mathrm{b}}$} \\
\hline$\leq 2.0$ & 22 & 19 & $(86)$ & 1.5 & 0.34 \\
\hline$>2.0$ or multiple nodules & 14 & 9 & $(64)$ & 3.4 & \\
\hline \multicolumn{6}{|l|}{ Size of the primary tumour $(\mathrm{cm})^{c}$} \\
\hline$\leq 2.0$ & 18 & 16 & (89) & 2.3 & 0.98 \\
\hline$>2.0$ & 23 & 16 & $(70)$ & 1.3 & \\
\hline \multicolumn{6}{|l|}{ Lymph node status of the primary tumour } \\
\hline Negative & 13 & 10 & $(77)$ & 2.4 & 0.62 \\
\hline Positive & 29 & 23 & $(79)$ & 2.0 & \\
\hline
\end{tabular}

¥ The estimated time since treatment of SR at which $50 \%$ of patients developed distant metastases;

* Log-rank test

a 3 unknown; ${ }^{b} 6$ unknown; ${ }^{c} 1$ unknown

\section{Discussion}

The rate of isolated SR found in this study was 1.0 percent (42/4669). Because followup information has only been recorded in the cancer registry since 1989, documentation was incomplete for early SR occurring in patients diagnosed between 1984 and 1988. These patients constituted $40 \%$ of the 4669 patients in the study interval. We assume that all patients with a histological or cytological confirmation of SR have been reported to the cancer registry by the pathologists. In the absence of a cytological or histological confirmation we had to rely on the follow-up information provided by the surgeons and the radiotherapists, which might have led to some small underreporting. Taking into account these two sources of incomplete follow-up the real rate of isolated SR was estimated to be approximately $1.5 \%$ to $2 \%$. This is slightly higher than the $0.5 \%$ reported by Halverson et al. in a study of 511 patients with Stage I and II breast cancer ${ }^{4}$. Comparison with other published studies is hampered by differences between the patient series with respect to tumour stage and treatment. Many (older) studies reported a much higher rate of SR because they contained a 
large proportion of patients with tumours larger than $5 \mathrm{~cm}$ or locally advanced breast cancer ${ }^{7,8}$, or patients without axillary dissection, whereas other studies were restricted to patients who underwent radical mastectomy ${ }^{9}$, or to patients with nodepositive breast cancer ${ }^{10}$. Moreover, unlike ours, most of the other studies were not restricted to isolated SR but also included SR occurring with or after other distant metastases. The median interval in our group between first treatment for breast cancer and the SR was 2.5 years comparable with the mean interval of 26 months in the publication of Hirn-Stadler ${ }^{3}$.

The prognosis in patients with SR was poor. The published 5-year overall survival rates of patients with isolated supraclavicular disease vary from $5 \%$ to $41 \%$ and mostly between 20 and $30 \%$. The prognosis of patients with supraclavicular metastases at first presentation and of patients with SR in the course of their disease seems comparable, although in most studies the two groups are not clearly separated. In a previous analysis of 59 breast cancer patients with axillary recurrence after axillary clearance, 5-year overall and distant recurrence-free survival rates were $39 \%(95 \% \mathrm{Cl}$ : 25-53) and $35 \%(95 \% \mathrm{Cl}: 21-50)^{11}$, which is only slightly better than for the patients with SR in the current study. In a study of Fentiman et al. survival of 35 patients with ipsilateral SR after radical mastectomy was compared with the survival of patients with a local skin recurrence and appeared to be intermediate between those with one and multiple skin nodules ${ }^{9}$. According to our results and those of others, tumour control of supraclavicular disease is not the main problem. Of the 42 patients in our series 35 (83\%) had a complete remission, and 12 of these 35 (34\%) experienced local progression during follow-up. So in 23 of the 42 patients (55\%) a long-lasting complete local remission was achieved. The main problem in patients with SR is the development of metastases at more distant sites. The distant disease-free survival after 5 years was only $22 \%$. This means that in most cases isolated SR is a precursor of widespread disseminated disease. More than two-thirds of the patients developed bone metastases and it seems likely that these were already present at the time of diagnosis of SR. Positron Emission Tomography (PET) has been proven to be a very sensitive technique for the detection of bone metastases ${ }^{12,13}$. It is possible that routine evaluation with PET of patients with SR will be able to protract the diagnosis of bone metastases and that this will have a significant effect on treatment planning. There are no specific guidelines for the treatment of patients with SR. Treatment of patients with SR is highly individualized and should be planned within a multidisciplinary team. In our study more than half of the patients underwent multimodality treatment with a combination of surgery, radiotherapy, hormonal treatment or chemotherapy. In the univariate analysis, use of radiotherapy showed a borderline significant association with the development of metastases at more distant sites; i.e., patients with SR receiving radiotherapy were less likely to develop metastases at distant sites other than the supraclavicular region (Table 5.2.4). One should realize that this finding is based on a non-randomised study and may be partly explained by differences in prognostic factors between those that got radiation and those that did 
not, such as prior irradiation. Therefore, we performed a separate analysis excluding all patients who received prior radiotherapy on the axillary and supraclavicular field. Despite the limited number of patients in this analysis, the patients receiving radiotherapy continued to show a significantly better distant recurrence-free survival than the patients not receiving radiotherapy for their SR. A favourable effect of radiotherapy was also found by Abraham et al.; in a series of 20 consecutive women with SR receiving high dose chemotherapy and autologous blood stem cell support they reported a significantly better progression-free survival among the 11 patients who had consolidative radiotherapy to the involved supraclavicular region after transplantation ${ }^{14}$. The median survival of their patients was 37 months, which is almost similar to the 41 months of our patients.

The optimum treatment for SR is not known. Radiotherapy accomplishes a reasonable local control, but the value of systemic therapy is less clear. In a small randomised trial of Pergolizzi et al., comparing chemotherapy alone $(n=18)$ with induction chemotherapy followed by radical radiation therapy $(n=19)$, the 5 -year overall survival rates were $17 \%$ and $36 \%$ respectively $(P=0.12)^{15}$. Another small trial showed a better disease-free survival (no better overall survival) after the addition of tamoxifen to radiotherapy in the treatment of breast cancer patients with predominantly chest wall recurrences or skin metastases ${ }^{16}$. Some authors recommend aggressive multimodality treatment because of the relatively small tumour burden of supraclavicular disease ${ }^{8,14}$. Brito et al. from The University of Texas M.D. Anderson Cancer Center found a significantly better survival after multi-modality treatment in 70 patients with solitary ipsilateral supraclavicular metastasis at first presentation compared with patients with non supraclavicular metastatic disease ${ }^{8}$. They advocated the inclusion of supraclavicular disease in the stage III and not in the stage IV category, because this may lead to undertreatment. Their recommendation has been followed by the UICC in the latest edition of the TNM Classification of Malignant Tumors; patients with metastases in supraclavicular lymph nodes are now classified as N3c/pN3c and a new stage (stage IIIC) has been introduced that includes any T N3 (pN3a, pN3b, pN3c) $\mathrm{MO}^{17,18}$. In the previous editions these patients had been classified as distant metastasis (M1), which is stage IV disease.

Patients with SR have a poor prognosis, probably similar to patients with supraclavicular disease at first presentation of breast cancer. However, it is slightly better than for patients with metastatic disease at other sites. Involved field radiotherapy, in addition to systemic treatment, seems to play an important role in achieving local control of disease and may even improve the distant recurrence-free survival rate. 


\section{References}

1. Debois JM. The significance of a supraclavicular node metastasis in patients with breast cancer. A literature review. Stralenther Onkol 1997;173:1-12.

2. Hietanen $\mathrm{P}$, Miettinen $\mathrm{M}$, Makinen J. Survival after first recurrence in breast cancer. Eur J Cancer Clin Oncol 1986;22:913-9

3. Hirn-Stadler B. The supraclavicular recurrence from breast cancer. Stralenther Onkol 1990;166:774-7.

4. Halverson KJ, Perez CA, Kuske RR, Garcia DM, Simpson JR, Fineberg B. Survival following locoregional recurrence of breast cancer: univariate and multivariate analysis. Int J Radiat Oncol Biol Phys 1992;23:285-91

5. Kiricuta IC, Willner J, Kölbl O, Bohndorf W. The prognostic significance of the supraclavicular lymph node metastases in breast cancer patients. Int J Radiat Oncol Biol Phys 1993;28:387-93.

6. Voogd AC, van Beek MW, Crommelin MA, Kluck HM, Repelaer van Driel OJ, Coebergh JW. Management of early breast cancer in the Southeastern Netherlands since 1984: a population based study. Regional Breast Cancer Study Group. Acta Oncol 1994;33:753-7.

7. Jackson SM. Carcinoma of the breast--the significance of supraclavicular lymph node metastases. Clin Radiol 1966;17:107-14

8. Brito RA, Valero V, Buzdar AU, Booser DJ, Ames F, Strom E, Ross M, Theriault RL, Frye D, Kau SW, Asmar L, McNeese M, Singletary SE, Hortobagyi GN. Long-term results of combined-modality therapy for locally advanced breast cancer with ipsilateral supraclavicular metastases: the University of Texas M.D. Anderson Cancer Centre Experience. J Clin Oncol 2001;19:628-33.

9. Fentiman IS, Lavelle MA, Caplan D, Miller N, Millis RR, Hayward JL. The significance of supraclavicular fossa node recurrence after radical mastectomy. Cancer 1986;57:908-1009.

10. Treurniet-Donker AD, Helle PA, van Putten WL. Adjuvant post-operative radiotherapy in operable node positive mammary cancer: a comparison of three treatment protocols. Int J Radiat Oncol Biol Phys 1986;12:2067-72.

11. De Boer R, Hillen HF, Roumen RM, Rutten HJ, van der Sangen MJ, Voogd AC. Detection, treatment and outcome of axillary recurrence after axillary clearance for invasive breast cancer. $\mathrm{Br} J$ Surg 2001;88:118-22.

12. Cook GJ, Houston S, Rubens R, Maisey MN, Fogelman I. Detection of bone metastases in breast cancer by 18FDG PET: differing metabolic activity in osteoblastic and osteolytic lesions. J Clin Oncol 1998;16:3375-9.

13. Schirrmeister H, Guhlmann A, Kotzerke J, Santjohanser C, Kühn T, Kreienberg R, Messer P, Nüssle K, Elsner K, Glatting G, Träger H, Neumaier B, Diederichs C, Reske SN. Early detection and accurate description of extent of metastatic bone disease in breast cancer with fluoride ion and positron emission tomography. J Clin Oncol 1999;17:2381-9.

14. Abraham R, Nagy T, Goss PE, Crump M. High dose chemotherapy and autologous stem cell support in women with breast carcinoma and isolated supraclavicular lymph node metastases. Cancer 2000;88:790-5.

15. Pergolizzi S, Settineri N, Santacaterina A, Spadaro P, Maisano R, Caristi N, Adamo V, De Renzis C, Mesiti M, Cascinu S. Ipsilateral supraclavicular lymph node metastases from breast cancer as only site of disseminated disease. Chemotherapy alone vs. induction chemotherapy to radical radiation therapy. Ann Oncol 2001;1091-5.

16. Borner M, Bacchi M, Goldhirsch A, Greiner R, Harder F, Castiglione M, Jungi WF, Thürlimann B, Cavalli $\mathrm{F}$, Obrecht JP, et al. First isolated loco-regional recurrence following mastectomy for breast cancer: results of a phase III multicenter study comparing systemic treatment with observation after excision and radiation. Swiss Group for Clinical Cancer Research. J Clin Oncol 1994;12:1071-7.

17. Sobin LH, Wittekind C (eds.). TNM classification of maligant tumors. 6th edition. New-York: Wiley, 2002:131-41.

18. Singletary SE, Allred C, Ashley P, Bassett LW, Berry D, Bland KI, Borgen PI, Clark G, Edge SB, Hayes DF Hughes LL, Hutter RV, Morrow M, Page DL, Recht A, Theriault RL, Thor A, Weaver DL, Wieand HS, Greene FL. Revision of the American Joint Committee on Cancer staging system for breast cancer. J Clin Oncol 2002;20:3628-36. 


\section{Chapter 6}

General discussion and future perspectives 


\section{General discussion and future perspectives}

New insights into the pathogenesis of breast cancer have led to remarkable improvements in the diagnosis, treatment and cure rates of this disease over a relatively short period of time. Locoregional tumour control has also improved considerably in the past decades, in such a way that locoregional recurrence can now be considered as a rare event, with a risk well below $5 \%$ after 5 years, even in young patients $^{1,2}$.

\section{Local recurrence}

In a Dutch study among breast cancer patients who had been operated between 2003 and $2006(n=31992)$, the local recurrence rates after 5 years were $2.0 \%$ and $3.2 \%$ after breast-conserving therapy (BCT) and mastectomy respectively. (van der Heiden, EJC, submitted for publication) One of the studies in this thesis proved that these low percentages are also attainable for young patients nowadays ${ }^{2}$. It showed a drop in the five-year local recurrence rate from $9.8 \%$ in the period $1988-1998$ to $3.3 \%$ in the period 2006-2010. The high risks of local recurrence of $2 \%$ per year or more, reported in the eighties and nineties of the previous century, rightfully raised doubts about the safety of BCT for young women. However, based on aforementioned results, BCT turns out to have become a safe treatment for the vast majority of patients with a T1-2 breast cancer, irrespective of their age. On the other hand, the use of (neo)adjuvant systemic therapy appears to be a prerequisite to obtain a favourable result, especially for young patients.

Although BCT has been proven to be a safe treatment for young women, its safety still remains a matter of debate for patients who are known to be BRCA1/2 mutation carrier $^{3}$. Equal as well as higher risks of local recurrence can be found in the literature for BRCA1/2 mutation carriers compared to non-carriers ${ }^{4-6}$. Up to now no survival advantage of ipsilateral mastectomy for breast cancer patients with a BRCA $1 / 2$ mutation has been demonstrated ${ }^{5}$. The risk of contralateral breast cancer is remarkably high $^{7,8}$. The preventive effects of adjuvant systemic therapy or oophorectomy on the incidence of local recurrence and contralateral breast cancer also apply to BRCA mutation carriers ${ }^{6,8}$.

\section{Regional recurrence}

A regional tumour recurrence is an even rarer event than a local recurrence, and the risk has remained low with the introduction of the sentinel lymph node dissection. The axillary recurrence rate in the ACOSOG Z0011 trial, which included patients with one or two positive sentinel nodes, was $0.5 \%$ after additional axillary dissection and $0.9 \%$ after sentinel lymph node dissection alone, after a median follow-up of 6.3 years $^{9,10}$. Neither locoregional recurrence, nor survival between both groups differed 
significantly. The IBCSG 23-01 multicentre, phase 3 trial randomised patients with micrometastatic sentinel node involvement between axillary dissection and no axillary dissection ${ }^{11,12}$. The majority of patients (91\%) underwent breast-conserving surgery. After a median follow-up of 5 years there was no difference in disease-free survival or overall survival between the two arms. Also in this trial the axillary recurrence rates were low $(0.2 \%$ for the axillary dissection group and $1.1 \%$ for the observation group). These two landmark studies led to the recommendation to omit axillary dissection after breast-conserving surgery and breast radiation in patients with T1-2 breast cancer with a limited tumour burden in the sentinel nodes. As an additional condition, these women should be treated with adjuvant systemic therapy. For patients with micrometastatic sentinel node involvement undergoing mastectomy or partial breast irradiation omitting of axillary dissection might be acceptable, although the numbers in the subgroup analysis were too small to draw definitive conclusions ${ }^{11}$. Also in these patients regional recurrence rates tend to increase to considerably higher levels if they are not receiving systemic treatment ${ }^{13}$.

Results in this thesis show that the risk of a clinically apparent relapse of the tumour in the parasternal lymph nodes is negligible. This low risk contrasts sharply with the relatively high percentage of positive sentinel nodes in the parasternal region ${ }^{14}$. Apparently, only a small part of the patients with positive nodes will develop clinically manifest disease in this area. This phenomenon is already well established for axillary metastases ${ }^{15}$.

\section{Explaining improved locoregional tumour control}

The causes of the strongly improved locoregional tumour control are diverse. Improvements have occurred in the entire chain of breast cancer diagnosis and treatment.

In the field of imaging for instance, diagnostically led biopsies of abnormalities in the breast, using mammography, ultrasonography or MRI, have replaced diagnostic excisional biopsies. MRI is increasingly used preoperatively to visualize the tumour extension and can reduce the rate of tumour-positive resection margins ${ }^{16}$. Ultrasonography and cytological examination have become routine procedures in the clinical assessment of the axilla. More recently, digital mammography has been introduced, which has further increased the detection rate of the screening programme $^{17}$. The BI-RADS classification is a fixed part in the diagnostic final assessment now.

Major developments have been achieved in the field of pathology as well. Tumour characteristics, such as histological type, size, grade, margin involvement, hormonal and HER2 receptor status and nodal status, are documented in a standardized pathology report, which is the basis of an individualized treatment plan. The use of a standardized pathology report has been set as a performance indicator in the NABON Breast Cancer Audit (NBCA). During the last decades, immunohistochemistry has 
gained permanent footing within pathology. New factors, such as the HER2 status have been added and validated nationally. Increased knowledge of prognostic factors for locoregional recurrence has resulted in a more evidence-based selection of patients for breast-conserving surgery and mastectomy. Much more effort is put in the microscopically complete removal of the tumour. Non-palpable tumours are localised preoperatively and radioactive seed localisation seems to be superior to the traditional wire-guided localisation in terms of involved margin status and reoperation rates ${ }^{18}$. Each tumour specimens is inked to allow a detailed histological assessment of the resection margins and a re-excision is usually performed when positive surgical margins are observed with more than focal irradicality.

Postoperative radiotherapy reduces locoregional and distant recurrence and improves survival ${ }^{19,20}$. An overview of randomised trials with local treatment comparisons showed that, in the hypothetical absence of other causes of death, about one breast cancer death over the next 15 years would be avoided for every four local recurrences avoided $^{19}$. A recent meta-analysis from the Early Breast Cancer Trialists' Collaborative Group (EBCTCG) made it clear that after breast-conserving surgery, radiotherapy to the conserved breast halves the rate at which the disease recurs (locoregional or distant) and reduces the breast cancer death rate by about a sixth ${ }^{20}$. Radiotherapy has made progress both in the field of patient selection and applied technology. CT-based computer planning with three dimensional conformal radiotherapy (3D-CRT) and intensity modulated radiotherapy (IMRT) techniques are widely used nowadays and guarantee a more precise determination of the so-called target volume and a more adequate and homogeneous dose distribution. For breast irradiation after breastconserving surgery, part of the patients is given an extra dose of irradiation (boost) on the tumour bed. The fact that a higher dose leads to more fibrosis and thus leads to a worse cosmetic outcome was already known. Initially, it was not well-known whether a boost was always really necessary. The value of adding a boost dose has finally been demonstrated through European randomised research ${ }^{21}$. A boost dose of $16 \mathrm{~Gy}$ provides the same relative reduction of the recurrence rate for all age categories, but leads to a substantial, absolute risk reduction of more than $10 \%$ after 10 years for women aged 40 years or younger.

A problem concerning the current indications for locoregional radiotherapy is the fact that they are derived from studies performed at a time when systemic therapy was much less effective and applied at a much more limited scale. The question remains whether or not these indications would still stand up to scrutiny with the systemic treatment regimens which are currently in use.

The largest contribution to the improved locoregional tumour control has certainly been made by the increased use of (neo)adjuvant systemic therapy. Most studies point at a reduction of the risk of locoregional recurrence by at least $50 \%$ by administering adjuvant systemic therapy. According to our studies performed in the south of the Netherlands, the use of systemic therapy for resectable, non-metastatic breast cancer has more than doubled, especially since the turn of the century ${ }^{2}$. For 
instance, in the period $1988-1998,32 \%$ of patients with breast cancer of 40 years and younger received (neo)adjuvant systemic therapy against $83 \%$ in the period 2006 2010. This remarkable increase started after the publication of the results of numerous randomised trials on the effects of adjuvant administration of tamoxifen and polychemotherapy, as summarized in the meta-analysis by the EBCTCG in 1998. This meta-analysis provided convincing evidence that adjuvant systemic treatment is very effective in reducing the risk of locoregional and distant relapse of breast cancer and improving overall survival ${ }^{22,23}$. To this end, the indications for adjuvant systemic treatment have been extended for an ever-increasing group of patients over the years. A more recent update of the EBCTCG meta-analysis has confirmed the increased survival after adjuvant polychemotherapy ${ }^{24}$.

Apart from expanding the indications for adjuvant systemic treatment, new drugs have also been developed. For instance, aromatase inhibitors were introduced at the end of the nineties of the previous century. These turned out to be effective agents for post-menopausal patients both in the (neo)adjuvant and metastatic setting. For chemotherapy, the classical CMF regimen made way for anthracycline-containing combinations in the nineties. In more recent years, taxanes were added to this. In about $10-15 \%$ of the patients overexpression of the so-called human epidermal growth factor receptor 2 (HER2+) is observed. This is an unfavourable prognostic factor for both local recurrence and survival and is consistent with aggressive tumour behaviour. Randomised trials have demonstrated that the addition of trastuzumab to chemotherapy in patients with a HER2-positive tumour results in an improvement of the disease-free survival of approximately $40 \%{ }^{25}$. After the publication of these convincing results the use of trasuzumab in the adjuvant setting was recommended in the Dutch guidelines in 2005 and rapidly implemented in all Dutch hospitals ${ }^{26}$.

The increased use of systemic therapy and the simultaneous availability of more effective means, such as anthracyclines, taxanes and trastuzumab did not only reduce the risk of breast cancer-related death, but also the risk of locoregional recurrence. This effect is most pronounced for patients with high-risk disease, such as triple negative and HER2-positive breast cancer ${ }^{27-29}$.

\section{Follow-up after breast cancer treatment}

Early discovery of isolated locoregional recurrence and contralateral breast cancer for patients without symptoms has been proven to have a positive effect on survival, as compared to detection in a symptomatic stage $\mathrm{e}^{30}$. However, the yield and thus the cost-effectiveness of routine follow-up to detect a locoregional recurrence or contralateral breast cancer are low, especially for young women ${ }^{31,32}$. Despite frequent mammographic and clinical examination, more than half of all local recurrences appearing in young women are discovered by the patients themselves ${ }^{32}$. The same is true for the discovery of contralateral breast cancer in this group. (Koedijk, accepted for publication, EJSO) 


\section{Treatment for locoregional recurrent disease}

Both local and regional recurrences have a negative impact on the prognosis of patients with breast cancer ${ }^{33,34}$. As described in this thesis, the prognosis of a local recurrence tends to be more favourable if it occurs after a relatively long disease-free interval, preferably of 5 years or more. This better prognosis is ascribed to the fact that, in many cases, these late recurrences are not 'true recurrences', which are often an expression of an aggressive phenotype, but new primary tumours.

The life expectancy after treatment of an axillary or supraclavicular recurrence, occurring in patients undergoing axillary lymph node dissection, is much less favourable than after a local recurrence ${ }^{33-35}$. However, here too, cure is possible, provided that multimodality treatment is given ${ }^{36,37}$.

At the end of 2012, the results of the CALOR trial were made public at the San Antonio Breast Cancer Conference. This randomised trial studied the added value of chemotherapy after local therapy in patients with an isolated locoregional recurrence. After 5 years, an absolute survival advantage of $12 \%$ in the chemotherapy group was visible. The sample size of the trial was too small for subgroup analyses. In any case, the CALOR trial gives us proof that it is meaningful to treat locoregional recurrences aggressively, both locally and systemically.

\section{Lobular breast cancer}

Lobular breast cancer is the second-most prevalent histological type after ductal breast cancer and comprises approximately $11 \%$ of all breast cancers in the Netherlands ${ }^{38,39}$. It is often difficult to determine the margins and extent of these tumours, both by physical examination and by conventional imaging. Most lobular breast cancers are low-grade, ER+ and HER2-, consistent with the Luminal A subtype. In general, they have a course and prognosis comparable to invasive ductal breast cancer of the Luminal A type. This might explain the relative insensitivity to chemotherapy when used in a neo-adjuvant setting and possibly also in the adjuvant setting ${ }^{40}$. Our observation that there appears to be an increased sensitivity of lobular breast cancer to radiotherapy, contrary to the relative insensitivity to chemotherapy, is striking. Despite the high risk of patients with lobular cancer of having tumourpositive surgical margins after breast-conserving surgery (17\%), their local recurrence rate following post-operative radiotherapy was surprisingly low $(6.4 \%$ after 8 years actuarial) ${ }^{41}$. This increased radiosensitivity is confirmed by others ${ }^{42,43}$. There is ample evidence from these and other studies that local recurrence rates after BCT are similar for patients with lobular or ductal carcinoma, indicating that lobular histology by itself should not be a contra-indication for $\mathrm{BCT}^{44-46}$. As was shown by us, post-mastectomy thoracic wall irradiation also proved to be very effective for patients with lobular breast cancer ${ }^{47}$. Despite a less favourable tumour stage, the 5-year local tumour control rate of the irradiated patients was considerably better than for the patients 
who did not receive radiotherapy (2.1\% versus $8.7 \%$ ), even after adjustment for various potential confounding factors, including adjuvant systemic therapy.

\section{Future perspectives}

Intensity, toxicity and effectiveness of treatment often go hand in hand. When effectiveness of the total treatment is high, the question arises whether or not a less intensive and thus less toxic approach can suffice for one or more modalities without having to sacrifice too much effectiveness. The multimodality treatment of Hodgkin's lymphoma is a good example of this approach. Using consecutive and well-attuned randomised studies, the therapy has been adjusted and refined over the past decades $^{48}$. With the knowledge from these trials, patient and disease characteristics have been translated into an individual risk profile which eventually determines which treatment regimen should be used. In this way, the toxicity of the treatment has been reduced for most patients without substantially reducing the chances for cure. The most intensive treatment is reserved for patients with the most unfavourable prognosis from the start. A similar development is currently taking place in the treatment of breast cancer.

\section{Towards less extensive locoregional therapy}

In the 1970s it became clear that the Halstedian surgical techniques were not a prerequisite for good local tumour control. By now, lumpectomy with additional radiotherapy has become a widely accepted, alternative approach. Up to the 1990s, the axillary dissection was the standard lymph node staging procedure. Based on research, the concept of the sentinel node turned out to be valid and became the standard treatment for clinically node-negative patients since the beginning of this century. This has led to a considerable decrease in morbidity with respect to lymphatic oedema, pain and shoulder dysfunction while maintaining comparable regional tumour control and survival ${ }^{49}$. In 2010, the aforementioned ACOSOG Z0011 study and in 2013 the IBCSG 23-01 study heralded a further shift towards a less prominent role for the surgeon $^{9-11}$. For patients treated with BCT and limited sentinel node involvement, it is safe to refrain from axillary dissection if followed by adjuvant systemic therapy and whole breast irradiation. The AMAROS trial compared the effectiveness of axillary lymph node dissection with that of axillary and periclavicular radiation in women with sentinel node-positive breast cancer ${ }^{50}$. Results presented at ASCO 2013 showed comparable regional control but radiotherapy has been shown to halve the incidence of lymphedema. It is expected that ultimately the indication for an axillary dissection will be limited to patients with extensive nodal involvement at clinical examination. In the context of an even more limited locoregional approach, the question arises whether or not additional examination and local treatment is 
necessary for the clinically negative axilla and even the sentinel node-positive axilla ${ }^{51}$. Current research and research in the immediate future will clarify these issues in the years to come.

The use of radiotherapy has decreased over the past years too. Hypofractionation, that is radiotherapy with a larger than $2 \mathrm{~Gy}$ dose per fraction and with a lower total number of fractions over a shorter period of time, is currently widely used in breast cancer treatment. The effectiveness and safety of this approach has been confirmed by long-term results of large-scale English and Canadian trials ${ }^{52-54}$. Hypofractionation actually has become the standard, meaning that the total duration of radiotherapy has been reduced to 3-4 weeks from over 5-6 weeks with equal or even lower toxicity. A further reduction in the number of fractions is currently being studied in the English FAST and FAST FORWARDS trials ${ }^{55}$. In the latter trial there is a limitation of only 1 week of irradiation in 5 sessions of the whole breast. If effectiveness is proven, this will mean an enormous reduction in manpower, means and funds.

Another development within radiotherapy is the so-called accelerated partial breast irradiation (APBI). Older trials by the NSABP and also European studies with lumpectomy without radiotherapy already revealed that most of the local recurrences occur in the direct vicinity of the primary tumour ${ }^{56-58}$. Studies by Holland et al. provide an explanation for this ${ }^{59}$. The highest cell density of remaining tumour cells outside of the primary tumour are found in the shell around the original tumour area. This implies that it is perhaps sufficient to only irradiate the area in the direct proximity of the tumour instead of the total breast. Partial irradiation of the breast can be applied in various ways. Examples are brachytherapy, intraoperative external irradiation with electrons or photons and postoperative irradiation with photons or protons. The techniques all have the same goal, namely eradicating residual tumour cells. However, the dose distribution and fractionation of the various forms of ABPI are very different, which can have substantial impact on outcome. At the moment, worldwide large randomised studies are under way totalling more than 16000 patients. Results of earlier studies with APBI are promising, but caution is required. For instance, some recent analyses showed an increased toxicity and increased chance of local recurrence ${ }^{60,61}$. Apart from the choice of the most optimal technique, the challenge lies in the selection of exactly those subgroups of breast cancer patients that benefit from this form of radiotherapy.

From the start of the application of BCT, leaving out radiotherapy for patient groups with favourable prognostic factors has been attempted. The BASO II trial randomised 1135 patients with an invasive, node negative breast cancer $(<2 \mathrm{~cm}$, grade 1 or prognostically favourable subtype) between wide lumpectomy, lumpectomy plus radiotherapy, lumpectomy plus tamoxifen and lumpectomy plus radiotherapy and tamoxifen $^{62}$. After a median follow-up of 10 years, annual local recurrence rates published in 2013 were $1.9 \%, 0.7 \%, 0.8 \%$ and $0 \%$, respectively. Ten other randomised studies considered all together also showed a high incidence of local recurrence up to $26 \%$ after 5 years in patients undergoing lumpectomy only ${ }^{19}$. Up to now, attempts 
have not been successful to define a patient subgroup with a recurrence rate of less than $1 \%$ per year with lumpectomy alone.

Over the past years, due to breast cancer screening and the improved quality of the (now digital) mammography techniques, there has been a marked increase in the number of patients with in situ carcinoma ${ }^{17}$. The fact that only a part of all untreated in situ carcinomas will eventually develop into an invasive carcinoma is known. Here, too, the question arises for which type of in situ carcinoma radiotherapy or even surgery can be safely withheld. Just like for invasive breast cancer, published studies have been unable to define a subset of patients with in situ carcinoma that has an annual recurrence rate of less than $1 \%$ without radiotherapy ${ }^{63,64}$.

Even though the aforementioned is a description of a number of trends that limit or attempted to limit the role of radiotherapy, at the same time trials are still ongoing that study the potential benefits of extending the indications for radiotherapy. The EORTC 22922/10925 trial investigates the potential survival benefit and toxicity of elective irradiation of the internal mammary and medial supraclavicular nodes in stage I-III breast cancer ${ }^{65}$. The intergroup MA20 trial studies whether adding regional nodal radiation to modern systemic therapy improves survival with acceptable limited toxicity in moderate to high risk patients undergoing breast-conserving therapy ${ }^{66}$. The 5 -year results already showed a $5 \%$ reduction in disease-free survival and distant disease-free survival. There was a strong trend towards improved overall survival. The SUPREMO trial has been designed to assess the role of chest wall irradiation in women with intermediate risk breast cancer following mastectomy ${ }^{67}$. Finally, we may mention the YOUNG BOOST trial, which started in 2004 because of the high local recurrence rate ( $>1 \%$ per year) in young women after BCT in the previous decades. In this trial the effect of an additional boost dose to the tumor bed (26 Gy versus $16 \mathrm{~Gy}$ ) on local recurrence and cosmetic outcome is explored. With today's low recurrence rates in young patients it seems unlikely that this trial will find a clinically meaningful benefit. The results of these trials are to be expected within now and 5 years.

\section{Personalised treatment and follow-up}

Breast cancer is a heterogeneous disease with many subtypes, each with a different course. Recognising these subtypes with their specific characteristics is essential for the progress of breast cancer care. The future lies in so-called 'personalised' locoregional and systemic treatment. For this, it is necessary to be able to make a reliable assessment of the risk of locoregional and distant relapse and to subsequently predict to which extent each specific treatment modality and their combinations can contribute to cure and prolonging of life expectancy. The size of the absolute risk reduction of tumour recurrence and death is dependent on the absolute risks of these events.

As mentioned above, the application of adjuvant systemic therapy has increased strongly from the turn of the century onwards. The majority of the lymph node- 
negative patients is currently receiving systemic therapy, based on the survival advantage that has been demonstrated in trials and that can be estimated for each individual patient by decision making tools like Adjuvant! Online or Predict. However, most breast cancers are low-grade, ER+, HER2- and, as such, usually of the so-called Luminal A subtype. For a substantial part of these patients, the disease has an inherently, relatively favourable course and little extra advantage is to be expected of adjuvant chemotherapy. At this time, however, it is not possible to make a sufficiently clear distinction between the patients within this large and rather heterogeneous group for which the effect of additional chemotherapy does or does not offset the extra toxicity. Over the last decade genomic assays like Mammaprint and Oncotype DX have been introduced as a treatment decision aid for physicians and breast cancer patients. However, these genetic biomarkers mainly still have a prognostic value. Additional proof of the predictive value will have to be demonstrated by various large, prospectively randomised validation studies, such as the MINDACT and the TAILORX trial. Besides predictive tests for the effects of systemic therapy, predictive profiles for the effect of radiotherapy are currently worked on ${ }^{68,69}$. These types of new tools, together with specific clinical and pathological factors, should provide a better prediction of the prognosis and the expected risk reduction of treatment in the near future. Treatments can then be administered selectively for those patients who truly need it and for whom, at the same time, there is a reasonable chance of success in proportion with the added toxicity. That extra toxicity is involved with such treatment is beyond doubt. Breast cancer treatment in general and systemic treatment in particular has a large impact on many aspects of life. Apart from quality of life, the issue of fertility and the desire to have children are also important to young patients ${ }^{70}$. With respect to the follow-up of breast cancer patients, our and other studies have demonstrated that the role of physical examination is very limited and that for young women the sensitivity of mammography is insufficient mainly due to the dense structure of their breast tissue. This is especially worrisome considering the high risk of contralateral breast cancer and its impact on prognosis in young women ${ }^{71,72}$. In the field of imaging, rapid developments are taking place that can improve the chance of early detection of a recurrence or new primary tumour. For instance, the added value of the 3D ultrasound is promising and future studies will possibly indicate when MRI can be used earlier on in selected cases $^{73}$.

Apart from the efficiency, the frequency and content of the follow-up visit is up for discussion ${ }^{74}$. More weight should be given to the actual needs, and the risk profile of the patient in question when drawing up a follow-up plan. Similar to what is happening in the treatment, it is expected that breast cancer follow-up will become more 'personalised' and at the same time more cost-effective.

Translation of results of randomised trials into daily practice can sometimes be difficult due to selective inclusion of patients. That is why population-based studies are still necessary to monitor the effectiveness and safety of new interventions and to serve as a feedback instrument for care providers in their day-to-day medical practice. 
With the help of population-based cancer registries it is possible to draw unselected samples of patients to answer such clinically relevant questions. For example, without population-based registries, such as the Eindhoven Cancer Registry, it would have been impossible for us to demonstrate the strongly improved local control after BCT for women of 40 years or younger. It is expected that these results will take away some of the existing reluctance among surgeons and radiation oncologists to apply this treatment to young women. Now that locoregional recurrence has become a rarity, the question arises as to whether it is still a reliable quality indicator and its time-consuming monitoring by the cancer registry can be discontinued. Like cancer care, cancer registration needs to be dynamic and prioritise. New quality parameters will arise, although old determinants can still be of great value in a research context under changing policy. 


\section{References}

1. Lammers EJ, Huibers $\mathrm{P}$, van der Sangen MJ, et al. Factors contributing to improved local control after mastectomy in patients with breast cancer aged 40 years or younger. Breast 2010;19:44-9.

2. van Laar C, van der Sangen MJ, Poortmans PM, et al. Local recurrence following breast-conserving treatment in women aged 40years or younger: Trends in risk and the impact on prognosis in a population-based cohort of 1143 patients. Eur J Cancer 2013.

3. Croshaw RL, Marshall ML, Williams TL, Erb KM, Julian TB. Prophylactic and Therapeutic Breast Conservation in BRCA1/2 Mutation Carriers. Int J Breast Cancer 2011;2011:481563.

4. Garcia-Etienne CA, Barile M, Gentilini OD, et al. Breast-conserving surgery in BRCA1/2 mutation carriers: are we approaching an answer? Ann Surg Oncol 2009;16:3380-7.

5. Kirova YM, Savignoni A, Sigal-Zafrani B, et al. Is the breast-conserving treatment with radiotherapy appropriate in BRCA1/2 mutation carriers? Long-term results and review of the literature. Breast Cancer Res Treat 2010; 120:119-26.

6. Pierce LJ, Phillips KA, Griffith KA, et al. Local therapy in BRCA1 and BRCA2 mutation carriers with operable breast cancer: comparison of breast conservation and mastectomy. Breast Cancer Res Treat 2010;121:389-98.

7. Graeser MK, Engel C, Rhiem K, et al. Contralateral breast cancer risk in BRCA1 and BRCA2 mutation carriers. J Clin Oncol 2009;27:5887-5892.

8. Metcalfe K, Gershman S, Lynch HT, et al. Predictors of contralateral breast cancer in BRCA1 and BRCA2 mutation carriers. Br J Cancer 2011;104:1384-92.

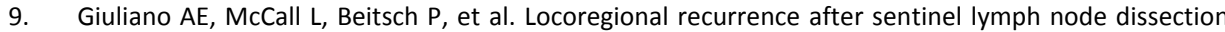
with or without axillary dissection in patients with sentinel lymph node metastases: the American College of Surgeons Oncology Group Z0011 randomized trial. Ann Surg 2010;252:426-32; discussion 32-3.

10. Giuliano $\mathrm{AE}$, Hunt $\mathrm{KK}$, Ballman $\mathrm{KV}$, et al. Axillary dissection vs no axillary dissection in women with invasive breast cancer and sentinel node metastasis: a randomized clinical trial. JAMA 2011;305: 569-75.

11. Galimberti V, Cole BF, Zurrida S, et al. Axillary dissection versus no axillary dissection in patients with sentinel-node micrometastases (IBCSG 23-01): a phase 3 randomised controlled trial. Lancet Oncol 2013;14:297-305.

12. Benson JR. Management of breast-cancer patients with sentinel-node micrometastases. Lancet Oncol 2013;14:266-7.

13. Pepels $\mathrm{MJ}$, de Boer $\mathrm{M}$, Bult $\mathrm{P}$, et al. Regional recurrence in breast cancer patients with sentinel node micrometastases and isolated tumor cells. Ann Surg 2012;255:116-21.

14. Heuts EM, van der Ent FW, von Meyenfeldt MF, Voogd AC. Internal mammary lymph drainage and sentinel node biopsy in breast cancer - A study on 1008 patients. Eur J Surg Oncol 2009;35:252-7.

15. Fisher B, Jeong JH, Anderson S, Bryant J, Fisher ER, Wolmark N. Twenty-five-year follow-up of a randomized trial comparing radical mastectomy, total mastectomy, and total mastectomy followed by irradiation. N Engl J Med 2002;347:567-75.

16. Obdeijn IM, Tilanus-Linthorst MM, Spronk S, et al. Preoperative breast MRI can reduce the rate of tumor-positive resection margins and reoperations in patients undergoing breast-conserving surgery. Am J Roentgenol 2013;200:304-10.

17. Nederend J, Duijm LE, Louwman MW, Groenewoud JH, Donkers-van Rossum AB, Voogd AC. Impact of transition from analog screening mammography to digital screening mammography on screening outcome in The Netherlands: a population-based study. Ann Oncol 2012;23:3098-103.

18. Ahmed M, Douek M. Radioactive seed localisation (RSL) in the treatment of non-palpable breast cancers: Systematic review and meta-analysis. Breast 2013.

19. Clarke M, Collins R, Darby S, et al. Effects of radiotherapy and of differences in the extent of surgery for early breast cancer on local recurrence and 15-year survival: an overview of the randomised trials. Lancet 2005;366:2087-106.

20. Darby S, McGale P, Correa C, et al. Effect of radiotherapy after breast-conserving surgery on 10-year recurrence and 15-year breast cancer death: meta-analysis of individual patient data for 10,801 women in 17 randomised trials. Lancet 2011;378:1707-16. 
21. Bartelink H, Horiot JC, Poortmans PM, et al. Impact of a higher radiation dose on local control and survival in breast-conserving therapy of early breast cancer: 10-year results of the randomized boost versus no boost EORTC 22881-10882 trial. J Clin Oncol 2007;25:3259-65.

22. Tamoxifen for early breast cancer: an overview of the randomised trials. Early Breast Cancer Trialists' Collaborative Group. Lancet 1998;351:1451-67.

23. Polychemotherapy for early breast cancer: an overview of the randomised trials. Early Breast Cancer Trialists' Collaborative Group. Lancet 1998;352:930-42.

24. Peto R, Davies C, Godwin J, et al. Comparisons between different polychemotherapy regimens for early breast cancer: meta-analyses of long-term outcome among 100,000 women in 123 randomised trials. Lancet 2012;379:432-44.

25. Moja L, Tagliabue L, Balduzzi S, et al. Trastuzumab containing regimens for early breast cancer. Cochrane database of systematic reviews (Online) 2012;4:CD006243.

26. de Munck L, Schaapveld M, Siesling S, et al. Implementation of trastuzumab in conjunction with adjuvant chemotherapy in the treatment of non-metastatic breast cancer in the Netherlands. Breast Cancer Res Treat 2011;129:229-33.

27. Voduc KD, Cheang MC, Tyldesley S, Gelmon K, Nielsen TO, Kennecke H. Breast cancer subtypes and the risk of local and regional relapse. J Clin Oncol 2010;28:1684-91.

28. Lowery AJ, Kell MR, Glynn RW, Kerin MJ, Sweeney KJ. Locoregional recurrence after breast cancer surgery: a systematic review by receptor phenotype. Breast Cancer Res Treat 2012;133:831-41.

29. Kiess AP, McArthur HL, Mahoney $\mathrm{K}$, et al. Adjuvant trastuzumab reduces locoregional recurrence in women who receive breast-conservation therapy for lymph node-negative, human epidermal growth factor receptor 2-positive breast cancer. Cancer 2012;118:1982-8.

30. Lu WL, Jansen L, Post WJ, Bonnema J, Van de Velde JC, De Bock GH. Impact on survival of early detection of isolated breast recurrences after the primary treatment for breast cancer: a metaanalysis. Breast Cancer Res Treat 2009;114:403-12.

31. Geurts SM, de Vegt F, Siesling $\mathrm{S}$, et al. Pattern of follow-up care and early relapse detection in breast cancer patients. Breast Cancer Res Treat 2012;136:859-68.

32. van der Sangen MJ, Scheepers SW, Poortmans PM, Luiten EJ, Nieuwenhuijzen GA, Voogd AC. Detection of local recurrence following breast-conserving treatment in young women with early breast cancer: Optimization of long-term follow-up strategies. Breast 2013;22:351-6.

33. Wapnir IL, Anderson SJ, Mamounas EP, et al. Prognosis after ipsilateral breast tumor recurrence and locoregional recurrences in five National Surgical Adjuvant Breast and Bowel Project node-positive adjuvant breast cancer trials. J Clin Oncol 2006;24:2028-37.

34. Anderson SJ, Wapnir I, Dignam JJ, et al. Prognosis after ipsilateral breast tumor recurrence and locoregional recurrences in patients treated by breast-conserving therapy in five National Surgical Adjuvant Breast and Bowel Project protocols of node-negative breast cancer. J Clin Oncol 2009;27:2466-73.

35. de Boer R, Hillen HF, Roumen RM, Rutten HJ, van der Sangen MJ, Voogd AC. Detection, treatment and outcome of axillary recurrence after axillary clearance for invasive breast cancer. Br J Surg 2001;88: 118-22.

36. van der Sangen MJ, Coebergh JW, Roumen RM, Rutten HJ, Vreugdenhil G, Voogd AC. Detection, treatment, and outcome of isolated supraclavicular recurrence in 42 patients with invasive breast carcinoma. Cancer 2003;98:11-7.

37. Grotenhuis BA, Klem TM, Vrijland WW. Treatment outcome in breast cancer patients with ipsilateral supraclavicular lymph node metastasis at time of diagnosis: a review of the literature. Eur J Surg Oncol 2013;39:207-12.

38. Louwman MW, Vriezen M, van Beek MW, et al. Uncommon breast tumors in perspective: incidence, treatment and survival in the Netherlands. Int J Cancer 2007;121:127-35.

39. Kwast $A B$, Groothuis-Oudshoorn KC, Grandjean I, et al. Histological type is not an independent prognostic factor for the risk pattern of breast cancer recurrences. Breast Cancer Res Treat 2012;135:271-80.

40. Truin W, Voogd AC, Vreugdenhil G, van der Heiden-van der Loo M, Siesling S, Roumen RM. Effect of adjuvant chemotherapy in postmenopausal patients with invasive ductal versus lobular breast cancer. Ann oncol 2012;23:2859-65. 
41. van den Broek N, van der Sangen MJ, van de Poll-Franse LV, van Beek MW, Nieuwenhuijzen GA, Voogd AC. Margin status and the risk of local recurrence after breast-conserving treatment of lobular breast cancer. Breast Cancer Res Treat 2007;105:63-8.

42. Van Limbergen E, Van der Schueren E, Van den Bogaert W, Van Wing J. Local control of operable breast cancer after radiotherapy alone. Eur J Cancer 1990;26:674-9.

43. Voogd AC, Nielsen $\mathrm{M}$, Peterse $\mathrm{JL}$, et al. Differences in risk factors for local and distant recurrence after breast-conserving therapy or mastectomy for stage I and II breast cancer: pooled results of two large European randomized trials. J Clin Oncol 2001;19:1688-97.

44. Peiro G, Bornstein BA, Connolly JL, et al. The influence of infiltrating lobular carcinoma on the outcome of patients treated with breast-conserving surgery and radiation therapy. Breast Cancer Res Treat 2000;59:49-54.

45. Santiago RJ, Harris EE, Qin L, Hwang WT, Solin L. Similar long-term results of breast-conservation treatment for Stage I and II invasive lobular carcinoma compared with invasive ductal carcinoma of the breast: The University of Pennsylvania experience. Cancer 2005;103:2447-54.

46. Morrow M, Keeney K, Scholtens D, Wei J, Steel J, Khan SA. Selecting patients for breast-conserving therapy: the importance of lobular histology. Cancer 2006;106:2563-8.

47. Diepenmaat LA, van der Sangen MJ, van de Poll-Franse LV, et al. The impact of postmastectomy radiotherapy on local control in patients with invasive lobular breast cancer. Radiother Oncol 2009;91:49-53.

48. Kelsey CR, Beaven AW, Diehl LF, Prosnitz LR. Combined-modality therapy for early-stage Hodgkin lymphoma: maintaining high cure rates while minimizing risks. Oncology (Williston Park, NY) 2012;26:1182-9, 93.

49. Schijven MP, Vingerhoets AJ, Rutten HJ, et al. Comparison of morbidity between axillary lymph node dissection and sentinel node biopsy. Eur J Surg Oncol 2003;29:341-50.

50. Rutgers EJ, Meijnen P, Bonnefoi H. Clinical trials update of the European Organization for Research and Treatment of Cancer Breast Cancer Group. Breast Cancer Res 2004;6:165-9.

51. Milgrom S, Cody H, Tan L, et al. Characteristics and outcomes of sentinel node-positive breast cancer patients after total mastectomy without axillary-specific treatment. Ann Surg Oncol 2012;19:3762-70.

52. Bentzen SM, Agrawal RK, Aird EG, et al. The UK Standardisation of Breast Radiotherapy (START) Trial B of radiotherapy hypofractionation for treatment of early breast cancer: a randomised trial. Lancet 2008;371:1098-107.

53. Bentzen SM, Agrawal RK, Aird EG, et al. The UK Standardisation of Breast Radiotherapy (START) Trial A of radiotherapy hypofractionation for treatment of early breast cancer: a randomised trial. Lancet Oncol 2008;9:331-41.

54. Whelan TJ, Pignol JP, Levine MN, et al. Long-term results of hypofractionated radiation therapy for breast cancer. N Engl J Med 2010;362:513-20.

55. Agrawal RK, Alhasso A, Barrett-Lee PJ, et al. First results of the randomised UK FAST Trial of radiotherapy hypofractionation for treatment of early breast cancer (CRUKE/04/015). Radiother Oncol 2011;100:93-100.

56. Liljegren G, Holmberg L, Bergh J, et al. 10-Year results after sector resection with or without postoperative radiotherapy for stage I breast cancer: a randomized trial. J Clin Oncol 1999;17:232633.

57. Veronesi U, Marubini E, Mariani L, et al. Radiotherapy after breast-conserving surgery in small breast carcinoma: long-term results of a randomized trial. Ann Oncol 2001;12:997-1003.

58. Fisher B, Anderson S, Bryant J, et al. Twenty-year follow-up of a randomized trial comparing total mastectomy, lumpectomy, and lumpectomy plus irradiation for the treatment of invasive breast cancer. N Engl J Med 2002;347:1233-41.

59. Holland R, Veling SH, Mravunac M, Hendriks JH. Histologic multifocality of Tis, T1-2 breast carcinomas. Implications for clinical trials of breast-conserving surgery. Cancer 1985;56:979-90.

60. Presley CJ, Soulos PR, Herrin J, et al. Patterns of use and short-term complications of breast brachytherapy in the national medicare population from 2008-2009. J Clin Oncol 2012;30:4302-7.

61. Leonardi MC, Maisonneuve P, Mastropasqua MG, et al. Accelerated partial breast irradiation with intraoperative electrons: using GEC-ESTRO recommendations as guidance for patient selection. Radiother Oncol 2013;106:21-7. 
62. Blamey RW, Bates $T$, Chetty $U$, et al. Radiotherapy or tamoxifen after conserving surgery for breast cancers of excellent prognosis: British Association of Surgical Oncology (BASO) II trial. Eur J Cancer 2013;49:2294-302.

63. Hughes $L L$, Wang $M$, Page $D L$, et al. Local excision alone without irradiation for ductal carcinoma in situ of the breast: a trial of the Eastern Cooperative Oncology Group. J Clin Oncol 2009;27:5319-24.

64. Rakovitch E, Nofech-Mozes S, Narod SA, et al. Can we select individuals with low risk ductal carcinoma in situ (DCIS)? A population-based outcomes analysis. Breast Cancer Res Treat 2013;138:581-90.

65. Matzinger $\mathrm{O}$, Heimsoth I, Poortmans $\mathrm{P}$, et al. Toxicity at three years with and without irradiation of the internal mammary and medial supraclavicular lymph node chain in stage I to III breast cancer (EORTC trial 22922/10925). Acta Oncol 2010;49:24-34.

66. Olivotto IA, Chua B, Elliott EA, et al. A clinical trial of breast radiation therapy versus breast plus regional radiation therapy in early-stage breast cancer: the MA20 trial. Clin Breast Cancer 2003;4: 361-3.

67. Kunkler IH, Canney $P$, van Tienhoven G, Russell NS. Elucidating the role of chest wall irradiation in 'intermediate-risk' breast cancer: the MRC/EORTC SUPREMO trial. Clin Oncol 2008;20:31-4.

68. Kreike $\mathrm{B}, \mathrm{Halfwerk} \mathrm{H}$, Armstrong $\mathrm{N}$, et al. Local recurrence after breast-conserving therapy in relation to gene expression patterns in a large series of patients. Clin Cancer Res 2009;15:4181-90.

69. Mamounas EP, Tang G, Fisher B, et al. Association between the 21-gene recurrence score assay and risk of locoregional recurrence in node-negative, estrogen receptor-positive breast cancer: results from NSABP B-14 and NSABP B-20. J Clin Oncol 2010;28:1677-83.

70. Howard-Anderson J, Ganz PA, Bower JE, Stanton AL. Quality of life, fertility concerns, and behavioral health outcomes in younger breast cancer survivors: a systematic review. J Natl Cancer Inst 2012;104:386-405.

71. Schaapveld M, Visser O, Louwman WJ, et al. The impact of adjuvant therapy on contralateral breast cancer risk and the prognostic significance of contralateral breast cancer: a population based study in the Netherlands. Breast Cancer Res Treat 2008;110:189-97.

72. Font-Gonzalez A, Liu L, Voogd AC, et al. Inferior survival for young patients with contralateral compared to unilateral breast cancer: a nationwide population-based study in the Netherlands. Breast Cancer Res Treat 2013;139:811-9.

73. Kelly KM, Dean J, Lee SJ, Comulada WS. Breast cancer detection: radiologists' performance using mammography with and without automated whole-breast ultrasound. Eur Radiol 2010;20:2557-64.

74. Kimman ML, Dirksen CD, Voogd AC, et al. Nurse-led telephone follow-up and an educational group programme after breast cancer treatment: results of a $2 \times 2$ randomised controlled trial. Eur J Cancer 2011;47:1027-36. 
Summary 


\section{Summary}

New insights into the pathogenesis of breast cancer have led to remarkable improvements in the diagnosis, treatment and cure rates of this disease over a relatively short period of time. This thesis contains a number of observational studies relating to various aspects of local and regional tumour control in patients with breast cancer. The emphasis is on young age at diagnosis and on patients with a lobular tumour type. The studies are population-based, using data of patients treated in hospitals in the southeastern part of the Netherlands, which are served by the Eindhoven Cancer Registry (ECR). The studies cover a period of more than 20 years, which allows us to look at time trends and to identify significant changes in a number of important prognostic factors.

Since the introduction of breast-conserving therapy (BCT) there has been continuous debate about its safety and efficacy compared with mastectomy in young women with breast cancer. In chapter $\mathbf{2 . 1}$ we compare the effectiveness of BCT and mastectomy in women aged 40 years or younger treated for early-stage breast cancer between 1988 and 2005. It is an evaluation of a large cohort of 1451 patients with a sufficiently long follow-up to determine treatment results up to 15 years. A total of 562 patients underwent mastectomy and 889 patients received BCT. During follow-up, 23 patients treated with mastectomy and 135 patients treated with BCT developed a local relapse without previous or simultaneous evidence of distant disease. The local relapse risk for patients treated with mastectomy was $4.4 \%$ at 5 years and reached a plateau after 6 years at $6.0 \%$. After BCT, the 5-, 10- and 15 -year risks were $8.3 \%, 18.4 \%$ and $28.2 \%$, respectively $(P<0.0001)$. Adjuvant systemic therapy following BCT halved the 15 -year local relapse risk from $32.9 \%$ to $16.1 \%,(P=0.0007)$. In conclusion, local tumour control in young patients with early-stage breast cancer during this period of time is worse after BCT than after mastectomy. Adjuvant systemic therapy significantly improves local control following BCT and also for that reason it should be considered for most patients $\leq 40$ years. Long-term follow-up is highly recommended for young patients after $\mathrm{BCT}$, because even with systemic treatment an annual risk of local relapse of $1 \%$ remains up to 15 years after treatment.

In chapter 2.2 we evaluate the trends in the risk of local recurrences after BCT and examine the impact of local recurrence on distant relapse-free survival in a large cohort of women $(n=1143)$ aged $\leq 40$ years with early-stage breast cancer. After a median follow-up of 8.5 (0.1-24.6) years, 176 patients had developed an isolated LR. The 5-year LR-rate for the subgroups treated in the periods 1988-1998, 1999-2005 and $2006-2010$ were $9.8 \%, 5.9 \%$ and $3.3 \%$, respectively $(P=0.006)$. In a multivariate analysis, adjuvant systemic treatment was associated with a reduced risk of LR of nearly $60 \%$ (HR 0.42; $P<0.0001$ ). Patients who experienced an early isolated LR ( $\leq 5$ years after $\mathrm{BCT}$ ) had a worse distant relapse-free survival compared to patients 
without an early LR (HR 1.83; $P=0.001$ ). Late local recurrences did not negatively affect distant relapse free survival (HR 1.24; $P=0.407$ ).

Local control after BCT improved significantly over time and appeared to be closely related to the increased use and effectiveness of systemic therapy. These recent results underline the safety of BCT for young women with early-stage breast cancer nowadays.

One of the goals of follow-up after treatment for breast cancer is early detection of recurrent disease or a new primary cancer. In chapter 2.3 we investigate the detection of a local recurrence in young women with breast cancer after BCT in order to compare the impact of different long-term follow-up strategies. Between 1988 and 2005, 937 women aged $\leq 40$ years were treated with BCT for early-stage breast cancer in the southern part of the Netherlands. Up to October 2009, 152 had developed an isolated local recurrence. Information on follow-up visits was available for 124 of them. Fifty-four LRs (44\%) were diagnosed within 5 years and 70 (56\%) more than 5 years after BCT. Fifty-six LRs (45\%) were detected during routine follow-up visits and $68(55 \%)$ presented between two visits. Sixty-six LRs (53\%) were diagnosed in patients reporting symptoms. In 31 patients $(25 \%)$ the LR was found by mammography alone. About a quarter of the LRs was larger than $2 \mathrm{~cm}$ in diameter. These results imply that current follow-up strategies for young women with BCT do not guarantee a timely detection of LR.

Invasive lobular breast carcinoma is known for its diffusely infiltrative growth pattern, which makes it difficult to visualize by mammography. In addition, invasive lobular cancer is more likely to be non-palpable, multicentric, multifocal and bilateral than ductal carcinoma. These features may explain why it is associated with a relative high incidence of incomplete excision after BCT. The aim of the study in chapter $\mathbf{3 . 1}$ was to examine the influence of positive surgical margins on the local recurrence rate in patients diagnosed with invasive lobular cancer (ILC) and treated with BCT. All 416 women diagnosed with invasive lobular breast cancer and undergoing BCT between 1995 and 2002 were selected from the population-based ECR. Their medical records were reviewed and detailed information was collected. The risk of margin involvement was $29 \%$ after the first operation and $17 \%$ when taking into account the final margin status of the patients undergoing re-excision. During follow-up, 18 patients developed a local recurrence. The 5 year actuarial risk of developing a local recurrence was $3.5 \%$ and the 8 year risk was $6.4 \%$. There was no influence of positive surgical margins on the risk of local recurrence, neither in the univariate analysis nor after adjustment for age, tumour size, nodal status and adjuvant systemic treatment in a multivariate analysis. We conclude that patients with ILC undergoing BCT have a low risk of local recurrence, despite their high risk of having a microscopically incomplete excision of the tumour. 
In the previous study (chapter 3.1) about BCT in invasive lobular breast cancer (ILC) we showed a 5-year local recurrence risk of only $3.5 \%$ after BCT, despite the high risk (17\%) of an incomplete excision of the tumour. This may be explained by the relatively high sensitivity of ILC to radiotherapy. In chapter $\mathbf{3 . 2}$ we examine the impact of postmastectomy radiotherapy on the risk of local recurrence in patients with ILC. The population-based ECR was used to select 499 patients with ILC, who underwent mastectomy between 1995 and 2002. Of the 499 patients 383 patients fulfilled the eligibility criteria. Of these patients, 170 (44.4\%) had received postmastectomy radiotherapy. The median follow-up was 7.2 years. During follow-up 22 patients developed a local recurrence, of whom 4 had received postmastectomy radiotherapy. The 5-year actuarial risk of local recurrence was $2.1 \%$ for the patients with and $8.7 \%$ for the patients without postmastectomy radiotherapy. After adjustment for age at diagnosis, tumour stage and adjuvant systemic treatment, the patients who underwent postmastectomy radiotherapy were found to have a more than 3 times lower risk of local recurrence compared to the patients without radiotherapy (HR 0.30; $P=0.03$ ). Local control is excellent for patients with ILC who undergo postmastectomy radiotherapy and significantly better than for patients not receiving radiotherapy.

It has long been known that a local recurrence in the breast occurring shortly after primary treatment has a negative impact on prognosis. In chapter 4.1 we examine the characteristics and the prognosis of patients with a local recurrence occurring more than 5 years after BCT. In the period 1982-1997, 3280 patients with invasive breast cancer underwent BCT in one of the eight community hospitals in the South-eastern part of The Netherlands. Of these patients, 98 developed a local recurrence in the breast more than 5 years after BCT. Eighty-five of the 98 recurrences were invasive, 12 were purely in situ and for one patient this information was not available. The 5 years distant recurrence-free survival rate of 85 patients with a late invasive local recurrence was $68 \%$, and significantly better than the rate of $41 \%$ in an existing cohort of 173 patients with invasive recurrence within 5 years after BCT ( $P=0.007)$. Local excision of the recurrence was followed by a significantly lower local control rate than salvage mastectomy (50 versus $89 \% ; P=0.004$ ). The prognosis of patients with a local recurrence more than 5 years after $\mathrm{BCT}$ is significantly better than of patients with local recurrence within 5 years after BCT.

In chapter 4.2 we study the outcome and related prognostic factors in 124 patients with an isolated local recurrence in the breast following breast-conserving surgery and radiotherapy for early stage breast cancer diagnosed at the age of 40 years or younger. Data from the population-based ECR were used to select the patients who were diagnosed with breast cancer and received BCT between 1988 and 2005. The median follow-up of the patients after diagnosis of LR was 7.0 years. At 10 years from the date of salvage treatment, the overall survival rate was $73 \%$, the distant 
recurrence-free survival rate was $61 \%$, and the local control rate (i.e. survival without subsequent LR or local progression) was $95 \%$. In the multivariate analysis, the risk of distant metastases also tended to be higher for patients with LR occurring within 5 years after $B C T$, as compared to patients with LR more than 5 years after BCT (HR 1.89; $P=0.09$ ). A worse distant recurrence-free survival was also observed for patients with a LR measuring more than $2 \mathrm{~cm}$ in diameter, compared to those with a LR of $2 \mathrm{~cm}$ or smaller (HR 2.88; $P=0.007$ ), and for patients with a $L R$ causing symptoms or suspicious findings at clinical breast examination, compared to those with a LR detected by breast imaging only (HR 3.70; $P=0.03$ ). These results suggest that early detection of LR after BCT in young women can improve treatment outcome.

Studies investigating the lymphatic drainage of the breast report drainage to the axillary lymph nodes in $64-95 \%$ of the patients, but also to the internal mammary lymph nodes (IMLN) in $9-45 \%$ of the patients. One to five percent of the tumours exclusively drain to the IMLN. Despite the frequent drainage to the IMLN clinically apparent recurrences in these nodes are very rare. Follow-up of nearly 6000 breast cancer patients in chapter $\mathbf{5 . 1}$ resulted in the tracing of only six patients with IMLN recurrence. IMLN recurrence was defined as breast cancer recurrence in an internal mammary lymph node without a distant metastasis before the recurrence and confirmed by cytology and/or CT-scan. The time interval between diagnosis of the primary tumour and the recurrence varied between 5 months and 8 years and 6 months. One patient showed no symptoms, the other five all had a swelling and one of them also had pain. The size of the parasternal swelling varied from 3 to $9 \mathrm{~cm}$; in one patient the size was unknown. Treatment resulted in a complete remission in four patients. In five of the six patients distant metastases occurred. The time interval between IMLN recurrence and the diagnosis of distant metastasis varied between 0 and 37 months. One patient was still free of distant metastasis in the time of this study. This large population-based study confirms the almost negligible risk of clinically apparent, isolated IMLN recurrence. Considering the high percentage of positive lymph nodes in studies evaluating sentinel node biopsy of the internal mammary chain, it becomes clear that just a fraction of these becomes clinically apparent as a recurrence. In almost all patients with IMLN it is a forerunner of metastatic disease.

Supraclavicular nodes are part of a continuum of regional lymph node drainage of the breast. The division of nodal regions is based on anatomic landmarks and has prognostic significance. Tumour involvement of the supraclavicular lymph nodes is known as an unfavorable prognostic indicator. In chapter $\mathbf{5 . 2}$ we study the diagnosis, treatment, outcome and prognostic factors of patients with an isolated supraclavicular recurrence. In the period 1984-1994, 4669 patients with invasive breast carcinoma underwent axillary dissection. During follow-up until 2002, 42 patients with isolated supraclavicular recurrence were identified. The median interval 
between treatment of the primary tumour and diagnosis of the supraclavicular recurrence was 2.5 years (range, $0.2-11.5$ years). Radiotherapy was administered to 25 patients (60\%), 5 of whom also underwent surgery and 16 of whom also received chemotherapy or hormonal therapy. Eleven patients received hormonal therapy only, and four received chemotherapy only. One patient received surgical treatment only, and one patient remained untreated. Complete remission was achieved in 35 patients (83\%), but a second supraclavicular recurrence occurred in 12 (34\% of patients who achieved complete remission). Overall, 6 patients (14\%) were alive without evidence of disease after a follow-up period of 4.4-8.3 years. The 5-year actuarial overall survival and distant disease-free survival rates, based on the date of diagnosis of supraclavicular recurrence, were $38 \%$ and $22 \%$, respectively. The distant disease-free survival rate was somewhat better for the 25 patients who underwent radiotherapy as part of the treatment for supraclavicular recurrence than it was for the 17 patients who did not receive radiotherapy $(P=0.06)$; the difference became even more pronounced after the exclusion of 8 patients who had already received axillary and supraclavicular radiotherapy as part of treatment for the primary tumour $(P=0.002)$. Although complete remission can be obtained in most patients with isolated supraclavicular recurrence, the prognosis for these patients is poor. Involved field radiotherapy appears to play an important role in the treatment of supraclavicular recurrence and may improve the distant recurrence-free survival rate.

Locoregional tumour control in breast cancer has improved considerably in the past decades, in such a way that locoregional recurrence can now be considered as a rare event, with a risk well below $5 \%$ after 5 years, even in young patients. The future lies in so-called 'personalised' locoregional and systemic treatment. For this, it is necessary to be able to make a reliable assessment of the risk of locoregional and distant relapse and to subsequently predict to which extent each specific treatment modality and their combinations can contribute to cure or a prolonging of the life expectancy of the patient. Such an assessment should also take into account the expected short- and long-term toxicity of each modality. 
Samenvatting 


\section{Samenvatting}

Nieuwe inzichten in de pathogenese van borstkanker hebben in relatief korte tijd geleid tot opmerkelijke verbeteringen in de diagnose, behandeling en genezing van deze aandoening. Dit proefschrift bevat een aantal observationele studies met betrekking tot diverse aspecten van lokale- en regionale tumorcontrole bij patiënten met borstkanker. De nadruk van deze studies ligt op patiënten bij wie borstkanker op jonge leeftijd is ontdekt en op patiënten met een invasief lobulair tumortype. Alle studies zijn population-based, gebaseerd op patiënten behandeld in de ziekenhuizen en radiotherapie-instituten in Zuid-Nederland. De patiënten zijn geselecteerd via de kankerregistratie van het Integraal Kankercentrum Zuid en aanvullende gegevens werden overgenomen uit hun medische dossiers. De studies bestrijken een periode van meer dan 20 jaar, waardoor het mogelijk was om trends in de tijd te onderzoeken en om significante veranderingen in een aantal belangrijke prognostische factoren te identificeren.

Sinds de introductie van de borstsparende behandeling bestaat er discussie over de werkzaamheid en veiligheid van deze procedure bij jonge vrouwen met borstkanker. In hoofdstuk 2.1 vergelijken we de effectiviteit van borstsparende behandeling met mastectomie bij vrouwen van 40 jaar en jonger die tussen 1988 en 2005 behandeld zijn voor een vroeg stadium borstkanker. Het betreft de evaluatie van een cohort van 1.451 patiënten met een voldoende lange follow-up om de resultaten tot 15 jaar na initiële behandeling te onderzoeken. Van deze groep ondergingen 562 patiënten een mastectomie en 889 patiënten borstsparende behandeling. Tijdens de follow-up ontwikkelden 23 patiënten na mastectomie en 135 patiënten na borstsparende behandeling een lokaal recidief (LR) zonder voorafgaande of gelijktijdige metastasering op afstand. Het lokale recidiefpercentage van patiënten behandeld met mastectomie was $4,4 \%$ na 5 jaar en dit bereikte na 6 jaar een plateau van 6,0\%. Na borstsparende behandeling waren de 5 -, 10 - en 15-jaars lokale recidiefpercentages respectievelijk $8,3 \%, 18,4 \%$ en $28,2 \%,(P<0,0001)$. Adjuvante systemische therapie na borstsparende behandeling halveerde het 15-jaars LR-risico na borstsparende behandeling van $32,9 \%$ naar $16,1 \%,(P=0,0007)$. Concluderend kunnen we stellen dat de lokale tumorcontrole bij jonge patiënten met een vroeg stadium borstkanker in deze tijdspanne minder goed was na borstsparende behandeling dan na mastectomie. Adjuvante systemische therapie verbetert de lokale tumorcontrole na borstsparende behandeling en dient ook om die reden voor de meeste patiënten met een leeftijd van $\leq 40$ jaar te worden overwogen. Langdurige nacontrole is voor jonge, borstsparend behandelde patiënten gewenst, aangezien er zelfs na adjuvante systemische therapie tot 15 jaar na de behandeling een jaarlijkse kans van circa $1 \%$ op het ontwikkelen van een LR blijft bestaan. 
In hoofdstuk 2.2 evalueren we de trends in de tijd met betrekking tot de kans op het ontwikkelen van een LR na borstsparende behandeling. Tegelijkertijd onderzoeken we de invloed van een LR op de metastasevrije overleving in een groot cohort vrouwen $(n=1.143)$ in de leeftijd $\leq 40$ jaar met een vroeg stadium borstkanker. Na een mediane follow-up van 8,5 jaar (0,1-24,6 jaar), hadden 176 patiënten een geïsoleerd LR ontwikkeld. De 5-jaars lokale recidiefpercentages voor de subgroepen behandeld in de periodes 1988-1998, 1999-2005 en 2006-2010 waren respectievelijk 9,8\%, 5,9\% en $3,3 \%,(P=0,006)$. In een multivariate analyse bleek adjuvante systemische therapie het risico op een LR met bijna $60 \%$ (HR 0,42; $P<0,0001)$ te verminderen. Patiënten met een vroeg geïsoleerd lokaal recidief (optredend binnen 5 jaar na borstsparende behandeling) hadden een slechtere metastasevrije overleving in vergelijking met patiënten zonder een vroeg $\operatorname{LR}(H R 1,83 ; P=0,001)$. Late lokale recidieven hadden geen negatieve invloed op de metastasevrije overleving (HR 1,24; $P=0,407$ ).

Uit dit onderzoek blijkt dat de lokale tumorcontrole na borstsparende behandeling in de loop der tijd aanzienlijk is verbeterd en nauw gerelateerd is aan de toename van zowel het gebruik als de effectiviteit van systemische therapie. Deze recente resultaten onderstrepen de hedendaagse veiligheid van de borstsparende behandeling voor jonge vrouwen met een vroeg stadium borstkanker.

Een van de doelstellingen van nacontrole voor borstkanker is vroege opsporing van nieuwe manifestaties van de ziekte. In hoofdstuk $\mathbf{2 . 3}$ onderzoeken we de detectie van een LR bij jonge vrouwen na borstsparende behandeling om de lange termijn invloed van verschillende nacontrolestrategieën te vergelijken. Tussen 1988 en 2005 werden in de IKZ regio 937 vrouwen in de leeftijd $\leq 40$ jaar borstsparend behandeld voor een vroeg stadium borstkanker. Tot oktober 2009 ontwikkelden 152 van deze patiënten een geïsoleerd LR. Informatie over de nacontrole was beschikbaar voor 124 van hen. Vierenvijftig van de lokale recidieven (44\%) werden binnen 5 jaar en 70 (56\%) meer dan 5 jaar na de borstsparende behandeling gediagnosticeerd. Zesenvijftig lokale recidieven (45\%) werden tijdens routine nacontrolebezoeken ontdekt en 68 lokale recidieven (55\%) presenteerden zich tussen twee bezoeken. Zesenzestig lokale recidieven (53\%) werden gediagnosticeerd door symptomen van patiënten en bij 31 patiënten (25\%) kwam het LR alleen door de mammografie aan het licht. Ongeveer een kwart van de lokale recidieven was bij ontdekking groter dan $2 \mathrm{~cm}$. Deze resultaten tonen aan dat de huidige opzet van de nacontrole voor jonge vrouwen na borstsparende behandeling geen garantie is voor een vroegtijdige detectie van een LR.

Het invasief lobulair mammacarcinoom staat bekend om zijn slechte afgrensbaarheid en gaat gepaard met een relatief hoge incidentie van irradicale excisie na borstsparende operatie. Het doel van de studie in hoofdstuk 3.1 was om de invloed van positieve chirurgische sneevlakken op de lokale recidiefkans bij borstsparend behandelde patiënten met invasief lobulair carcinoom (ILC) te onderzoeken. In totaal werden uit de kankerregistratie van het IKZ binnen de periode tussen 1995 en 2002 
416 borstsparend behandelde vrouwen met ILC geselecteerd. Uit hun medische dossiers werd gedetailleerde informatie verzameld. Het percentage patiënten met positieve sneevlakken was $29 \%$ na de eerste operatie en $17 \%$ wanneer er rekening werd gehouden met de definitieve sneevlakstatus na eventuele re-excisie. Tijdens de follow-up ontwikkelden 18 patiënten een LR. Het actuariële risico op het ontwikkelen van een LR was 3,5\% na 5 jaar en $6,4 \%$ na 8 jaar. Er was geen invloed van positieve chirurgische sneevlakken op de kans op een LR, noch in de univariate analyse noch na correctie voor leeftijd, tumorgrootte, nodale status en adjuvante systemische therapie. We concluderen dat borstsparend behandelde patiënten met ILC een laag risico op een LR hebben, ondanks hun hoog risico op een microscopisch onvolledige resectie.

In de vorige studie (hoofdstuk 3.1) bij patiënten met een borstsparend behandeld ILC zagen we ondanks het hoge risico van $17 \%$ op een uiteindelijk onvolledige resectie een LR risico van slechts 3,5\% na 5 jaar. In hoofdstuk $\mathbf{3 . 2}$ onderzoeken we de invloed van postoperatieve radiotherapie op de lokale recidiefkans bij patiënten met ILC na mastectomie. Met behulp van de kankerregistratie van het IKZ werden 499 patiënten met ILC geselecteerd die tussen 1995 en 2002 een mastectomie hadden ondergaan. Van de 499 patiënten voldeden er 383 patiënten aan de inclusiecriteria van het onderzoek. Van deze 383 patiënten ondergingen er 170 (44.4\%) postoperatieve radiotherapie op de thoraxwand. De mediane follow-up bedroeg 7,2 jaar. Tijdens de follow-up ontwikkelden 22 patiënten een LR, van wie er 4 postoperatieve radiotherapie hadden gekregen. Het 5-jaars actuariële risico op een LR bedroeg 2,1\% voor de patiënten met en $8,7 \%$ voor de patiënten zonder postoperatieve radiotherapie. Na correctie voor leeftijd bij diagnose, tumorstadium en adjuvante systemische behandeling, werd bij patiënten die na een mastectomie radiotherapie ondergingen een meer dan 3 keer lager risico op het ontwikkelen van een LR gevonden in vergelijking met patiënten zonder postoperatieve radiotherapie (HR 0,30; $P=0,03)$. Uit deze studie blijkt dat de lokale tumorcontrole bij patiënten met ILC die na mastectomie radiotherapie ondergaan, uitstekend is en significant beter dan voor patiënten zonder postoperatieve radiotherapie.

Het is al langer bekend dat het kort na de primaire behandeling optreden van een LR in de borst een negatieve invloed heeft op de prognose. In hoofdstuk 4.1 beschrijven we de kenmerken en de prognose van patiënten met een LR dat meer dan 5 jaar na de borstsparende behandeling is ontstaan. In de periode 1982-1997 ondergingen 3.280 patiënten met invasieve borstkanker een borstsparende behandeling in een van de acht ziekenhuizen in Zuid-Oost Nederland. Van deze patiënten ontwikkelden er 98 een LR in de borst meer dan 5 jaar na de borstsparende behandeling. In 85 van de 98 recidieven betrof het invasieve tumoren, in 12 gevallen waren het louter in situ carcinomen en voor één patiënt was deze informatie niet beschikbaar. De 5 -jaars metastasevrije overlevingskans van de 85 patiënten met een laat, invasief LR bedroeg 
$68 \%$, en dat was beduidend beter dan het percentage van $41 \%$ in een bestaand cohort van 173 patiënten met een invasief LR binnen 5 jaar na borstsparende behandeling $(P=0,007)$. Enkel lokale excisie van het recidief resulteerde in een significant lager lokale tumorcontrole dan 'salvage'-mastectomie ( $50 \%$ versus $89 \%, P=0,004)$. Uit deze studie blijkt dat de prognose van patiënten met een LR dat meer dan 5 jaar na borstsparende behandeling optreedt, significant beter is dan die van patiënten met een LR binnen 5 jaar na borstsparende behandeling .

In hoofdstuk 4.2 bestuderen we het ziektebeloop en prognostische factoren van 124 patiënten met een geïsoleerd LR in de borst na borstsparende behandeling op de leeftijd van 40 jaar of jonger. Gegevens van de kankerregistratie van het IKZ werden gebruikt om de tussen 1988 en 2005 borstsparend behandelde borstkankerpatiënten te selecteren. De mediane follow-up van de patiënten na de diagnose van een LR was 7,0 jaar. De totale overleving na 10 jaar vanaf de datum van salvage behandeling bedroeg $73 \%$, de metastasevrije overleving was $61 \%$, en de locale controle $95 \%$. In de multivariate analyse leek het risico van metastasen op afstand hoger te zijn voor patiënten met een LR ontstaan binnen 5 jaar na borstsparende behandeling in vergelijking met patiënten met een LR meer dan 5 jaar na borstsparende behandeling (HR 1,89; $P=0,09$ ). Een slechtere metastasevrije overleving werd ook waargenomen bij patiënten met een $L R$ van meer dan $2 \mathrm{~cm}$ in diameter, vergeleken met een $L R$ van 2 $\mathrm{cm}$ of kleiner (HR 2,88; $P=0,007$ ), en bij patiënten met een LR ontdekt door symptomen of verdachte bevindingen bij klinisch borstonderzoek, in vergelijking met een enkel door beeldvormend onderzoek gedetecteerd LR (HR 3,70; $P=0,03$ ). Deze resultaten suggereren dat vroege detectie van een LR na borstsparende behandeling bij jonge vrouwen het behandelresultaat kan verbeteren.

Studies naar de lymfedrainage van tumoren in de borst beschrijven lymfeafvloed naar de okselklieren bij 64-95\% van de patiënten, waarbij bij 9-45\% van hen tevens sprake is van afvloed naar de parasternale lymfeklieren. Een tot vijf procent van de borsttumoren draineert uitsluitend naar de parasternale klierketen. Ondanks dit gegeven zijn klinische parasternale recidieven zeer zeldzaam. In hoofdstuk $\mathbf{5 . 1}$ heeft onderzoek naar follow-up van bijna 6.000 patiënten met borstkanker geleid tot het opsporen van slechts zes patiënten met een parasternaal recidief. Een parasternaal recidief werd in deze studie gedefinieerd als recidief borstkanker in de parasternale klierketen zonder metastasen op afstand vóór het vaststellen van het recidief en bevestigd door pathologisch onderzoek en/of een CT-scan. Het tijdsinterval tussen de diagnose van de primaire tumor en het optreden van het parasternaal recidief varieerde tussen 5-102 maanden. Een patiënt bleek asymptomatisch, de andere vijf presenteerden zich met een zwelling en bij een van hen was er ook sprake van pijn. De grootte van de parasternale zwelling varieerde van 3-9 cm; bij één patiënt was de grootte onbekend. Behandeling leidde tot een volledige remissie bij vier patiënten. Vijf van de zes patiënten ontwikkelden uiteindelijk metastasen op afstand. Het 
tijdsinterval tussen de diagnose van het parasternaal recidief en de diagnose van de metastasen op afstand varieerde tussen 0-37 maanden. Een patiënt was nog vrij van metastasen op afstand ten tijde van de evaluatie. Dit onderzoek bevestigt het bijna te verwaarlozen risico van klinisch evidente, geïsoleerde parasternale klierrecidivering. Gezien het hoge percentage van positieve parasternale schildwachtklieren, wordt het duidelijk dat slechts een fractie van deze parasternale lymfekliermetastasen klinisch manifest wordt. Bij bijna alle patiënten met een parasternaal recidief is dit recidief een voorloper van gemetastaseerde ziekte.

Supraclaviculaire lymfeklieren maken deel uit van de regionale lymfeklieren van de borst. De indeling en ligging van de lymfekliergebieden is gebaseerd op anatomische oriëntatiepunten en heeft bij metastatische betrokkenheid prognostische betekenis. Metastasering in de supraclaviculaire lymfeklieren staat bekend als een ongunstig prognostisch teken. In hoofdstuk 5.2 bestuderen we de diagnose, behandeling, resultaten en prognostische factoren van patiënten met een geïsoleerd supraclaviculair recidief. In de periode 1984-1994 ondergingen 4.669 patiënten met invasieve borstkanker een okselklierdissectie. Tijdens de nacontrole werd tot 2002 bij 42 patiënten een geïsoleerd supraclaviculair klierrecidief gediagnosticeerd. Het mediane interval tussen behandeling van de primaire tumor en de diagnose van het supraclaviculaire recidief bedroeg 2,5 jaar (0,2-11,5 jaar). In totaal ondergingen 25 patiënten (60\%) radiotherapie, waarvan 5 patiënten ook geopereerd werden en 16 patiënten tevens behandeling met chemotherapie of hormonale therapie ontvingen. Elf patiënten kregen alleen hormonale therapie en vier patiënten alleen chemotherapie. Een patiënt werd alleen chirurgisch behandeld en één patiënt bleef onbehandeld. Een complete remissie trad bij 35 patiënten (83\%) op, echter 12 patiënten ontwikkelden een tweede supraclaviculair recidief (34\% van de patiënten met initieel een complete remissie). Na een follow-up periode van 4,4-8,3 jaar waren er nog 6 patiënten (14\%) in leven zonder tekenen van ziekte. De 5-jaars actuariële totale en metastasevrije overleving bedroegen respectievelijk $38 \%$ en $22 \%$, gerekend vanaf de datum van diagnose van het supraclaviculaire recidief. De metastasevrije overleving was iets beter voor de 25 patiënten die radiotherapie ondergingen als onderdeel van de behandeling van het supraclaviculaire recidief dan voor de 17 patiënten die geen radiotherapie ontvingen $(P=0,06)$. Het verschil was meer uitgesproken na uitsluiting van 8 patiënten die reeds axillaire en supraclaviculaire radiotherapie als onderdeel van de behandeling van de primaire tumor $(P=0,002)$ hadden ontvangen. We concluderen dat er bij de meeste patiënten met een geïsoleerd supraclaviculair recidief een complete remissie bereikt kan worden, maar dat desalniettemin de uiteindelijke prognose ongunstig is. Radiotherapie op het betrokken gebied lijkt een belangrijke rol te spelen bij de behandeling van het supraclaviculaire recidief en kan de metastasevrije overleving mogelijk verbeteren. 
De locoregionale tumorcontrole van borstkanker is in de afgelopen jaren zodanig verbeterd, dat een locoregionaal recidief nu als een zeldzaamheid beschouwd kan worden. Het locoregionaal recidiefrisico ligt momenteel beduidend onder de $5 \%$ na 5 jaar en dat geldt ook voor jonge patiënten. De toekomst ligt in de zogenaamde 'personalised medicine' met een op maat van de individuele patiënt toegesneden, locoregionale en systemische behandeling. Hiervoor is het nodig om een betrouwbare inschatting van het recidiefrisico te kunnen maken en vervolgens te voorspellen in welke mate elke afzonderlijke behandelingsmodaliteit of combinaties daarvan kunnen bijdragen tot genezing of verlenging van de levensverwachting. Bij deze inschatting dient ook rekening te worden gehouden met de te verwachten toxiciteit van de behandeling. 
Abbreviations 


\section{Abbreviations}

\begin{tabular}{|c|c|}
\hline $\begin{array}{l}\text { ACOSOG } \\
\text { ABPI }\end{array}$ & $\begin{array}{l}\text { American College of Surgeons Oncology Group } \\
\text { accelerated partial breast irradiation }\end{array}$ \\
\hline BCSG & Breast Cancer Study Group \\
\hline BCT & breast-conserving therapy \\
\hline BOOG & Borstkanker Onderzoekgroep \\
\hline CBE & clinical breast examination \\
\hline $\mathrm{Cl}$ & confidence interval \\
\hline $\mathrm{CMF}$ & cyclophosphamide, methotrexate, 5-fluorouracil \\
\hline CT & chemotherapy \\
\hline DBCG & Danish Breast Cancer Cooperative Group \\
\hline DCIS & ductal carcinoma in situ \\
\hline DFRS & distant recurrence-free survival \\
\hline EBCTCG & Early Breast Cancer Trialists' Collaborative Group \\
\hline ECR & Eindhoven Cancer Registry \\
\hline ER & oestrogen receptor \\
\hline FU & follow-up \\
\hline HER2 & human epidermal growth factor receptor 2 \\
\hline $\mathrm{HR}$ & hazard ratio \\
\hline HT & hormonal therapy \\
\hline IBCSG & International Breast Cancer Study Group \\
\hline IBTR & ipsilateral breast tumour recurrence \\
\hline IDC & invasive ductal cancer \\
\hline IKZ & Integraal Kankercentrum Zuid \\
\hline IMNL & internal mammary lymph nodes \\
\hline ILC & invasive lobular cancer \\
\hline NABON & Nationaal Borstkankeroverleg Nederland \\
\hline LR & local recurrence \\
\hline LRs & local recurrences \\
\hline LVI & lymphovascular invasion \\
\hline NLIC & non-lobular invasive carcinoma \\
\hline PR & progesterone receptor \\
\hline RT & radiotherapy \\
\hline SR & supraclavicular recurrence \\
\hline
\end{tabular}




\section{List of publications}




\section{List of publications}

1. van Laar C, van der Sangen MJ, Poortmans PM, et al. Local recurrence following breast-conserving treatment in women aged 40years or younger: Trends in risk and the impact on prognosis in a population-based cohort of 1143 patients. Eur J Cancer 2013.

2. van der Sangen MJ, Scheepers SW, Poortmans PM, Luiten EJ, Nieuwenhuijzen GA, Voogd AC. Detection of local recurrence following breast-conserving treatment in young women with early breast cancer: optimization of long-term follow-up strategies. Breast 2013;22:351-6.

3. van der Sangen MJ, Poortmans PM, Scheepers SW, et al. Prognosis following local recurrence after breast conserving treatment in young women with early breast cancer. Eur J Surg Oncol 2013;39:892-8.

4. Wink CJ, Woensdregt K, Nieuwenhuijzen GA, van der Sangen MJ, Hutschemaekers S, Roukema JA, Tjan-Heijnen VC, Voogd AC. Hormone treatment without surgery for patients aged 75 years or older with operable breast cancer. Ann Surg Oncol 2012;19:1185-91.

5. van Hagen $P$, Hulshof $M C$, van Lanschot JJ, Steyerberg EW, van Berge Henegouwen MI, Wijnhoven BP, Richel DJ, Nieuwenhuijzen GA, Hospers GA, Bonenkamp JJ, Cuesta MA, Blaisse RJ, Busch OR, ten Kate FJ, Creemers GJ, Punt CJ, Plukker JT, Verheul HM, Spillenaar Bilgen EJ, van Dekken $\mathrm{H}$, van der Sangen MJ, Rozema T, Biermann K, Beukema JC, Piet AH, van Rij CM, Reinders JG, Tilanus HW, van der Gaast A. Preoperative chemoradiotherapy for esophageal or junctional cancer. N Engl J Med 2012;366:2074-84.

6. Ruiterkamp J, Voogd AC, Tjan-Heijnen VC, Bosscha K, van der Linden YM, Rutgers EJ, Boven E, van der Sangen MJ, Ernst MF. SUBMIT: Systemic therapy with or without up front surgery of the primary tumor in breast cancer patients with distant metastases at initial presentation. BMC Surgery 2012;12:5.

7. Kwast AB, Groothuis-Oudshoorn KC, Grandjean I, Ho VK, Voogd AC, MenkePluymers MB, van der Sangen MJ, Tjan Heijnen VC, Kiemeney LA, Siesling S. Histological type is not an independent prognostic factor for the risk pattern of breast cancer recurrences. Breast Cancer Res Treat 2012;135:271-80.

8. Hurkmans CW, Dijckmans I, Reijnen M, van der Leer J, van Vliet-Vroegindeweij C, van der Sangen M. Adaptive radiation therapy for breast IMRT-simultaneously integrated boost: three-year clinical experience. Radiother Oncol 2012;103:183-7.

9. Boersma LJ, Janssen T, Elkhuizen PH, Poortmans P, van der Sangen MJ, Scholten AN, Hanbeukers B, Duppen JC, Hurkmans C, van Vliet C. Reducing interobserver variation of boost-CTV delineation in breast conserving radiation therapy using a pre-operative CT and delineation guidelines. Radiother Oncol 2012;103:178-82. 
10. Aarts MJ, Hamelinck VC, Bastiaannet E, Coebergh JW, Liefers GJ, Voogd AC, van der Sangen MJ, Louwman, WJ. Small but significant socioeconomic inequalities in axillary staging and treatment of breast cancer in the Netherlands. Br J Cancer 2012;107:12-7.

11. van der Sangen MJ, van de Wiel FM, Poortmans PM, et al. Are breast conservation and mastectomy equally effective in the treatment of young women with early breast cancer? Long-term results of a population-based cohort of 1,451 patients aged $</=40$ years. Breast Cancer Res Treat 2011;127:207-15.

12. Truin W, Voogd AC, Vreugdenhil G, van der Sangen MJ, van Beek MW, Roumen RM. Influence of histology on the effectiveness of adjuvant chemotherapy in patients with hormone receptor positive invasive breast cancer. Breast 2011;20:505-9.

13. Voogd AC, van der Sangen MJ. Response to "benefit of radiation boost after whole-breast radiotherapy". (Int J Radiat Oncol Biol Phys 2009;75:1029-1034). Int J Radiat Oncol Biol Phys. 2010;77:316; author reply 316.

14. van Mourik AM, Elkhuizen PH, Minkema D, Duppen JC, van Vliet-Vroegindeweij C. Multiinstitutional study on target volume delineation variation in breast radiotherapy in the presence of guidelines. Radiother Oncol 2010;94:286-91.

15. Lammers EJ, Huibers $P$, van der Sangen MJ, et al. Factors contributing to improved local control after mastectomy in patients with breast cancer aged 40 years or younger. Breast 2010;19:44-9.

16. Derkx F, Maaskant-Braat AJ, van der Sangen MJ, et al. Staging and management of axillary lymph nodes in patients with local recurrence in the breast or chest wall after a previous negative sentinel node procedure. Eur J Surg Oncol 2010;36: 646-51.

17. Hurkmans C, Admiraal M, van der Sangen M, Dijkmans I. Significance of breast boost volume changes during radiotherapy in relation to current clinical interobserver variations. Radiother Oncol 2009;90:60-5.

18. Diepenmaat LA, van der Sangen MJ, van de Poll-Franse LV, et al. The impact of postmastectomy radiotherapy on local control in patients with invasive lobular breast cancer. Radiother Oncol 2009;91:49-53.

19. van der Sangen MJ, Voogd AC, van de Poll-Franse LV, Tjan-Heijnen VC. [Breast cancer in young women: epidemiology and treatment dilemmas]. Ned Tijdschr Geneeskd 2008;152:2495-500.

20. van de Schoot L, Romme EA, van der Sangen MJ, et al. A highly active and tolerable neoadjuvant regimen combining paclitaxel, carboplatin, 5-FU, and radiation therapy in patients with stage II and III esophageal cancer. Ann Surg Oncol 2008;15:88-95.

21. van der Leest $M$, Evers $L$, van der Sangen $M J$, et al. The safety of breastconserving therapy in patients with breast cancer aged $<$ or $=40$ years. Cancer 2007;109:1957-64. 
22. van den Broek $N$, van der Sangen MJ, van de Poll-Franse $L V$, van Beek MW, Nieuwenhuijzen GA, Voogd AC. Margin status and the risk of local recurrence after breast-conserving treatment of lobular breast cancer. Breast Cancer Res Treat 2007;105:63-8.

23. Louwman $M W$, Vriezen $M$, van Beek MW, Nolthenius-Puylaert $M C$, van der Sangen MJ, Roumen R. M, Kiemeney L. A, Coebergh JW. Uncommon breast tumors in perspective: incidence, treatment and survival in the Netherlands. Int J Cancer 2007;121:127-35.

24. van der Sangen MJ, van de Poll-Franse LV, Roumen RM, et al. The prognosis of patients with local recurrence more than five years after breast conservation therapy for invasive breast carcinoma. Eur J Surg Oncol 2006;32:34-8.

25. van den Hurk CJ, van de Poll-Franse LV, Nolthenius-Puylaert MC, Roukema JA, van der Sangen MJ, Nieuwenhuijzen G. A, van den Eijnden-van Raaij AJ, Coebergh JW. [Compliance with the breast cancer guidelines in the region of the Comprehensive Cancer Centre South, 20031/'04]. Ned Tijdschr Geneeskd 2006;150:963-8.

26. Soerjomataram I, Louwman WJ, van der Sangen MJ, Roumen RM, Coebergh JW. Increased risk of second malignancies after in situ breast carcinoma in a population-based registry. Br J Cancer 2006;95:393-7.

27. Manders K, van de Poll-Franse LV, Creemers GJ, Vreugdenhil G, van der Sangen MJ, Nieuwenhuijzen GA, Roumen RM, Voogd AC. Clinical management of women with metastatic breast cancer: a descriptive study according to age group. BMC Cancer 2006;6:179.

28. Hurkmans CW, Meijer GJ, van Vliet-Vroegindeweij C, van der Sangen MJ, Cassee J. High-dose simultaneously integrated breast boost using intensity-modulated radiotherapy and inverse optimization. Int J Radiat Oncol Biol Phys. 2006;66: 923-30.

29. Voogd AC, van Oost FJ, Rutgers EJ, Elkhuizen PH, van Geel AN, Scheijmans LJ, van der Sangen MJ, Botke G, Hoekstra CJ, Jobsen JJ, van de Velde CJ, von Meyenfeldt MF, Tabak JM, Peterse JL, van de Vijver MJ, Coebergh JW, van Tienhoven G. Longterm prognosis of patients with local recurrence after conservative surgery and radiotherapy for early breast cancer. Eur J Cancer 2005;41:2637-44.

30. Voogd AC, Cranenbroek S, de Boer R, Roumen RM, Rutten HJ, van der Sangen MJ. Long-term prognosis of patients with axillary recurrence after axillary dissection for invasive breast cancer. Eur J Surg Oncol 2005;31:485-9.

31. Louwman WJ, Janssen-Heijnen ML, Houterman S, Voogd AC, van der Sangen MJ, Nieuwenhuijzen GA, Coebergh JW. Less extensive treatment and inferior prognosis for breast cancer patient with comorbidity: a population-based study. Eur J Cancer 2005;41:779-85.

32. Cranenbroek S, van der Sangen MJ, Kuijt GP, Voogd AC. Diagnosis, treatment and prognosis of internal mammary lymph node recurrence in breast cancer patients. Breast Cancer Res Treat 2005;89:271-5. 
33. Houterman S, Janssen-Heijnen ML, Verheij CD, Louwman WJ, Vreugdenhil G, van der Sangen MJ, Coebergh JW. Comorbidity has negligible impact on treatment and complications but influences survival in breast cancer patients. $\mathrm{Br} \mathrm{J}$ Cancer 2004;90:2332-7.

34. van der Sangen MJ, Coebergh JW, Roumen RM, Rutten HJ, Vreugdenhil G, Voogd AC. Detection, treatment, and outcome of isolated supraclavicular recurrence in 42 patients with invasive breast carcinoma. Cancer 2003;98:11-7.

35. Ernst MF, Roukema JA, Coebergh JW, Repelaer van Driel OJ, van Beek MW, van der Sangen MJ, Voogd AC. Breast cancers found by screening: earlier detection, lower malignant potential or both? Breast Cancer Res Treat 2002;76:19-25.

36. Voogd AC, de Boer R, van der Sangen MJ, Roumen RM, Rutten HJ, Coebergh JW. Determinants of axillary recurrence after axillary lymph node dissection for invasive breast cancer. Eur J Surg Oncol 2001;27:250-5.

37. de Boer R, Hillen HF, Roumen RM, Rutten HJ, van der Sangen MJ, Voogd AC. Detection, treatment and outcome of axillary recurrence after axillary clearance for invasive breast cancer. Br J Surg 2001;88:118-22.

38. Levendag PC, Nowak PJ, van der Sangen MJ, et al. Local tumor control in radiation therapy of cancers in the head and neck. Am J Clin Oncol 1996;19:469-77.

39. van Putten WL, van der Sangen MJ, Hoekstra CJ, Levendag PC. Dose, fractionation and overall treatment time in radiation therapy--the effects on local control for cancer of the larynx. Radiother Oncol 1994;30:97-108.

40. van der Sangen MJ, Wiggers T, Eggermont AM. [Thyroid metastases as cause of thyroid swelling]. Ned Tijdschr Geneeskd 1993;137:295-8. 
Dankwoord 


\section{Dankwoord}

Waar moet ik beginnen?

In 1995, tijdens mijn eerste jaar in Eindhoven, maakte ik kennis met een binnen het Integraal Kankercentrum Zuid (IKZ) ingebedde, actieve borstkankerwerkgroep. Mariad Crommelin, radiotherapeut van het eerste uur, introduceerde mij zowel in de locale als landelijke samenwerkingsverbanden. Na een door ziekte gedwongen, voortijdig afscheid nam ik zijn rol binnen de borstkankerwerkgroep over. Mariad dank voor je bezielende pionierswerk, begeleiding en introductie.

Binnen het IKZ maar ook landelijk was Adri Voogd al jaren voor mijn komst naar Eindhoven actief met onderzoek naar borstkanker. Beste Adri, jij hebt mij in de beginjaren enthousiast gemaakt voor het observationele, population based onderzoek. Hoe goed doen we het eigenlijk en waar kunnen we beter? In de jaren daarna droeg je steeds nieuwe ideeën aan, die bijna allemaal tot onderzoeksplannen en publicaties leidden. Ook na je vertrek naar Maastricht bleef je volop betrokken en zorgde voor de noodzakelijke inspiratie, kennis en zachte dwang. Adri, ik heb je in de loop der jaren leren kennen als een bescheiden, aimabel persoon die ik nog nooit boos gezien heb. Je hebt mij gemotiveerd tot deze stap en zonder jouw drijvende kracht was dit project niet tot stand gekomen. Ik hoop op nog vele jaren fijne samenwerking.

De verzameling van de basisgegevens van alle borstkankerpatiënten uit de IKZ regio is gedaan door de registratiemedewerkers van het IKZ. Uit deze gegevens konden de patiëntenpopulaties voor de onderzoeken van dit proefschrift worden geselecteerd. Door hun werk, onder leiding van Erica Masseling, is een solide dataregistratie tot stand gebracht. Erica, alle registratiemedewerkers en de leiding van het IKZ bedankt. Veel uit dit proefschrift is een uitvloeisel van aanvullende patiënt-, therapie en followupgegevens, gedocumenteerd door studenten geneeskunde, die hier hun wetenschapsstage aan besteedden. Dit betrof arbeidsintensief werk met alles bij elkaar velen honderden uren status- en later microfilm- en EPD onderzoek. Fenneke van de Wiel, Lotte van Laar, Sanne Scheepers, Naomi van den Broek, Lindy Diepenmaat, Suzanne Cranenbroek, ja allemaal vrouwen, heel veel dank. Ook zonder jullie was dit proefschrift niet mogelijk geweest.

Dank aan mijn maten van de maatschap radiotherapie, die het doen van wetenschappelijk onderzoek hebben ondersteund en gestimuleerd. Ook dank aan alle administratieve krachten, verpleegkundigen, radiotherapeutisch laboranten en collegae medisch specialisten in de twee radiotherapiecentra in Tilburg en Eindhoven en alle ziekenhuizen in de IKZ regio. Door jullie toedoen zijn de behandelingen tot stand gekomen en in goede banen geleid. Een speciaal woord van dank voor Philip Poortmans die de wetenschapstagiaires in Tilburg heeft begeleid en hun en ook mij altijd nuttige tips en ondersteuning gaf.

De leden van de beoordelingscommissie, dr. L. Boersma, dr. P. Hupperets, prof. dr. P. Lambin, prof. dr. E. Rutgers, dank voor de moeite om in jullie kostbare tijd het 
manuscript te beoordelen. Prof. dr. V.C.G. Tjan-Heijnen, beste Vivianne, ik ken je al vele jaren uit oncologiebesprekingen en landelijke werkgroepen als een zeer prettige en bevlogen collega die naast de vele beslommeringen van het hoogleraarschap de patiënt nog steeds centraal stelt. Ook heb ik bewondering voor je 'timemanagement'. Dank dat je mijn promotor wilde zijn. Prof. dr. J.W.W. Coebergh, beste Jan-Willem, jij hebt het IKZ mede groot gemaakt en kan het werken nog steeds niet laten. Heel veel dank voor je bezielende IKZ-leiding, 'hart voor de zaak' en kritische blik op het manuscript. Je uitgesproken en soms ook tegendraadse mening waardeer ik (meestal) zeer.

Tiny Wouters, dank voor je deskundige hulp om er een mooi opgemaakt boekje van te maken. Ook dat is een vak apart. Uiteraard ook dank aan de paranimfen, Hans-Peter Knol en John Stefelmanns, voor het mij ter zijde staan tijdens de ceremonie. Beste Hans-Peter, met jou heb ik het grootste deel van de opleiding een kamer gedeeld. Daar hebben vele aspecten van het leven de revue gepasseerd, zeker niet altijd werkgerelateerd, moet ik toegeven. Jouw openhartige, humoristische en relativerende inslag stel ik zeer op prijs. Beste John, jouw gastvrijheid en kookkunst hebben al tot menig gezellig etentje geleid; dank daarvoor en we staan open voor nieuwe culinaire verkenningen. Bestuursleden van het NABON en de BOOG, Elise van Leeuwen dank voor de prettige samenwerking en de kennisverdieping die ik dankzij jullie kon opdoen.

Achter de cijfers, tabellen en grafieken van dit proefschrift gaat voor meer dan duizend vrouwen een moeilijke periode in hun vaak nog jonge leven schuil. Levens die een andere wending hebben genomen dan vooraf bedacht. Het verloop van een overlevingscurve is wetenschappelijk interessant, maar betekent ook het verlies van partners, moeders en dochters. Het pad van de vooruitgang bevat naast successen ook mislukkingen, maar geeft tegelijkertijd richting aan zaken die beter kunnen. Voor het geven van dit inzicht ben ik alle patiënten die met hun levensloop onbewust deel uit maken van dit proefschrift dankbaar.

Verder iedereen die ik niet genoemd heb, maar die wel direct of indirect hebben bijgedragen, mijn hartelijke dank.

Liefste vader en moeder, dank voor jullie liefde, vertrouwen en stimulans om te gaan studeren. Jammer dat jullie dit niet meer mee kunnen maken; ik mis jullie. Beste zussen, Miriam en Yvonne, ook dank voor jullie steun; hopelijk zien we elkaar weer wat vaker. Liefste Carla, Niels, Anne en Erik. Jullie vormen het veilige, liefdevolle en gezellige thuisfront waar het altijd goed toeven is. Moge dat nog lang zo blijven. 
Curriculum Vitae 


\section{Curriculum Vitae}

Maurice van der Sangen werd in 1961 te Kerkrade geboren en groeide op in Sittard, alwaar hij in 1979 het gymnasium diploma behaalde aan de Serviam Scholengemeenschap. In 1986 slaagde hij cum laude voor het artsexamen aan de Medische faculteit van de Universiteit van Maastricht. Aansluitend werkte hij ruim 3 jaar als arts-assistent niet-in opleiding binnen de vakgroepen interne geneeskunde, cardiologie en radiotherapie alvorens in 1990 te starten met de opleiding tot radiotherapeut in de Dr. Daniël den Hoed kliniek te Rotterdam (opleider Prof. dr. P.C. Levendag). Deze opleiding werd in 1995 afgerond.

In hetzelfde jaar trad hij toe tot de maatschap radiotherapie van het Catharina Ziekenhuis te Eindhoven, alwaar hij tot de dag van vandaag werkzaam is. Hij is gehuwd met Carla Stefelmanns en samen hebben ze drie kinderen: Niels (1993), Anne (1995) en Erik (2001). 